\author{
Universidade de São Paulo \\ Instituto de Física de São Carlos
}

Carlos Renato Menegatti

\title{
Armadilha de dipolo para átomos $e$ moléculas
}

São Carlos 



\section{Carlos Renato Menegatti}

\section{Armadilha de dipolo para átomos $e$ moléculas}

Tese apresentada ao Programa de PósGraduação em Física do Instituto de Física de São Carlos da Universidade de São Paulo, para obtenção do título de Doutor em Ciências.

Área de Concentração: Física Básica

Orientador: Prof. Dr. Luís Gustavo Marcassa

Versão Corrigida

(versão original disponível na Unidade que aloja o Programa)

São Carlos 
AUTORIZO A REPRODUÇÃO E DIVULGAÇÃO TOTAL OU PARCIAL DESTE TRABALHO, POR QUALQUER MEIO CONVENCIONAL OU ELETRÔNICO, PARA FINS DE ESTUDO E PESQUISA, DESDE QUE CITADA A FONTE.

Ficha catalográfica elaborada pelo Serviço de Biblioteca e Informação IFSC/USP

Menegatti,Carlos Renato

Armadilha de dipolo para átomos e moléculas./Carlos Renato Menegatti ; orientador Luis Gustavo Marcassa.-versão corrigida -São Carlos, 2011.

$162 p$.

Tese (Doutorado-Programa de Pós-Graduação em Ciências.Área de concentração:Física Básica) - Instituto de Física de São Carlos, Universidade de São Paulo.

1. Átomos frios. 2. Moléculas frias. 3. Armadilha de dipolo. 4. Fotoassociação. 5.Colisões frias. I.Título. 
Ficha de aprovação 

À tia Cida, Nair e Júlio Menegatti 



\section{Agradecimentos}

Primeiramente gostaria de agradecer a minha maravilhosa família José, Maria, Fernanda e Carla que sempre está presente e com quem posso sempre contar.

Ao professor Dr. Luís Gustavo Marcassa e sua esposa Luciana, pela orientação, pelo apoio, profissionalismo e amizade durante todo esse caminho.

Ao Bruno S. Marangoni, pela amizade e ao seu indispensável suporte no desenvolvimento de softwares e drives para os experimentos deste trabalho.

Aos professores Lino Misoguti, Cleber Renato Mendonça, Cláudio Lenz Cesar, Vanderlei Salvador Bagnato e Sérgio Carlos Zílio.

Aos meus companheiros de trabalho Jader, Jorge, Luis Felipe, Caio, que sempre estão presentes nos melhores e piores momentos.

A todos os companheiros de trabalho: Marcão, PH, Jonatan, Renato, Jorge, Edwin, Gaucho, Gugs, Boto, Marcelo, André, Chê, Juliana, Anderson.

Ao pessoal oficina do Carlinhos e aos secretários do grupo de óptica: Isabel , Benê, e Daniel pelo grande trabalho em organizar toda nossa papelada com $100 \%$ de eficiência.

Aos grandes irmãos que convivi por muitos anos Daniel Papoti, Daniel Vieira ,Paulino, Ana, Lúcia, Leonardo.

Aos "FERAS": Gian, Juliano, Waguim, Junior, Marcelo, Clayton, Vinni, Leonardo, Lambão, Wladimir pelas fortes emoções nos fins de semana.

Aos amigos de ontem e de toda vida: Codo, Diego, Rondinelli, Márcio, Veio, Niego, David, Bellotte, Clodoaldo, Alanis, Sidney.

À Silmara por ser uma pessoa tão especial e carinhosa e que esteve presente me confortando nos momentos finais deste trabalho. Sou apaixonado por você!

À FAPESP e CNPQ, pelo apoio financeiro. 



\section{Resumo}

MENEGATTI, C. R. Armadilha de dipolo para átomos e moléculas. 2011. 162p. Tese (Doutorado em Ciências) - Instituto de Física de São Carlos, Universidade de São Paulo, São Carlos, 2011.

Neste trabalho apresentamos a construção de um novo sistema experimental para aprisionamento de átomos e moléculas. Trata-se de uma armadilha de dipolo cruzada totalmente óptica, formada por um laser de fibra com $40 \mathrm{~W}$ de potência com comprimento de onda em $1064 \mathrm{~nm}$. Nesse sistema foi demonstrado o aprisionamento de átomos Rb e K e moléculas $\mathrm{Rb}_{2}$. Realizamos dois experimentos distintos neste se novo sistema: No primeiro, estudamos a evolução temporal de amostras dos isótopos ${ }^{85} \mathrm{Rb}$ e ${ }^{87} \mathrm{Rb}$ na armadilha de dipolo cruzada. Pudemos medir pela primeira vez o processo de mudança de estrutura hiperfina em átomos sem a presença de luz ressonante, e observamos a fotoassociação dos átomos pelo laser da armadilha de dipolo. E no segundo, desenvolvemos uma técnica que permite o estudo rápido e direto do decaimento no número de moléculas de $\mathrm{Rb}_{2}$ na armadilha. Com essa técnica, observamos também o comportamento dessas moléculas na presença de átomos preparados em um determinado estado hiperfino do estado fundamental. Estes resultados juntamente com um desenvolvimento teórico, nos sugerem novas perspectivas rumo a produção de um sistema que possa produzir e aprisionar moléculas KRb no estado fundamental ${ }^{1} \Sigma^{+}(v=0)$.

Palavras-chave: Átomos frios. Moléculas frias. Armadilha de dipolo. Fotoassociação. Colisões frias. 



\section{Abstract}

MENEGATTI, C. R. A dipole trap for atoms and molecules. 2011. 162p. Tese (Doutorado em Ciências) - Instituto de Física de São Carlos, Universidade de São Paulo, São Carlos, 2011.

In this work, we present the construction of a new experimental system for trapping atoms and molecules. It is an all optical crossed dipole trap, formed by a fiber laser with $40 \mathrm{~W}$ of power at $1064 \mathrm{~nm}$. In this system, we have trapped $\mathrm{K}$ and $\mathrm{Rb}$ atoms as well as $\mathrm{Rb}_{2}$ molecules. We have carried out two experiments in this new system. In the first, we studied the temporal evolution of atomic samples of different isotopes, ${ }^{85} \mathrm{Rb}$ and ${ }^{87} \mathrm{Rb}$, in the crossed trap dipole. We were able to measure for the first time the hyperfine-changing collisions of atoms in the absence of resonant light, and we have observed photoassociation of atoms by the dipole trap laser beam. In the other experiment, we have developed a technique that allows us to study the trapped molecule population decay in the trap. It was also observed the molecule population decay in the presence of atoms prepared in a given hyperfine state of the ground state. These results together with a theoretical development may suggest us new perspectives towards the production of a system that can produce and trap KRb molecules in the ground state ${ }^{1} \Sigma^{+}(v=0)$.

Keywords: Cold atoms. Cold molecules. Dipole trap. Photoassociation. Cold collisions. 



\section{Lista de Figuras}

Figura 2.1 - Transição entre um estado vibracional $v_{a}$ de um estado eletrônico A para o vibracional $v_{b}$ de $u m$ estado eletrônico $B$. Considerando o princípio de Franck-Condon a transição deve ocorrer através de uma linha perpendicular ao eixo R (linha verde). O acoplamento depende do overlap entre as funções de onda do estado fundamental $\left(\psi_{\mathrm{va}}\right)$ e excitado $\left(\psi_{\mathrm{vb}}\right) \ldots . . .41$

Figura 2.2 - Fotoassociação e decaimento espontâneo da transição free-bound envolvida no processo que leva à formação de moléculas no estado fundamental. Os estados $S_{1 / 2}+S_{1 / 2}$ e $S_{1 / 2}+P_{3 / 2}$ representam os estados eletrônicos fundamental e excitado de um par atômico qualquer. A linha azul representa a função de onda $\mathrm{S}$ de uma colisão de dois átomos livres que é acoplada a um estado ligado por um fóton $\left(\omega_{\mathrm{PA}}\right)$. Este, por sua vez, decai por emissão espontânea $\left(\omega_{3}\right)$ formando uma molécula no estado fundamental. Nesse processo, há uma baixa intensidade da função de onda (linha azul) na parte interna do potencial, a qual se acopla melhor com os estados vibracionais de alto valor de $v$ do estado eletrônico excitado e estes, conseqüentemente, se acoplam melhor aos estados vibracionais excitados no fundamental eletrônico.

Figura 2.3 - Tempo de vida de moléculas de $\mathrm{Cs}_{2}(\boldsymbol{v}=32-47)$ aprisionadas na armadilha de dipolo na presença de átomo de $\mathrm{Cs}$ em $\mathrm{F}=3$ e na ausência. A densidade medida dos átomos para a medida foi de $9 \times 10^{10} \mathrm{~cm}^{-3}$. Figura extraída de (65).

Figura 2.4 - Dependência da taxa de perda molecular $\mathbf{B}$ para os estados $(\boldsymbol{v}=32-47)$ e ( $\boldsymbol{v}$ = 4-6) em função da densidade dos átomos. Figura extraída de (65).

Figura 2.5 - Número de moléculas de KRb na armadilha de dipolo (1064 nm) em função da aplicação do pulso de radiofreqüência, o qual associa átomos em moléculas pelo processo de ressonância de Feschbach. O campo magnético utilizado para tal foi de $B_{0}=546,17 \mathrm{G}$. A linha preta representa um ajuste exponencial do decaimento. Figura extraída de (66).

Figura 2.6 - Esquema para formação e detecção das moléculas de RbCs no estado fundamental. a) O par atômico é fotoassociado para o estado ligado excitado da molécula RbCs. b) Decaimento espontâneo para o estado 
tripleto $\mathbf{a}^{3} \Sigma^{+}(\boldsymbol{v}=37)$. c) Moléculas são excitadas para o nível i e em d) são estimuladas para o estado $\mathbf{X}^{\mathbf{1}} \boldsymbol{\Sigma}_{\mathbf{g}}^{+}(\boldsymbol{v}=0)$. e) A detecção é feita levando as moléculas novamente ao estado excitado $i$ e ionizando-as em (f). Figura extraída de (56).

Figura 2.7 - Esquema para bombeamento de moléculas para o estado eletrônico fundamental em $\mathbf{v}_{\mathbf{x}}=0$. As freqüências que acoplam o estado $\mathbf{v}_{\mathbf{x}}=0$ para algum estado $\mathbf{v}_{\mathbf{x}}$, são bloqueadas (transições representadas pelas setas vermelhas).

Figura 2.8 - (A) Espectro de freqüências utilizado, bloqueio de freqüências feito em $13,030 \mathrm{~cm}^{-1}$. (B) Fatores de Franck-Condon relacionado às probabilidades de transição entre os estados $\mathbf{v}_{\mathbf{x}}$ (estado eletrônico fundamental) $\mathbf{v}_{\mathbf{b}}$ (estado eletrônico excitado ). (C) Bombeamento óptico de uma molécula partido de $\mathbf{v}_{\mathbf{x}}=4$ e chegando em $\mathbf{v}_{\mathbf{x}^{\prime}}=0$. Figura extraída de (55).

Figura 2.9 - (A) Espectro sem o corte no feixe de bombeamento, picos corresponde a transições do estado fundamental $\mathbf{v}_{\mathbf{x}}=1$ a 7 para vários níveis do estado excitado C. (B) Espectro aplicando-se o corte de freqüência no feixe de bombeamento (corte em $13030 \mathrm{~cm}^{-1}$ ). Nele são observados transições $\mathbf{V}_{\mathbf{x}}$ $=0$ a $\mathbf{v}_{\mathbf{c}}=0$ a 3 com maior intensidade. Figura extraída de (55).

Figura 2.10 - Fatores de Franck-Condon calculados para a molécula de $\mathrm{KRb}$ a partir do software "level 8.0". No gráfico temos as probabilidades de transição entre os estados $v_{x}$ (estado eletrônico fundamental) e $v_{b}$ (estado eletrônico excitado). As setas verdes representam o bombeamento óptico de uma molécula inicialmente em $\mathrm{v}_{\mathrm{x}}=5$ e chegando em $\mathrm{v}_{\mathrm{x}^{\prime}}=0$, a freqüência de corte calculada para esse sistema foi de $15031 \mathrm{~cm}^{-1}$. Neste cálculo consideramos os níveis vibracionais do estado excitado ${ }^{1} \Pi$ do $\mathrm{KRb}$

Figura 2.11 - Esquema para a fotoassociação de LiCs em $\mathbf{X}^{\mathbf{1}} \boldsymbol{\Sigma}_{\mathbf{g}}^{+}\left(\boldsymbol{v}^{\prime}=0, \mathrm{~J}^{\prime}=0\right)$ e detecção. a) Fotoassociação por um laser de Ti:As em 946,56 nm. b) Decaimento espontâneo para o estado fundamental. c) Ionização por dois fótons. d) Excitação das moléculas do estado fundamental. e) Redistribuição da população do estado fundamental. Figura extraída de (57).

Figura 2.12 - Esquema para formação de moléculas de KRb no estado fundamental via técnica STIRAP. a) A molécula é levada para o estado fundamental tripleto $\mathbf{a}^{3} \boldsymbol{\Sigma}(\boldsymbol{v}=\mathbf{0})$ pelo acoplamento de dois lasers com freqüências $\boldsymbol{\Omega}_{\mathbf{1}}(1023$ $\mathrm{nm})$ e $\boldsymbol{\Omega}_{\mathbf{2}}(998 \mathrm{~nm})$. b) A molécula é levada para estado fundamental 
singleto $\mathbf{X}^{\mathbf{1}} \boldsymbol{\Sigma}_{\mathbf{g}}(\boldsymbol{v}=0)$ pelo acoplamento de dois lasers com freqüências $\boldsymbol{\Omega}_{\mathbf{1}}(970 \mathrm{~nm})$ e $\boldsymbol{\Omega}_{\mathbf{2}}(690 \mathrm{~nm})$. Figura extraída de (58)).

Figura 2.13 - Potenciais para a molécula de $\mathrm{Rb}_{2}$. A seta vermelha representa em escala a energia do laser em 1064 nm, mostrando a possibilidade de acoplamento entre o estado fundamental e os estados excitados $A^{1} \Sigma_{u}$ e $b^{3} \Pi_{u}$.

Figura 2.14 - Processo de bombeamento molecular para estados vibracionais mais baixos. A cada ciclo de absorção ( setas vermelhas 1 e 3 ) e emissão(setas verdes 2 e 4) de um fóton a molécula é levada a um estado vibracional v menor, este processo deve continuar até que o laser da armadilha (1064 $\mathrm{nm}$ ) não acople mais a nenhum estado vibracional excitado $v^{\prime}$.

Figura 2.15 - a) Distribuição de níveis moleculares após a fotoassociação dos átomos pelo laser de fibra. b) Distribuição final de moléculas devido ao bombeamento molecular após a fotoassociação. Para chegar à configuração estacionária em (b) foram necessárias 10 interações. Os níveis utilizados para as interações foram: $\mathrm{X}^{1} \Sigma_{\mathrm{g}}^{+}$e $\mathrm{A}^{1} \Sigma_{\mu}^{+}$

Figura 2.16 - Distribuição de níveis moleculares após 10 interações considerando o laser com uma largura de $3 \mathrm{~nm}$. Os níveis utilizados para as interações foram: $\mathbf{X}^{\mathbf{1}} \boldsymbol{\Sigma}_{\mathbf{g}}^{+}$(estado fundamental), $\mathbf{A}^{\mathbf{1}} \boldsymbol{\Sigma}_{\boldsymbol{\mu}}^{+}+$e $\mathbf{b}^{\mathbf{3}} \boldsymbol{\Pi}_{\boldsymbol{\mu}}$ (estados excitados).

Figura 2.17 - Potenciais de interesse para a molécula KRb. A seta vermelha representa o laser em 1064 nm (em escala) que possui energia suficiente para acoplar estados vibracionais do potencial fundamental $\left({ }^{1} \Sigma^{+}\right)$com estados vibracionais do potencial excitado.

Figura 2.18 - a) Distribuição de níveis moleculares após a fotoassociação dos átomos de $\mathrm{K}$ e $\mathrm{Rb}$ pelo laser de fibra. b) Distribuição final de moléculas devido ao bombeamento molecular após a fotoassociação. Para chegar à configuração estacionária em (b) foram necessárias 10 interações. Os potenciais utilizados para as interações foram: ${ }^{1} \Sigma^{+} \mathrm{e}^{3} \Pi$ do KRb.

Figura 2.19 - Curvas de potencias do estado excitado para a molécula de KRb considerando a estrutura fina do estado 5P. Na área indicada pelo quadrado temos os potencias que podem ser acoplados pelo laser em $1064 \mathrm{~nm}$ e participar do processo de bombeamento.

Figura 2.20 - Simulação utilizando os potenciais mencionados na figura 2.19. Quando consideradas todas as possibilidades de acoplamento, encontramos uma distribuição de estados finais bem reduzidas obtendo a maior parte das moléculas em níveis vibracionais abaixo de $v=10$. 
Figura 3.1 - a) Desenho esquemático da montagem dividido em três partes: b) o forno misto, c) o desacelerador de átomos, d) a câmara de aprisionamento com suportes onde serão acopladas as fibras ópticas para a armadilha. As letras B1, B2, B3 representam as bombas iônicas do sistema e na parte inferior temos a bomba de sublimação de Ti em um formato de $\mathrm{L}$.

Figura 3.2 - Forno misto para produção do feixe de átomos de $\mathrm{Rb}$ e K. As regiões $\mathbf{A}$ e $\mathbf{B}$ são mantidas a $140^{\circ} \mathrm{C}$ para gerar um fluxo colimado de $2 \times 10^{16}$ átomos $/ \mathrm{s}$ por espécie na saída do forno (D). Uma placa fria de cobre (E) atua como uma barreira impedindo o vapor residual de se propagar até a região de aprisionamento. Em $\mathbf{F}$ temos uma válvula pneumática de segurança, e em $\mathbf{G}$ (diâmetro $=4,77 \mathrm{~mm}$ e comprimento $=127 \mathrm{~mm}$ ) temos o tubo que para gerar o diferencial de pressão de $10^{-3}$ torr entre o forno e a câmara.

Figura 3.3 - Perfil do campo magnético projetado e medido e foto do solenóide.

Figura 3.4 - Imagem do corte da câmara de aprisionamento e seus componentes em detalhes.

Figura 3.5 - Força restauradora espacial em uma dimensão. $O$ estado fundamental $F=0$, não sofre variação em sua energia $\Delta \mathrm{E}=0$, já o estado excitado $\mathrm{F}^{\prime}=1$ sofre variação de $\Delta \mathrm{E}=\left(\mathrm{m}_{\mathrm{F}^{\prime}}=-1,0,+1\right)$.

Figura 3.6 - Níveis de energia das espécies ${ }^{87} \mathrm{Rb},{ }^{85} \mathrm{Rb},{ }^{39} \mathrm{~K}$. As setas vermelhas representam as freqüências para aprisionamento $e$ as verdes as freqüências para rebombeio. As freqüências de aprisionamento apresentam uma dessintonia de $-20 \mathrm{MHz}$ para o ${ }^{87} \mathrm{Rb}$ e ${ }^{85} \mathrm{Rb}$ e $-30 \mathrm{MHz}$ para ${ }^{39} \mathrm{~K}$.

Figura 3.7 - Montagem experimental para feixe de aprisionamento rebombeio e desaceleração de ${ }^{87} \mathrm{Rb}$ e ${ }^{85} \mathrm{Rb}$ 1) Espectroscopia de absorção saturada por polarização, sistema travado a - $187 \mathrm{MHz}$. 2) e 4) Feixe ajustado a - 187 $\mathrm{MHz}$. 3) Feixe para aprisionamento de ${ }^{87} \mathrm{Rb}$ ajustado a - $20 \mathrm{MHz}$. 5) Feixe para injeção em laser escravo ajustado a $-687 \mathrm{MHz}$ ). 6) Laser escravo (LD) para desaceleração ajustado a - $687 \mathrm{MHz}$. 7) Feixe para imagem ajustado na transição. Freqüências de 1 a 7 estão ajustadas com relação às transições $5 S_{1 / 2}(F=2,3)-5 P_{3 / 2}\left(F^{\prime}=3,4\right)$ do ${ }^{87} R b$ e ${ }^{85} R b$ respectivamente .8) Espectroscopia de absorção saturada por polarização, sistema travado a - $80 \mathrm{MHz}$. 9) Feixe ajustado a $-80 \mathrm{MHz}$. 10) Feixe para rebombeio do desacelerador ajustado a - $430 \mathrm{MHz}$. 11) Feixe para o rebombeio da armadilha ajustado na transição. Freqüências de 8 a 11 estão ajustadas com relação às transições $5 S_{1 / 2}(F=1,2)-5 P_{3 / 2}\left(F^{\prime}=2,3\right)$ do ${ }^{87} R b$ e ${ }^{85} R b$ respectivamente. 
Figura 3.8 - Montagem experimental para feixe de aprisionamento, rebombeio e desaceleração de ${ }^{39} \mathrm{~K}$. 1) Espectroscopia de absorção saturada por polarização, sistema travado a $-200 \mathrm{MHz}$. 2) Feixe ajustado a $-200 \mathrm{MHz}$. 3) Feixe para aprisionamento e rebombeio ajustado a - $30 \mathrm{MHz}$ e -420 $\mathrm{MHz}$ (adicionado através de modulão eletro-óptica) respectivamente. 4) Feixe para o injeção no laser escravo. 5) Feixe para desaceleração de ${ }^{39} \mathrm{~K}$ ajustado a $-662 \mathrm{MHz}$ e rebombeio a - $435 \mathrm{MHz}$. 6) Feixe para imagem ajustado na transição. As freqüências estão ajustadas com relação à transição $4 \mathrm{~S}_{1 / 2}(\mathrm{~F}=2)-4 \mathrm{P}_{3 / 2}$, é importante lembrar que o espectro de ${ }^{39} \mathrm{~K}$ não possui resolução para distinguirmos as estruturas hiperfinas $\mathrm{F}^{\prime}$.

Figura 3.9 - Fibra óptica desenvolvida para o acoplamento dos feixes de desaceleração das duas espécies $\mathrm{Rb}$ e $\mathrm{K}$.

Figura 3.10 - Montagem para armadilha magneto óptica. 1) Fibra óptica dos feixes de aprisionamento de $\mathrm{Rb}$ e K. 2) Ajuste da polarização em $\sigma$ - ou $\sigma+$.3) Telescópio para expansão do feixe em aproximadamente $25 \mathrm{~mm}$ de diâmetro.

Figura 3.11 - Montagem experimental para armadilha de dipolo óptica com feixes cruzados. 1) Cintura do feixe reduzida por um fator de 2 para obtermos melhor eficiência no modulador acusto-óptico. 2) Modulador acustoóptico para controle e estabilidade de potência do feixe da armadilha. 3) Feixe reduzido por um fator de 2/3. 4) Feixe para armadilha de dipolo focalizado com uma lente de $200 \mathrm{~mm}$ para produzir uma cintura de $\mathrm{w}=$ $57 \mu \mathrm{m}$ no foco. Devido à geometria de nossa câmara, os feixes da armadilha cruzam em um ângulo de $68^{0}$. 5) Bloqueador arrefecido com água.

Figura 3.12 - a) Interface do controle dos módulos digilock 110 da Toptica. Nele temos um espectro de absorção saturada do ${ }^{85} \mathrm{Rb}$ (amarelo) e sua dispersão gerada pela técnica lock-in (vermelho). b) Espectro do ${ }^{39} \mathrm{~K}$ feito através de absorção saturada por polarização, neste modelo de espectroscopia o sinal gerado transformas os picos das transições curvas dispersivas que podem ser diretamente travados pela opção de lock-side. A seta indicando a posição do side lock representa a transição $4 S_{1 / 2}(F=2)$ para o estado $4 \mathrm{P}_{3 / 2}$ do ${ }^{39} \mathrm{~K}$, as estruturas hiperfinas $\mathrm{F}^{\prime}=0$ a 3 do estado excitado são muito próximas em freqüência e não podem ser resolvidas.

Figura 3.13 - Interface para controle do experimento.

Figura 3.14 - Seqüência temporal para carregamento da armadilha de dipolo para o ${ }^{85} \mathrm{Rb}$ e ${ }^{87} \mathrm{Rb}$. O MOT é carregado por $8 \mathrm{~s}$ e passa por um estagio de 
resfriamento e carregamento por 50 ms, na seqüência todos os campos e lasers não desligados ficando apenas o laser da armadilha em 1064 nm....... 99

Figura 3.15 - Seqüência temporal para carregamento da armadilha de dipolo para $0^{39} \mathrm{~K}$. O MOT é carregado por $8 \mathrm{~s}$ e passa por um estágio de resfriamento e carregamento por $30 \mathrm{~ms}$, na seqüência todos os campos e lasers são desligados ficando apenas o laser da armadilha em $1064 \mathrm{~nm}$.

Figura 3.16 - Imagens de fluorescência. a) Carregamento da armadilha utilizando apenas um feixe. Nela observamos a nuvem de átomos do MOT caindo pela ação da gravidade (esquerda para direita) enquanto uma fração de átomos é aprisionada. b) Carregamento da armadilha com um feixe cruzado

Figura 3.17 a) Imagem de fluorescência de uma armadilha óptica de ${ }^{39} \mathrm{~K}$. b) Imagem sem o laser de aprisionamento.

Figura 3.18 - Montagem óptica para imagens de absorção.

Figura 3.19 - Imagem de absorção de átomos de ${ }^{85} \mathrm{Rb}$ na armadilha de dipolo cruzada. a) imagem dos átomos, b) imagens sem átomos, c) imagem de fundo na ausência de átomos e do feixe de absorção. d) Imagem final processada. A freqüência utilizada foi a transição $5 S_{1 / 2}(F=3)-5 P_{3 / 2}\left(F^{\prime}=4\right)$.

Figura 3.20 - Software para análise das imagens, nele podemos medir o número de átomos, densidade e tamanho da armadilha.

Figura 3.21 - Técnica de medida da temperatura por imagens de absorção. Neste caso particular os átomos são aprisionados por $50 \mathrm{~ms}$ e liberados, sofrendo uma expansão livre. Em a) temos o ajuste dos dados experimentais pela expressão 3.21, em b) temos as imagens propriamente ditas para alguns intervalos de expansões. Neste presente, obtivemos uma temperatura de $36 \mu \mathrm{K}$ para o ${ }^{85} \mathrm{Rb}$.

Figura 3.22 - Espectro de tempo de vôo de ${ }^{85} \mathrm{Rb}^{+} \mathrm{e}{ }^{85} \mathrm{Rb}_{2}{ }^{+}$fotoionizados no MOT. Nele podemos distinguir o sinal de íons atômicos e moleculares pela diferença de tempo que as partículas levam para atingirem o detector.

Figura 3.23 - Esquema para Fotoionização de $\mathrm{Rb}_{2}$ no estado fundamental.

Figura 3.24 - Laser de corante (Jaguar) para fotoionização de moléculas de Rb2. 1) Laser de bombeamento Nd: Yag pulsado em $530 \mathrm{~nm}$. 2) Oscilador gerando laser com eficiência em 600 a 610 nm. 3) Amplificador. 
Figura 4.1 - a) Gráfico do tempo de vida de átomos de ${ }^{85} \mathrm{Rb}$ na armadilha de dipolo com população $100 \%$ no estado hiperfino inferior $F=2$. A linha vermelha $(-)$ corresponde ao ajuste pela equação 4.2. b) Temperatura da respectiva amostra, ${ }^{85} \mathrm{Rb}(\mathrm{F}=2)$, em função do tempo de aprisionamento. A linha preta (-) foi introduzida apenas para melhor visualização.

Figura 4.2 - a) Gráfico do tempo de vida de átomos de ${ }^{85} \mathrm{Rb}$ na armadilha de dipolo com população $100 \%$ no estado hiperfino inferior $F=3$. A linha vermelha $(-)$ corresponde ao ajuste pela equação 4.2 . b) Temperatura da respectiva amostra, ${ }^{85} \mathrm{Rb}(\mathrm{F}=3)$, em função do tempo de aprisionamento. A linha preta (-) foi introduzida apenas para melhor visualização.

Figura 4.3 - a) Gráfico do tempo de vida de átomos de ${ }^{87} \mathrm{Rb}$ na armadilha de dipolo com população $100 \%$ no estado hiperfino inferior $F=1$. A linha vermelha $(-)$ corresponde ao ajuste pela equação 4.2. b) Temperatura da respectiva amostra, ${ }^{87} \mathrm{Rb}(\mathrm{F}=1)$, em função do tempo de aprisionamento. A linha preta (-) foi introduzida apenas para melhor visualização.

Figura 4.4 - a) Gráfico do tempo de vida de átomos de ${ }^{87} \mathrm{Rb}$ na armadilha de dipolo com população $100 \%$ no estado hiperfino inferior $F=2$. A linha vermelha $(-)$ corresponde ao ajuste pela equação 4.2. b) Temperatura da respectiva amostra, ${ }^{87} \mathrm{Rb}(\mathrm{F}=2)$, em função do tempo de aprisionamento. A linha preta (-) foi introduzida apenas para melhor visualização.

Figura 4.5 - Esquema de evaporação do sistema. A curva vermelha representa o potencial da armadilha com potencial $U_{0}$. As curvas azuis $T_{1}$ e $T_{2}$ são as distribuições Maxwell do sistema antes e depois de um processo evaporativo.

Figura 4.6 - Comparações entre as curvas experimentais de decaimento de número de átomos ( $a$ e c) e temperatura ( $b$ e d) (linhas vermelhas) com as curvas geradas pelas simulações do modelo evaporativo (linhas pretas). As medidas foram feitas com ambas as espécies ${ }^{85} \mathrm{Rb}$ e ${ }^{87} \mathrm{Rb}$ no estado fundamental hiperfino inferior. Observamos uma grande discrepância entre o experimento e a teoria mostrando que o mecanismo de evaporação que ocorre em nosso sistema não pode explicar os decaimentos medidos.

Figura 4.7 - Processo de formação de moléculas por 3 corpos. A colisão entre três átomos resulta na formação de uma molécula diatômica e um átomo livre. $O$ átomo livre resultante recebe o excedente de energia na forma de energia cinética mantendo a conservação de energia e momentum do sistema. 
Figura 4.8 - Ajuste dos quatro primeiros pontos das curvas de decaimento para $0{ }^{87} \mathrm{Rb}$ (a) $\mathrm{e}^{85} \mathrm{Rb}$ (b) nos estados hiperfinos inferiores por uma reta. O coeficiente angular dessa reta é a taxa $d N / d t$.

Figura 4.9 - Potenciais de interesse para a molécula de $\mathrm{Rb}_{2}$. A seta vermelha representa em escala a energia do laser em $1064 \mathrm{~nm}$ mostrando a possibilidade de acoplamento entre o estado fundamental e os estados excitados $A^{1} \Sigma_{u}$ e $b^{3} \Pi$

Figura 4.10 - Modelos para interpolação dos potenciais de longo e curto alcance do estado fundamental singleto. A interpolação obtida pela linha tracejada sugere que os fatores de Franck-Condon aumentam em função da energia de espalhamento de uma colisão para átomos de ${ }^{85} \mathrm{Rb}$. Obs: Figura extraída da referência (72).

Figura.5.1 - Seqüência experimental para a observação de moléculas de ${ }^{85} R b_{2}$ e ${ }^{87} R b_{2}$ na armadilha de dipolo.

Figura 5.2 - Decaimento da amostra molecular $\left({ }^{85} \mathrm{Rb}_{2}\right)$ em uma armadilha de dipolo.

Figura 5.3 - a) Esquema do experimento. b) Demonstração da técnica, as curvas de tempo de vida da armadilha medidas a partir de 400 a 1600 ms complementam perfeitamente a curva medida no instante 0 . Assim, mostramos que a fração de íons produzida pelo laser pulsado é desprezível não prejudicando a medida como um todo. c) Neste gráfico ilustrativo, a curva preta representa o decaimento real das moléculas, as curvas azul e vermelha representam o decaimento caso o laser pulsado perturbasse a medida.

Figura 5.4 - a) Gráfico do tempo de vida das moléculas para vários valores de energia/pulso do laser pulsado. Observamos curvas de 0,5 a 1,7 mJ/pulso as quais estão no limite inferior e superior e de operação do laser. Conforme a potência de operação é aumentada a medida sofre uma perturbação, no tempo $1,5 \mathrm{~s}$ a medida com baixa potência acusa um número de 2,5 vezes maior que o medido com alta potência. b) Decaimento exponencial da população de moléculas da amostra para 1,7 $\mathrm{mJ} /$ pulso.

Figura 5.5 - Gráfico do tempo de vida de moléculas e átomos de ${ }^{85} \mathrm{Rb}$ na armadilha de dipolo. A linha verde $(-)$ corresponde à medida do número de moléculas, as bolas pretas ( $\circ$ ) ao número de átomos e os quadrados vermelhos ( $\square$ ) ao número de átomos na presença do laser pulsado. Vemos que os três resultados são idênticos mostrando que o laser pulsado não interfere no tempo de vida dos átomos na armadilha. 
Figura 5.6 - Medida da temperatura das moléculas na armadilha de dipolo. As moléculas são carregadas e aprisionadas por $50 \mathrm{~ms}$ na armadilha, na seqüência a amostra sofre uma expansão livre e o laser pulsado prova o número de moléculas remanescentes em função do tempo da expansão.

Figura 5.7 - a) Tempo de vida da armadilha de dipolo para as duas espécies moleculares ${ }^{85} \mathrm{Rb}_{2}$ e ${ }^{87} \mathrm{Rb}_{2}$. O decaimento da população de moléculas é estudado para duas condições: moléculas com átomos no estado fundamental hiperfino inferior ( $F=1$ e $F=2$ ), e moléculas com átomos no estado fundamental hiperfino superior ( $F=2$ e $F=3$ ). b) Neste temos a mesma medida, porém com o número de moléculas normalizado.

Figura 5.8 - Decaimento da população molecular ${ }^{85} \mathrm{Rb}_{2}$ na armadilha de dipolo. A linha vermelha representa o ajuste exponencial .....

Figura 5.9 - Gráfico da taxa de perda B da armadilha em função da densidade dos átomos. ${ }^{87} \mathrm{Rb}_{2}$ com população de ${ }^{87} \mathrm{Rb} 100 \%$ em $\mathrm{F}=1$ (•). ${ }^{85} \mathrm{Rb}_{2}$ com população de ${ }^{85} \mathrm{Rb} 100 \%$ em $\mathrm{F}=2$ (匹). ${ }^{85} \mathrm{Rb}$, com população de ${ }^{85} \mathrm{Rb} 100 \%$ em $\mathrm{F}=3(\boldsymbol{\Delta}) .{ }^{87} \mathrm{Rb}_{2}$ com população de ${ }^{87} \mathrm{Rb} 100 \%$ em $\mathrm{F}=2(\boldsymbol{\nabla}) \ldots \ldots \ldots \ldots \ldots . . . . .145$ 



\section{Lista de Tabelas}

Tabela 3.1 - Valores da profundidade do potencial de aprisionamento de um feixe simples focalizado calculados para $\mathrm{Rb}$ e $\mathrm{K}$ normalizados pelo fator de Boltzmann $K_{B}$. Para uma armadilha com feixes cruzados devemos multiplicar os valores das profundidades por um fator de 2. A potência considerada nos cálculos foi $25 \mathrm{~W}$.

Tabela 3.2 - Valores das freqüências de oscilação calculados para $w_{0}=57 \mu \mathrm{m}$ e potência $25 \mathrm{~W}$. $\omega_{\mathrm{r}}$ foi calculado considerando um feixe cruzado, $\omega_{z}$ foi calculado para um feixe simples.

Tabela 3.3 - Valores típicos obtidos nas armadilhas de dipolo para o ${ }^{85} \mathrm{Rb}$ e ${ }^{87} \mathrm{Rb}$.

Tabela 4.1 - Tabela das constantes $\mathbf{N}_{0}, \mathbf{n}_{0}, \boldsymbol{\gamma}$ e $\boldsymbol{\beta}$ calculadas pelo ajuste da equação 4.3. 0 valor de $\mathbf{w}$ considerado nesta expressão foi $52 \mu \mathrm{m}$ e $62 \mu \mathrm{m}$ para ${ }^{87} \mathrm{Rb}$ e ${ }^{85} \mathrm{Rb}$ respectivamente.

Tabela 4.2 - Coeficentes para taxa de três corpos calculados para o ${ }^{85} \mathrm{Rb}$ e ${ }^{87} \mathrm{Rb}$. 



\section{Sumário}

2.1 Introdução

2.2 Fundamentos da teoria diatômica 37

2.2.1 A aproximação de Born-Oppenheimer $\quad 37$

2.2.2 O princípio de Franck-Condon 40

2.3 Fotoassociação de moléculas homo e heteronucleares. 42

2.4 Aprisionamento de moléculas em armadilhas de dipolo. 45

2.4.1 Aprisionamento de $\mathrm{Cs}_{2} \quad 46$

2.4.2 Aprisionamento de KRb 48

2.5 Produção de moléculas ultrafrias no estado fundamental $(v=0)$

2.5.1 Produção de RbCs $\quad 51$

2.5.2 Produção de $\mathrm{Cs}_{2} \quad 52$

2.5.3 Produção de LiCs $\quad 57$

2.5.4 Produção de KRb $\quad 59$

2.6 Fotoassociação de átomos de $R b$ e resfriamento vibracional de moléculas $R b_{2}$ e $K R b$ com laser em $1064 \mathrm{~nm}$. $\quad 61$

$\underline{3} \underline{\text { A armadilha de dipolo para átomos e moléculas }} 71$

3.1 Armadilha de dipolo: o sistema de vácuo $\quad 71$

$\begin{array}{lll}3.1 .1 & \text { O forno misto } & 74\end{array}$

$\begin{array}{ll}3.1 .2 & \text { O desacelerador misto } \\ & 76\end{array}$

3.1.3 Câmara de aprisionamento $\quad 79$

3.2 O MOT duplo $\quad 81$

3.2.1 Considerações teóricas $\quad 81$

3.2.2 Montagem óptica 84

3.2.3 Alinhamento do MOT duplo $\quad 87$

3.3 A armadilha de dipolo óptica 89

3.3.1 Considerações teóricas 89

3.3.2 Montagem óptica $\quad 92$

3.4 Sistemas de Controle do Experimento 95

3.4.1 Sistema de lock digital 95

$\begin{array}{ll}\text { 3.4.2 Software para controle do experimento } & 97\end{array}$ 
3.5 Carregamento da armadilha de dipolo 98

3.6 Métodos de detecção 100

3.6.1 Imagens de fluorescência 100

3.6.2 Imagens de Absorção 103

3.6.3 Deteç̧ão de moléculas por fotoionização 108

4 Átomos de Rb aprisionados na armadilha de dipolo em $1064 \mathrm{~nm} \quad 113$

4.1 Evolução temporal de átomos aprisionados 113

4.2 Evaporação em um potencial constante e colisões de três corpos 120

$\begin{array}{lll}4.3 & \text { Fotoassociação com laser em } 1064 \mathrm{~nm} & 128\end{array}$

$\underline{5}$ Moléculas $\mathrm{Rb}_{2}$ aprisionadas em uma armadilha de dipolo 131

5.1 A técnica de trem de pulsos para observação de moléculas aprisionadas 131

5.2 Caracterização da técnica de trem de pulsos 134

5.3 Temperatura da amostra molecular usando a técnica de trem de pulsos 139

5.4 Moléculas aprisionadas em uma armadilha de dipolo. 141

$\underline{6}$ Conclusões e perspectivas $\quad 147$

\begin{tabular}{lr} 
Referências & 153 \\
\hline
\end{tabular} 


\section{Introdução}

Os fundamentos para o desenvolvimento moderno da área de física atômica e molecular teve suas origens em meados de 1917, onde ocorreu a primeira análise substancial da pressão de radiação. Naquele ano, Einstein analisou em seu artigo (1) intitulado: "On the Quantum Theory of Radiation", a transferência de momentum entre átomos e fótons devido ao processo de absorção e emissão espontânea. Quarenta anos depois, com a invenção do laser, o trabalho de Einstein encontrou sua aplicação prática e algumas décadas depois, as técnicas de resfriamento e aprisionamento de átomos foram desenvolvidas.

Em 1975, dois grupos introduziram independentemente a idéia de laser cooling, desacelerando átomos utilizando radiação. Suas propostas deram origem à invenção do Zeeman Slower em 1985 realizada por William Phillips. Neste aparato, uma série de bobinas geravam um gradiente de campo magnético mantendo os átomos em ressonância com o laser incidente (2), desacelerando-os. O Zeeman Slower se tornou uma ferramenta comum em física atômica e molecular desacelerando átomos. Contudo, a temperatura final da amostra ainda era da ordem de centenas de mK.

Em 1986, Chu e colaboradores (3), demonstraram o primeiro resfriamento óptico de átomos, atingindo temperaturas de centenas de $\mu \mathrm{K}$. Neste sistema, aproximadamente 50000 átomos de sódio foram resfriados em um meio viscoso formado por três pares de feixes contrapropagantes, este meio veio a ser denominado posteriormente como optical molasses, ou melaço óptico. Entretanto, este sistema apenas demonstrou a prova do princípio de resfriamento atômico, mas ainda não era possível aprisionar os átomos. O MOT (Magneto optical trap), ou a armadilha magneto-óptica, demonstrada em 1987 (4), foi a técnica que possibilitou a produção de amostras numerosas e densas de átomos frios. Esta armadilha é basicamente formada por uma radiação ressonante e um gradiente de campo 
magnético e atualmente é o sistema elementar na maioria dos laboratórios de física atômica.

Com esta combinação de campo magnético estático e radiação, pode-se criar um ambiente que resfria e aprisiona átomos cujas temperaturas iniciais sejam da ordem de $1 \mathrm{~K}$. Com isso, é possível obter amostras atômicas com temperaturas da ordem de centenas de $\mu \mathrm{K}$, densidades entre $10^{10}$ e $10^{12}$ átomos $/ \mathrm{cm}^{3}$ e um total de átomos aprisionados entre $10^{6} \mathrm{e}$ $10^{9}$. Este tipo de armadilha foi fundamental para o desenvolvimento da área de Física Atômica nos últimos vinte anos, permitindo o estudo de colisões atômicas em um regime de temperatura até então inédito (5).

Além das armadilhas magneto-ópticas, existem também, outros tipos de armadilhas como as armadilhas magnéticas e as armadilhas de dipolo ópticas. Nas armadilhas magnéticas, é utilizado um gradiente de campo magnético de modo a interagir com o momento de dipolo magnético dos átomos confinando-os na região de menor campo. Em armadilhas de dipolo, os átomos são confinados pela força de dipolo que o campo elétrico da radiação induz na amostra, estas armadilhas são basicamente formadas por feixes intensos focalizados e com comprimento de onda abaixo das transições atômicas. As armadilhas de dipolo classificam-se em duas: FORT ("Far off ressonance traps") e QUEST ("Quasi eletrostatical traps"), nomes relacionados as suas características básicas, como potência e comprimento de onda. Em (6) podemos encontrar uma boa referência explorando o funcionamento de todos esses sistemas.

O sucesso dessas técnicas de aprisionamento e resfriamento propiciou um avanço considerável no estudo de colisões atômicas nos regimes frios e ultrafrios, em que se encontram um fascinante objeto de estudo teórico e experimental. Neste cenário, podemos citar o desenvolvimento de relógios atômicos obtidos em experimentos com metrologia de tempo e freqüência com alta precisão $(7,8)$; a condensação de Bose-Einstein (BEC) (9-12) obtida pela primeira vez em 1995; e a formação de moléculas no estado eletrônico fundamental $(13,14)$ o qual será o principal objeto de estudo deste trabalho.

Nos últimos anos, a produção e o estudo de moléculas ultrafrias vem sofrendo um rápido progresso. A expansão do estudo de átomos ultrafrios para sistemas moleculares ultrafrios é um importante passo para o estudo de uma estrutura mais complexa (15). Por 
possuírem mais graus de liberdade internos, moléculas ultrafrias abrirão novas oportunidades para a investigação experimental. A produção de moléculas diatômicas heteronucleares alcalinas no estado vibracional fundamental absoluto, ${ }^{1} \Sigma^{+}(v=0)$, abriria certamente a possibilidade de realizar avançados experimentos em várias áreas da Física. Podemos encontrar modelos teóricos na literatura (16-19) que propõem um computador quântico utilizando moléculas diatômicas em redes ópticas. Nesta proposta, devido à magnitude do momento de dipolo elétrico das moléculas heteronucleares (20), pode-se orientar esses momentos de dipolo por um campo elétrico externo formando os chamados qubits (21), que são a base da teoria em computação quântica.

A investigação e o controle de reações químicas ultrafrias (22), que utilizam experimentos de colisões átomo-molécula, são experimentos promissores nessa área. Medidas precisas de constantes fundamentais também são uma boa proposta para experimentos com moléculas frias, podemos citar: medidas da variação temporal da razão da massa próton-elétron (23) e a busca do momento de dipolo permanente do elétron (EDM) (24).

O desafio de se trabalhar com moléculas ultrafrias advém do fato da impossibilidade de resfriamento e confinamento em um MOT do mesmo modo que é feito com os átomos. Moléculas diatômicas possuem em seus estados eletrônicos, vários níveis vibracionais e rotacionais, tornando inviável a criação de um ciclo fechado de aprisionamento e rebombeio entre seus níveis. Diante disso, surgiram, há alguns anos atrás, propostas para o aprisionamento de moléculas. Dentre elas, destacamos o trabalho proposto por Bahlns e colaboradores (15) o qual propõe uma técnica ("Multi-single-frequency") para reduzir seqüencialmente as energias rotacionais, translacionais e vibracionais da molécula. Neste esquema, vários ciclos de transições seriam aplicados às moléculas. Entretanto, este método requer uma fonte de radiação com múltiplas freqüências a qual se torna experimentalmente complexo. Weinstein e colaboradores $(25,26)$ utilizaram um método, conhecido como Buffer Gas que possibilitou o resfriamento de moléculas paramagnéticas em armadilhas magnéticas através do processo de termalização. Neste método, $10^{8}$ moléculas de $\mathrm{CaH}$ foram produzidas a uma temperatura de $400 \mathrm{mK}$ (26). Também se podem produzir amostras mais numerosas ao custo de uma temperatura mais elevada como é reportado em $(27,28)$, em que obtiveram $10^{12}$ moléculas de $\mathrm{PbO}$ a $4 \mathrm{~K}$ e $10^{12}$ moléculas de $\mathrm{NH}$ a uma temperatura 
menor que $6 \mathrm{~K}$. Esta é uma técnica geral podendo ser aplicada a qualquer molécula paramagnética. Outro método alternativo para o resfriamento de moléculas foi demonstrado por Bethlem e colaboradores. Neste, um feixe supersônico de moléculas de CO a uma velocidade média de $225 \mathrm{~m} / \mathrm{s}$ foi desacelerada para $98 \mathrm{~m} / \mathrm{s}$ (29) utilizando um desacelerador Stark, neste sistema um campo elétrico variável é aplicado durante o percurso do feixe reduzindo a energia translacional das moléculas, os detalhes dessa técnica podem ser encontrados em (30). Embora essas técnicas tenham grande aplicação, as amostras moleculares geradas por elas ainda se encontram em temperaturas muito elevadas, acima de $10 \mathrm{mK}$, e densidades muito baixas.

A alternativa mais viável no momento para trabalhar com moléculas ultrafrias é produzi-las diretamente de uma amostra de átomos frios. Atualmente, existem duas técnicas empregadas para tal. Uma delas é a utilização do processo de fotoassociação (PA) de pares atômicos, o qual foi teoricamente investigado por Thorsheim e colaboradores. em 1987 (31, 32). A outra técnica é conhecida como magnetoassocição (MA), induzindo ressonâncias de Feshbach nos pares atômicos através de campos magnéticos (32-34).

No processo de PA, cria-se uma molécula excitada pela colisão de dois átomos na presença de um fóton ressonante. As moléculas resultantes produzidas pelo processo de PA e seu subseqüente decaimento por emissão espontânea, são em geral, moléculas com níveis vibracionais $(v)$ elevados. No trabalho de Fioretti e colaboradores (13) em 1998 foi observado a primeira molécula ultrafria de $\mathrm{Cs}_{2}$ formada por fotoassociação. Alguns anos depois, várias outras moléculas puderam ser formadas e observadas em que destacamos: A molécula de $K_{2}$ produzida por Nikolov e colaboradores $(35,36) ; R_{2}$ observado por Gabbanini e colaboradores (14) em 2000; $\mathrm{Na}_{2}$ observado em 2001 por Fatemi e colaboradores (37). Moléculas heteronucleares também puderam ser produzidas recentemente pelo processo de PA: RbCs produzidas por Kerman e colaboradores $(38,39)$; KRb por Mancini e colaboradores (40) e Wang e colaboradores (41); NaCs por Haimberger e colaboradores em (42) e LiCs observadas por Kraft e colaboradores $(43,44)$.

No processo de MA, moléculas são formadas aplicando-se um campo magnético externo. Este campo sintoniza o comprimento de espalhamento durante a colisão de modo que o par atômico encontre um estado ligado molecular (44). As moléculas resultantes do 
processo de ressonância de Feshbach se encontram nos mais altos níveis vibracionais do estado fundamental molecular. Em 2002, Donley e colaboradores (45) produziram e detectaram uma amostra mista de átomos e moléculas utilizando um $\mathrm{BEC}$ de ${ }^{85} \mathrm{Rb}$ via ressonâncias de Feshbach variando sutilmente seu campo magnético. No mesmo ano, Chin e colaboradores (46) observaram a dinâmica de formação de moléculas quasi-ligadas de $\mathrm{Cs}_{2}$ próximas a ressonâncias de Feshbah em uma amostra ultrafria de átomos de Cs. Eles atingiram uma densidade atômica de $10^{13} \mathrm{~cm}^{-3}$ a uma temperatura de $5 \mu \mathrm{K}$ com mais de $5 \mathrm{x}$ $10^{5}$ moléculas de $\mathrm{Cs}_{2}$ em um único estado rovibracional coexistindo com $10^{8}$ átomos de Cs. Em 2003, Regal e colaboradores (47) produziram aproximadamente $2,5 \times 10^{5}$ moléculas de ${ }^{40} \mathrm{~K}_{2}$ aprisionadas, ao mesmo tempo, Strecker e colaboradores (48) converteram átomos de ${ }^{6} \mathrm{Li}$ de um sistema ultrafrio em moléculas ${ }^{6} \mathrm{Li}_{2}$. Aproximadamente $1,5 \times 10^{5}$ moléculas de ${ }^{6} \mathrm{Li}_{2}$ foram produzidas com eficiência de $50 \%$. Em seguida, dois grupos europeus também reportaram a criação de moléculas de ${ }^{6} \mathrm{Li}_{2}$; Cubizolles e colaboradores (49) obtiveram a transferência de $85 \%$ e Joachim e colaboradores (50) produziram uma amostra pura com $3 \mathrm{x}$ $10^{5}$ moléculas em uma armadilha óptica. Xu e colaboradores (51) produziram $10^{5}$ moléculas de $\mathrm{Na}_{2}$ ultrafrias em um BEC com uma eficiência de conversão de $4 \%$. Finalmente, citamos aqui os trabalhos de Jin, Grimm e Ketterle formando moléculas a partir de BECs explorando as ressonâncias de Feshbach (52-54).

Uma vez que moléculas são produzidas por PA ou MA, o passo seguinte é detectá-las seletivamente resolvendo os estados vibracionais moleculares. No caso de moléculas formadas via ressonância de Feshbach, pode-se detectá-las seletivamente através da aplicação de radio freqüência (RF), pois sua energia de ligação é muito baixa, da ordem de alguns $\mathrm{MHz}$ (52) ou por técnica de imagens por absorção convertendo-as novamente em átomos livres. Moléculas produzidas pelo processo de PA são geralmente produzidas em níveis rovibracionais mais profundos e na maioria dos casos só podem ser detectadas através de ionização por dois fótons.

Com relação à produção de moléculas alcalinas no estado fundamental, ou seja, ${ }^{1} \Sigma^{+}$ $(v=0)$, destacamos o trabalho de cinco grupos de pesquisa. As moléculas produzidas até o momento foram: $\mathrm{K}_{2}, \mathrm{Cs}_{2}, \mathrm{RbCs}$, LiCs, KRb (55-58). Nestes trabalhos, moléculas são inicialmente formadas pelos processos de PA ou MA nos níveis vibracionais mais altos do estado eletrônico fundamental. Assim, através de técnicas de bombeamento óptico por 
laser de banda larga, como reportado em (55) ou a técnica STIRAP (Stimulated Raman Adiabatic Passage) reportado em $(57,58)$, moléculas são bombeadas para estados vibracionais mais profundos inclusive o estado vibracional fundamental $v=0$. Dentre estes trabalhos destacamos o trabalho realizado com moléculas de $\mathrm{KRb}$, o qual apresenta uma maior complexidade experimental, envolvendo um MOT duplo, aprisionamento magnético e óptico, dois estágios de evaporação para obtenção de um BEC, um estágio de ressonância de Feshbach e finalmente a utilização da técnica STIRAP. Apesar de sua complexidade foi o único trabalho com o qual se pode pela primeira vez produzir e aprisionar opticamente moléculas no estado fundamental. Os detalhes experimentais desses sistemas serão detalhados ao desenvolver desta tese. Como ficará claro, todos estes experimentos envolvem técnicas muito complexas, o que inviabiliza sua disseminação para outros grupos de pesquisa.

Diante do problema do aprisionamento e da produção de moléculas ultrafrias no estado fundamental, descreveremos nesse trabalho, a construção de um novo sistema experimental bem simplificado. Trata-se de uma armadilha de dipolo totalmente óptica, formada por um laser de fibra com $40 \mathrm{~W}$ de potência com comprimento de onda em 1064 $\mathrm{nm}$. A grande vantagem desse sistema é que as armadilhas de dipolo são um método mais universal de aprisionamento. Essas armadilhas operam com lasers com grandes dessintonias para o vermelho com freqüências muito abaixo da primeira freqüência de ressonância confinando partículas na região de maior intensidade. Nesse sistema será possível o aprisionamento de átomos $\mathrm{Rb}$ e $\mathrm{K}$ e moléculas $\mathrm{Rb}_{2}, \mathrm{~K}_{2}$ e $\mathrm{KRb}$ em densidades muito altas, e em períodos de tempo da ordem de $1 \mathrm{~s}$.

No capítulo 2, apresentaremos os fundamentos teóricos sobre a estrutura molecular diatômica como a aproximação de Born-Oppenheimer e o princípio de Franck-Condon. Exploraremos a física envolvida no processo de PA para uma colisão de um par atômico genérico. Descreveremos em detalhes as técnicas desenvolvidas atualmente para a produção de moléculas no estado fundamental ${ }^{1} \Sigma^{+}(v=0)$, e os trabalhos realizados com o aprisionamento de moléculas em armadilhas ópticas. Finalizaremos este capítulo com nosso desenvolvimento teórico sobre a possibilidade de fotoassociação de átomos de $\mathrm{Rb} e$ resfriamento vibracional de moléculas de $\mathrm{Rb}_{2}$ e $\mathrm{KRb}$ por um laser em $1064 \mathrm{~nm}$, o qual será utilizado para o aprisionamento dessas espécies. 
No capítulo 3, mostraremos toda a etapa de construção do experimento. Nele descreveremos o sistema de vácuo projetado para a desaceleração e o aprisionamento de duas espécies atômicas ( $\mathrm{Rb}$ e K) simultaneamente com apenas um desacelerador (Zeeman slower) a partir de um forno misto a uma temperatura de $140^{\circ} \mathrm{C}$. Este sistema foi projetado para operar em regimes de UHV (ultra alto vácuo), isto é, pressões abaixo de $10^{-10}$ torr na região de aprisionamento. Os projetos desse sistema foram desenvolvidos em Solid Works e serão apresentados em detalhes nas primeiras seções desse capítulo. As montagens ópticas e os conceitos teóricos para a realização do MOT duplo, desaceleração, armadilha de dipolo e sistemas de imagens serão apresentados também. Na seqüência, apresentaremos todo o desenvolvimento de softwares e hardwares para o controle e aquisição de dados do experimento e finalizaremos explicando as técnicas de deteç̧ão utilizadas as quais destacamos: imagens por absorção e fluorescência e a técnica de tempo de vôo para detecção de íons moleculares.

Seguiremos com o capítulo 4 demonstrando o mecanismo de transferência e aprisionamento de átomos de ${ }^{85} \mathrm{Rb},{ }^{87} \mathrm{Rb}$ e ${ }^{39} \mathrm{~K}$ na armadilha de dipolo óptica previamente aprisionados em um MOT. As curvas de decaimento das espécies ${ }^{85} \mathrm{Rb},{ }^{87} \mathrm{Rb}$ serão analisadas para amostras produzidas em diferentes estados hiperfinos do estado fundamental. Um modelo teórico foi desenvolvido para explicar esta dinâmica. O aprisionamento de moléculas de ${ }^{85} \mathrm{Rb}_{2},{ }^{87} \mathrm{Rb}_{2}$ na armadilha de dipolo será demonstrado no capítulo 5 . Neste, desenvolvemos uma técnica que permite o estudo rápido e direto do decaimento no número de moléculas na armadilha e observamos o comportamento dessas moléculas na presença de átomos preparados em um determinado estado hiperfino do estado fundamental. Analisando esses resultados, teremos finalmente no capítulo 6, as conclusões e perspectivas rumo a produção de um sistema que possa produzir e aprisionar moléculas no estado fundamental ${ }^{1} \Sigma^{+}(v=0)$. 



\section{A busca por moléculas frias}

\subsection{Introdução}

O objetivo deste capítulo é fazer uma revisão básica de conceitos físicos moleculares e da literatura recente sobre a produção de moléculas frias a partir de átomos aprisionados. Detalhes maiores em conceitos moleculares podem ser encontrados em (59). Finalizaremos apresentando uma proposta teórica de aprisionamento e bombeamento de moléculas de $\mathrm{Rb}_{2}$ e KRb com laser de $1064 \mathrm{~nm}$ para baixos estados vibracionais no estado eletrônico fundamental.

\subsection{Fundamentos da teoria diatômica}

\subsubsection{A aproximação de Born-Oppenheimer}

O modelo molecular é baseado na distribuição espacial de elétrons em torno de núcleos constituídos por prótons e nêutrons. Apesar de sua estrutura ser considerada mais complicada que a dos átomos isolados, podemos simplificar o problema pelo fato de que a massa do elétron é muito menor que a massa do núcleo, assim as acelerações a que as partículas estão submetidas diferem por algumas ordens de grandeza. 
Comparando as ordens de grandeza das energias de vibração $\left(E_{v}\right)$ e rotação $\left(E_{r}\right)$ moleculares (equações 2.1 e 2.2) com a energia cinética do elétron $\left(E_{e} \simeq e V\right.$ ) em sua orbita obtemos razões da ordem de $10^{-2}$ e $10^{-4}$, pois as razões $(\mathrm{m} / \mathrm{M})$ estão em um intervalo de $10^{-3}$ a $10^{-5}$. Devido a essas estimativas fica claro que os períodos de rotação e vibração do núcleo são muito maiores do que o período orbital dos elétrons, assim seus movimentos podem ser tratados independentemente, sendo esta uma boa aproximação para a determinação de estados eletrônicos quando fixamos um valor de separação internuclear. Essa aproximação é conhecida como a aproximação de Born-Oppenheimer. Uma discussão sobre os limites da aproximação de Born-Oppenheimer pode ser encontrada na referência (60).

$$
\begin{aligned}
& E_{v} \simeq\left(\frac{m}{M}\right)^{1 / 2} E_{e} \\
& E_{r} \simeq \frac{m}{M} E_{e}
\end{aligned}
$$

A equação de Schroedinger independente do tempo para um sistema molecular diatômico é dada por:

$$
\left[T_{n}+T_{e}+V\right] \Psi\left(R ; r_{1}, r_{2}, \ldots . r_{N}\right)=E \Psi\left(R ; r_{1}, r_{2}, \ldots . r_{N}\right)
$$

em que $T_{n}$ e $T_{e}$ são as energias cinética das partículas do núcleo e elétrons respectivamente e $\mathbf{V}$ é a soma das interações de Coulomb entre todos os pares de partículas. A função de onda pode ser escrita como:

$$
\Psi\left(R ; r_{1}, r_{2}, \ldots . r_{N}\right)=\sum_{q} F_{q}(R) \Phi_{q}\left(R ; r_{1}, r_{2}, \ldots . r_{N}\right)
$$


em que $F_{q}(R)$ são funções que representam o movimento do núcleo e $\Phi_{q}\left(R ; r_{1}, r_{2}, \ldots . r_{N}\right)$ são as funções de onda de cada elétron calculada a partir de uma distância internucelar $\mathbf{R}$ fixada.

Considerando a aproximação de Born-Oppenheimer, teremos que $\nabla_{R} \Phi_{q} \ll \nabla_{R} F_{q}(R)$, assim os estados de rotação e vibração do núcleo desacoplam-se dos estados eletrônicos, fazendo a energia total do sistema ser igual a soma da energia dos elétrons $E_{S}\left(R_{0}\right)$ com a energia rotacional $E_{r}$ e a vibracional do núcleo $E_{v}$ :

$$
E_{s, v, r}=E_{s}\left(R_{0}\right)+E_{r}+E_{v}
$$

A nomenclatura dos estados moleculares, no caso de moléculas diatômicas, é dada por:

$$
{ }^{2 S+1} \Lambda_{\mathrm{g}, \mathrm{u}}^{+,-}
$$

nesta representação, $\boldsymbol{\Lambda}$ é o número quântico da projeção do momento angular eletrônico total no eixo internuclear que pode ser: $\Sigma=0, \Pi=1, \Delta=2, \Phi=3, \ldots ; \mathbf{S}$ é o spin individual dos elétrons, os símbolos + e - indicam se a função de onda é invariante ao se aplicar uma reflexão no plano contendo o eixo do núcleo; $\mathbf{g}$ e $\mathbf{u}$ indicam se a função é invariante a uma operação do tipo $\mathrm{r}_{i} \rightarrow-\mathrm{r}_{i}$ em que todos os elétrons são invertidos com respeito a origem (esses índices são usados apenas no caso de moléculas diatômicas homonucleares). Geralmente colocam-se mais um símbolo indicando o estado eletrônico, como por exemplo $X^{1} \Sigma_{\mathrm{g}}^{+}$, neste caso particular $\mathrm{X}$ é o estado fundamental eletrônico de uma molécula diatômica.

Os potenciais moleculares podem ser escritos como uma série de potências em $1 / R$ (eq. 2.7). Estes são calculados principalmente considerando as perturbações entre dois 
átomos separados, e da magnitude da interação entre diferentes momenta angulares e seu acoplamento com o eixo molecular, definidos por diferentes casos de Hund (61).

$$
V(R)=-\Sigma_{\mathrm{n}} \frac{C_{n}}{R^{n}}
$$

No caso das assíntotas fundamentais $\mathrm{S}+\mathrm{S}$ das moléculas homo e heteronucleares a interação corresponde a $n=6$, ou seja, uma interação atrativa de Van der Walls $-C_{6} / R^{6}$. Para a primeira assíntota excitada $\mathrm{S}+\mathrm{P}$, a interação predominante para o caso de dois átomos idênticos é a interação de dipolo-dipolo ressonante $-C_{3} / R^{3}$, e no caso hetero temos a interação de Van der Walls $\pm C_{6} / R^{6}$ como predominante.

\subsubsection{0 princípio de Franck-Condon}

O fato dos períodos de rotação e de vibração nucleares serem muito maiores que o período orbital dos elétrons, nos permite considerar que as transições eletrônicas devem ser instantâneas com relação à escala de tempo das vibrações e rotações, isto é, elas ocorrem a um valor constante $R$ e $d R / d t$, ou seja a separação e a velocidade relativa dos núcleos não varia. Assim, considerando a energia potencial em função da distância internuclear (R), uma transição entre um estado eletrônico A e vibracional $v_{a}$ para um estado B e vibracional $v_{b}$ deve ocorrer através de uma linha perpendicular ao eixo R (figura 2.1). Este por sua vez é conhecido como o princípio de Franck-Condon. 


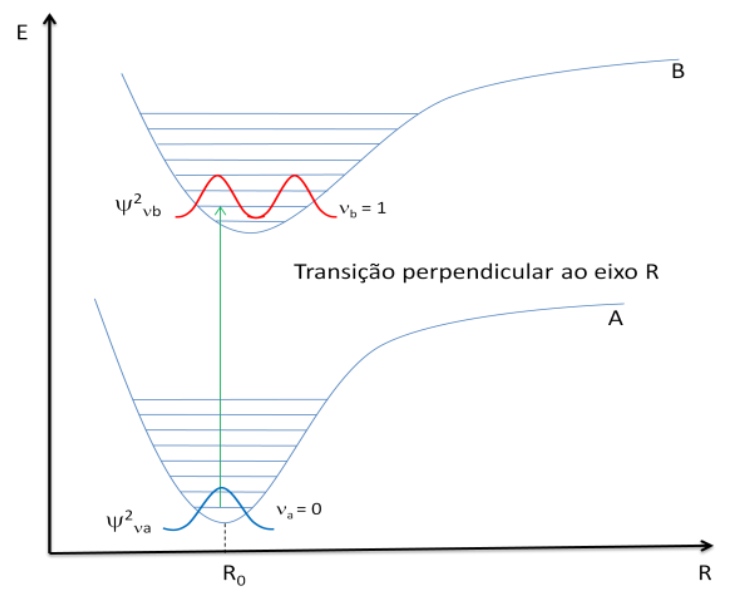

Figura 2.1 - Transição entre um estado vibracional $v_{a}$ de um estado eletrônico A para o vibracional $v_{b}$ de um estado eletrônico $B$. Considerando o princípio de Franck-Condon a transição deve ocorrer através de uma linha perpendicular ao eixo $R$ (linha verde). $O$ acoplamento depende do overlap entre as funções de onda do estado fundamental ( $\left.\psi_{v a}\right)$ e excitado $\left(\psi_{v b}\right)$.

A amplitude dessa transição é proporcional ao elemento de matriz do operador de dipolo. Sendo $\Psi_{\mathrm{b}}$ o estado final e $\Psi_{\mathrm{a}}$ o estado inicial, teremos:

$\left\langle\Psi_{\mathrm{b}}|D| \Psi_{\mathrm{a}}\right\rangle$

$=e \int d R \int d r F_{b}^{*}(R) \Phi_{\mathrm{b}}^{*}\left(R ; r_{1}, r_{2}, \ldots r_{n}\right)\left(\sum_{\mathrm{i}=1}^{2} z_{i} R_{i}-\Sigma_{\mathrm{j}} r_{j}\right) F_{a}(R) \Phi_{\mathrm{a}}\left(R ; r_{1}, r_{2}, \ldots r_{n}\right)$

devido a ortogonalidade das funções de onda eletrônicas $\left(\Phi_{\mathrm{b}}\right.$ e $\left.\Phi_{\mathrm{a}}\right)$, o primeiro termo das expressão é nulo, assim temos;

$$
\left\langle\Psi_{\mathrm{b}}|D| \Psi_{\mathrm{a}}\right\rangle=\int d R F_{b}^{*}(R) D_{e l}(R) F_{a}(R)
$$

em que: 


$$
\begin{gathered}
F_{a}(R)=\psi_{v_{a}} \phi_{J, M, \Lambda} \\
D_{e l}(R)=-e \int d r \Phi_{\mathrm{b}}^{*}\left(R ; r_{1}, r_{2}, \ldots . r_{N}\right)\left(\sum_{j} r_{j}\right) \Phi_{a}\left(R ; r_{1}, r_{2}, \ldots . r_{N}\right)
\end{gathered}
$$

Considerando $D_{e l}(R)$ independente de $\mathrm{R}$ concluímos que a amplitude de transição da expressão (2.9) é proporcional ao fator de Franck-Condon:

$$
f_{v_{b} v_{a}}=\int d R \psi_{v_{b}}^{*} \psi_{v_{a}}
$$

esta quantidade nada mais é que o superposição das funções de onda vibracionais $\psi_{v_{a}}$ e $\psi_{v_{b}}^{\prime}$ entre diferentes estados eletrônicos.

\subsection{Fotoassociação de moléculas homo e heteronucleares.}

O processo de fotoassociação (PA) (31) é comum em armadilhas magneto-ópticas, e podem ocorrer naturalmente devido ao laser da armadilha, ou então pela utilização de um laser extra. Neste processo, dois átomos no estado fundamental com energia cinética relativa $\mathbf{E}$, colidem na presença de um laser com freqüência $\omega_{P A}$ sintonizado abaixo da ressonância atômica $\omega_{0}$. Como mostra a figura 2.2, eles podem absorver esse fóton e acoplar a um estado ligado excitado molecular, este processo pode ser escrito pela equação 2.13: 


$$
A(S)+A(S)+\hbar \omega_{P A} \rightarrow A_{2}\left(\Lambda_{\mathrm{g}, \mu} ;\left(v^{\prime}, J^{\prime}\right)\right)
$$

com energia de ligação:

$$
\hbar \Delta=\hbar \omega_{0}-\hbar \omega_{P A}-E
$$

em que $v^{\prime}$ e $J^{\prime}$ são os números quânticos dos estados vibracionais e rotacionais. Para átomos inicialmente no estado fundamental assumimos a energia interna $\mathrm{E}(\mathrm{s})=0$, e $\Delta \mathrm{E}=E(P)-$ $E(S)=\hbar \omega_{0}$, assim a energia final desse estado excitado será dada por:

$$
E_{f}\left(v^{\prime}, J^{\prime}\right)=\Delta E-\Delta \mathrm{E}_{\mathrm{b}}\left(v^{\prime}, J^{\prime}\right)=\hbar \omega_{0}-\Delta E_{b}\left(v^{\prime}, J^{\prime}\right)
$$

Em que $\Delta E_{b}\left(v^{\prime}, J^{\prime}\right)$ é a energia de ligação deste estado.

As moléculas excitadas, formadas por PA, têm um curto tempo de vida (quasemolécula) e decaem por emissão espontânea. Dependendo da separação internuclear (R) em que ocorre o decaimento pode-se gerar um par de átomos livres ou uma molécula no estado eletrônico fundamental. No primeiro caso ( equação 2.16) o decaimento ocorre na região de longo alcance ou na intermediária de separação internucleares, nesse caso o par atômico recebe um acréscimo na sua energia cinética de $\hbar \omega_{2}$ sendo capaz de romper o potencial de uma armadilha magneto-óptica (processo de trap loss) (62). No segundo caso (equação 2.17) o decaimento ocorre na região de curto alcance e a molécula decai em um estado vibracional do potencial fundamental (singleto ou tripleto) contínuo por emissão espontânea. Esse processo de decaimento espontâneo também leva em conta os fatores de Franck-Condon da transição, portanto este acoplamento será mais intenso com os estados vibracionais de alto valor de $\boldsymbol{v}$ do estado eletrônico fundamental, pois a molécula do estado excitado é fotoassociada também com um nível vibracional $\boldsymbol{v}$ elevado. 


$$
A_{2}\left(\Lambda_{\mathrm{g}, \mu} ;\left(v^{\prime}, J^{\prime}\right)\right) \rightarrow A(S)+A(s)+\hbar \omega_{2}
$$

$$
A_{2}\left(\Lambda_{\mathrm{g}, \mu} ;\left(v^{\prime}, J^{\prime}\right)\right) \rightarrow A_{2}\left(X(a)^{1(3)} \Sigma_{\mathrm{g}(\mu)}^{+} ;(v, J)\right)+\hbar \omega_{3}
$$

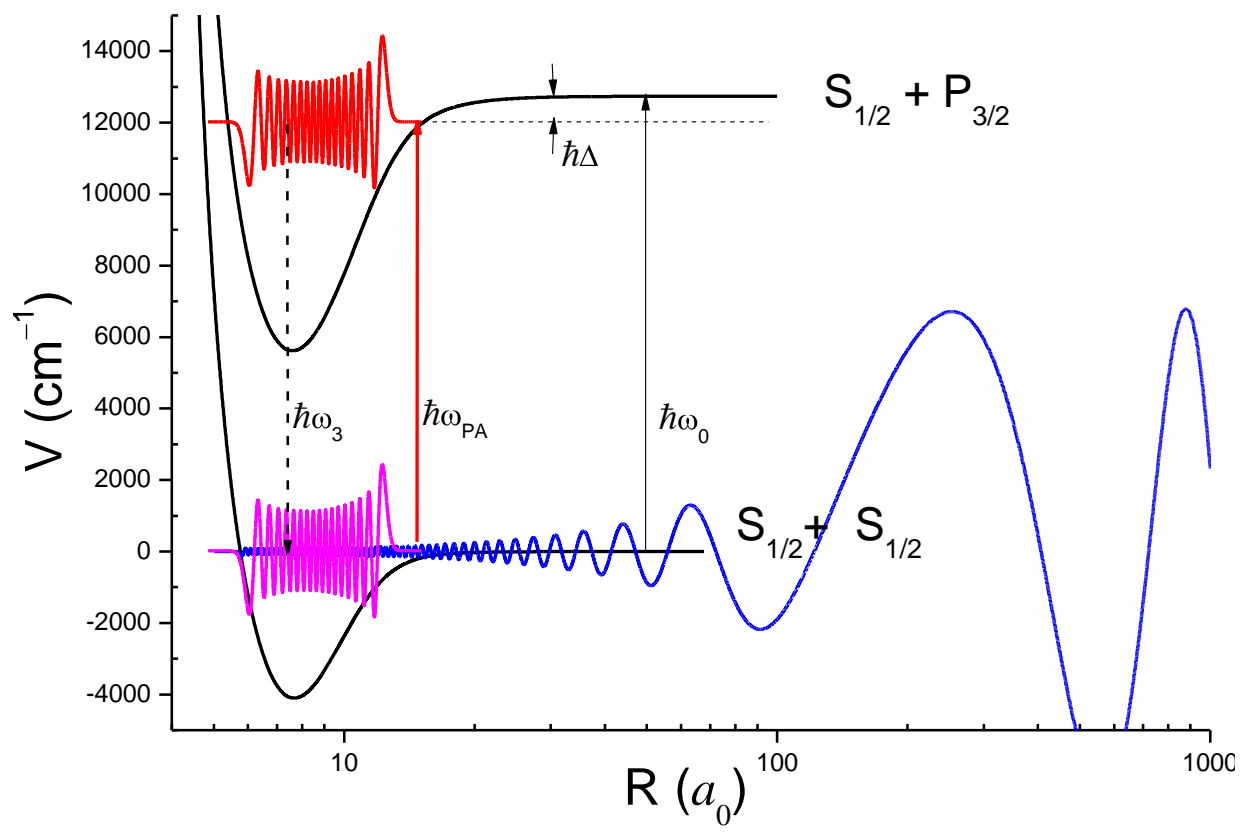

Figura 2.2 - Fotoassociação e decaimento espontâneo da transição free-bound envolvida no processo que leva à formação de moléculas no estado fundamental. Os estados $S_{1 / 2}+S_{1 / 2}$ e $S_{1 / 2}+$ $P_{3 / 2}$ representam os estados eletrônicos fundamental e excitado de um par atômico qualquer. A linha azul representa a função de onda $S$ de uma colisão de dois átomos livres que é acoplada a um estado ligado por um fóton ( $\left.\omega_{P A}\right)$. Este, por sua vez, decai por emissão espontânea $\left(\omega_{3}\right)$ formando uma molécula no estado fundamental. Nesse processo, há uma baixa intensidade da função de onda (linha azul) na parte interna do potencial, a qual se acopla melhor com os estados vibracionais de alto valor de $v$ do estado eletrônico excitado e estes, conseqüentemente, se acoplam melhor aos estados vibracionais excitados no fundamental eletrônico.

Através do processo de fotoassociação já foi possível observar, em ordem cronológica, as seguintes moléculas homo e heteronucleares ultrafrias no estado fundamental: $\mathrm{Cs}_{2}, \mathrm{~K}_{2}, \mathrm{Rb}_{2}, \mathrm{Na}_{2}, \mathrm{RbCs}, \mathrm{KRb}, \mathrm{NaCs}$, $\operatorname{LiCs}(13,14,35,37,39,40,42,43)$. A observação direta das moléculas foi feita por fotoionização por dois fótons e detecção do íon por espectro de tempo de vôo, entraremos em mais detalhes sobre está técnica no capítulo 3. 


\subsection{Aprisionamento de moléculas em armadilhas de dipolo.}

Moléculas diatômicas produzidas em um MOT possuem densidades algumas ordens de grandeza menores que a dos átomos e também não podem ser confinadas utilizando a força espontânea da radiação. Isto ocorre porque seus estados eletrônicos possuem vários níveis vibracionais e rotacionais tornando inviável a criação de um ciclo fechado de aprisionamento e rebombeio entre seus níveis (esta afirmação se esclarecerá na seção 3.2.1 em que discutiremos o funcionamento da armadilha magneto-óptica). O aprisionamento de moléculas via armadilhas magnéticas já foi demonstrado em $(63,64)$, porém com pouco sucesso. O potencial de aprisionamento dessas armadilhas depende essencialmente da interação do momento magnético da molécula com o gradiente de campo aplicado. $\mathrm{Na}$ prática as moléculas formadas não são polarizadas, assim uma pequena fração ( 20 \%) terá uma interação com o campo de modo que o potencial de aprisionamento supere a força da gravidade. Além do mais, devido à fraca interação com o campo, moléculas ocuparão um volume relativamente grande limitando a densidade da amostra.

Para aumentar a densidade de moléculas na amostra, métodos para aprisionamento de moléculas foram implementados. Enquanto armadilhas magnéticas podem aprisionar apenas alguns tipos de moléculas (moléculas polares e paramagnéticas), as armadilhas de dipolo são um método mais universal de aprisionamento. Essas armadilhas operam com lasers com grandes dessintonias para o vermelho com freqüências muito abaixo da primeira freqüência de ressonância confinando partículas na região de maior intensidade, discutiremos esse processo em mais detalhes na seção 3.3.1 . Assim, nesta seção, revisamos dois importantes trabalhos realizados com moléculas aprisionadas em armadilhas de dipolo ópticas. 


\subsubsection{Aprisionamento de $\mathrm{Cs}_{2}$}

Primeiramente descrevemos o trabalho realizado com moléculas de $\mathrm{Cs}_{2}$ por Peter Staanum, e colaboradores (65). Neste trabalho foi demonstrado o aprisionamento dessas moléculas e um estudo de colisões átomo-molécula e molécula-molécula na armadilha. Basicamente moléculas eram fotoassociadas a partir de átomos aprisionados em uma armadilha de dipolo com laser $\mathrm{CO}_{2}$. A seqüência experimental começava com um MOT de onde era carregado $2 \times 10^{5}$ átomos de Cs no estado hiperfino fundamental $F=3$ na armadilha de dipolo resultando numa densidade de $10^{11} \mathrm{~cm}^{-3}$. Os átomos eram bombeados opticamente para o estado $\mathrm{F}=4$ e fotoassociados em moléculas durante $100 \mathrm{~ms}$ por um laser Ti:Sa de $600 \mathrm{~W} / \mathrm{cm}^{2}$ produzindo $~ 5000$ moléculas na armadilha. Essas moléculas eram fotoassociadas pelos estados vibracionais $v^{\prime}=6$ ou $v^{\prime}=79$ do potencial $O_{g}{ }^{-}\left({ }^{2} \mathrm{P}_{3 / 2}\right)$ de modo que podiam decair respectivamente nos níveis do estado tripleto fundamental $\left(a^{3} \Sigma_{\mu}^{+}\right)$ $v=32-47$ ou $v=4-6$. Na figura 2.3 , mostramos a população molecular em função do tempo na ausência e na presença de átomos de Cs no estado $F=3$. Com uma densidade de átomos média da ordem de $9 \times 10^{10} \mathrm{~cm}^{-3}$, o tempo de vida das moléculas é reduzido por um fator de 7 comparado com o experimento sem átomos.

Neste caso as colisões com átomos podem induzir perdas devido à redução dos níveis vibracionais e rotacionais das moléculas ou pela mudança de estrutura hiperfina (para átomos de $\mathrm{Cs}$ em $\mathrm{F}=4$ ), nos dois casos a energia liberada pela colisão ( $2 \mathrm{mK}$ ) excede a profundidade do potencial de aprisionamento. Como o número de moléculas é muito menor que o número de átomos na armadilha, a evolução temporal das moléculas foi descrita pela equação de taxa:

$$
\dot{N}_{m o l}=-\left[\frac{8}{\sqrt{27}} \beta \mathrm{n}_{\mathrm{at}}(\mathrm{t})+\Gamma_{\text {mol }}\right] N_{m o l}
$$


em que $\beta$ é a taxa de colisão inelástica átomo-molécula, $\Gamma_{\text {mol }}$ é a taxa de perda de moléculas por colisões com o vapor de fundo, $\mathrm{n}_{\mathrm{at}}(\mathrm{t})$ é a densidade atômica, cuja variação é muito lenta comparada com a variação da densidade molecular. 0 fator $8 / \sqrt{27}$ surge da média da distribuição espacial dos átomos e moléculas assumindo uma mesma temperatura para ambos. Variando a densidade atômica da armadilha os autores mediram a dependência da taxa de perda na armadilha molecular do sistema (figura 2.4), definida por:

$$
\mathrm{B}=\left[\frac{8}{\sqrt{27}} \beta \mathrm{n}_{\mathrm{at}}(\mathrm{t})+\Gamma_{\mathrm{mol}}\right]
$$

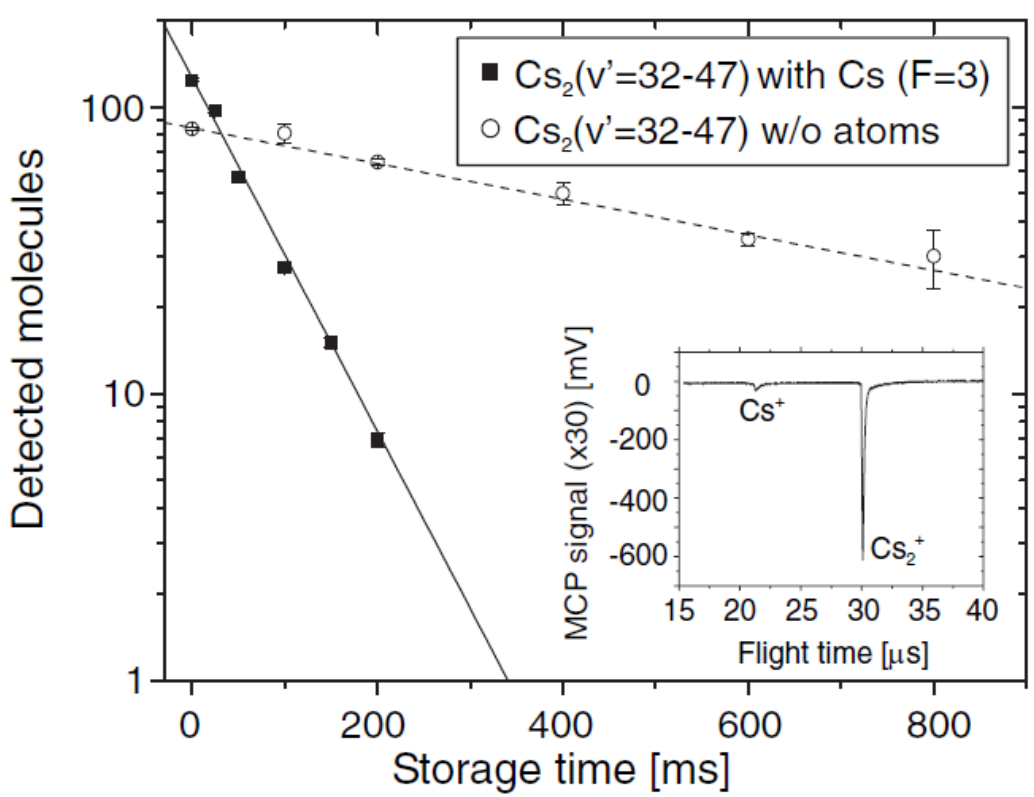

Figura 2.3 - Tempo de vida de moléculas de $\mathrm{Cs}_{2}(\boldsymbol{v}=32-47)$ aprisionadas na armadilha de dipolo na presença de átomo de $\mathrm{Cs}$ em $\mathrm{F}=3$ e na ausência. A densidade medida dos átomos para a medida foi de $9 \times 10^{10} \mathrm{~cm}^{-3}$. Figura extraída de (65). 


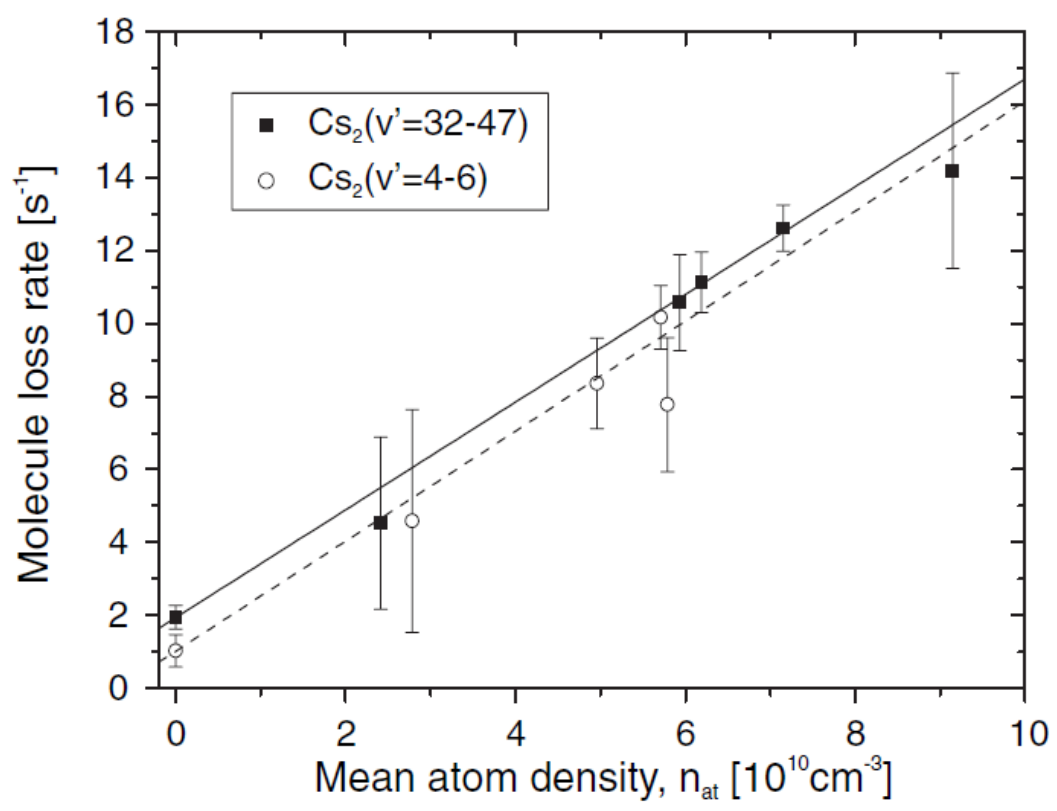

Figura 2.4 - Dependência da taxa de perda molecular $\boldsymbol{B}$ para os estados $(\boldsymbol{v}=32-47)$ e $(\boldsymbol{v}=4-6)$ em função da densidade dos átomos. Figura extraída de (65).

\subsubsection{Aprisionamento de KRb}

O aprisionamento de moléculas de KRb em uma armadilha de dipolo foi realizado por J. J. Zirbel, e colaboradores (66). Este sem dúvida foi um trabalho que exigiu uma maior complexidade experimental. Nele átomos de ${ }^{87} \mathrm{Rb}$ e ${ }^{40} \mathrm{~K}$ eram carregados em um MOT duplo a partir de uma célula de vapor, depois de carregados eram transferidos para uma armadilha de quadrupolo magnético móvel de modo a levar a amostra para uma região de ultra alto vácuo da câmara de vácuo. Nesta região os átomos eram transferidos para uma armadilha magnética (loffe-Pritchard) para realizar o resfriamento evaporativo forçado via aplicação de micro ondas. Este processo é iniciado com $10^{9}$ átomos de $\mathrm{Rb}$ e $10^{7}$ de $\mathrm{K}$ na armadilha magnética, depois da evaporação permanecem $5 \times 10^{6}$ átomos de $\mathrm{Rb}$ e $1 \times 10^{6}$ de $\mathrm{K}$ a $3 \mu \mathrm{K}$. Somente depois do processo evaporativo os átomos são carregados na armadilha de dipolo gerada a partir de um laser de fibra com comprimento de onda em 1064 nm. 
Depois de carregados na armadilha de dipolo, diminuem controladamente a potência do laser de aprisionamento fazendo a amostra passar novamente por outro processo evaporativo até obterem $3 \times 10^{5}$ átomos de $\mathrm{Rb}$ a T/T $\sim 1,1$ e $1 \times 10^{5}$ átomos de $\mathrm{K}$ a $\mathrm{T} / \mathrm{T}_{\mathrm{F}} \sim 0,6$, em que $T_{c}$ e $T_{F}$ são respectivamente a temperatura crítica para a condensação de BoseEinstein (BEC) e a temperatura de Fermi. No final da evaporação aumentam novamente a potência do laser da armadilha de dipolo para atingirem as freqüências radiais de aprisionamento de 211 e $133 \mathrm{~Hz}$ respectivamente para $\mathrm{K}$ e $\mathrm{Rb}$. No final do processo a amostra atinge uma temperatura de $150 \mathrm{nK}$.

Para criar moléculas na armadilha de dipolo, eles utilizam a técnica de ressonância de Feschbach preparando átomos de $R b$ em $\left(F=1, m_{F}=1\right)$ e $K$ em $\left(F=9 / 2, M_{F}=-7 / 2\right)$ em um campo de $B_{0}=546,76 \mathrm{G}$. Nessas condições os átomos estão próximos a ressonância de Feschbach, assim utilizam um campo de radiofreqüência para realizar a transição $(F=9 / 2$, $\left.M_{F}=-7 / 2\right) \rightarrow\left(F=9 / 2, M_{F}=-9 / 2\right)$ do $K$ convertendo-os em moléculas (67). Através da técnica de imagem de absorção por seleção de spin (spin-state-selective absorpiton imaging), puderam observar o efeito da associação das moléculas feita pela radiofreqüência na armadilha. O número de moléculas observadas como função do tempo de aplicação do pulso de radiofreqüência está representado na figura 2.5. No eixo x temos a largura do pulso (pulso gaussiano) de rf aplicado. O número de moléculas aumenta rapidamente nos primeiros 100 microsegundos e começa a decair, resultado das colisões átomo-molécula. Nesse sistema eles podem associar $10 \%$ do número de átomos de $\mathrm{K}$ criando moléculas a uma temperatura de aproximadamente 310 nk com uma energia de ligação de no máximo 26 $\mathrm{MHz}$ com relação à energia dos átomos livres. 


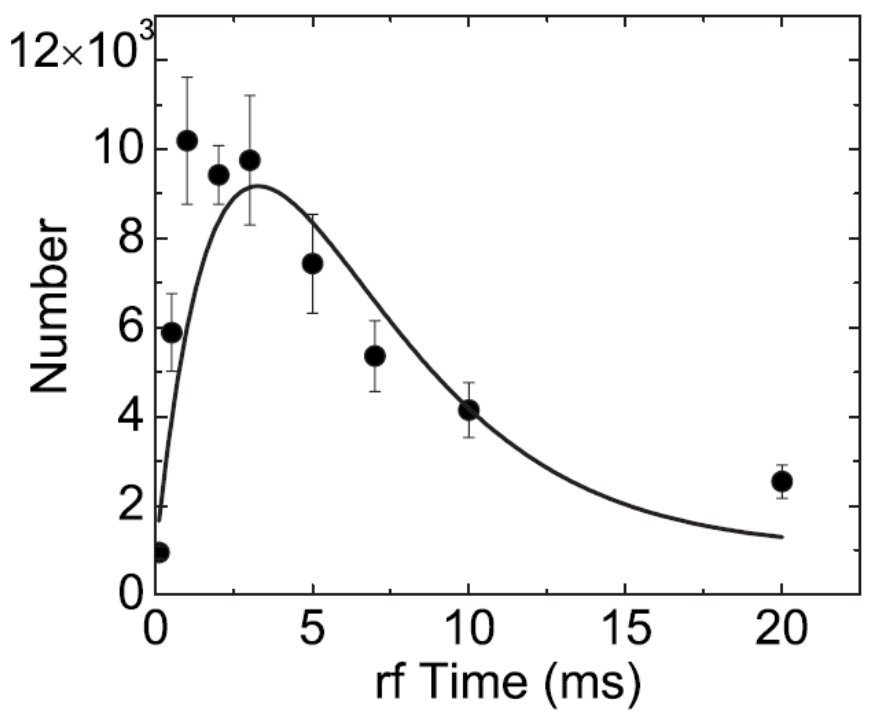

Figura 2.5 - Número de moléculas de KRb na armadilha de dipolo (1064 nm) em função da aplicação do pulso de radiofreqüência, o qual associa átomos em moléculas pelo processo de ressonância de Feschbach. O campo magnético utilizado para tal foi de $B_{0}=546,17 \mathrm{G}$. $A$ linha preta representa um ajuste exponencial do decaimento. Figura extraída de (66).

\subsection{Produção de moléculas ultrafrias no estado fundamental $(v=0)$}

A fotoassociação é um processo que ocorre naturalmente em armadilhas magnetoópticas $(13,14)$. Nela, o mesmo laser que faz o aprisionamento pode fotoassociar átomos gerando moléculas em um processo contínuo. Essas moléculas são eletronicamente estáveis, mas, devido aos fatores de Frack-Condon, são produzidas nos mais altos níveis vibracionais do estado fundamental eletrônico. Conforme as propostas levantadas no capítulo 1, seria desejável a produção de moléculas em $v=0$. Diante disso, alguns grupos vêm trabalhando para resfriá-las reduzindo seu nível vibracional, ou mesmo induzindo uma fotoassociação controlada de modo a produzir moléculas no nível vibracional $v=0$ do $X^{1} \Sigma_{\mathrm{g}}^{+}$. Assim, nessa seção, descrevemos em ordem cronológica os métodos mais recentes encontrados na literatura para a produção de moléculas no estado fundamental. 


\subsubsection{Produção de RbCs}

O primeiro trabalho que descreveremos é o trabalho conduzido por Jeremy M. Sage, e colaboradores (56) de 2005. Neste trabalho os autores demonstraram a produção de moléculas polares de $\mathrm{RbCs}$ no estado vibracional e eletrônico fundamental via fotoassociação seguida por um processo de transferência estimulado via laser. Seu sistema experimental consistia de um MOT duplo de ${ }^{133} \mathrm{Cs}$ e ${ }^{85} \mathrm{Rb}$ e o método de produção dessas moléculas está descrito na figura 2.6. Neste processo, o par atômico é fotoassociado por um laser para um nível molecular excitado muito bem conhecido $\left(0^{-}, J^{P}=1^{+}\right)$, localizado a 38,02 $\mathrm{cm}^{-1}$ abaixo da assíntota $\mathrm{Rb} 5 \mathrm{~S}_{1 / 2}(\mathrm{~F}=2)+\mathrm{Cs} 6 \mathrm{P}_{1 / 2}(\mathrm{~F}=3)$, de modo que uma fração ( 7\%) decaia no estado fundamental tripleto com nível vibracional bem determinado $\boldsymbol{a}^{3} \boldsymbol{\Sigma}^{+}(\boldsymbol{v}=\mathbf{3 7})$. Depois deste período de PA um pulso de laser ressonante (laser pulsado) bombeia essas moléculas para um determinado estado intermediário (i). Para aferir este estado intermediário, aplica-se outro pulso ionizante (laser pulsado) de modo a produzir íons moleculares $\mathrm{RbCs}^{+}$que são monitorados via espectro de tempo de vôo.

Para inicialmente produzir moléculas em $X^{1} \Sigma_{\mathrm{g}}^{+}(v=0)$, um segundo laser (dump pulse) é utilizado para estimular o decaimento das moléculas no estado $i$ para $X^{1} \Sigma_{\mathrm{g}}^{+}(v=0)$, isso é observado monitorando o decaimento do número de íons produzidos a partir do estado $\boldsymbol{i}$, como descrito anteriormente. Para observar diretamente as moléculas formadas no estado fundamental, eles deixam a população do estado $\boldsymbol{i}$ decair espontaneamente durante certo tempo deixando este estado sem população alguma. Assim um terceiro pulso, com a mesma freqüência do dump pulse excitam apenas as moléculas do $X^{1} \Sigma_{\mathrm{g}}^{+}(v=0)$ novamente para o estado $\boldsymbol{i}$ que são novamente detectadas por ionização. Com esta técnica eles puderam produzir moléculas de $\mathrm{RbCs}$ no estado fundamental mas não observaram o aprisionamento via armadilha de dipolo. A taxa de produção dessas moléculas foi de $5 \times 10^{2}$ moléculas/s sujeita a uma incerteza de um fator de 2 . 


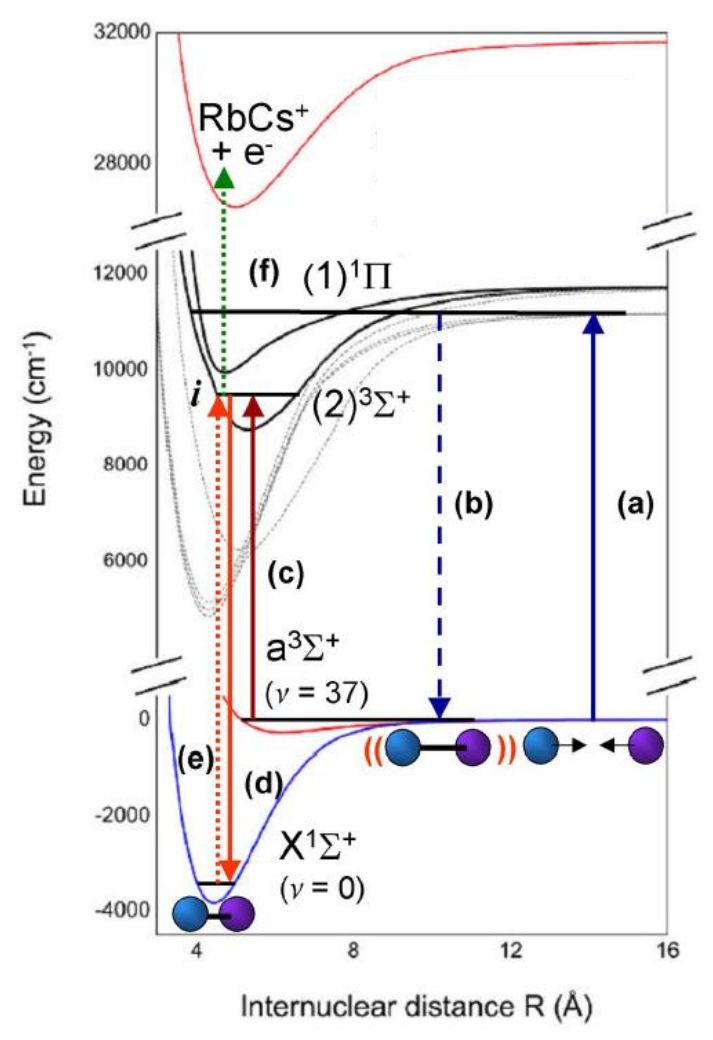

Figura 2.6 - Esquema para formação e deteç̧ão das moléculas de RbCs no estado fundamental. a) $O$ par atômico é fotoassociado para o estado ligado excitado da molécula RbCs. b) Decaimento espontâneo para o estado tripleto $a^{3} \Sigma^{+}(v=37)$. c) Moléculas são excitadas para o nível $i$ e em d) são estimuladas para o estado $\boldsymbol{X}^{\mathbf{1}} \boldsymbol{\Sigma}_{\boldsymbol{g}}^{+}(\boldsymbol{v}=0)$. e) $\boldsymbol{A}$ detecção é feita levando as moléculas novamente ao estado excitado i e ionizando-as em (f). Figura extraída de (56).

\subsubsection{Produção de $\mathrm{Cs}_{2}$}

Na seqüência, o trabalho que descreveremos é sobre a produção de $\mathrm{Cs}_{2}$ no estado fundamental, desenvolvido por Matthieu Viteau, e colaboradores (55). Neste trabalho as moléculas de $\mathrm{Cs}_{2}$ são continuamente fotoassociadas em um MOT através da aplicação de um laser extra de aproximadamente $1 \mathrm{~cm}^{-1}$ abaixo da transição atômica $6 \mathrm{~S}_{1 / 2}-6 \mathrm{P}_{3 / 2}$ em seus mais altos níveis vibracionais do estado fundamental eletrônico $X^{1} \Sigma_{\mathrm{g}}^{+}$. Assim que produzidas, as moléculas são excitadas por um laser de banda larga de modo que com 
alguns ciclos de bombeamento óptico pode-se popular o estado eletrônico fundamental em $v=0$. Nesta técnica de bombeamento, é utilizado um laser com um espectro de tal modo que freqüências que excitariam moléculas em $v=0$ são bloqueadas (figura 2.7). Este pode ser representado da seguinte forma:

$$
C s_{2}\left(v_{x}\right)+h v \rightarrow C s_{2}\left(v_{b}\right) \rightarrow \text { decaimento } \rightarrow C s_{2}\left(v_{x}^{\prime}\right)
$$

em $v_{b}$ é um estado vibracional do estado excitado da molécula e $v_{x}$ e $v_{x}^{\prime}$ são estados vibracionais do estado fundamental de modo que $v_{x}^{\prime}<v_{x}$. Esse processo faz o estado vibracional inicial ser reduzido energeticamente.

Experimentalmente, para gerar este bloqueio na freqüência, utilizaram uma grande de difração separando espacialmente as freqüências do laser e com um anteparo, freqüências acima de $13,030 \mathrm{~cm}^{-1}$ eram bloqueadas (figura $2.8 \mathrm{~A}$ ).

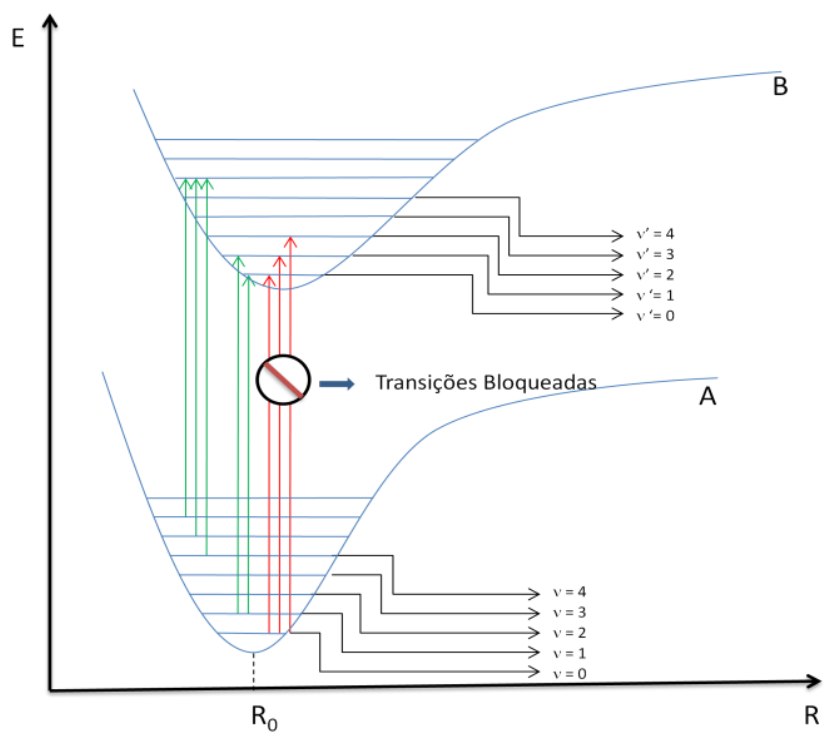

Figura 2.7 - Esquema para bombeamento de moléculas para o estado eletrônico fundamental em $\boldsymbol{v}_{\boldsymbol{x}}$ $=0$. As freqüências que acoplam o estado $\boldsymbol{v}_{\boldsymbol{x}}=0$ para algum estado $\boldsymbol{v}_{\boldsymbol{x}}^{\prime}$ são bloqueadas (transições representadas pelas setas vermelhas). 
Na figura 2.8 B temos o cálculo dos fatores de Franck-Condon para a molécula de $\mathrm{Cs}_{2}$, o eixo $\mathrm{x}$ representa os estados vibracionais $\left(v_{x}\right)$ do estado eletrônico fundamental $\left(X^{1} \Sigma_{\mathrm{g}}^{+}\right)$, o eixo y representa os estados vibracionais $\left(v_{b}\right)$ do primeiro estado eletrônico excitado $\left(B^{1} \Pi_{\mathrm{u}}\right)$, a linha diagonal é a faixa onde as freqüências são cortadas. Neste modelo foram usados os potenciais (figura $2.8 \mathrm{C}$ ) dos estados $\times \Sigma_{\mathrm{g}}^{+}$e $\mathrm{B}^{1} \Pi_{\mathrm{u}}$ determinados experimentalmente na literatura $(68,69)$. Para melhor compreender este modelo consideremos uma molécula no estado $v_{x}=4$, esta terá uma maior probabilidade de ser excitada para o estado $v_{b}=1$ que por sua vez te a chance de $30 \%$ de decair para o estado $v_{x}^{\prime}$ $=0$ e $70 \%$ igualmente distribuídos entre os estados $v_{x}^{\prime}=3,4$ e 5 .

Aplicando pulsos com o laser banda larga (laser de fentosegundo, $\lambda=773 \mathrm{~nm}$, largura de banda de $54 \mathrm{~cm}^{-1}$ ) com parte do espectro bloqueado conforme a figura $2.9 \mathrm{~A}$, observaram picos de transição do estado vibracional $v_{x}=0$ a $v_{c}=0$ a 3 . Estes picos estão representados pela linha preta no gráfico (figura 2.9B) e possuem maior intensidade indicando a transferência eficiente de moléculas para $v_{x}=0$. A taxa de produção dessas moléculas nesse sistema foi de $10^{5}$ moléculas por segundo, que representa $1 \%$ do fluxo de carregamento de seu MOT. Através de uma simulação teórica, representando a evolução temporal dos estados em $v_{x}=0$ a 15 , puderam estimar que mais de $70 \%$ da população foi transferida para o nível $v_{x}=0$ quando assumida uma distribuição de níveis vibracionais próximos ao valor experimental. 

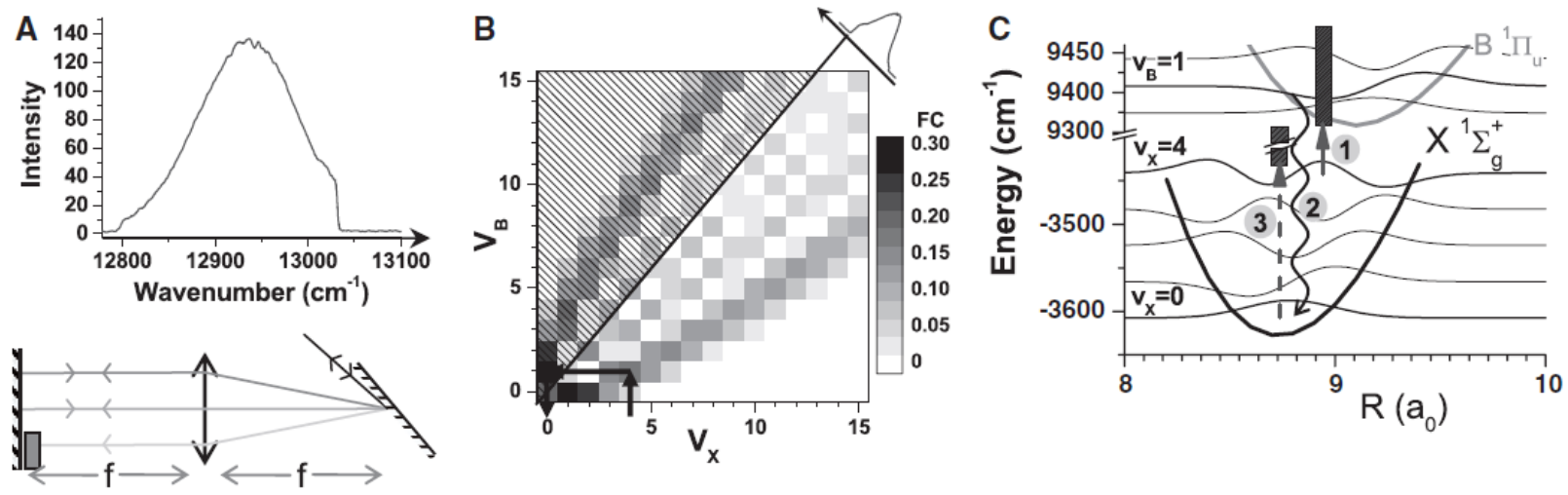

Figura 2.8 - (A) Espectro de freqüências utilizado, bloqueio de freqüências feito em $13,030 \mathrm{~cm}^{-1}$. (B) Fatores de Franck-Condon relacionado às probabilidades de transição entre os estados $\boldsymbol{v}_{\boldsymbol{x}}$ (estado eletrônico fundamental) $\boldsymbol{v}_{\boldsymbol{B}}$ (estado eletrônico excitado ). (C) Bombeamento óptico de uma molécula partido de $\boldsymbol{v}_{\boldsymbol{x}}=4$ e chegando em $\boldsymbol{v}_{\boldsymbol{x}}^{\prime}=0$. Figura extraída de (55).

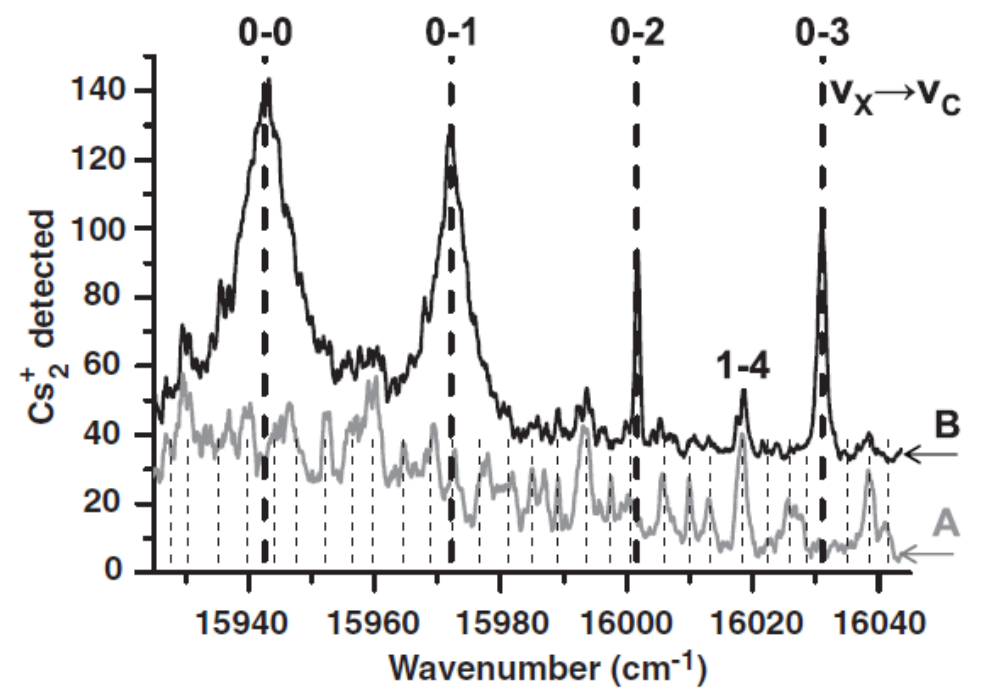

Figura 2.9 - (A) Espectro sem o corte no feixe de bombeamento, picos corresponde a transições do estado fundamental $\boldsymbol{v}_{\boldsymbol{x}}=1$ a 7 para vários níveis do estado excitado $C$. (B) Espectro aplicando-se o corte de freqüência no feixe de bombeamento (corte em $13030 \mathrm{~cm}^{-1}$ ). Nele são observados transições $v_{x}=0 a v_{c}=0$ a 3 com maior intensidade. Figura extraída de (55).

Concluindo, esta é uma técnica eficaz, porém neste experimento as moléculas eram apenas bombeadas para o estado vibracional fundamental e não foram aprisionadas. Contudo, este princípio pode ser aplicado a outras espécies moleculares, ou mesmo em um sistema heteronuclear. Para isso, desenvolvemos o cálculo dos coeficientes de FranckCondon para uma molécula de KRb. A freqüência de corte nesse sistema foi aplicada ao 
comprimento de onda de $15031 \mathrm{~cm}^{-1}$ que é a menor energia necessária para excitar o estado vibracional fundamental, isto é, fazer a transição $v_{x}=0$ para $v_{B}=0$. Neste caso consideramos os níveis vibracionais do estado excitado ${ }^{1} \Pi$ do $\mathrm{KRb}$. Na figura 2.10 temos o bombeamento de um estado partindo de $v_{x}=5$ indo para $v_{B}=2$ que por sua vez tem a probabilidade de $23 \%$ de decair em $v_{x}=0,16 \%$ para $v_{x}=2$ e $21,8 \% v_{x}=5$. Este esquema prova a possibilidade de utilizar esta técnica em outros experimentos.

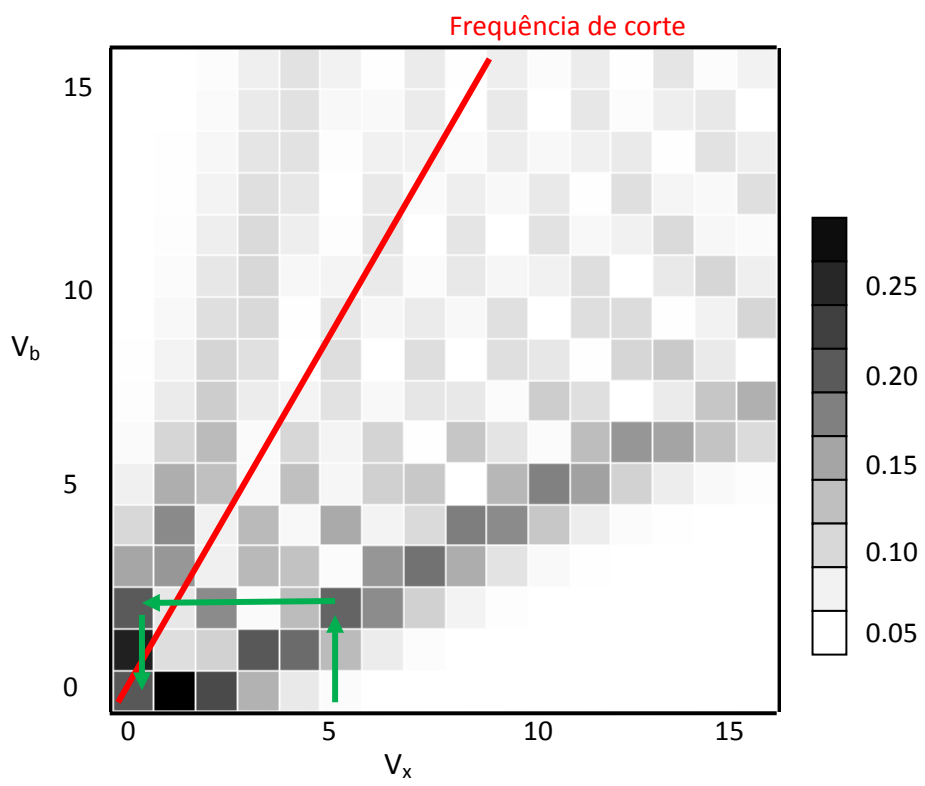

Figura 2.10 - Fatores de Franck-Condon calculados para a molécula de KRb a partir do software "level 8.0". No gráfico temos as probabilidades de transição entre os estados $v_{x}$ (estado eletrônico fundamental) e $v_{B}$ (estado eletrônico excitado). As setas verdes representam o bombeamento óptico de uma molécula inicialmente em $v_{x}=5$ e chegando em $v_{x}^{\prime}=0, a$ freqüência de corte calculada para esse sistema foi de $15031 \mathrm{~cm}^{-1}$. Neste cálculo consideramos os níveis vibracionais do estado excitado ${ }^{1} \Pi$ do $K R b$. 


\subsubsection{Produção de LiCs}

Outro trabalho, posterior a produção de $\mathrm{Cs}_{2}$, foi a produção de LiCs, desenvolvido por J. Deiglmayra e colaboradores (57), publicado em 2008. Neste trabalho, os autores produziram moléculas ultrafrias de LiCs no estado eletrônico fundamental vibracional e rotacional absoluto, ou seja, $X^{1} \sum_{\mathrm{g}}^{+}\left(v^{\prime}=0, J^{\prime}=0\right)$ com apenas um passo de fotoassociação diretamente de átomos em um MOT. Em seu experimento, a amostra atômica era constituída por um MOT duplo com $97 \%$ dos átomos de Cs estado fundamental $(F=3)$ e 80 $\%$ dos átomos de Li no estado fundamental $(F=2)$, assim as colisões entre as espécies eram principalmente governadas pela assíntota $\mathrm{Li}\left(2^{2} \mathrm{~S}_{1 / 2}, \mathrm{~F}=2\right)+\mathrm{Cs}\left(6^{2} \mathrm{~S}_{1 / 2}, \mathrm{~F}=3\right)$. Um laser de Ti:Sa com $500 \mathrm{~mW}$ de potência e comprimento de onda de 946,56 nm era utilizado para a fotoassociação do par atômico (figura 2.11 a) em um estado vibracional e rotacional bem definidos do estado excitado $B^{1} \Pi\left(v^{\prime \prime}=4, J^{\prime}=1\right.$ e $\left.J^{\prime}=2\right)$. Neste estado excitado, moléculas em $v^{\prime \prime}=4$ decaem espontaneamente (figura 2.11 b) somente nos níveis vibracionais do estado $X^{1} \sum_{\mathrm{g}}^{+}$. Através das curvas experimentais dos potenciais $(70,71)$, calcularam os fatores de Franck-Condon para os decaimentos e obtiveram a seguinte distribuição: 23 \% decaem para o estado $v^{\prime}=0$ do $X^{1} \Sigma_{\mathrm{g}}^{+} ; 12 \%$ para $v^{\prime}=2 ; 8 \%$ para $v^{\prime}=5 ; 6 \%$ para $v^{\prime}=9$ e $5 \%$ para $v^{\prime}=8$ outros estados entre $v^{\prime}=0-10$ são populados com valores menor igual a $3 \%$, entre $v^{\prime}=11-20$ a soma das porcentagens dos estados populados é de $35 \%$. 


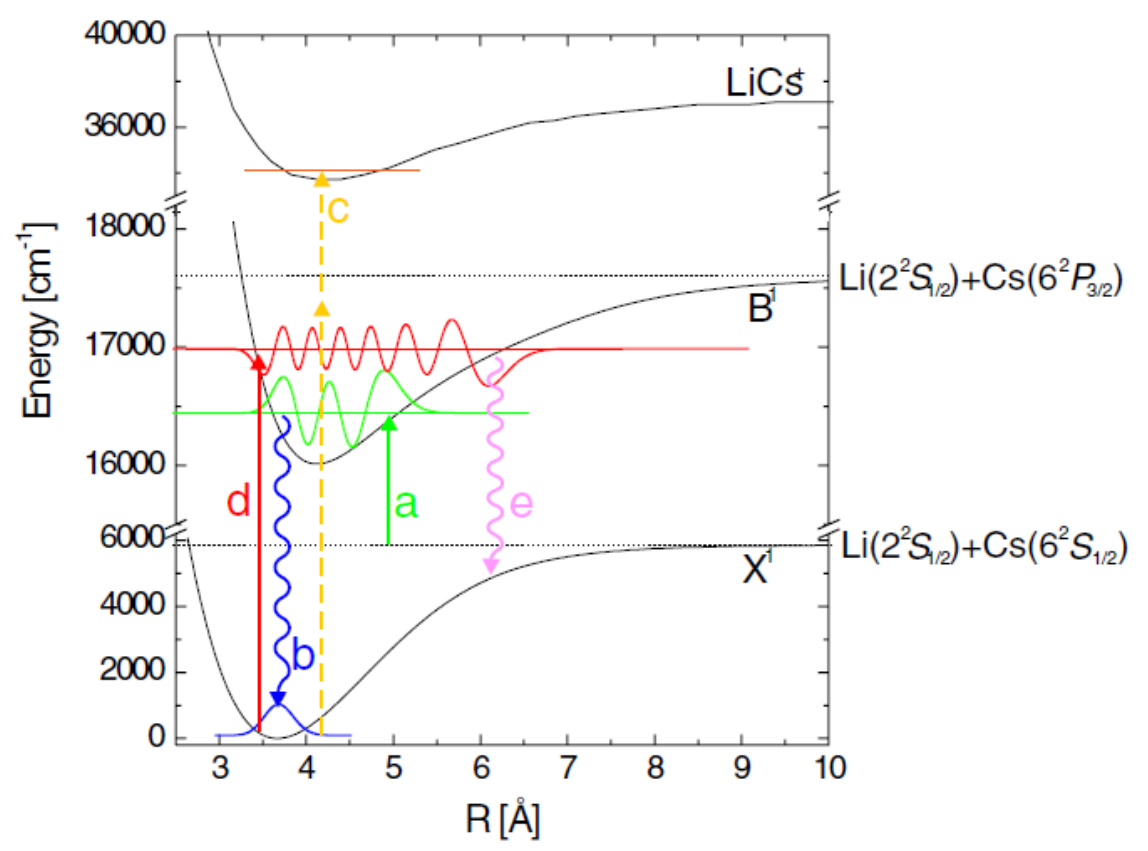

Figura 2.11 - Esquema para a fotoassociação de LiCs em $\boldsymbol{X}^{\mathbf{1}} \boldsymbol{\Sigma}_{g}^{+}\left(\boldsymbol{\nu}=0, J^{\prime}=0\right)$ e detecção. a) Fotoassociação por um laser de Ti:As em $946,56 \mathrm{~nm}$. b) Decaimento espontâneo para o estado fundamental. c) lonização por dois fótons. d) Excitação das moléculas do estado fundamental. e) Redistribuição da população do estado fundamental. Figura extraída de (57).

Para a determinação precisa dos estados rovibracionais do estado fundamental das moléculas formadas, eles utilizam a técnica de espectroscopia chamada depletion spectroscopy. Nesta técnica, um laser adicional de banda estreita bombeia a população de moléculas do estado $\boldsymbol{X}^{\mathbf{1}} \boldsymbol{\Sigma}_{\mathbf{g}}^{+}$(figura 2.11d) para específicos estados rovibracionais do estado eletrônico $B^{1} \Pi$. Assim, a componente rotacional de um determinado estado vibracional é detectada pela redução do número de moléculas ionizadas durante a ionização por dois fótons (figura 2.11c). As ressonâncias da depletion spectroscopy serão obtidas quanto $\hbar \omega_{0}+B^{\prime \prime} J^{\prime \prime}\left(J^{\prime \prime}+1\right)-B^{\prime} J^{\prime}\left(J^{\prime}+1\right)$ em que $\hbar \omega_{0}$ é a diferença de energia entre o estados vibracionais do estado eletrônico fundamental e excitado e $B^{\prime \prime}$ e $B^{\prime}$ são as constantes rotacionais do estados excitado e fundamental que podem ser calculadas pelas curvas experimentais do potencial $(70,71)$.

Os resultados mostraram que podem produzir em $X^{1} \Sigma_{\mathrm{g}}^{+}\left(v=0, J^{\prime}=0\right)$ por fotoassociação via $B^{1} \Pi\left(v=4, J^{\prime \prime}=1\right)$ a uma taxa de $10^{2}$ moléculas/s, considerando as moléculas produzidas em $X^{1} \Sigma_{\mathrm{g}}^{+}\left(v=0, J^{\prime}=2\right)$ via $B^{1} \sqcap\left(v=4, J^{\prime \prime}=2\right)$ ele conseguem produzir 
um total de $5 \times 10^{3}$ moléculas por segundo em $v=0$, o qual é um valor de 20 vezes menor comparado a taxa de produção conseguida no sistema para $\mathrm{Cs}_{2}$.

\subsubsection{Produção de KRb}

A produção de moléculas de $K R b$ no estado fundamental foi um trabalho desenvolvido por $K$. $-K$. Ni, e colaboradores (58). Neste, $10^{4}$ moléculas de KRb são formadas por ressonância de Feshbach com uma energia de ligação de $\mathrm{h} \times 230 \mathrm{KHz}$ (onde $\mathrm{h}$ é a constante de Planck) no estado fundamental tripleto $a^{3} \Sigma$, o procedimento para tal foi descrito na seção 2.4.2. Daí então, eles utilizam a técnica STIRAP (Stimulated Raman Adiabatic Passage) para bombear essas moléculas para o estado fundamental tripleto $a^{3} \Sigma(v=0)$ ou o estado fundamental singleto $X^{1} \Sigma_{\mathrm{g}}(v=0)$.

Em ambos os casos utilizam dois lasers que acoplam três níveis moleculares: $i\rangle$ estado inicial, $e\rangle$ estado intermediário e $g$ > o estado final. No primeiro, figura 2.12a, a molécula é excitada para o estado $2^{3} \Sigma \quad\left(v^{\prime}=10\right)$ com um laser $\Omega_{1}$ com comprimento de onda de $1023 \mathrm{~nm}$ e depois decai ao estado $a^{3} \Sigma(v=0)$ por emissão estimulada gerada por um segundo laser $\Omega_{2}$ com comprimento de onda de $998 \mathrm{~nm}$. No segundo caso, figura 2.12b, a molécula passa pelo mesmo processo, mas inicialmente é excitada ao nível intermediário $2{ }^{3} \Sigma \quad\left(v^{\prime}=23\right)$ com um laser $\Omega_{1}$ com comprimento de onda de $970 \mathrm{~nm}$ e decai ao estado $X^{1} \Sigma_{\mathrm{g}}(v=0)$ também por emissão estimulada gerada por um laser $\Omega_{2}$ com comprimento de onda em $690 \mathrm{~nm}$. A eficiência de transferência para os estados fundamentais tripleto e singleto são de $31 \%$ e $69 \%$ respectivamente das moléculas inicialmente formadas por ressonância de Feschbach. 

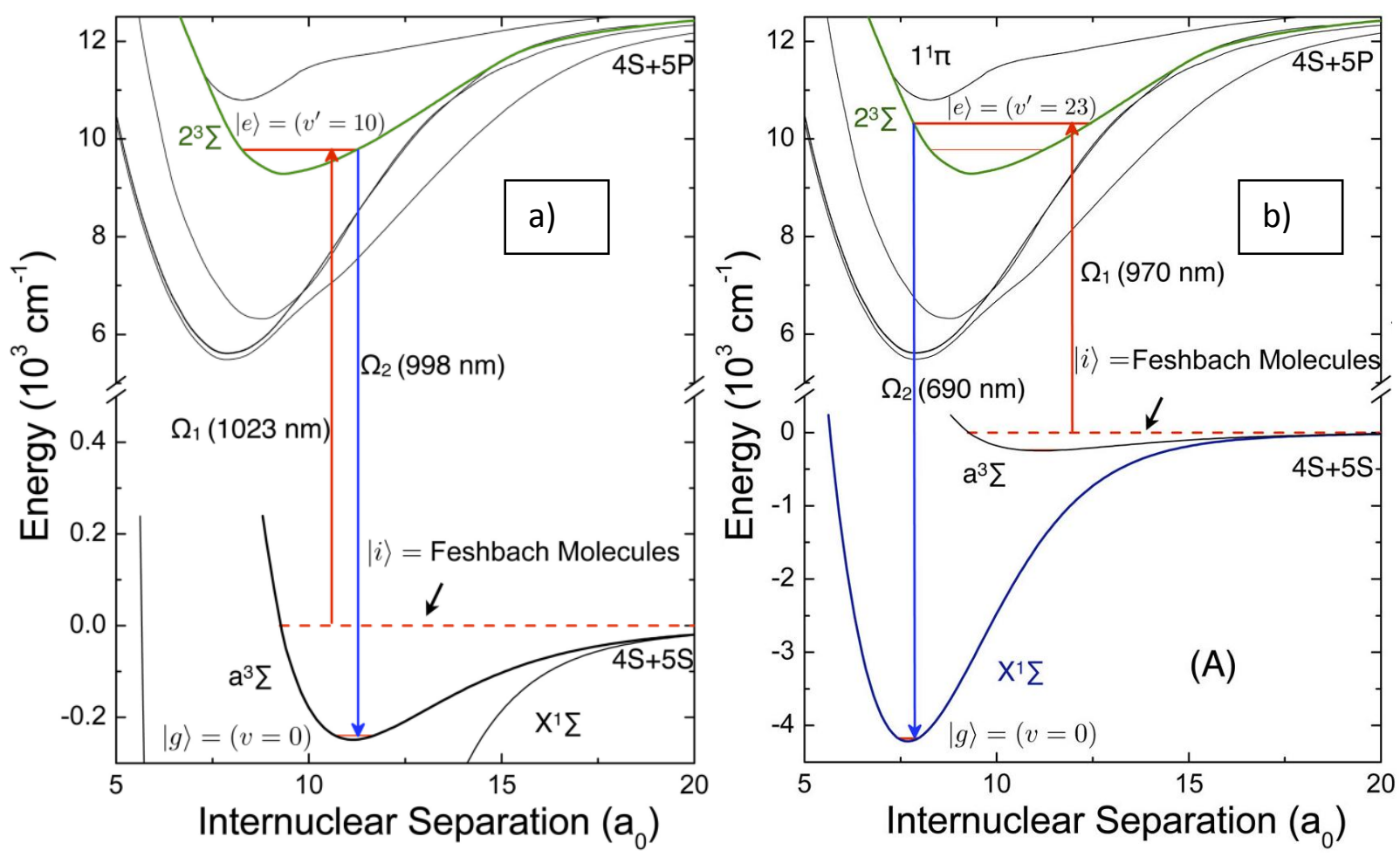

Figura 2.12 - Esquema para formação de moléculas de KRb no estado fundamental via técnica STIRAP. a) A molécula é levada para o estado fundamental tripleto $\boldsymbol{a}^{\mathbf{3}} \boldsymbol{\Sigma}(\boldsymbol{v}=\mathbf{0})$ pelo acoplamento de dois lasers com freqüências $\boldsymbol{\Omega}_{\mathbf{1}}(1023 \mathrm{~nm})$ e $\boldsymbol{\Omega}_{\mathbf{2}}(998 \mathrm{~nm})$. b) A molécula é levada para estado fundamental singleto $\boldsymbol{X}^{\mathbf{1}} \boldsymbol{\Sigma}_{\boldsymbol{g}}(\boldsymbol{v}=0)$ pelo acoplamento de dois lasers com freqüências $\boldsymbol{\Omega}_{\mathbf{1}}(970 \mathrm{~nm})$ e $\boldsymbol{\Omega}_{\mathbf{2}}(690 \mathrm{~nm})$. Figura extraída de (58)).

Finalizando, este foi o único experimento o qual produziu e aprisionou moléculas no estado fundamental até o momento. Nele as moléculas produzidas no tripleto $a^{3} \Sigma(v=0)$ obtiveram um curto tempo de vida de aprisionamento de $170 \mu$ s. Este foi justificado pelo decaimento de moléculas para o estado singleto através da mudança de spin induzidas por colisões com átomos do gás de fundo. No caso das moléculas produzidas no singleto $X^{1} \Sigma_{\mathrm{g}}$ $(v=0)$ obtiveram um tempo de vida da ordem de $30 \mathrm{~ms}$. 


\subsection{Fotoassociação de átomos de $\mathrm{Rb} e$ resfriamento vibracional de moléculas $\mathrm{Rb}_{2}$ e KRb com laser em 1064 nm.}

O mecanismo de fotoassociação de átomos de $\mathrm{Rb}$ com laser em $1064 \mathrm{~nm}$ foi proposto na referência (72). Neste trabalho, os autores propõem a fotoassociação de átomos pela técnica REAR ( resonantly enhanced anti-Stokes Raman) e a transferência de moléculas para o estado vibracional fundamental pela técnica STIRAP (stimulated Raman adiabatic passage). Desse modo, o feixe em $1064 \mathrm{~nm}$ permite que um par de átomos colidindo no estado fundamental acesse os potenciais excitados, como mostrado na figura 2.13. A fotoassociação ocorre para um estado vibracional baixo dos potenciais ${ }^{3} \Pi_{u}$ e ${ }^{1} \Sigma_{u}$, relacionados aos estados 5S+5P. Em seguida o par pode decair espontaneamente e formar uma molécula em um nível vibracional $(\nu<100)$ no potencial eletrônico fundamental ${ }^{1} \Sigma^{+}$. A teoria desenvolvida na referência (72) sugere que a taxa de fotoassociação é da ordem de $10^{-12} \mathrm{~cm}^{3} / \mathrm{s}$ para uma intensidade do laser de $1064 \mathrm{~nm}$ de $10^{4} \mathrm{~W} / \mathrm{cm}^{2}$.

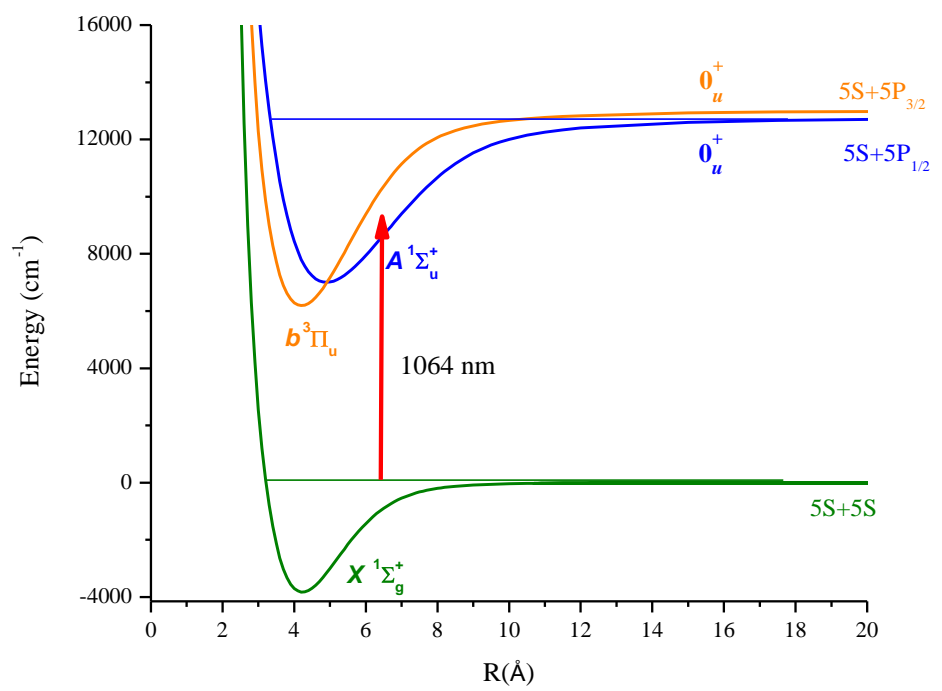

Figura 2.13 - Potenciais para a molécula de $R b_{2}$. A seta vermelha representa em escala a energia do laser em $1064 \mathrm{~nm}$, mostrando a possibilidade de acoplamento entre o estado fundamental e os estados excitados $A^{1} \Sigma_{u}$ e $b^{3} \Pi_{u}$. 
O fato da fotoassociação neste comprimento de onda se torna interessante quando consideramos a possibilidade de acoplamento entre os estados vibracionais do estado fundamental e excitados da molécula de $\mathrm{Rb}_{2}$. Uma vez que a molécula é formada em um estado vibracional elevado $(v=106-113)$ do estado fundamental, fato que ocorre naturalmente em armadilhas magneto-ópticas, esta molécula poderia absorver outro fóton em $1064 \mathrm{~nm}$ e ir para um estado vibracional mais profundo dos potenciais $b^{3} \Pi_{u}$ e $A^{1} \Sigma_{u}$. (seta 1 da figura 2.14). Conseqüentemente, decairia para um estado mais profundo do potencial ${ }^{1} \Sigma^{+}$(seta da 2 da figura 2.14). Isso aconteceria até que o fóton em $1064 \mathrm{~nm}$ não acoplasse mais o potencial ${ }^{1} \Sigma_{\mathrm{g}}{ }^{+}$aos $b^{3} \Pi_{\mathrm{u}}$ e $\mathrm{A}^{1} \Sigma_{\mathrm{u}}$. Ou seja, após vários ciclos de excitação e decaimento, haveria um acúmulo de moléculas em um conjunto de estados vibracionais baixos do potencial ${ }^{1} \Sigma_{\mathrm{g}}^{+}$(figura 2.14).

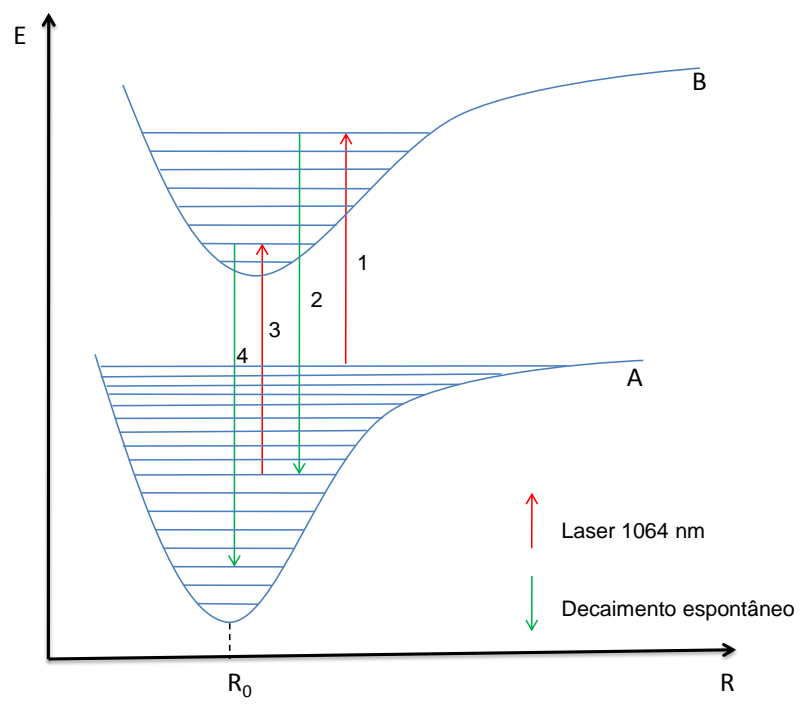

Figura 2.14 - Processo de bombeamento molecular para estados vibracionais mais baixos. A cada ciclo de absorção ( setas vermelhas 1 e 3) e emissão(setas verdes 2 e 4) de um fóton a molécula é levada a um estado vibracional $v$ menor, este processo deve continuar até que o laser da armadilha (1064 nm) não acople mais a nenhum estado vibracional excitado $v^{\prime}$.

Para analisar este processo quantitativamente utilizamos o programa Level 8.0, desenvolvido pelo professor Robert LeRoy da Universidade de Waterloo, para calcular a 
posição energética de cada nível vibracional dos estados moleculares ${ }^{1} \Sigma_{\mathrm{g}}{ }^{+}, \mathrm{b}^{3} \Pi_{\mathrm{u}}$ e $A^{1} \Sigma_{\mathrm{u}}$. Nossos cálculos indicam que os átomos livres de Rb seriam excitados para níveis vibracionais moleculares em torno de $v^{\prime}=59$ (dos potenciais $A^{1} \Sigma_{\mathrm{u}}^{+}$e $b^{3} \Pi_{\mathrm{u}}$ ) e depois decairiam para uma distribuição de estados vibracionais do estado eletrônico fundamental molecular, como mostrado no gráfico da figura 2.15a. Assumindo esta nova distribuição de estados vibracionais, com mais um ciclo de absorção-emissão, parte dessas moléculas podem ser novamente bombeadas para o estado excitado e decaírem por emissão espontânea de modo a modificar a distribuição de níveis vibracionais anteriores.

Nos arquivos gerados pelo programa level 8.0, já foram calculadas as grandezas como a posição energética de cada nível vibracional, a diferença de energia e os fatores de FranckCondon entre níveis vibracionais do estado fundamental $\left({ }^{1} \Sigma_{\mathrm{g}}^{+}\right)$com relação a níveis vibracionais de um estado molecular excitado $\left(b^{3} \Pi_{u}\right.$ ou $\left.A^{1} \Sigma_{u}\right)$. Utilizando o software Mathematica 5.2, desenvolvemos um programa que analisa esses arquivos gerados. Assim podemos selecionar quais estados vibracionais do estado ${ }^{1} \Sigma_{\mathrm{g}}{ }^{+}$serão excitados com o comprimento de onda em 1064 nm; e pela análise dos fatores de Franck-Condon, podemos produzir uma distribuição de níveis vibracionais do estado fundamental considerando o decaimento de um estado excitado por emissão espontânea. Assim, a cada ciclo interativo deste programa (o qual representa a absorção de um fóton em 1064 nm e emissão espontânea de outro fóton), geramos uma nova distribuição de estados vibracionais do estado fundamental. Notamos que após 10 interações, chegamos a uma distribuição final, dado pelo gráfico da figura $2.15 \mathrm{~b}$, a qual não se altera mais, ou seja, estes estados não podem ser mais excitados com o laser em $1064 \mathrm{~nm}$. Para realizar as interações do programa, utilizamos os valores do manual de nosso laser de fibra, onde constava o real comprimento de onda do laser de $1071 \mathrm{~nm}$ com uma largura de aproximadamente $2 \mathrm{~nm}$. 

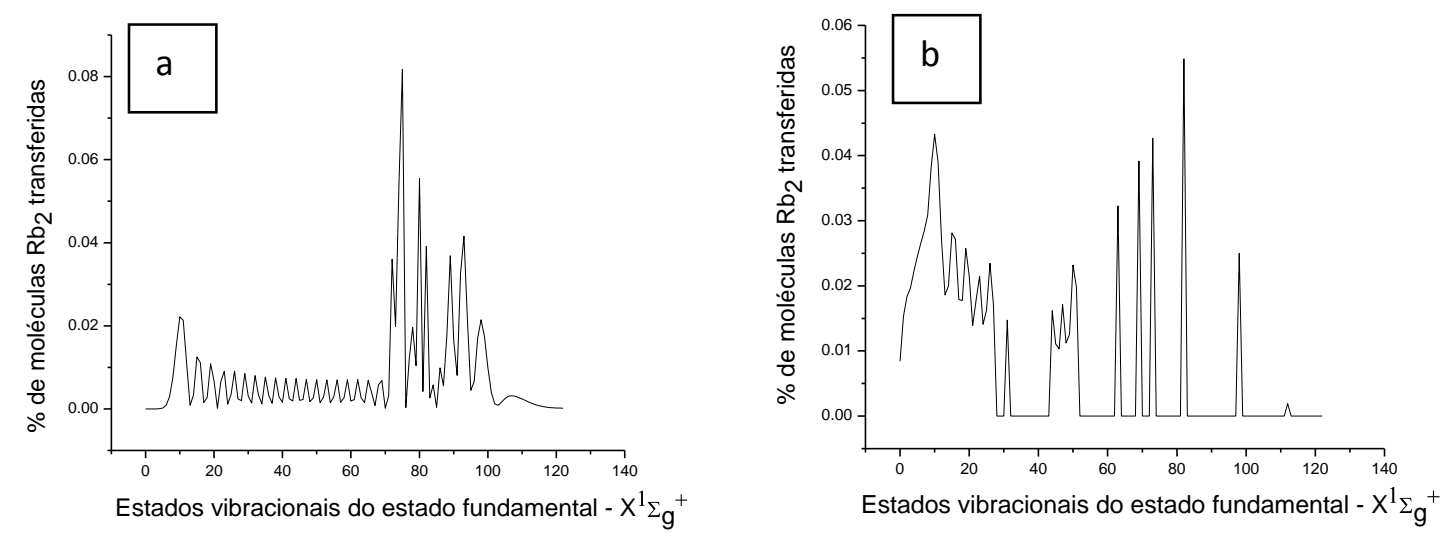

Figura 2.15 - a) Distribuição de níveis moleculares após a fotoassociação dos átomos pelo laser de fibra. b) Distribuição final de moléculas devido ao bombeamento molecular após a fotoassociação. Para chegar à configuração estacionária em (b) foram necessárias 10 interações. Os níveis utilizados para as interações foram: $X^{1} \Sigma_{g}^{+}$e $A^{1} \Sigma_{u}^{+}$.

O estado $b^{3} \Pi_{\mathrm{u}}$ foi introduzido no processo de bombeamento, contudo vimos que ele não contribuía efetivamente para o processo. Notamos também que o resultado final da distribuição apresenta muita sensibilidade com relação à largura do laser. Como o nosso laser está focalizado em uma pequena região espacial, produzimos uma alta intensidade $\mathbf{I}=$ $0,24 \mathrm{MW} / \mathrm{cm}^{2}$, assim a largura efetiva do laser que devemos considerar pode ser maior do que a descrita no seu manual $(\Delta \lambda=2 \mathrm{~nm})$. Assim, consideramos uma largura de $3 \mathrm{~nm}$ e levamos em conta o estado $b^{3} \Pi_{u}$, pois nessa condição o estado começa a contribuir com o bombeamento. O resultado está na figura 2.16. 


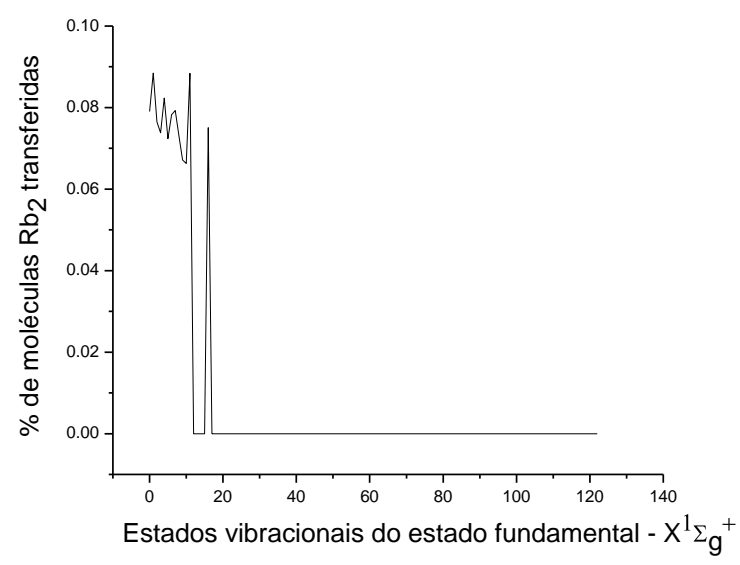

Figura 2.16 - Distribuição de níveis moleculares após 10 interações considerando o laser com uma largura de $3 \mathrm{~nm}$. Os níveis utilizados para as interações foram: $\boldsymbol{X}^{\mathbf{1}} \boldsymbol{\Sigma}_{g}^{+}$(estado fundamental), $\boldsymbol{A}^{\mathbf{1}} \boldsymbol{\Sigma}_{\boldsymbol{u}}^{+}$e $\boldsymbol{b}^{\mathbf{3}} \boldsymbol{\Pi}_{\boldsymbol{u}}$ (estados excitados).

Analisando os resultados das figuras 2.15 e 2.16, concluímos que existe a possibilidade de formar moléculas em níveis moleculares mais baixos. Para futuros experimentos esse mecanismo de bombeamento seria ideal, pois a perda do número de moléculas é baixa ( 3\% em todo o processo) e nos provem uma distribuição molecular bem ampla para níveis abaixo de $v=20$, facilitando o trabalho de bombeamento para $v=0$, posteriormente.

Assim como no caso do $\mathrm{Rb}$, esperamos que tanto o $\mathrm{K}$ quanto o $\mathrm{KRb}$ possam ser fotoassociados a partir de dois átomos livres devido ao laser em $1064 \mathrm{~nm}$. Na figura 2.17 mostramos os potenciais de interesse para a molécula KRb, podemos notar que o laser em $1064 \mathrm{~nm}$ acessará tais potenciais. Vale notar que tais potenciais não consideram a estrutura fina do estado 5P. 


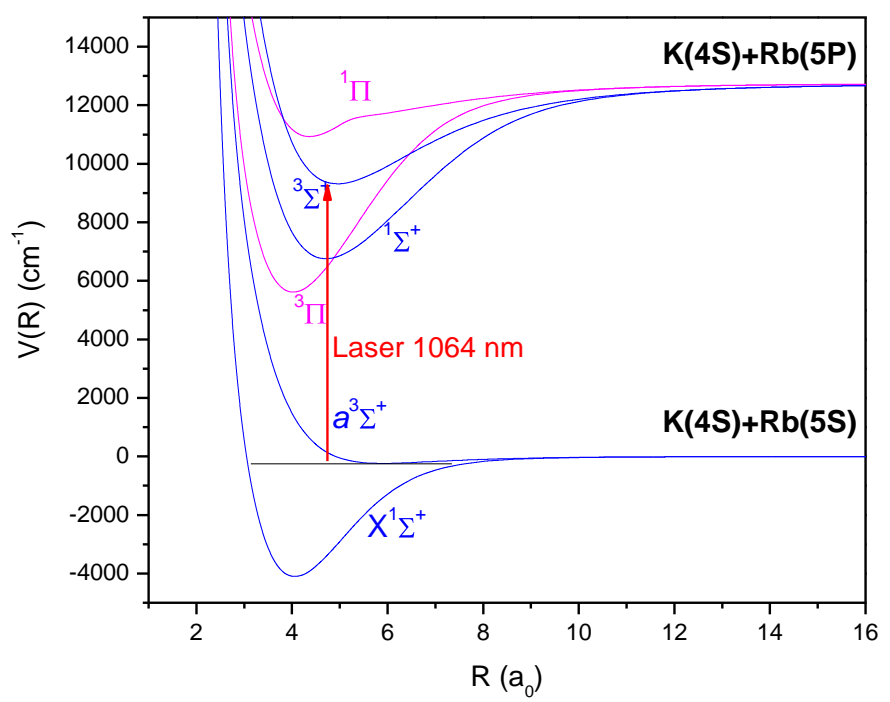

Figura 2.17 - Potenciais de interesse para a molécula KRb. A seta vermelha representa o laser em $1064 \mathrm{~nm}$ (em escala) que possui energia suficiente para acoplar estados vibracionais do potencial fundamental $\left(\Sigma^{1} \Sigma^{+}\right)$com estados vibracionais do potencial excitado.

A mesma simulação foi feita para a molécula de KRb. Nesta utilizamos primeiramente os potenciais ${ }^{1} \Sigma^{+}$e ${ }^{3} \Pi$, respectivamente para o estado fundamental e o excitado. A figura 2.18a mostra a distribuição de estados vibracionais do potencial fundamental logo após a fotoassociação pelo laser de 1064 nm, a figura 2.18b mostra a distribuição de estados final, os quais também não podem ser mais excitados com o laser em 1064 nm. Esta condição também é atingida após 10 ciclos de absorção e emissão. 

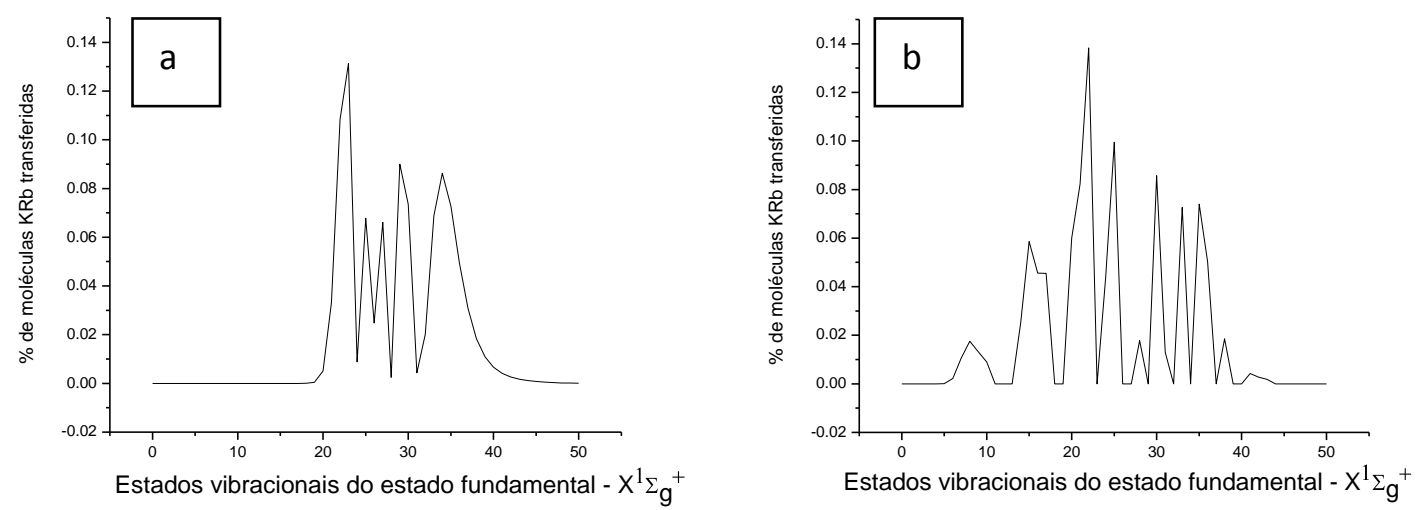

Figura 2.18 - a) Distribuição de níveis moleculares após a fotoassociação dos átomos de $K$ e Rb pelo laser de fibra. b) Distribuição final de moléculas devido ao bombeamento molecular após a fotoassociação. Para chegar à configuração estacionária em (b) foram necessárias 10 interações. Os potenciais utilizados para as interações foram: ${ }^{1} \Sigma^{+} e^{3} \Pi$ do $K R b$.

Nota-se que ainda há uma elevada ocupação de estados entre $v=40$ e 10. Considerando os potenciais que levam em conta a estrutura fina do estado $5 P_{1 / 2}$ e $5 P_{3 / 2}$, fornecidos pelo Dr. O. Dulieu do Laboratório Aimé Cotton em Orsay (figura 2.19), em nossas simulações, novas possibilidades de acoplamento entre os níveis vibracionais do potencial fundamental são incorporadas. Utilizando essas seis curvas obtemos o bombeamento final para a molécula de KRb depois de 10 ciclos (figura 2.20). Nesta nova simulação observamos uma distribuição de estados finais bem reduzidas obtendo a maior parte das moléculas em níveis vibracionais abaixo de $v=10$. 


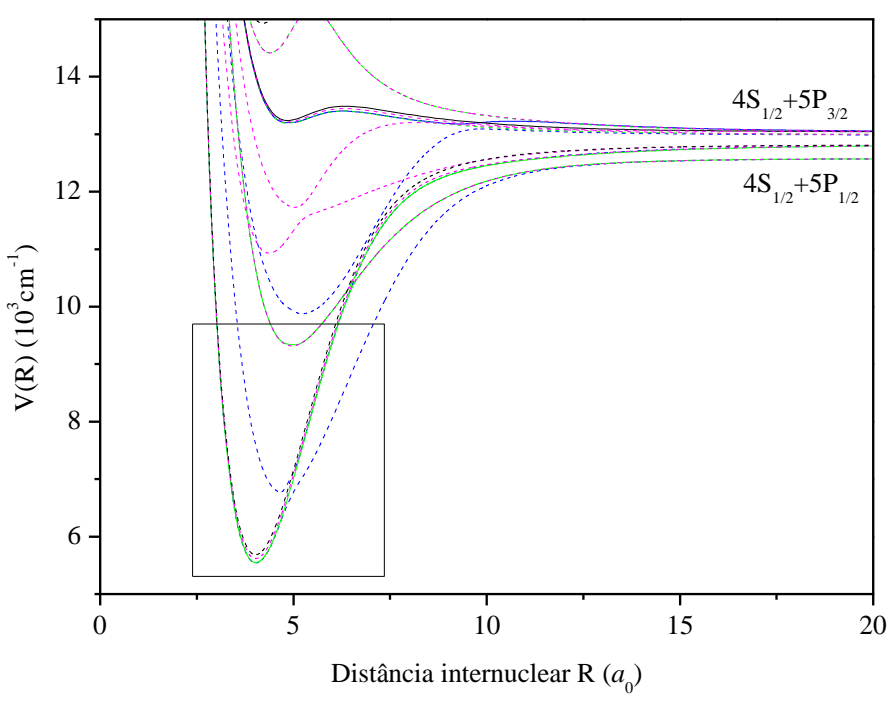

Figura 2.19 - Curvas de potencias do estado excitado para a molécula de KRb considerando a estrutura fina do estado 5P. Na área indicada pelo quadrado temos os potencias que podem ser acoplados pelo laser em $1064 \mathrm{~nm}$ e participar do processo de bombeamento.

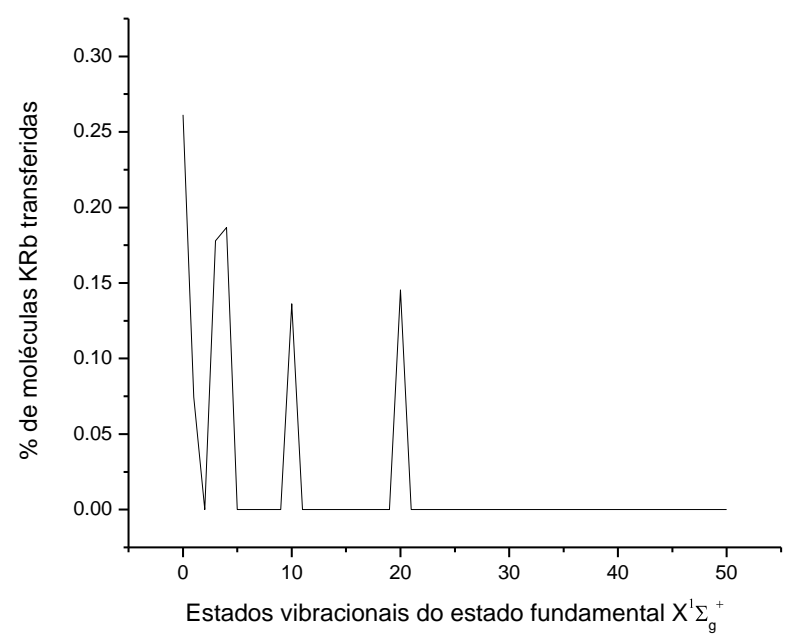

Figura 2.20 - Simulação utilizando os potenciais mencionados na figura 2.19. Quando consideradas todas as possibilidades de acoplamento, encontramos uma distribuição de estados finais bem reduzidas obtendo a maior parte das moléculas em níveis vibracionais abaixo de $v=10$. 
Devemos ressaltar que estas previsões teóricas são preliminares, e que as distribuições finais que serão obtidas podem variar devido às características espectrais do laser em $1064 \mathrm{~nm}$ e devido aos detalhes dos potenciais. De qualquer forma, esperamos que haja um acúmulo de população nos estados vibracionais mais baixos e em futuros experimentos poderemos detectá-las. 


\section{A armadilha de dipolo para átomos e moléculas}

Neste capítulo, descreveremos a montagem experimental da nossa armadilha de dipolo para átomos e moléculas e todos os procedimentos para a produção das amostras e suas respectivas detecções. O sistema de vácuo, os sistemas ópticos das armadilhas magneto-óptica e de dipolo e os sistemas de deteç̧ão serão descrito em detalhes. Concomitantemente serão apresentados os princípios básicos para desaceleração de átomos e o funcionamento de ambas as armadilhas ópticas. Os procedimentos de carregamento da armadilha magneto-óptica dupla e da armadilha de dipolo também serão apresentados, incluindo os programas utilizados. Finalizando discutiremos os métodos de deteç̧ão do experimento como técnicas de imagens de fluorescência e imagens de absorção, o processamento de imagens via softwares e a técnica de tempo de vôo utilizada para os experimentos com moléculas de $\mathrm{Rb}_{2}$.

\subsection{Armadilha de dipolo: o sistema de vácuo}

O sistema foi desenhado para desacelerar átomos de $\mathrm{Rb}$ e $\mathrm{K}$, aprisioná-los em um MOT e transferi-los para uma armadilha de dipolo gerada por um laser de fibra de alta potência em $1064 \mathrm{~nm}$. Além disso, foi projetado para obter pressões menores que $1 \times 10^{-10}$ torr na região de aprisionamento dos átomos. Espera-se com isso uma máquina que possa operar por vários anos consecutivos para vários experimentos, e eventualmente atingir o regime de degenerescência quântica $(9,10)$. Neste capítulo, subdividimos a máquina em três 
regiões distintas: o forno misto; o solenóide desacelerador de átomos; e a câmara de aprisionamento. O projeto foi desenvolvido no programa Solid Works, e a máquina é composta de peças comerciais de vácuo (MDC vaccum), peças fabricadas na oficina do IFSC e uma câmara construída empresa Sharon Vacuum.

É conveniente termos uma visão geral da máquina antes de detalhar as diferentes partes. A montagem completa está mostrada na figura 3.1. Na região do forno (figura 3.1b) temos as ampolas de $\mathrm{Rb}$ e $\mathrm{K}$ mantidas a $140{ }^{\circ} \mathrm{C}$ para gerar os feixes de átomos com os dois elementos. Na região do desacelerador (figura 3.1c) temos o solenóide que possui aproximadamente $1 \mathrm{~m}$ de comprimento com um tubo de diâmetro interno de $16 \mathrm{~mm}$. Conectada ao desacelerador está a câmara de aprisionamento.

O sistema a vácuo possui três bombas iônicas, duas bombas (B1 e B2), modelos $45 \mathrm{~L}$ e $55 \mathrm{~L}$, são conectadas a região do forno; outra bomba (B3), modelo $75 \mathrm{~L}$, é conectada na região da câmara; todas as bombas são fabricadas pela empresa Varian. Na parte inferior da câmara temos uma bomba de sublimação de Ti, com seis filamentos no total com uma capacidade de bombeamento de $1000 \mathrm{l} / \mathrm{s}$. Esse conjunto de bombas mantêm um diferencial de $10^{-3}$ entre a região do forno $\left(10^{-7}\right.$ torr) e a região da câmara ( $10^{-10}$ torr), operando com o forno aquecido.

O procedimento para obter pressões no regime de ultra alto vácuo UHV (73), ou seja, pressões abaixo de $1 \times 10^{-9}$ torr, inicia-se com o bombeamento do sistema por uma bomba turbomolecular ( fabricante Pfeiffer Vacuum vazão $=56$ Litros/segundo). Na seqüência todo o sistema é aquecido a temperaturas de $160{ }^{\circ} \mathrm{C}$ com fitas resistivas para aumentar a taxa de degaseificação das impurezas do sistema, este processo é conhecido como processo de baking out do sistema. Este processo dura em torno entre duas e três semanas. Este procedimento de aquecimento e bombeamento pela bomba turbomolecular é realizado inicialmente na câmara e no solenóide desacelerador, e depois separadamente no forno. 

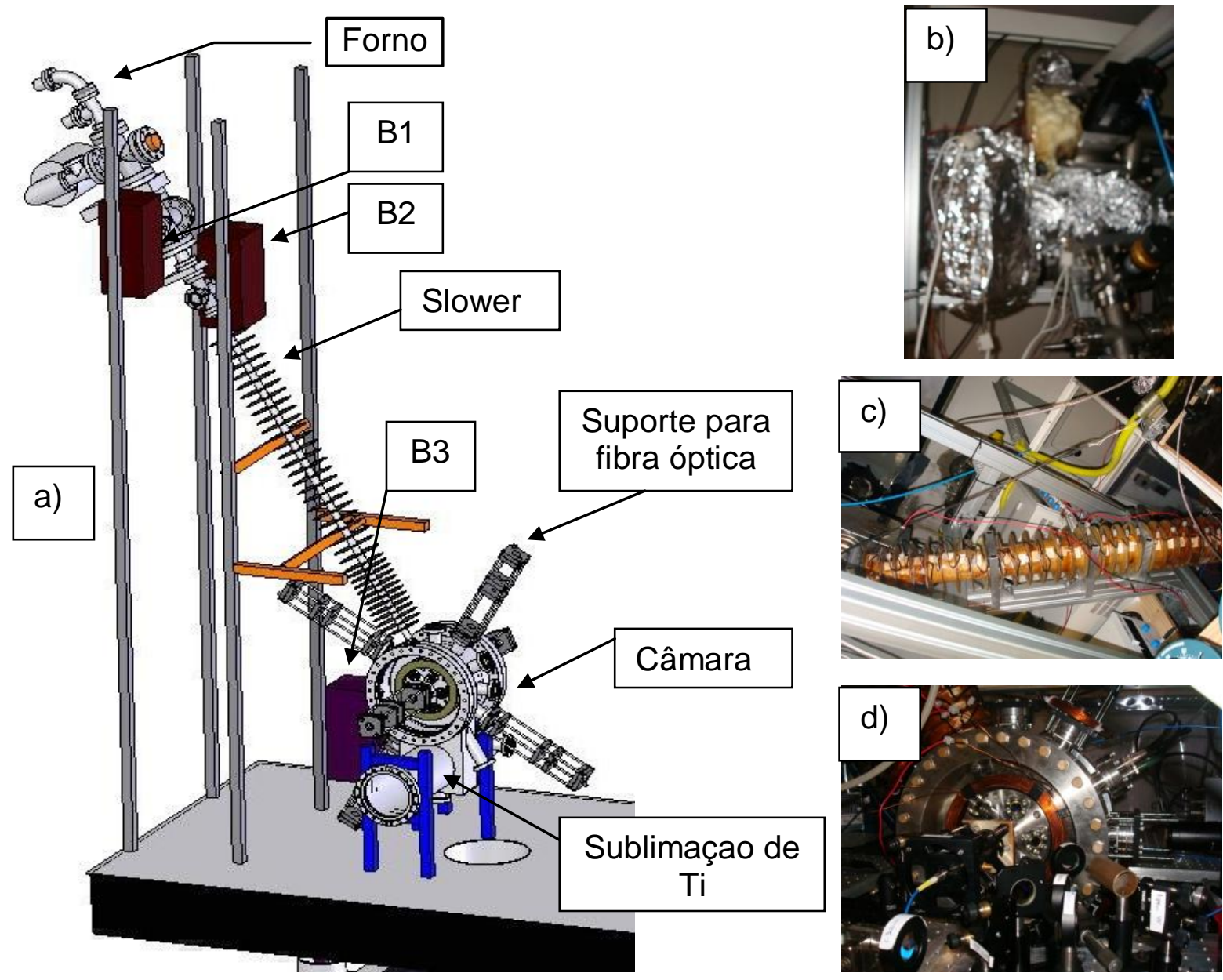

Figura 3.1 - a) Desenho esquemático da montagem dividido em três partes: b) o forno misto, c) o desacelerador de átomos, d) a câmara de aprisionamento com suportes onde serão acopladas as fibras ópticas para a armadilha. As letras B1, B2, B3 representam as bombas iônicas do sistema e na parte inferior temos a bomba de sublimação de Ti em um formato de $L$.

No final da primeira semana, as bombas iônicas (B2 e B3) são ligadas e os filamentos da bomba de sublimação de Ti são aquecidos. Os filamentos passam por três ciclos de 2 horas de aquecimento com correntes de $40 \mathrm{~A}$. No final deste processo o sistema atinge uma pressão em torno de $8 \times 10^{-8}$ torr e quando resfriado a temperatura ambiente, a pressão é reduzida por duas ordens de grandeza chegando a $8 \times 10^{-10}$ torr. Neste estágio as bombas de sublimação de Ti são ligadas por três ciclos de 45 minutos, isso aumenta a taxa de bombeamento do sistema levando o a um pressão final abaixo de $1 \times 10^{-10}$ torr.

Em seguida, o aquecimento é feito na região do forno, até o ponto em que a bomba iônica (B1) é ligada. Terminado o processo de bombeamento, o forno é aberto para o 
depósito das ampolas de $\mathrm{Rb}$ e $\mathrm{K}$ e é bombeado novamente por três dias, com a bomba turbomolecular conectada na região do forno, a uma temperatura de $60{ }^{\circ} \mathrm{C}$. Este último aquecimento é realizado para eliminar qualquer impureza na amostra nas ampolas. Terminado este procedimento de aquecimento a válvula de selo metálico é fechada e o sistema é isolado atingindo a pressão final de $1 \times 10^{-8}$ torr.

\subsubsection{0 forno misto}

O forno misto foi projetado para a produção de um feixe atômico com um fluxo de átomos de mesma proporção de $\mathrm{Rb}$ e $\mathrm{K}$ que operasse a uma única temperatura. Isto é necessário, visto que a pressão de vapor de $\mathrm{Rb}$ é maior do que a do $\mathrm{K}$ para uma dada temperatura. Um desenho esquemático do forno é mostrado na figura 3.2 com seus compartimentos internos. Com este forno somos capazes de gerar um feixe de átomos com um fluxo de $2 \times 10^{16}$ átomos/s por espécie na saída do forno (D), isso é possível mantendo a região A (ampola de $\mathrm{Rb}$ ) e $\mathbf{B}$ (ampola de $\mathrm{K}$ ) a $140{ }^{\circ} \mathrm{C}$ e separadas por uma válvula $\mathbf{C}$. Este valor para o fluxo e o projeto é baseado em outros projetos utilizados por outros grupos de pesquisa $(74,75)$.

Como a pressão de vapor de $\mathrm{Rb}$ é 1,48 vezes maior que a do $K$, as dimensões da válvula C foram calculadas e obtivemos as suas dimensões: diâmento $\mathbf{d}=5 \mathrm{~mm}$ e comprimento I = 26,8 mm. Neste cálculo consideramos que a diferença de pressão entre dois reservatórios conectados por um tubo de condutividade $\mathbf{K}$ deve gerar um fluxo $\mathbf{\Phi}$ (eq. 3.1). Isto exige que os fluxos parciais das espécies fossem iguais a $2 \times 10^{16}$ átomos/s no furo D. O furo foi feito em ângulo de modo que seu feixe de átomos produzisse uma mistura homogênea na região entre os furos $\mathbf{C}$ e $\mathbf{D}$.

$$
\Phi_{\text {fluxo }}=\beta K\left[\mathrm{P}_{1}-\mathrm{P}_{2}\right]
$$


O valor de $\mathbf{K}$ é dado pela equação 3.2 , nela $\overline{\boldsymbol{v}}$ representa a velocidade média dos átomos, d e I são diâmetro do e o comprimento da válvula $\mathbf{C}$.

$$
K=\frac{\pi \bar{v} d^{3}}{12 l}
$$

O fluxo de $2 \times 10^{16}$ átomos/s parte do furo $\mathrm{D}$ e uma fração de 0,5\% dos átomos atingem o tubo diferencial $\mathbf{G}$ (diâmetro $=4,77 \mathrm{~mm}$ e comprimento $=127 \mathrm{~mm}$ ) sendo colimada e seguindo para o desacelerador na região H. Uma placa de cobre E com um furo de diâmetro de $7,4 \mathrm{~mm}$ é mantida a $-20{ }^{\circ} \mathrm{C}$, atuando como uma barreira, impedindo que o vapor residual se propague até a região de aprisionamento. Em $\mathbf{F}$ temos uma válvula pneumática de segurança que é fechada automaticamente caso ocorra uma queda de tensão.

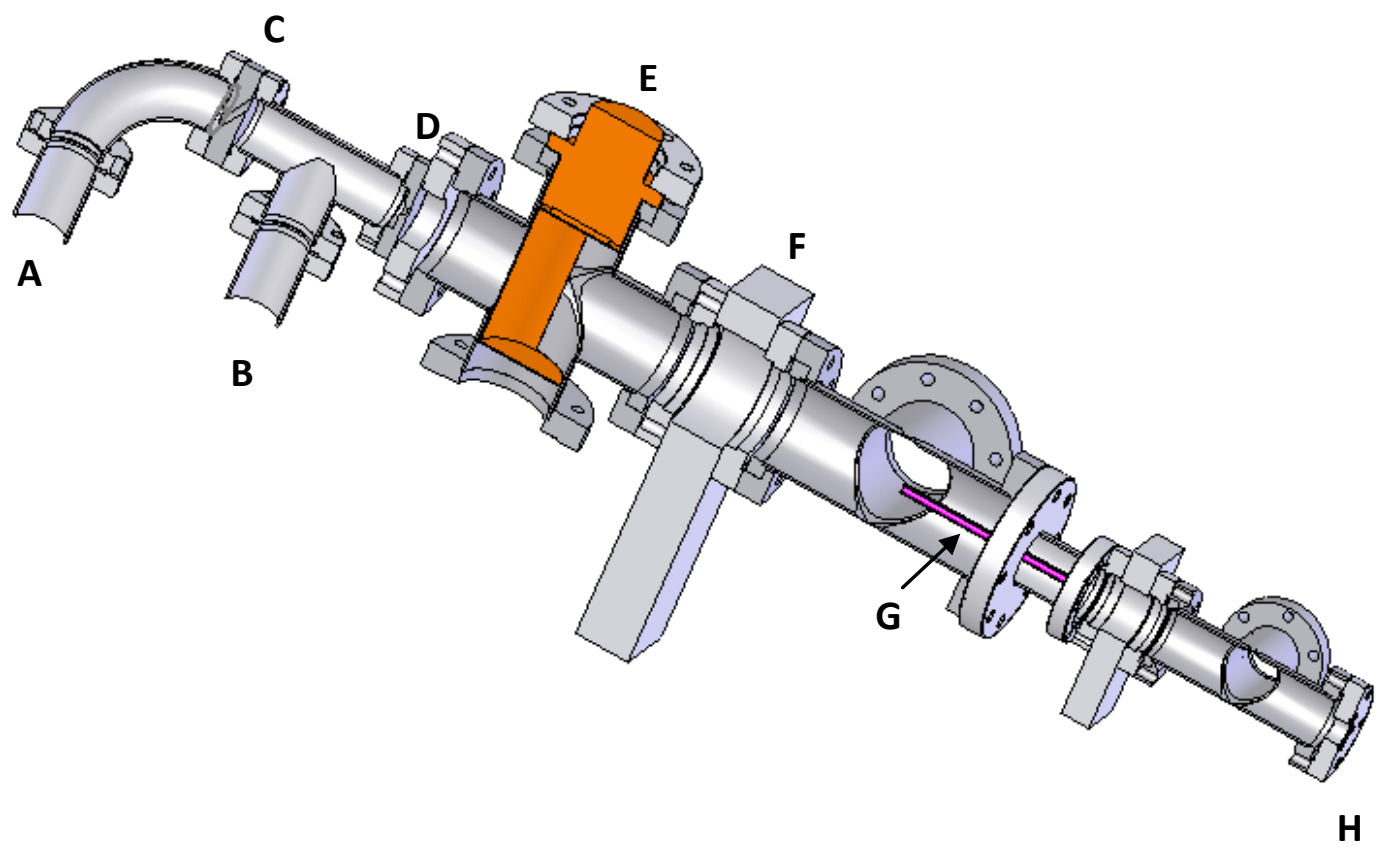

Figura 3.2 - Forno misto para produção do feixe de átomos de $R b$ e $K$. As regiões $\boldsymbol{A}$ e $\boldsymbol{B}$ são mantidas a $140^{\circ} \mathrm{C}$ para gerar um fluxo colimado de $2 \times 10^{16}$ átomos/s por espécie na saída do forno (D). Uma placa fria de cobre (E) atua como uma barreira impedindo o vapor residual de se propagar até a região de aprisionamento. Em $\boldsymbol{F}$ temos uma válvula pneumática de segurança, e em $\boldsymbol{G}$ (diâmetro $=4,77 \mathrm{~mm}$ e comprimento $=127 \mathrm{~mm}$ ) temos o tubo que para gerar o diferencial de pressão de $10^{-3}$ torr entre o forno e a câmara. 


\subsubsection{0 desacelerador misto}

O processo de desaceleração de feixes atômicos é bem compreendido e estudado (2). Nossa intenção aqui é apenas fornecer os conceitos básicos do processo. Inicialmente, consideramos um átomo sobre o qual incide radiação eletromagnética ressonante com uma de suas transições eletrônicas. Para cada fóton de luz absorvido temos um recuo atômico devido à transferência de momento do fóton, de valor $\hbar \vec{K}$ (em que $\vec{K}$ é o vetor de onda e $\hbar$ é a constante de Planck dividida por $2 \pi$ ). Supondo um átomo inicialmente em repouso, este absorverá um fóton, sendo levado ao seu estado excitado e recebendo o momento do fóton na direção de propagação da luz. Após a emissão espontânea, o átomo volta ao seu estado fundamental e sofre mais uma transferência de momento $\hbar \vec{K}$, porém desta vez em uma direção aleatória. Como resultado deste ciclo absorção-emissão, o átomo acaba recebendo um determinado momento resultante.

Considerando vários ciclos de absorção-emissão temos que a força resultante será na direção da absorção. Logo é necessária a propagação de um feixe de luz ressonante na direção contrária ao movimento do átomo para desacelerá-lo. Por outro lado, como a emissão espontânea é aleatória o feixe experimentará uma difusão transversal. Como exemplo prático, podemos analisar um sistema com átomos de Rb. Para estes átomos, a linha de absorção conhecida como D2 (correspondente à transição $5 \mathrm{~S}_{1 / 2} \rightarrow 5 \mathrm{P}_{3 / 2}$ ) apresenta um comprimento de onda $\lambda=780 \mathrm{~nm}$. Cada fóton dessa radiação absorvido ou emitido gera uma variação de $0,6 \mathrm{~cm} / \mathrm{s}$ para o rubídio na velocidade atômica. Como inicialmente os átomos em média possuem uma velocidade da ordem de $10^{5} \mathrm{~cm} / \mathrm{s}$, serão necessários aproximadamente 150 mil fótons para trazê-lo ao repouso. Como o feixe laser possui freqüência fixa, à medida que há absorção (desaceleração) o átomo sofre variação na sua freqüência de ressonância devido ao efeito Doppler. Em outras palavras, absorção de poucos fótons gera uma variação tão grande na velocidade do átomo que o processo de desaceleração é interrompido.

Assim, para conseguirmos baixas velocidades torna-se necessário um ajuste da freqüência de ressonância a cada nova velocidade que ocorre após a absorção de fótons. 
Isto pode ser feito com a utilização de um campo magnético variando convenientemente no espaço. Conforme a velocidade é variada, o campo magnético local sintoniza os níveis eletrônicos através do efeito Zeeman, mantendo permanente condição de ressonância. Essa técnica leva o nome de "Zeeman tuning technique", proposta em 1982 (76) e utilizada com sucesso em vários experimentos (77). Assim, um átomo com velocidade $\vec{v}$ contrapropagante a um feixe de luz numa região onde existe um campo magnético inomogêneo $B(z)$, sendo $v_{l}$ a freqüência do laser e $v_{0}$ a freqüência de absorção do átomo em repouso na ausência de campo, a absorção de fótons ocorrerá quando a condição de ressonância estiver satisfeita :

$$
K \vec{v}=\left(v_{0}-v_{l}\right)-\gamma B(z)
$$

O termo $\gamma B(z)$ é o espaçamento Zeeman entre os níveis considerados que, no caso dos átomos de interesse é linear com o campo. Essa equação diz que sempre que o efeito Doppler for compensado pelo efeito Zeeman, o átomo permanece ressonante. Supondo uma desaceleração constante $\boldsymbol{a}$, uma velocidade inicial $\boldsymbol{v}_{0}$, a velocidade pode ser dada pela equação de Torricelli:

$$
v(z)=\sqrt{v_{0}^{2}-2 a z}
$$

Logo aplicando a equação 3.4 em 3.3, o campo magnético que mantém o átomo constantemente desacelerado será:

$$
B(z)=B_{b}-B_{0} \sqrt{1-\beta z}
$$


com $B_{0}=\frac{K v_{0}}{\gamma}, \beta=\frac{2 a}{v_{0}^{2}}$ e $B_{b}$ uma constante escolhida de modo que para uma determinada freqüência do laser seleciona-se uma determinada velocidade inicial máxima. O termo constante também auxilia no desdobramento dos níveis de energia atômicos, pelo efeito Zeeman, impedindo efeitos de bombeamento óptico advindos do fato de o átomo não ser um sistema de dois níveis e uma vez que houver transição a algum estado que não seja o inicial, o átomo sai de ressonância (78).

A desaceleração máxima que uma partícula pode sofrer no processo é dada por $a_{\text {max }}=\frac{\hbar k \Gamma}{2 M}$. Assim obtemos os valores $0,10 \times 10^{8} \mathrm{~cm} / \mathrm{s}^{2}$ e $0,23 \times 10^{8} \mathrm{~cm} / \mathrm{s}^{2}$ para o $\mathrm{Rb}$ e $\mathrm{K}$ respectivamente. Considerando um desacelerador de $100 \mathrm{~cm}$, iremos desacelerar $\mathrm{Rb}$ e $\mathrm{K}$ a velocidades próximas de zero quando as velocidades iniciais forem menores ou iguais a 447 $\mathrm{m} / \mathrm{s}$ para o Rb e $678 \mathrm{~m} / \mathrm{s}$ para o K. Construindo um solenóide para operar na desaceleração máxima, qualquer pequena variação (devido a imperfeições na construção) poderia levar a perda de átomos durante o processo. Assim projetamos o solenóide para operar a 0,6 da $a_{\text {max }}$ do $\mathrm{Rb}$, portanto iremos desacelerar átomos de $\mathrm{Rb}$ e $\mathrm{K}$ com velocidades a partir de 346 $\mathrm{m} / \mathrm{s}$ e $525 \mathrm{~m} / \mathrm{s}$. Isso nos leva a um determinado campo teórico, o qual não é possível de se construir. Então resolvemos utilizar um programa que simula o perfil de campo utilizando 38 bobinas independentes (diâmetro $=90 \mathrm{~mm}$ e largura $=30 \mathrm{~mm}$ ) com número de voltas variável e cinco fontes de alimentação independentes de máximo $5 \mathrm{~A}$. O programa ajustou o número de voltas em cada bobina para que o campo real fosse o mais próximo possível do teórico.

O resultado final é apresentado na figura 3.3 em que mostramos o perfil de campo projetado, o medido experimentalmente e uma foto do solenóide. Vale ressaltar que o solenóide atingiu a temperatura final de $45{ }^{\circ} \mathrm{C}$ após 4 horas de operação, e manteve assim por mais 8 horas. A temperatura limite do fio é de $200{ }^{\circ} \mathrm{C}$, ou seja, não há necessidade de refrigeração do mesmo, simplificando sua operação. 

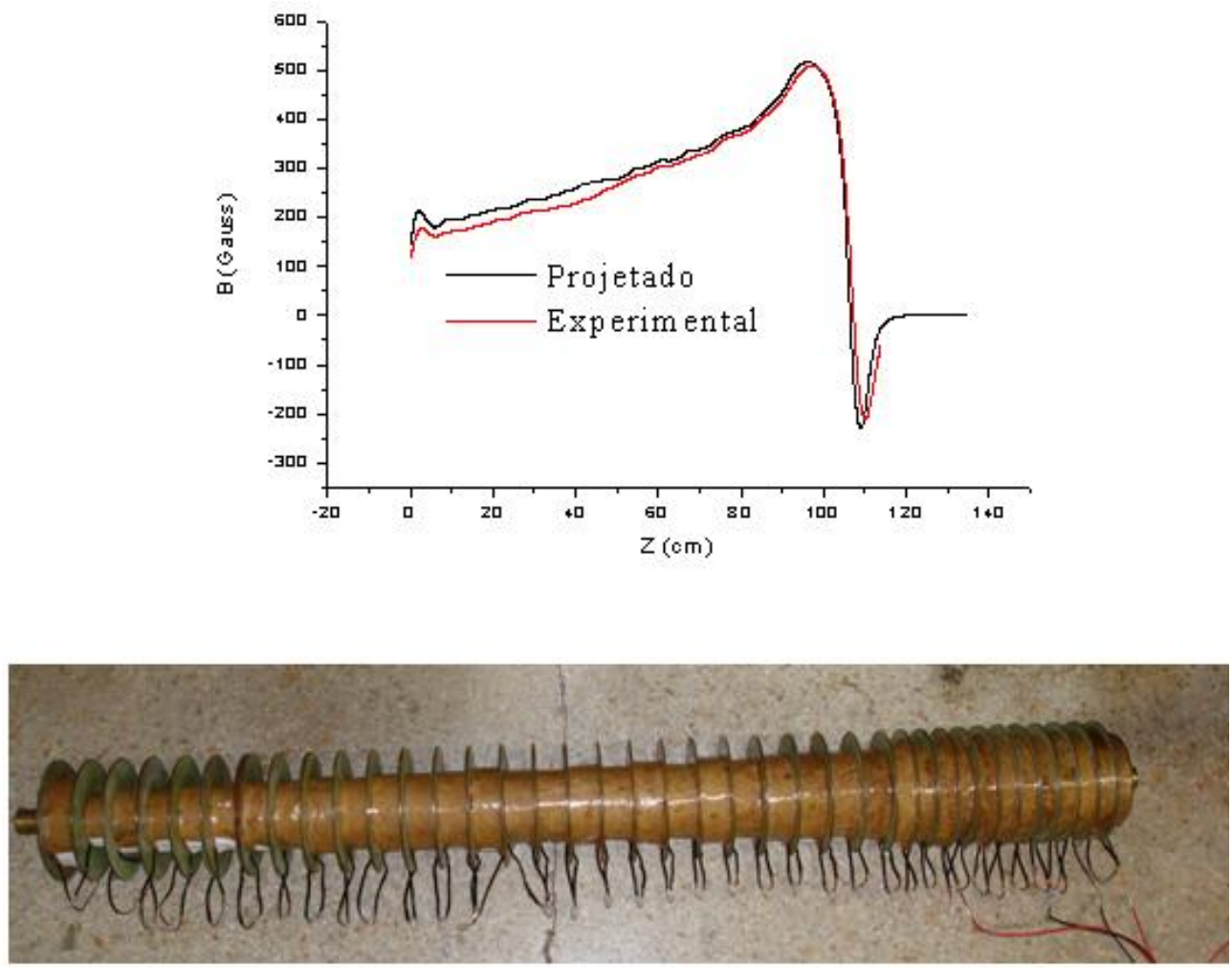

Figura 3.3 - Perfil do campo magnético projetado e medido e foto do solenóide.

\subsubsection{Câmara de aprisionamento}

Na figura 3.4 mostramos um desenho esquemático da câmara de aprisionamento. A câmara possui quatorze janelas de $2-3 \backslash 4$ " das quais utilizaremos seis para o MOT, duas para o feixe do desacelerador, duas para o sistema de imagens, uma para o detector de íons e uma para conexões elétricas das placas internas. As janelas 1-1/ 3"do plano horizontal recebem os feixes para a armadilha de dipolo cruzada. O tubo na parte inferior é uma bomba de sublimação de titânio constituída por uma grande área com um comprimento total de $80 \mathrm{~cm}$ e diâmetro de 8 ". Seis suportes de fibra óptica são acoplados para os feixes do MOT, estes polarizam circularmente e expandem os feixes. 
As bobinas para o gradiente de campo do MOT vão encaixados às janelas angulares de 8 ". Foram adicionadas ao sistema placas que podem gerar um campo de $1 \mathrm{KV} / \mathrm{cm}$, esta aplicação será interessante em estudos de colisões moleculares polarizadas em futuros experimentos. Finalmente temos o detector de íons do tipo channeltron em seu interior.

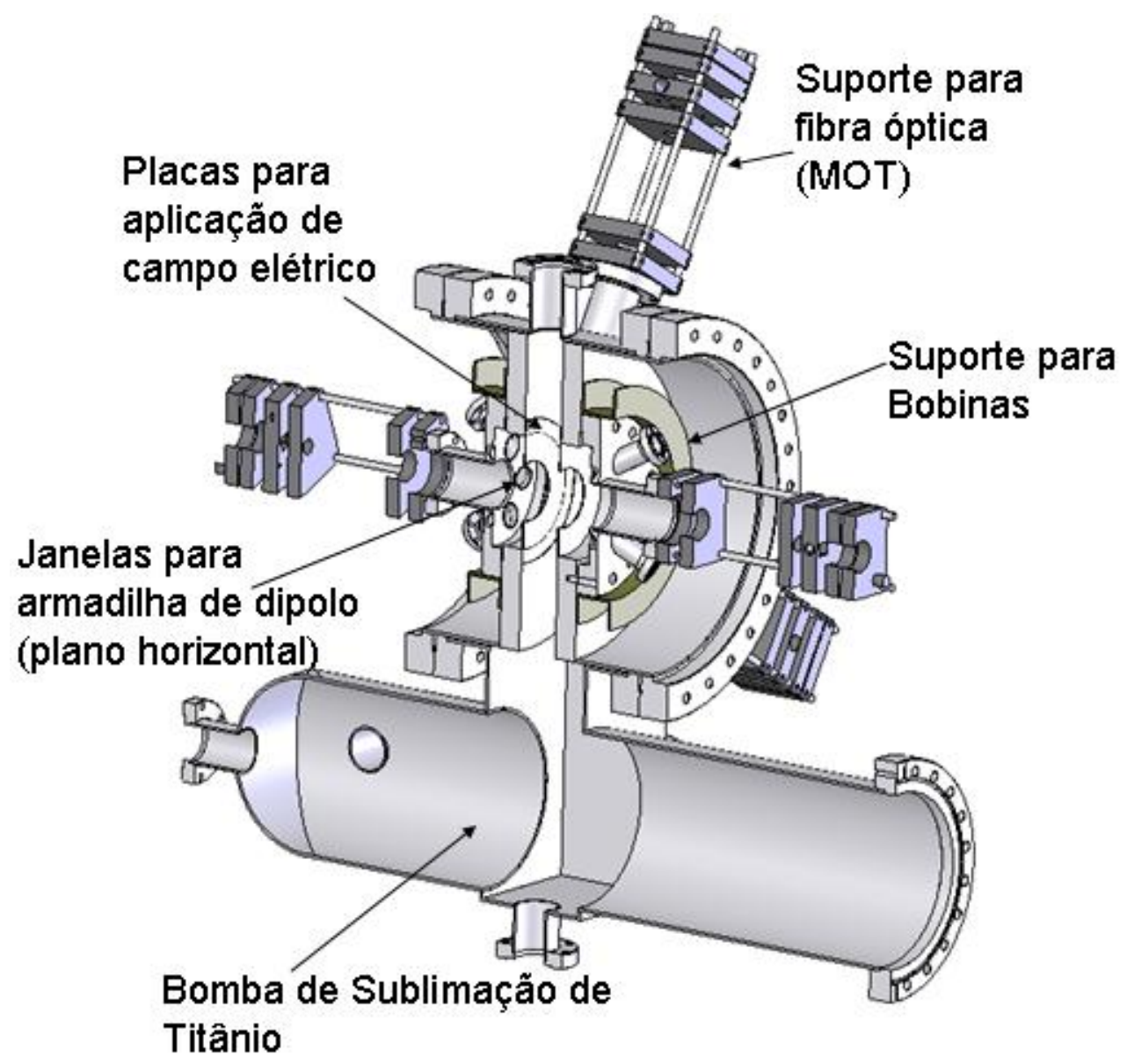

Figura 3.4 - Imagem do corte da câmara de aprisionamento e seus componentes em detalhes. 


\subsection{MOT duplo}

\subsubsection{Considerações teóricas}

Após a desaceleração dos átomos, o próximo passo é o aprisionamento das duas espécies pela armadilha magneto-óptica (MOT). A armadilha magneto-óptica é constituída de três pares de feixes contrapropagantes perpendiculares e um gradiente de campo magnético. Para entendermos melhor seu funcionamento consideraremos um átomo de dois níveis em uma dimensão iluminado por feixes de laser contrapropagantes sintonizados abaixo da ressonância, ou seja, $\omega_{\text {laser }}<\omega_{0}$, em que $\omega_{0}$ é a freqüência de ressonância do estado excitado. Quando o átomo se move para a esquerda, devido ao efeito Doppler, ele absorverá um fóton de momento $\mathbf{k}$ contrario ao seu movimento, o mesmo acontece quando ele se move para a direita. Isso produz uma força que se opõe ao movimento do átomo provocando uma desaceleração em seu movimento.

Imaginando esse mesmo sistema, mas agora com três pares de feixe, geramos um meio viscoso para os átomos, este meio foi chamada de melaço óptico ou optical molasses e criado pela primeira vez em 1985 por Steven Chu e colaboradores (79). Embora os átomos sejam desacelerados não temos uma amostra confinada espacialmente. Assim devemos introduzir um gradiente de campo magnético, gerando uma regra de seleção espacial. Desse modo, a probabilidade de absorção do fóton pelo átomo será maior dependendo da sua posição com relação ao gradiente de campo e da polarização circular incidente $\left(\sigma^{+}\right.$ou $\left.\sigma^{-}\right)$. Esse mecanismo acaba confinando os átomos na região de campo nulo. A figura 3.5 mostra o esquema de aprisionamento em uma dimensão.

Neste esquema o campo magnético é nulo no centro e aumenta linearmente. Assim o átomo que estiver numa região de campo não nulo sofrerá uma quebra da degenerescência dos estados formando subníveis de energia determinados pelo número 
quântico $m_{\mathbf{F}}$. Esses níveis de energia tendem a se separar proporcionalmente com a intensidade do campo magnético em $m_{F^{\prime}}=-1,0,+1$ devido ao efeito Zeeman.

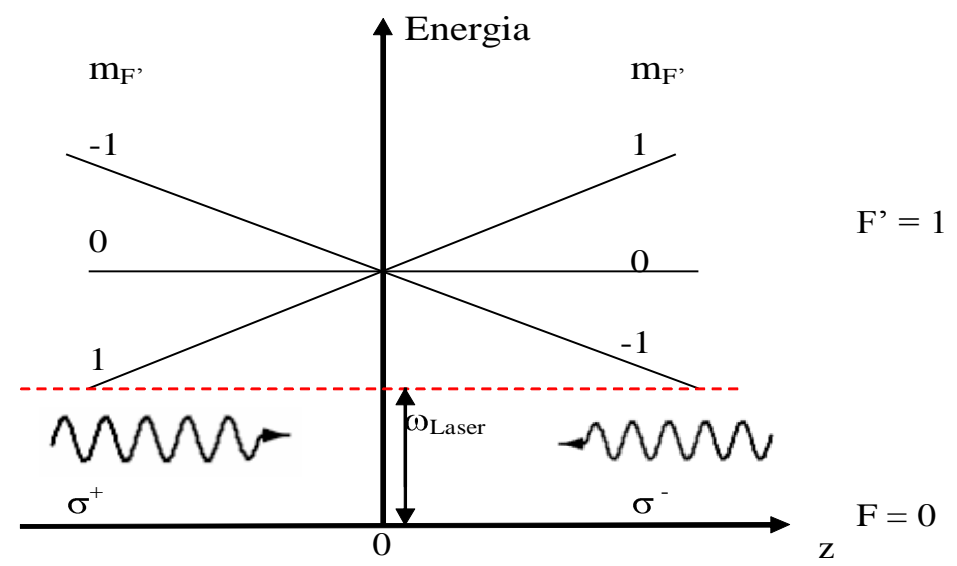

Figura 3.5 - Força restauradora espacial em uma dimensão. $O$ estado fundamental $F=0$, não sofre variação em sua energia $\Delta E=0$, já o estado excitado $F^{\prime}=1$ sofre variação de $\Delta E=\left(m_{F^{\prime}}=\right.$ $1,0,+1)$.

Assim ajustando a polarização do laser que se propaga para a esquerda para uma polarização circular $\sigma^{-}$só poderá realizar transições de $F=0$ para o subnível $m_{F^{\prime}}=-1$. Ao contrário do que acontece com o laser que se propaga para a direita, que é ajustado para uma polarização circular $\sigma^{+}$onde só poderá realizar transições de $\mathrm{F}=0$ para o subnível $\mathrm{m}_{\mathrm{F}^{\prime}}=$ +1. Deste modo o átomo tende a se localizar na região de força nula, nesta posição ele sofrerá menor interação com a radiação. Para um problema real devemos considerar as três dimensões, e para isso basta fazer as mesmas considerações para o eixo x e y, assim esse sistema de feixes aprisiona os átomos na região de menor campo magnético.

Na figura 3.6 temos as transições utilizadas para o aprisionamento de ${ }^{85} \mathrm{Rb},{ }^{87} \mathrm{Rb}$ e ${ }^{39} \mathrm{~K}$ e as freqüências de aprisionamento (setas vermelhas) e rebombeio (setas verdes). O ciclo de aprisionamento torna-se completo quando adicionamos um feixe extra ao sistema chamado de feixe de rebombeio, isso é necessário devido à estrutura hiperfina do estado fundamental dos átomos. Ou seja, não existem átomos de dois níveis apenas. Como exemplo, podemos considerar $0{ }^{87} \mathrm{Rb}$ inicialmente no estado $5 s_{1 / 2}(F=2)$, existe uma probabilidade não nula do átomo sofrer uma transição para o estado $5 p_{3 / 2}\left(F^{\prime}=2\right)$ e decair para o estado $5 s_{1 / 2}(F=1)$. Com feixe de rebombeio podemos trazê-lo novamente para o estado $5 \mathrm{p}_{3 / 2}\left(\mathrm{~F}^{\prime}=2\right)$ que por 
sua vez pode decair no estado $5 s_{1 / 2}(F=2)$ participando novamente do ciclo de aprisionamento. É importante lembrar que um feixe de rebombeio também deve estar presente no mecanismo de desaceleração pelo mesmo princípio.

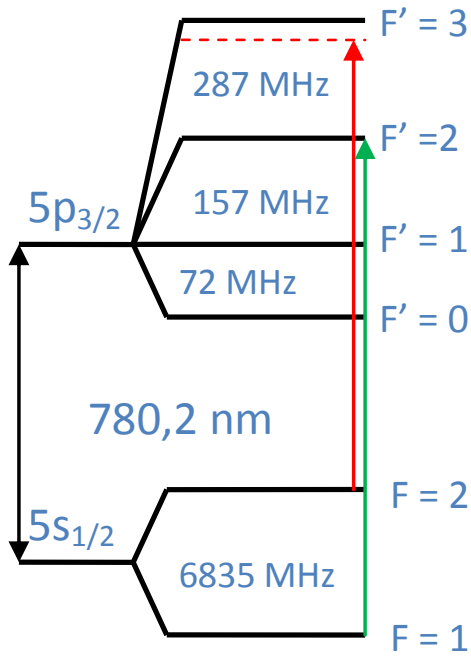

${ }^{87} \mathrm{Rb}$

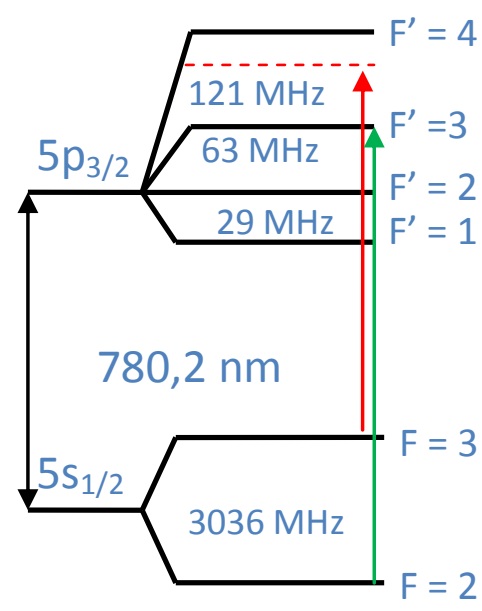

${ }^{85} \mathrm{Rb}$

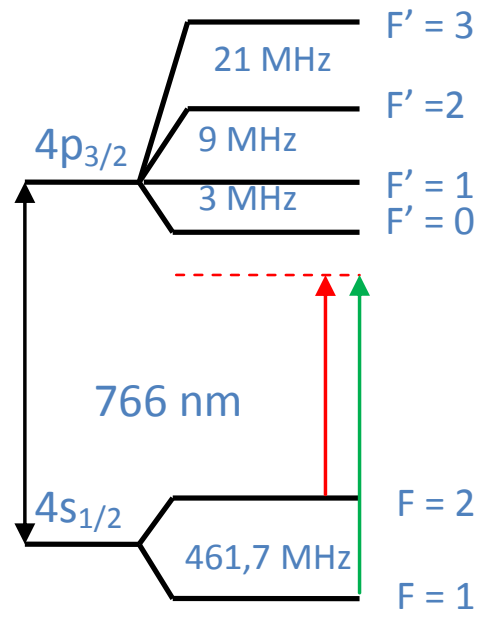

${ }^{39} \mathrm{~K}$

Figura 3.6 - Níveis de energia das espécies ${ }^{87} R b,{ }^{85} R b,{ }^{39} K$. As setas vermelhas representam as freqüencias para aprisionamento $e$ as verdes as freqüências para rebombeio. As freqüencias de aprisionamento apresentam uma dessintonia de $-20 \mathrm{MHz}$ para ${ }^{87} \mathrm{Rb} e$ ${ }^{85} \mathrm{Rb} e-30 \mathrm{MHz}$ para ${ }^{39} \mathrm{~K}$.

A limitação desse tipo de armadilha é devido ao fato do átomo estar continuamente espalhando fótons. Desse modo ele também executa um movimento randômico no espaço dos momentos, recebendo um recuo em uma direção definida, devido à absorção, mas recebe um impulso em uma direção qualquer devido à emissão. Assim existe um limite para a mínima temperatura conhecida como o limite Doppler (6). Para o ${ }^{85} \mathrm{Rb}, \mathrm{T}_{\min }=141 \mu \mathrm{K}$, este são valores típicos de temperatura em uma armadilha magneto-óptica obtidos pela técnica de resfriamento Doppler. 


\subsubsection{Montagem óptica}

$\mathrm{Na}$ figura 3.7 apresentamos um diagrama da montagem óptica para o Rb. Nela destacamos o laser de diodo da Toptica DLX 110 que possui $600 \mathrm{~mW}$ de potência em 780 $\mathrm{nm}$, o qual gera as freqüências de aprisionamento, desaceleração e imagem para o ${ }^{87} \mathrm{Rb}$ e ${ }^{85} \mathrm{Rb}$. Devido à necessidade de maior potência no feixe do desacelerador, foi usado um laser escravo, fabricado pela Topitca, modelo LD (765 - $795 \mathrm{~nm})$, o qual possui $80 \mathrm{~mW}$ de potência em $780 \mathrm{~nm}$ controlado pelos controladores da Thorlabs LDC 205C e TED 200C. Para as freqüências de rebombeio da armadilha e rebombeio do desacelerador utilizamos outro laser da Toptica modelo DL 100 que possui $130 \mathrm{~mW}$ de potência em $780 \mathrm{~nm}$. Todas as freqüências são geradas via modulares acusto-ópticos fabricados pela empresa Intraaction.

Na figura 3.8 temos a montagem para o K, o laser utilizado também é um modelo DLX 110 da Toptica com 500 mW de potência em 766 nm. Nesta montagem também geramos os feixes de aprisionamento, rebombeio e imagem. Outro laser escravo é utilizado para gerar a freqüências de desaceleração. A diferença desse sistema é que os feixes para rebombeio tanto da armadilha quanto do desacelerador são gerados com moduladores eletro-ótpcos confeccionados em nosso laboratório.

Os feixes 3 e 11 da figura 3.7 e 3 da figura 3.8 são os feixes de aprisionamento e rebombeio de $\mathrm{Rb}$ e K. Estes são acoplados a fibra óptica, mono modo (fabricante Canadian Instrumentation \& Research Ltd.) com eficiência de acoplamento de aproximadamente 40 \% da potência. Este tipo de fibra possui quatro entradas e seis saídas, ou seja, os feixes de aprisionamento de $\mathrm{Rb}$ e $\mathrm{K}$ e seus rebombeios são misturados e tem suas potências divididas entre as 6 saídas. Esse é um método bem robusto de construir um sistema para MOT duplo. As potências líquidas para as armadilhas nesse sistema são: $90 \mathrm{~mW}$ e $10 \mathrm{~mW}$ para aprisionamento e rebombeio de $\mathrm{Rb}$ e $14 \mathrm{~mW}^{*}$ para aprisionamento e rebombeio de $\mathrm{K}$.

\footnotetext{
* Em nosso sistema, o feixe modulado eletro-ópticamente, tem sua potência total resultante dividida aproximadamente em três partes iguais: $1 / 3$ da potência é composta pelo modo fundamental $\left(v_{0}\right)$ do feixe, o qual não sofre alteração na freqüência; os outros $2 / 3$ é composto pela primeira ordem de modulação $\left(v_{0} \mp \Delta v\right)$. Assim considerando a potência total de $42 \mathrm{~mW}$, apenas 2/3 é aproveitada para a armadilha do $\mathrm{K}$.
} 


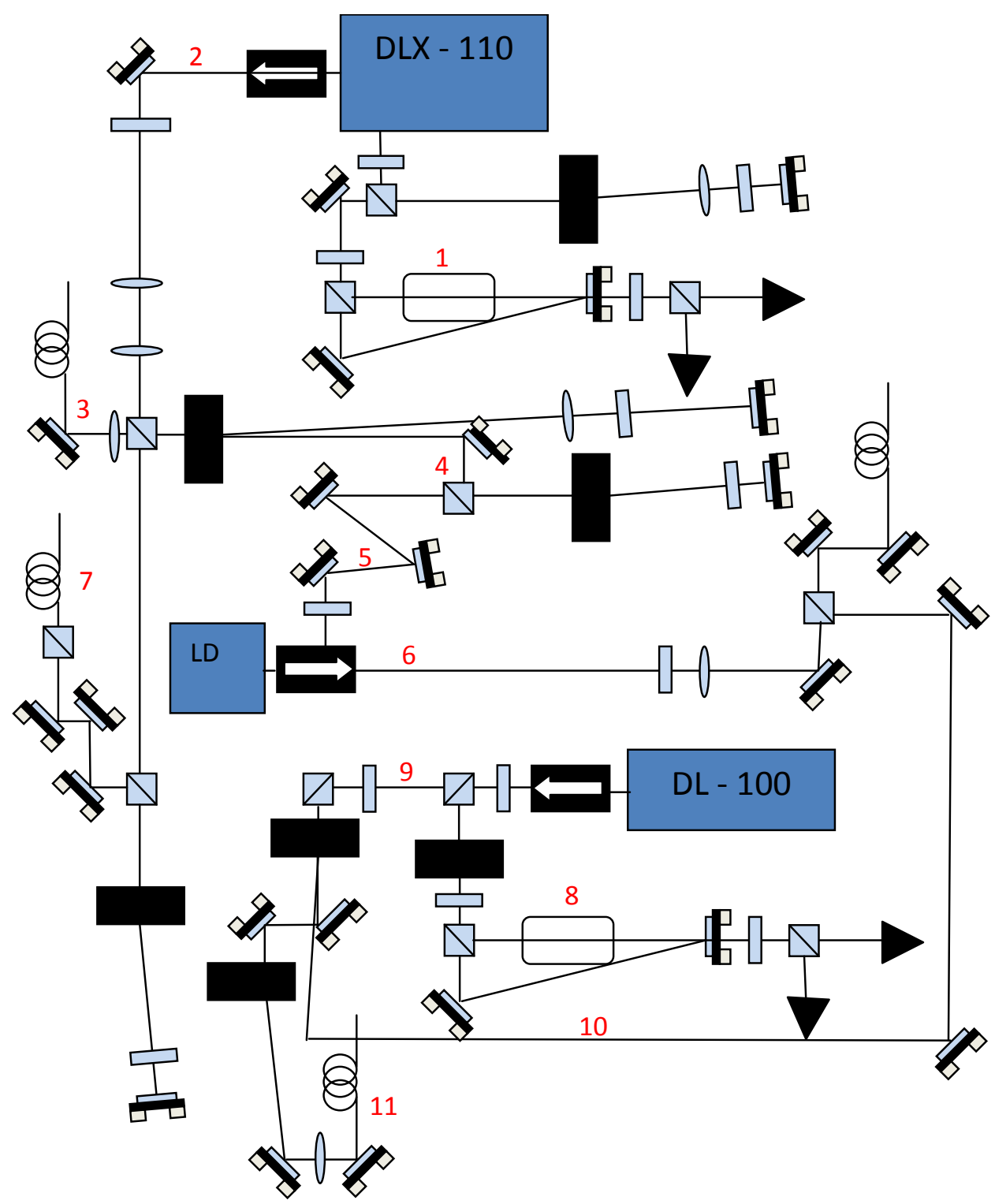

Figura 3.7 - Montagem experimental para feixe de aprisionamento rebombeio e desaceleração de ${ }^{87} R b e^{85} R b$ 1) Espectroscopia de absorção saturada por polarização, sistema travado a $187 \mathrm{MHz}$. 2) e 4) Feixe ajustado a - $187 \mathrm{MHz}$. 3) Feixe para aprisionamento de ${ }^{87} \mathrm{Rb}$ ajustado a - $20 \mathrm{MHz}$. 5) Feixe para injeção em laser escravo ajustado a - $687 \mathrm{MHz}$ ). 6) Laser escravo (LD) para desaceleração ajustado a - $687 \mathrm{MHz}$. 7) Feixe para imagem ajustado na transição. Freqüências de 1 a 7 estão ajustadas com relação às transições $5 S_{1 / 2}(F=2,3)-5 P_{3 / 2}\left(F^{\prime}=3,4\right)$ do ${ }^{87} R b$ e ${ }^{85} R b$ respectivamente .8$)$ Espectroscopia de absorção saturada por polarização, sistema travado a-80 $\mathrm{MHz}$. 9) Feixe ajustado a -80 $\mathrm{MHz}$. 10) Feixe para rebombeio do desacelerador ajustado a - $430 \mathrm{MHz}$. 11) Feixe para o rebombeio da armadilha ajustado na transição. Freqüências de 8 a 11 estão ajustadas com relação às transições $5 S_{1 / 2}(F=1,2)-5 P_{3 / 2}\left(F^{\prime}=2,3\right) d o{ }^{87} R b$ e ${ }^{85} R$ respectivamente. 


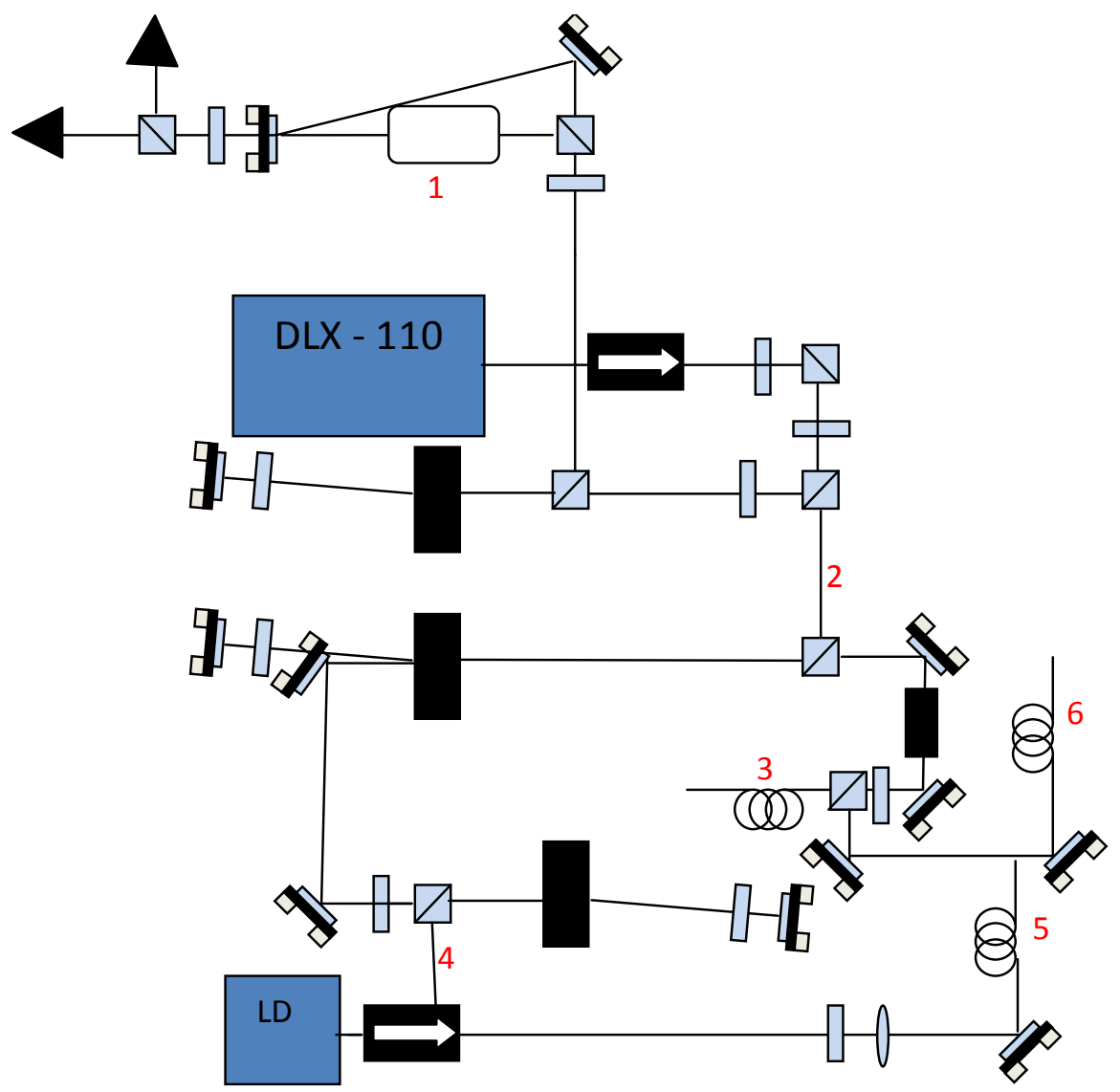

Figura 3.8 - Montagem experimental para feixe de aprisionamento, rebombeio e desaceleração de

${ }^{39} \mathrm{~K}$. 1) Espectroscopia de absorção saturada por polarização, sistema travado a -200 $\mathrm{MHz}$. 2) Feixe ajustado a - $200 \mathrm{MHz}$. 3) Feixe para aprisionamento e rebombeio ajustado a - $30 \mathrm{MHz}$ e $-420 \mathrm{MHz}$ (adicionado através de modulão eletro-óptica) respectivamente. 4) Feixe para o injeção no laser escravo. 5) Feixe para desaceleração de ${ }^{39} \mathrm{~K}$ ajustado a $662 \mathrm{MHz}$ e rebombeio a - $435 \mathrm{MHz}$. 6) Feixe para imagem ajustado na transição. As freqüências estão ajustadas com relação à transição $4 S_{1 / 2}(F=2)-4 P_{3 / 2}$, é importante lembrar que o espectro de ${ }^{39} \mathrm{~K}$ não possui resolução para distinguirmos as estruturas hiperfinas $F^{\prime}$.

Os feixes 6 e 10 da figura 3.7 são os feixes para a desaceleração de $\mathrm{Rb}$ e seu rebombeio que são misturados por um cubo polarizador e acoplados à fibra. Para a desaceleração de $\mathrm{K}$ temos apenas o feixe 5 da figura $3.8 \mathrm{com}$ seu rebombeio produzido por um modulador eletro-óptico. As potências líquidas para dos feixes são: $20 \mathrm{~mW}$ e $5 \mathrm{~mW}$ para o desacelerador e rebombeio do $\mathrm{Rb}$ e $7 \mathrm{~mW}$ para o desacelerador e rebombeio do $\mathrm{K}$.

Os feixes para a desaceleração de Rb e K são acoplados independentemente em fibras unidas em sua outra extremidade (figura 3.9), com isso geramos um único feixe para o desacelerador misto sem comprometer as potências, já que o acoplamento das fibras nos compromete em $50 \%$ dessa potência. 


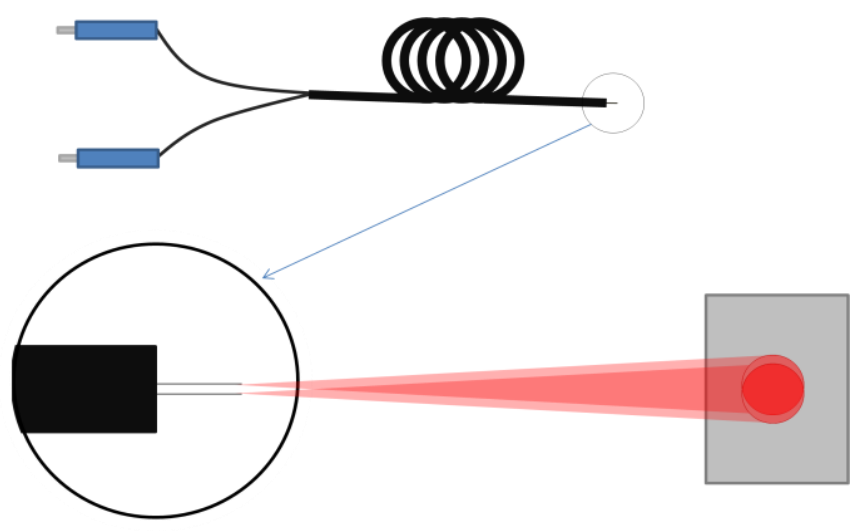

Figura 3.9 - Fibra óptica desenvolvida para o acoplamento dos feixes de desaceleração das duas espécies Rb e $K$.

Depois de acoplados à fibra, o feixe do desacelerador é expandido e focalizado de modo que entre na câmara de aprisionamento com um diâmetro de $17 \mathrm{~mm}$ e atinja o tubo diferencial (tubo $G$ da figura 3.2) com um diâmetro de $4,5 \mathrm{~mm}$, durante este percurso os feixes de Rb e K sofrem um pequeno desvio fazendo sua sobreposição ser aproximadamente $15 \%$ dispersa. Essa focalização do feixe é necessária para tornar o processo de desaceleração mais eficiente, pois o feixe de átomos tende a expandir como um cone durante o percurso. Quando o forno está aquecido podemos assistir à fluorescência das espécies com uma câmera CCD, colocada na janela de frente para a bomba iônica B2 (figura 3.2). Este é o método mais eficiente que encontramos para realizar o alinhamento do feixe do desacelerador.

\subsubsection{Alinhamento do MOT duplo}

Os feixes do MOT duplo, depois de acoplados às fibras ópticas, são conectados a um telescópio que projetamos e construímos em nossa oficina mecânica. Trata-se de um conjunto de componentes ópticos acoplados e conectados à câmara de aprisionamento 
(figura 3.10), nele os feixes são circularmente polarizados $\left(\sigma^{+}\right.$ou $\left.\sigma^{-}\right)$e são expandidos a diâmetros de aproximadamente $25 \mathrm{~mm}$.

Para garantir estabilidade nas polarizações também foi colocado um cubo polarizador e uma lâmina de meia onda $(\lambda / 2)$ nesse sistema óptico, pois as fibras ópticas são muito sensíveis a temperatura e tensões variando constantemente a polarização dos feixes gerando instabilidades no aprisionamento. Apesar do acoplamento das fibras serem de no máximo 40 \% de eficiência para lasers de diodo, o sistema se torna muito versátil e robusto em termos de alinhamento. São utilizados sete desses sistemas no total, seis para a armadilha e um para o feixe da imagem.

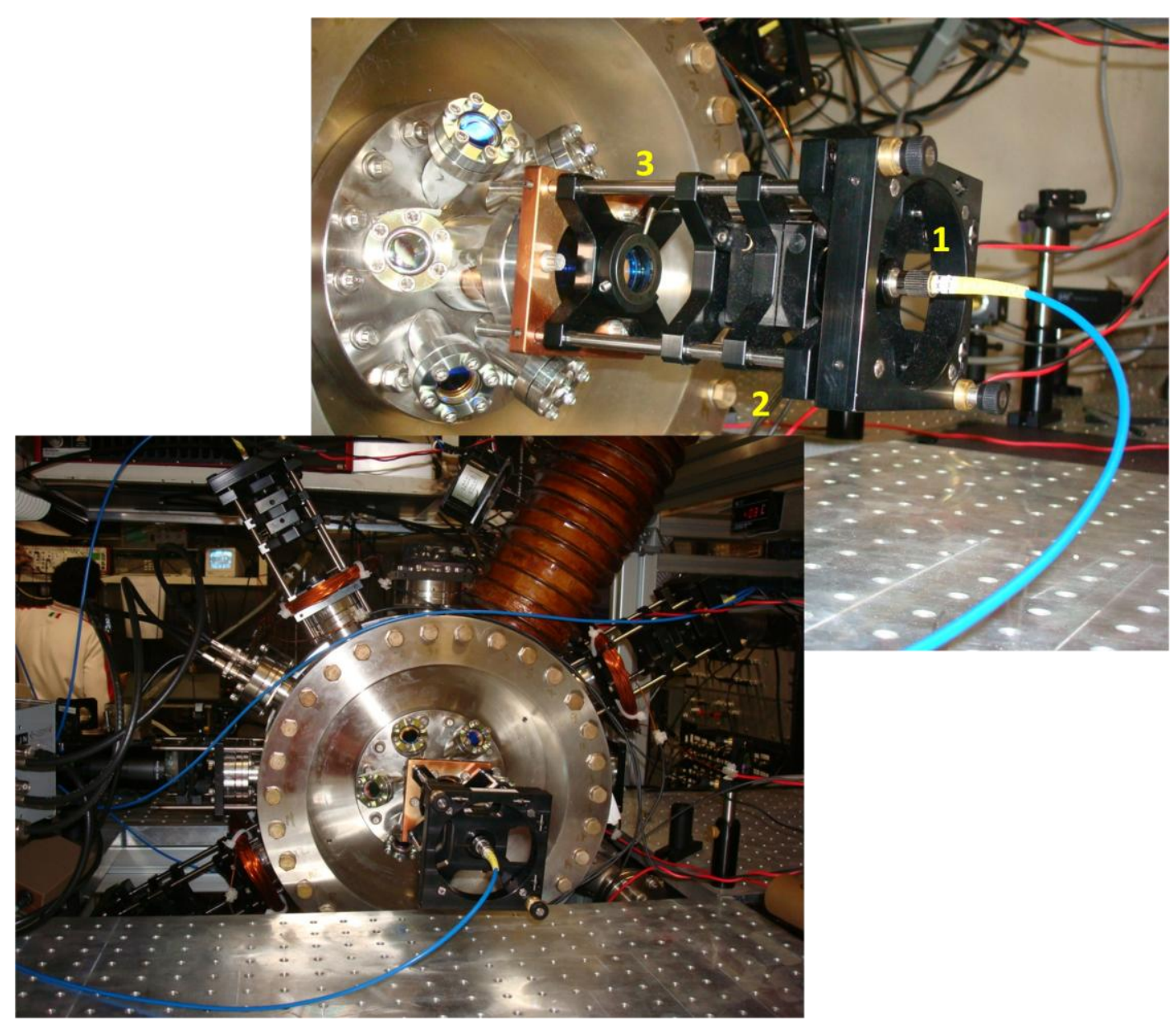

Figura 3.10 - Montagem para armadilha magneto óptica. 1) Fibra óptica dos feixes de aprisionamento de $R b$ e K. 2) Ajuste da polarização em $\sigma$ - ou $\sigma+$.3) Telescópio para expansão do feixe em aproximadamente $25 \mathrm{~mm}$ de diâmetro. 


\subsection{A armadilha de dipolo óptica}

\subsubsection{Considerações teóricas}

Um feixe gaussiano focalizado e sintonizado abaixo da ressonância foi uma das primeiras propostas para aprisionar átomos opticamente. Este foi sugerido pela primeira vez por Ashkin (1977) (80) e demonstrado por Chu (1986) (3). Tal feixe induziria um dipolo elétrico nos átomos e confinaria pela interação entre o dipolo induzido e o campo elétrico do laser. Conceitualmente a física é simples, podemos escrever o potencial de interação da forma:

$$
U=-\frac{1}{2} \overline{d \cdot E}
$$

Em que o fator $1 / 2$ é devido ao fato de que o dipolo é induzido e não permanente. Em termos de polarizabilidade o momento de dipolo pode ser escrito como $\boldsymbol{d}=\alpha \boldsymbol{E}$ tornando o potencial de interação uma função da intensidade da radiação:

$$
U(r, z, \phi)=-\frac{1}{4} \alpha E^{2}=-\frac{2 \pi}{c} \alpha I(r, z, \phi)
$$

Com isso mostramos que o potencial pode ser atrativo ou repulsivo dependendo do sinal da polarizabilidade $\alpha$ e sua dependência espacial depende basicamente da geometria espacial do feixe $I(r, z, \phi)$, definido em coordenadas cilindricas. Considerando a geometria de um feixe gaussiano focalizado (81) podemos escrever o potencial tridimensional confinante para átomos e moléculas: 


$$
U(r, z, \phi)=-\frac{U_{0}}{1+\left(z / z_{R}\right)^{2}} \exp \left(-2 \frac{r^{2}}{w_{0}^{2}}\right)
$$

Em que $z_{R}$ é o comprimento de Rayleigh e $U_{0}$ é a profundidade do potencial:

$$
z_{0}=\frac{\pi w_{0}^{2}}{\lambda}
$$

$$
U_{0}=\frac{\alpha P}{2 \varepsilon_{0} c \pi w_{0}^{2}}\left(\frac{v_{0}}{v_{0}-v}+\frac{v_{0}}{v_{0}+v}\right)
$$

em que onde $P$ é a potência do laser, $w_{0}$ é a cintura do feixe gaussiano, $v_{0}$ é a freqüência de ressonância do primeiro estado excitado e $v$ a freqüência do laser de aprisionamento. Para calcularmos as freqüências de oscilação radial e axial da armadilha podemos expandir a expressão 3.8 em valores de r e z próximos de zero tornando o potencial aproximadamente harmônico.

$$
U(r, z, \phi) \approx-U_{0}+\frac{M}{2}\left(\omega_{z}^{2} z^{2}+\omega_{r}^{2} r^{2}\right)
$$

Desse modo, próximo ao foco do laser, o átomo está sujeito à influência de um potencial harmônico anisotrópico com as respectivas freqüências axial de radial,

$$
\begin{aligned}
& \omega_{z}=\sqrt{\frac{2 U_{0}}{M z_{R}^{2}}} \\
& \omega_{r}=\sqrt{\frac{4 U_{0}}{M w_{0}^{2}}}
\end{aligned}
$$


em que $M$ é a massa do átomo.

A polarizabilidade do átomo pode ser calculada a partir de princípios básicos da interação da radiação com a matéria, podemos supor um átomo cujo elétron está harmonicamente ligado ao núcleo, assim sua equação de movimento será governada por:

$$
\ddot{x}+\omega_{0}^{2} x=\frac{e E(t)}{m_{e}}
$$

Em que $\omega_{0}$ é a freqüência natural de oscilação, $e$ e $m_{e}$ são respectivamente a carga e a massa do elétron. $\mathrm{Na}$ resolução desta equação podemos obter a polarizabilidade $(\alpha)$ considerando $\boldsymbol{d}=e \boldsymbol{x}=\alpha \mathbf{E}$ :

$$
\alpha=\frac{e^{2}}{2 \omega_{0} m_{e}}\left[\frac{1}{\omega_{0}-\omega}+\frac{1}{\omega_{0}+\omega}\right]=\frac{\mu^{2}}{\hbar}\left[\frac{1}{\omega_{0}-\omega}+\frac{1}{\omega_{0}+\omega}\right]
$$

Note que o dipolo oscila em fase quando $\alpha>0$, isto é, quando o campo aplicado tem freqüência abaixo da ressonância $\left(\omega<\omega_{0}\right)$, assim o átomo é atraído para a região de maior intensidade. Por outro lado, se o laser é sintonizado acima da transição atômica, isto é, $\omega>$ $\omega_{0}$ o dipolo oscila $180^{\circ}$ fora de fase e o átomo é repelido da região de maior intensidade. Isto nos sugere trabalhar com uma freqüência abaixo da transição atômica, disso surgem duas classes de armadilhas de dipolo ópticas: as QUESTs (Quase Eletrostatic Traps) que utilizam lasers com comprimento de onda de 10,6 $\mu \mathrm{m}$ e as FORTs (Far-off Ressonance Traps) que utilizam lasers com comprimento de onda na região de 850 - 1500 nm. 


\subsubsection{Montagem óptica}

A montagem experimental para a armadilha de dipolo é bem mais simples que a montagem dos MOTs, porém como trabalhamos com um laser de fibra de alta potência, é necessária uma atenção dobrada e a utilização de óculos de segurança. A figura 3.11 descreve essa montagem, nela utilizamos um laser de fibra fabricado por IPG Photonics modelo YLR-40-1070 com $42 \mathrm{~W}$ de potência, comprimento de onda central de $1070 \mathrm{~nm}$ e largura de banda de $2 \mathrm{~nm}$. Nesse aparato produzimos uma armadilha com feixes cruzados que possuem uma cintura de $\mathrm{w}_{0}=57 \mu \mathrm{m}$ no foco, focalizados com uma lente de distância focal de $200 \mathrm{~mm}$. O valor da cintura foi medido utilizando o método conhecido como knifeedge method $(82,83)$, que consiste na medida da potência de um feixe interrompido por uma peça metálica afiada de alta refletividade.

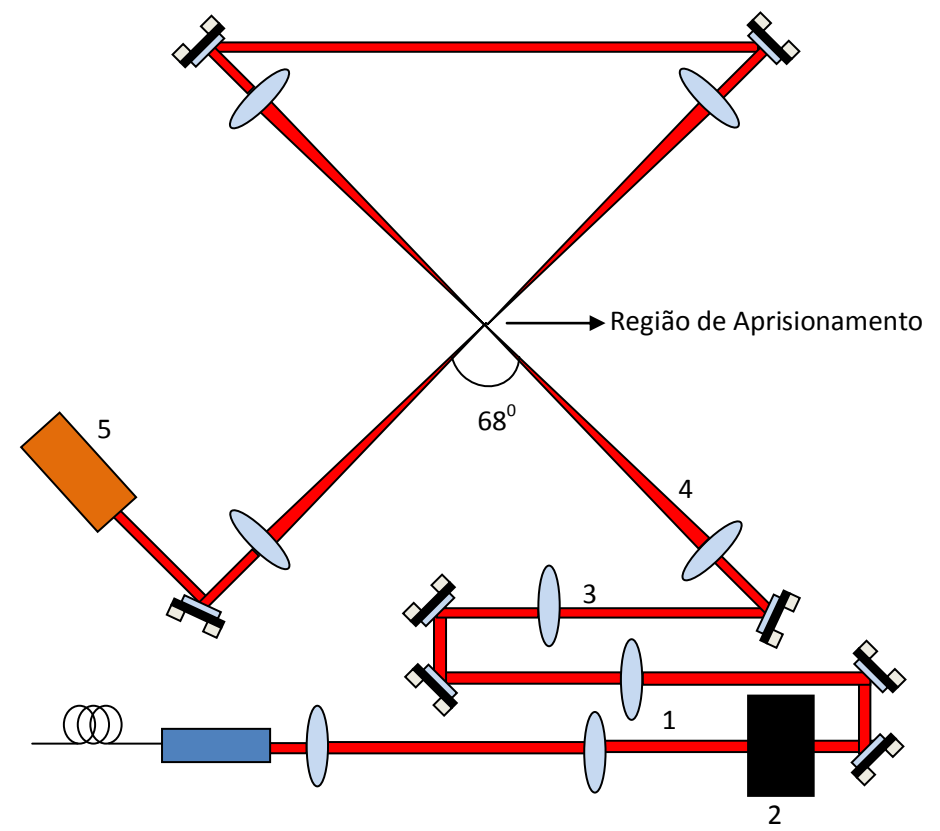

Figura 3.11 - Montagem experimental para armadilha de dipolo óptica com feixes cruzados. 1) Cintura do feixe reduzida por um fator de 2 para obtermos melhor eficiência no modulador acusto-óptico. 2) Modulador acusto-óptico para controle e estabilidade de potência do feixe da armadilha. 3) Feixe reduzido por um fator de 2/3. 4) Feixe para armadilha de dipolo focalizado com uma lente de $200 \mathrm{~mm}$ para produzir uma cintura de $w=57 \mu m$ no foco. Devido à geometria de nossa câmara, os feixes da armadilha cruzam em um ângulo de $68^{\circ}$. 5) Bloqueador arrefecido com água. 
Considerando alguns valores de cintura do feixe, a potência de operação do laser de $25 \mathrm{~W}$ e as polarizabilidades ( $\alpha=5,3 \times 10^{-39} \mathrm{C} \cdot \mathrm{m}^{2} / \mathrm{V}$ para o $\mathrm{Rb}$ e $4,8 \times 10^{-39} \mathrm{C} \cdot \mathrm{m}^{2} / \mathrm{V}$ para o K), calculamos as profundidades da armadilha para um feixe simples para o $\mathrm{Rb}$ e K (tabela 3.1) através da equação 3.9. Para um feixe cruzado podemos multiplicar por 2 os valores da tabela 3.1, devido ao princípio da superposição dos campos.

Tabela 3.1 - Valores da profundidade do potencial de aprisionamento de um feixe simples focalizado calculados para $R b$ e K normalizados pelo fator de Boltzmann $K_{B}$. Para uma armadilha com feixes cruzados devemos multiplicar os valores das profundidades por um fator de 2 . A potência considerada nos cálculos foi $25 \mathrm{~W}$.

\begin{tabular}{ccc}
\hline \hline $\mathbf{W}_{\mathbf{0}}(\mu \mathrm{m})$ & $\mathbf{R b}\left(\mathrm{U}_{0} / \mathrm{K}_{\mathrm{B}}\right)$ & $\mathrm{K}\left(\mathrm{U}_{0} / \mathrm{K}_{\mathrm{B}}\right)$ \\
\hline \hline 100 & $343 \mu \mathrm{K}$ & $225 \mu \mathrm{K}$ \\
70 & $508 \mu \mathrm{K}$ & $460 \mu \mathrm{K}$ \\
57 & $766 \mu \mathrm{K}$ & $694 \mu \mathrm{K}$ \\
30 & $2,77 \mathrm{mK}$ & $2,5 \mathrm{mK}$ \\
\hline
\end{tabular}

Assim para um feixe cruzado com $w_{0}=57 \mu m$ obtemos uma profundidade de 1,53 mK para o Rb e 1,38 mK para o K. Estes valores são consideráveis, pois os átomos serão transferidos do MOT onde teremos uma amostra de $\mathrm{Rb}$ a uma temperatura de aproximadamente $200 \mu \mathrm{K}$ e K a uma temperatura de $1 \mathrm{mK}$. As freqüências de oscilação da armadilha também foram calculadas para as duas espécies, aqui consideramos os mesmo valores de cintura $\left(w_{0}=57 \mu m\right)$ e potência do laser $(25 \mathrm{~W})$, na tabela 3.2 temos esses valores. O valor da oscilação radial $\left(\omega_{\mathrm{r}}\right)$ foi calculado considerando um feixe cruzado, para o valor da oscilação axial $\left(\omega_{z}\right)$ consideramos apenas um feixe simples. 
Tabela 3.2 - Valores das freqüências de oscilação calculados para $w_{0}=57 \mu m$ e potência $25 \mathrm{~W}$. $\omega_{\mathrm{r}}$ foi calculado considerando um feixe cruzado, $\omega_{z}$ foi calculado para um feixe simples.

\begin{tabular}{cccc}
\hline & ${ }^{85} \mathbf{R b}(\mathbf{H z})$ & ${ }^{87} \mathbf{R b}(\mathbf{H z})$ & ${ }^{39} \mathbf{K}(\mathbf{H z})$ \\
\hline \hline$\omega_{\mathrm{r}}$ & 2156,98 & 2132,04 & 3024,25 \\
$\omega_{\mathrm{z}}$ & 6,42 & 6,34 & 9,02 \\
\hline
\end{tabular}

Inicialmente planejamos utilizar um modulador acusto-óptico para controle e estabilização da potência do laser. Contudo devido ao mal funcionamento deste modulador, isso não foi implementado e acabamos controlando a potência do laser pela sua caixa de controle via sinal TTL. 


\subsection{Sistemas de Controle do Experimento}

Nesta sessão descrevemos programas que foram utilizados para o controle dos lasers do experimento bem como o procedimento de carregamento da armadilha de dipolo.

\subsubsection{Sistema de lock digital}

O aprisionamento de uma amostra mista é algo que depende da estabilidade de vários equipamentos, por isso é muito importante que os três lasers de diodo fiquem travados por longos períodos de tempo. Para o travamento das freqüências dos lasers de diodo, apresentados nas seções anteriores, utilizamos três sistemas de lock digitais da Toptica conhecidos tecnicamente como módulos Digilock 110. Esse três módulos podem ser controlados simultaneamente por seu software utilizando apenas um computador conectado via entrada USB.

Para gerar o sinal de referência, enviado ao digilock para o travamento dos lasers, utilizamos a técnica de absorção saturada por polarização (84) ( montagem 1 da figura 3.7). Esta técnica consiste em aplicar um feixe de bombeamento em uma célula de referência com uma polarização circular $\sigma^{+}$e um feixe de prova contrapropagante a este feixe com polarização $\sigma^{-}$. Com esta técnica é possível gerar um espectro dispersivo e travar o laser em uma determinada freqüência. A figura 3.12 mostra a interface de controle desse sistema e um espectro de absorção saturada por polarização do ${ }^{39} \mathrm{~K}$. Operamos o sistema no modo lock side, o qual trava o laser em uma rampa dispersiva, mas pode-se operá-lo no modo de lock via técnica lock-in (84), o qual gera seu próprio sinal dispersivo através de um sistema de modulação e demodulação de sinal. 
a)

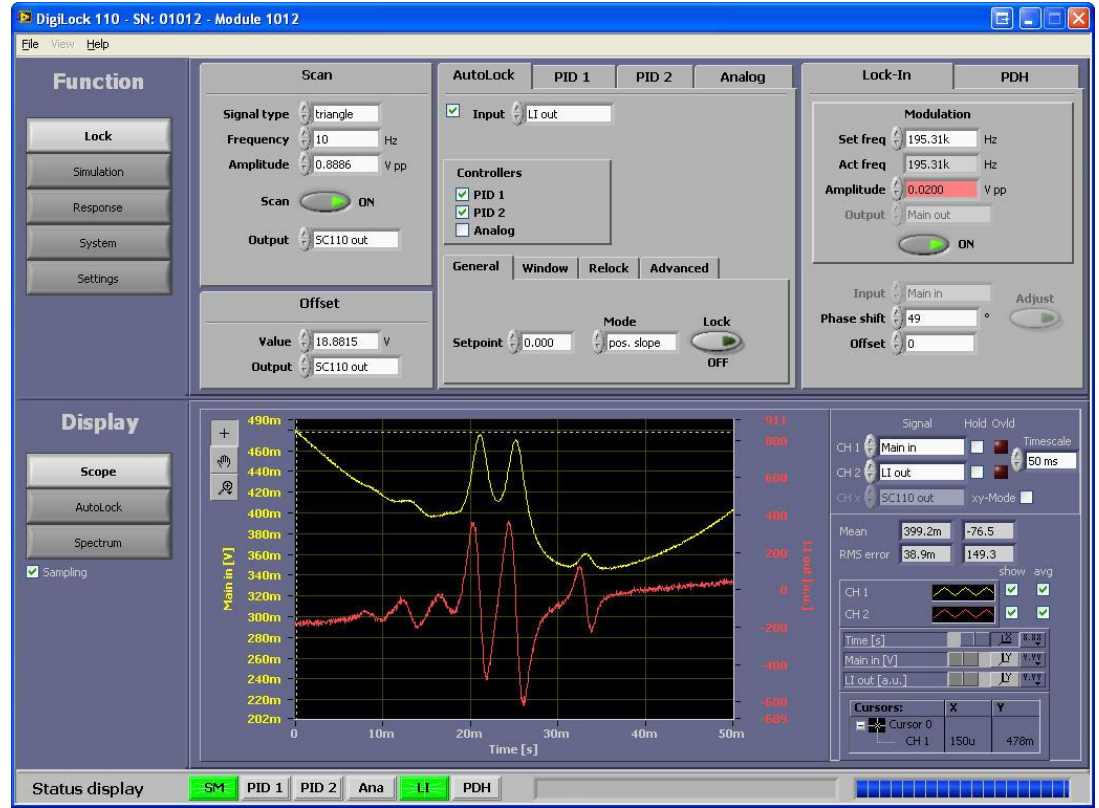

b)

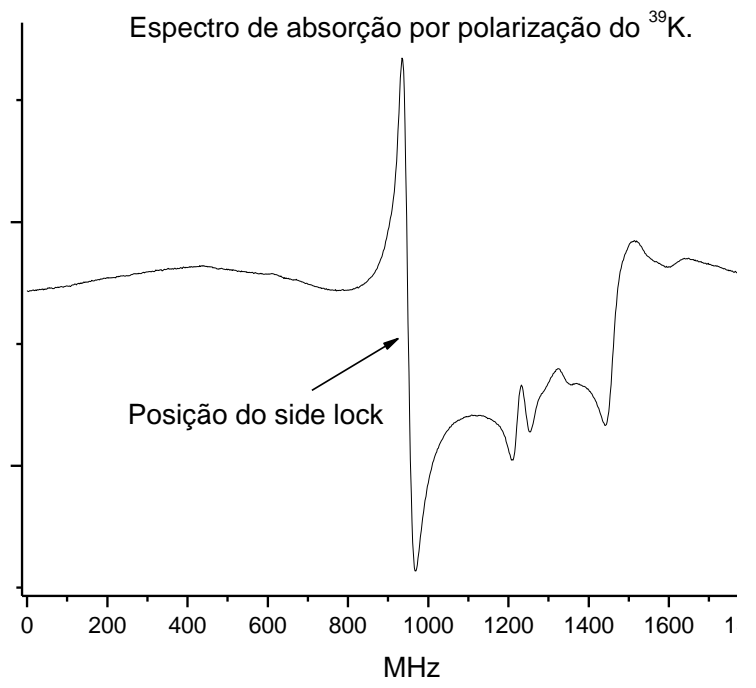

Figura 3.12 - a) Interface do controle dos módulos digilock 110 da Toptica. Nele temos um espectro de absorção saturada do ${ }^{85} \mathrm{Rb}$ (amarelo) e sua dispersão gerada pela técnica lock-in (vermelho). b) Espectro do ${ }^{39} \mathrm{~K}$ feito através de absorção saturada por polarização, neste modelo de espectroscopia o sinal gerado transformas os picos das transições curvas dispersivas que podem ser diretamente travados pela opção de lock-side. A seta indicando a posição do side lock representa a transição $4 S_{1 / 2}(F=2)$ para o estado $4 P_{3 / 2}$ do ${ }^{39} \mathrm{~K}$, as estruturas hiperfinas $F^{\prime}=0$ a 3 do estado excitado são muito próximas em freqüência e não podem ser resolvidas. 


\subsubsection{Software para controle do experimento}

Os experimentos são controlados através de duas placas sincronizadas: placa modelo PCI 6229, com oito canais analógicos e PCI 6221, com oito canais digitais e dois analógicos, ambas fabricadas pela National Instruments, e um software que desenvolvemos em LabView, figura 3.13. Neste software os canais analógicos e digitais ficam a nossa total disposição podendo ser operados com precisão de $100 \mu$ s.

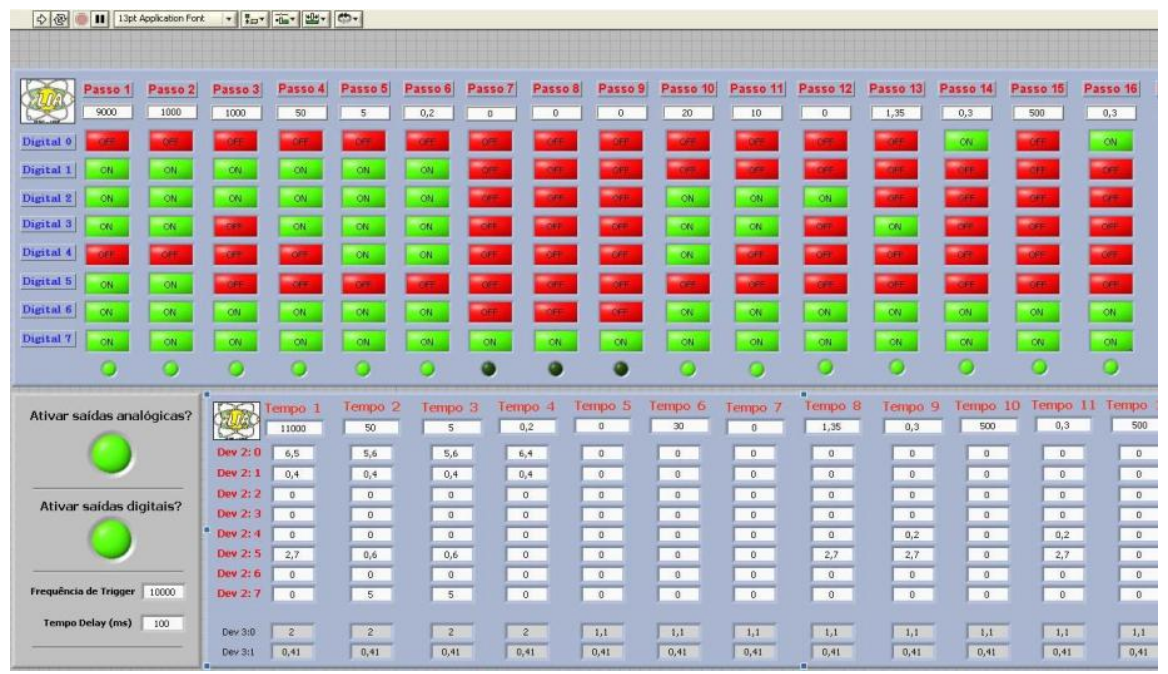

Figura 3.13 - Interface para controle do experimento.

Os principais controles do experimento são: controles de potência e freqüência dos lasers, controlados através dos drivers de radio freqüência fabricados pela empresas Intraaction e Isomet; controles para bloqueadores mecânico de feixe (shutters); controladores de corrente para desligamento de bobinas; controladores de câmeras de aquisição de imagens; sistema de segurança para lasers escravo ${ }^{*}$, sinais TTLs para ligamento e desligamento do laser de fibra e o laser pulsado.

\footnotetext{
* Na montagem experimental dos MOTs (figuras 3.7 e 3.8), notamos que os lasers escravos recebem feixes que variam sua potência conforme a potência do modulador do feixe da armadilha é alterada. Quando a potência deste modulador vai à zero, este feixe se torna muito intenso, assim o programa gera uma função acoplando os moduladores mantendo o feixe sempre em um mesmo nível de potência seguro ( $8 \mathrm{~mW}$ ).
} 


\subsection{Carregamento da armadilha de dipolo}

Uma boa referência para o carregamento de uma armadilha de dipolo pode ser encontrada em (85). A seqüência para carregar átomos de ${ }^{87} \mathrm{Rb}$ ou ${ }^{85} \mathrm{Rb}$ na armadilha de dipolo (figura 3.14) do MOT pode ser descrita pelas seguintes etapas:

1) Iniciamos o processo aprisionando $10^{8}$ átomos a uma densidade de $2 \times 10^{10} \mathrm{~cm}^{-3}$ na armadilha magneto-óptica durante $8 \mathrm{~s}$. Para $0{ }^{85} \mathrm{Rb}$, o laser de aprisionamento foi ajustado para o vermelho da transição atômica $5 \mathrm{~S}_{1 / 2}(\mathrm{~F}=3) \rightarrow 5 \mathrm{P}_{3 / 2}\left(\mathrm{~F}^{\prime}=4\right)$ e o laser de rebombeio foi ajustado para a transição atômica $5 S_{1 / 2}(F=2) \rightarrow 5 P_{3 / 2}\left(F^{\prime}=3\right)$. No caso do ${ }^{87} \mathrm{Rb}$, o laser de aprisionamento foi ajustado para o vermelho da transição atômica $5 \mathrm{~S}_{1 / 2}(\mathrm{~F}=2) \rightarrow 5 \mathrm{P}_{3 / 2}\left(\mathrm{~F}^{\prime}=3\right)$ e o laser de rebombeio foi ajustado para a transição atômica $5 \mathrm{~S}_{1 / 2}(\mathrm{~F}=1) \rightarrow 5 \mathrm{P}_{3 / 2}\left(\mathrm{~F}^{\prime}=2\right)$. Independentemente do isótopo aprisionado, a intensidade do laser de aprisionamento foi de $\mathrm{I}_{\mathrm{T}}=8 \mathrm{~mW} / \mathrm{cm}^{2}$ por feixe e sua dessintonia para o vermelho foi de $\Delta_{\mathrm{T}}=-3,4 \Gamma$, em que $\Gamma=2 \pi \times 5,9 \mathrm{MHz}$, a intensidade do rebombeio foi de $I_{R}=1,6 \mathrm{~mW} / \mathrm{cm}^{2}$ sem nenhuma dessintonia, ou seja, $\Delta_{\mathrm{R}}=0$. Nesta fase a armadilha de dipolo permanece desligada;

2) O próximo passo é a fase de carregamento da armadilha de dipolo, cuja duração era de $50 \mathrm{~ms}$. Nesta fase, o laser da armadilha de dipolo é ligado e a intensidade e freqüência do laser de aprisionamento e rebombeio são ajustadas para a condição de carregamento $\left(\mathrm{I}_{\mathrm{T}}=1,6 \mathrm{~mW} / \mathrm{cm}^{2}, \Delta_{\mathrm{T}} \sim-6 \Gamma, \mathrm{I}_{\mathrm{R}}=60 \mu \mathrm{W} / \mathrm{cm}^{2}\right.$ e $\left.\Delta_{\mathrm{R}}=0\right)$. Isto permitianos resfriar e aprisionar átomos na armadilha de dipolo.

3) $\mathrm{Na}$ seqüência os lasers do MOT e o campo magnético são desligados. E os átomos/moléculas ficam aprisionados por um determinado intervalo.

4) O último estágio é a detecção dos átomos que é feito com pulsos de laser ressonante obtendo-se imagens de fluorescência ou absorção, entraremos em mais detalhes na seção de imagens.

Para $0{ }^{39} \mathrm{~K}$ o procedimento (figura 3.15) é ligeiramente diferente do carregamento $\mathrm{Rb}$ : 
1) O MOT é carregado por $8 \mathrm{~s}$ com as seguintes intensidades e freqüências para o laser de aprisionamento e rebombeio $1,25 \mathrm{~mW} / \mathrm{cm}^{2} \mathrm{e}-5 \Gamma$ (em que $\Gamma=2 \pi \times 6,03 \mathrm{MHz}$ ) da transição $4 S_{1 / 2}(F=2)-4 P_{3 / 2}$.

2) A seguir o laser de aprisionamento é ligado e a amostra passa por um estágio de carregamento dividido em três etapas: a primeira $(20 \mathrm{~ms})$, a intensidade de rebombeio é reduzida para $0,9 \mathrm{~mW} / \mathrm{cm}^{2}$; na segunda $(8 \mathrm{~ms})$ a intensidade do laser de aprisionamento é reduzida $0,6 \mathrm{~mW} / \mathrm{cm}^{2}$ e o rebombeio para $0,4 \mathrm{~mW} / \mathrm{cm}^{2}$; na terceira (2 ms) é gerada uma rampa de tensão que aumentam as freqüências de aprisionamento e rebombeio de $-5 \Gamma$ para $-2,5 \Gamma$, ou seja, mais próximas da transição.

3) Na seqüência os lasers do MOT e o campo magnético são desligados e os átomos são detectados na armadilha de dipolo.

Nesse processo de resfriamento e transferência é muito importante que o campo magnético na região da armadilha seja nulo, caso contrário, haverá uma força repulsiva em uma direção devido aos lasers do MOT no momento em que o campo é desligado. Para isso três pares de bobinas na configuração Helmholtz são adicionadas ao sistema. Um método prático para anular o campo magnético, é observar o comportamento dos átomos no MOT por uma câmera CCD. Quando o campo das bobinas da armadilha é desligado é possível ver a direção em que os átomos escapam, assim o campo pode ser balanceado ajustando as correntes e o alinhamento da armadilha.

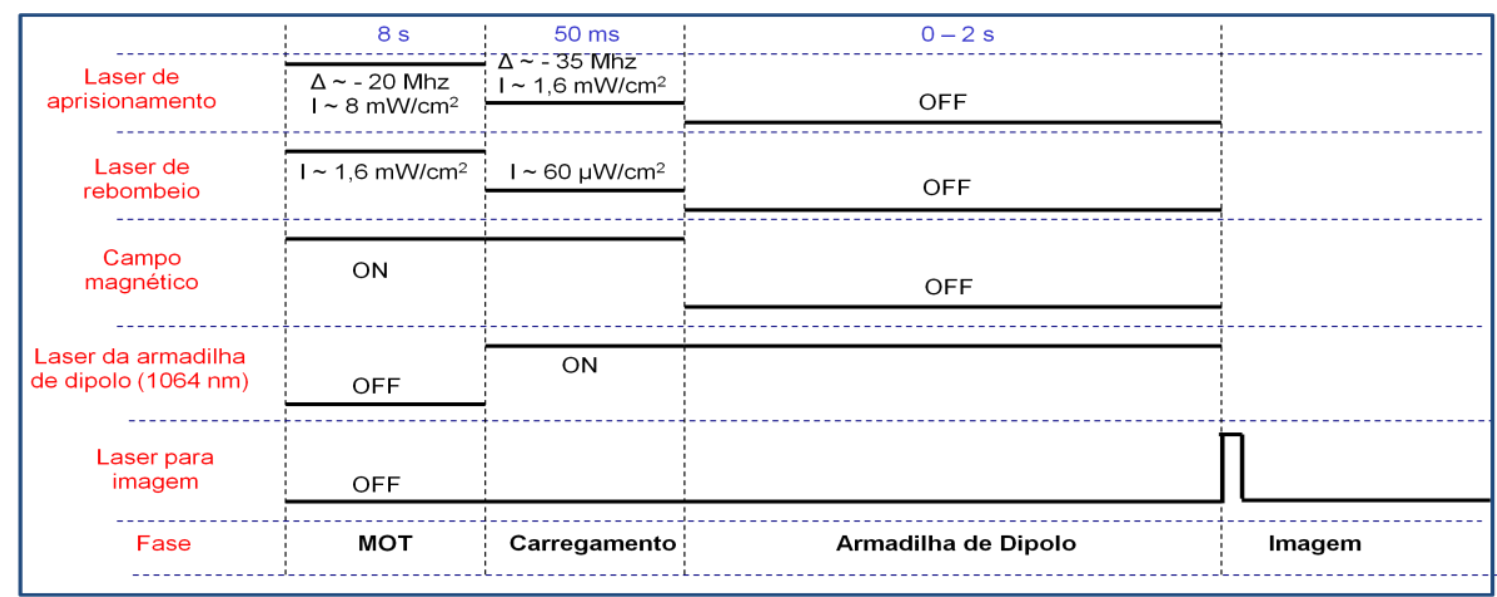

Figura 3.14 - Seqüência temporal para carregamento da armadilha de dipolo para $O^{85} R b e^{87} R b . O$ MOT é carregado por $8 \mathrm{~s}$ e passa por um estagio de resfriamento e carregamento por $50 \mathrm{~ms}$, na seqüencia todos os campos e lasers não desligados ficando apenas o laser da armadilha em $1064 \mathrm{~nm}$. 


\begin{tabular}{|c|c|c|c|c|c|c|}
\hline & $8 \mathrm{~s}$ & $20 \mathrm{~ms}$ & $8 \mathrm{~ms}$ & $2 \mathrm{~ms}$ & $0-2 s$ & \\
\hline $\begin{array}{l}\text { Laser de } \\
\text { aprisionamento }\end{array}$ & $\begin{array}{l}\Delta \sim-30 \mathrm{MHz} \\
\mathrm{I} \sim 1,25 \mathrm{~mW} / \mathrm{cm}^{2}\end{array}$ & $\begin{array}{l}\Delta \sim-30 \mathrm{MHz} \\
1 \sim 1,25 \mathrm{~mW} / \mathrm{cm}^{2}\end{array}$ & $\begin{array}{l}1 \sim 0,6 \\
\mathrm{~mW} / \mathrm{cm}^{2}\end{array}$ & $\Delta \sim-15 \mathrm{MHz}$ & OFF & \\
\hline $\begin{array}{l}\text { Laser de } \\
\text { rebombeio }\end{array}$ & $\mathrm{I} \sim 1,25 \mathrm{~mW} / \mathrm{cm}^{2}$ & $1 \sim 0,9 \mathrm{~mW} / \mathrm{cm}^{2}$ & $\begin{array}{l}\mathrm{I} \sim 0,4 \\
\mathrm{~mW} / \mathrm{cm}^{2}\end{array}$ & & OFF & \\
\hline $\begin{array}{l}\text { Campo } \\
\text { magnético }\end{array}$ & ON & & & & OFF & \\
\hline $\begin{array}{l}\text { Laser da armadilha } \\
\text { de dipolo (1064 nm) }\end{array}$ & OFF & ON & & & & \\
\hline $\begin{array}{l}\text { Laser para } \\
\text { imagem }\end{array}$ & OFF & & & & & \\
\hline Fase & MOT & & Sarregame & & Armadilha de & Imagem \\
\hline
\end{tabular}

Figura 3.15 - Seqüencia temporal para carregamento da armadilha de dipolo para ${ }^{39} \mathrm{~K}$. O MOT é carregado por $8 \mathrm{~s}$ e passa por um estágio de resfriamento e carregamento por $30 \mathrm{~ms}$, na seqüência todos os campos e lasers são desligados ficando apenas o laser da armadilha em $1064 \mathrm{~nm}$.

\subsection{Métodos de detecção}

As técnicas de detecção de átomos e moléculas são fundamentais para a caracterização das amostras, bem como para os experimentos propriamente ditos. Assim nesta seção descreveremos as técnicas utilizadas neste trabalho.

\subsubsection{Imagens de fluorescência}

A técnica de fluorescência não é a mais apropriada quando precisamos de valores quantitativos para amostras atômicas. Contudo, ela pode ser bem conveniente para alinhamentos preliminares. Assim optamos por usá-la no alinhamento preliminar da 
armadilha de dipolo. O procedimento consiste em iluminar a amostra com feixes ressonantes (feixe de aprisionamento e rebombeio do MOT) com um tempo de exposição de 1 ms e observar a luz espalhada da amostra com uma câmera CCD sincronizada com experimento. A seqüência para esta medida pode ser observada na fase de imagem da figura 3.14, em que um pulso ilumina a amostra depois de certo tempo aprisionada. As figuras 3.16a e b mostram imagens de fluorescência da armadilha de dipolo de ${ }^{85} \mathrm{Rb}$. Na figura $3.16 \mathrm{a}$ podemos ver uma armadilha carregada com um único feixe em uma visão lateral, nela uma fração dos átomos do MOT é aprisionada e outra parte é perdida caindo pela ação da gravidade. Este tipo de imagem é muito importante para as primeiras otimizações de alinhamento da armadilha e ajuste dos parâmetros de carregamento. Geralmente observamos a imagem em 30 ms, tempo em que a nuvem do MOT já se dissipou e ajustamos os parâmetros para obter o máximo sinal de fluorescência medido pela câmera. O próximo passo é fazer o alinhamento da armadilha cruzada utilizando o mesmo feixe que faz o primeiro aprisionamento. Este feixe é colimado e focalizado novamente na amostra (figura 3.11). Isso é feito observando a amostra em um tempo de $30 \mathrm{~ms}$ de aprisionamento. Com a figura 3.16b fica claro quando atingimos a melhor sobreposição entre os feixes (vista por cima).

Na figura 3.17a temos o aprisionamento de ${ }^{39} \mathrm{~K}$ na armadilha de dipolo. Podemos perceber que o carregamento fica bem a desejar comparando com o $\mathrm{Rb}$, chegando ao limite do contraste da câmera. A figura 3.17b serve apenas para notarmos a diferença quando rodamos seqüência de carregamento com e sem o laser de aprisionamento. A dificuldade em se carregar um dipolo de $\mathrm{K}$ é devido à temperatura inicial do MOT ( $1 \mathrm{mK}$ ). Como as freqüências de rebombeio e aprisionamento não são independentes como no caso do $\mathrm{Rb}$, o processo de resfriamento fica limitado. Fomos capazes de atingir uma temperatura de 250 $\mu \mathrm{K}$ para o carregamento da armadilha. Com o MOT de Rb somos capazes de resfriar o MOT ( $200 \mu \mathrm{K}$ ) para temperaturas abaixo de $40 \mu \mathrm{K}$. Estas temperaturas foram obtidas por imagens de absorção, descreveremos os detalhes da medida de temperatura nas próximas seções.

Esta técnica é um passo inicial no aprendizado do carregamento de armadilhas de dipolo. É um método simples que não depende de um feixe extra, alinhamento e ajuste de 
freqüência, porém não podemos obter as características como número átomos, densidade e tamanho da armadilha com precisão.

a)

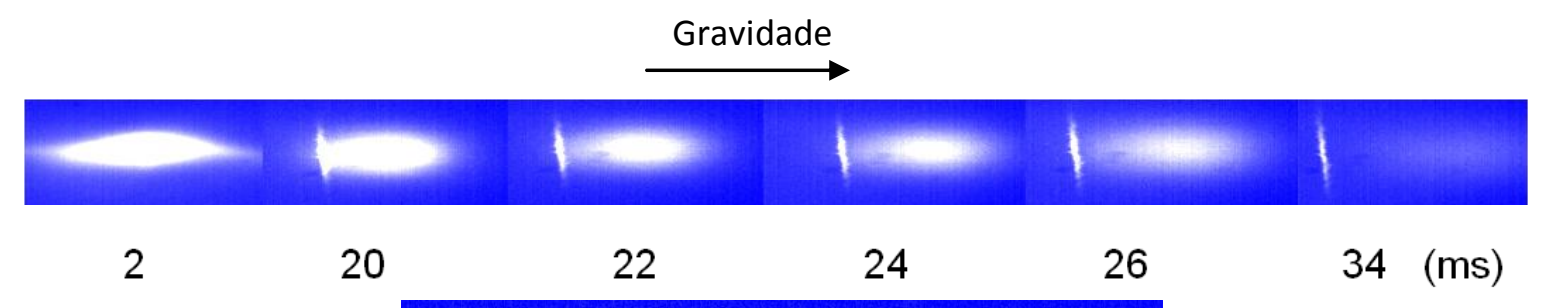

b)

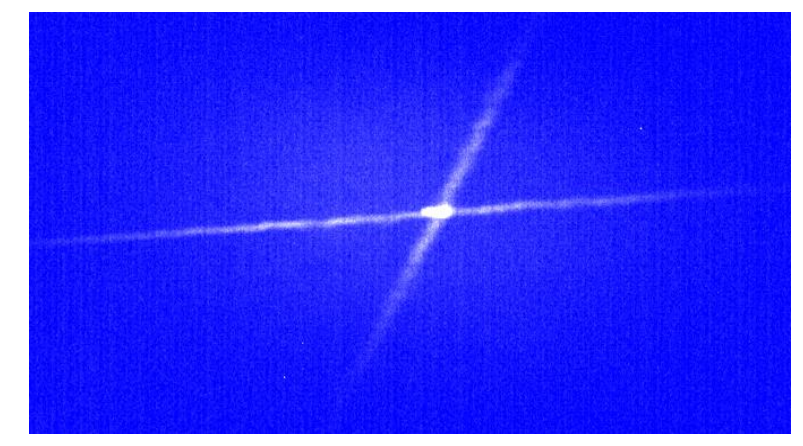

Figura 3.16 - Imagens de fluorescência. a) Carregamento da armadilha utilizando apenas um feixe. Nela observamos a nuvem de átomos do MOT caindo pela ação da gravidade (esquerda para direita) enquanto uma fração de átomos é aprisionada. b) Carregamento da armadilha com um feixe cruzado.
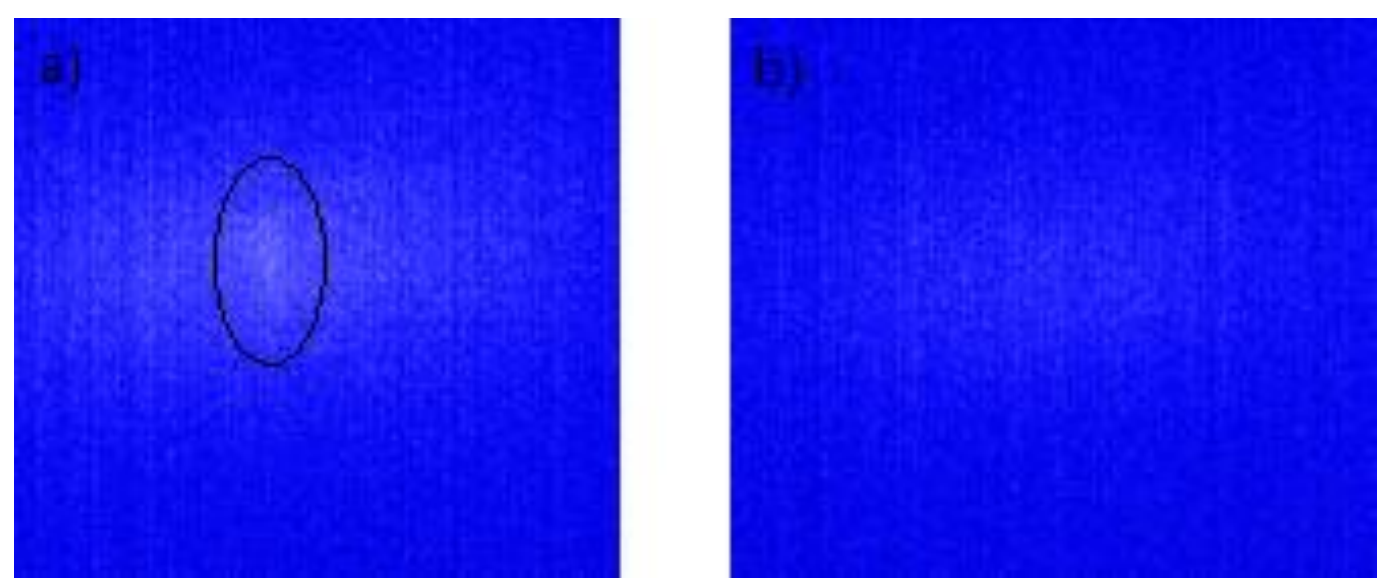

Figura 3.17 a) Imagem de fluorescência de uma armadilha óptica de ${ }^{39} \mathrm{~K}$. b) Imagem sem o laser de aprisionamento. 


\subsubsection{Imagens de Absorção}

O principio básico da técnica de imagem por absorção consiste em iluminar a amostra com um feixe de prova colimado e ressonante e observar a sombra no feixe causada pelos átomos. Assim que o feixe de prova passa pela amostra, sua intensidade diminui de acordo com a lei de Beer:

$$
\frac{d I}{d z}=-\sigma_{0} \operatorname{In}(x, y, z)
$$

em que $n(x, y z)$ é o perfil da densidade da amostra, $\sigma_{0}$ é a seção de choque de espalhamento. Neste caso, vamos assumir que a intensidade é menor que a intensidade de saturação dos átomos de modo a desprezar efeitos de saturação. Assim o perfil de intensidade do feixe de prova, depois da propagação pela amostra, é dado por:

$$
I(x, y)=I_{0}(x, y) \exp \left(-\bar{n}(x, y) \sigma_{0}\right)
$$

em que $\bar{n}(x, y)$ é a integral da densidade ao longo da direção z. Este perfil nos gera uma imagem com um perfil dado por:

$$
S(x, y)=S_{0}(x, y) \exp \left(-\bar{n}(x, y) \sigma_{0}\right)+S_{b}(x, y)
$$

em que $S_{b}(x, y)$ é a contribuição a luz de fundo (background do sistema. Devido à propagação do feixe pelos elementos ópticos, criando múltiplas reflexões, as imagens sofrem algumas distorções. Por isso, duas imagens extras são adicionadas no processo: uma 
imagem sem a presença dos átomos $S_{0}(x, y)$ e uma imagem apenas da luz de fundo $S_{b}(x, y)$, ou seja, sem átomos e sem o feixe de prova. Essas três imagens são combinadas gerando a transmissão:

$$
T(x, y)=\frac{s(x, y)-S_{b}(x, y)}{S_{0}(x, y)-S_{b}(x, y)}
$$

Assim a densidade de um dado pixel, localizado no ponto $(x, y)$ de uma imagem, é obtido por:

$$
\bar{n}(x, y)=-\frac{\ln (T(x, y))}{\sigma_{0}}
$$

Para obtermos o número de átomos, devemos integrar $\bar{n}(x, y)$ em $x$ e $y$. Assim:

$$
\begin{gathered}
N=\iint \bar{n}(x, y) d x d y=-\frac{1}{\sigma_{0}} \iint \ln (T(x, y)) d x d y \\
N=-\frac{A}{\sigma_{0}} \Sigma_{\text {pixels }} \ln (T)
\end{gathered}
$$

em que $A$ é a área da região de interesse ("ROI") selecionada na interface do programa.

A figura 3.18 mostra o aparato experimental para utilização desta técnica. Nela o feixe é levado por uma fibra óptica, é expandido em torno de $25 \mathrm{~mm}$ de diâmetro, atinge a amostra aprisionada, é expandido novamente por um fator de 2 e observado por uma câmera CCD. Em nosso sistema de detecção, a amostra é iluminada com três pulsos de 300 $\mu$ s e $200 \mu \mathrm{W}$ de potência separados por 500 ms, este feixe é sintonizado com relação as seguintes transições atômicas dependendo da espécie: para $0{ }^{87} \mathrm{Rb}$ utilizamos a transição $5 S_{1 / 2}(F=2)$ para $5 P_{3 / 2}\left(F^{\prime}=3\right)$, para o ${ }^{85} R b$ utilizamos a transição $5 S_{1 / 2}(F=3)$ para $5 P_{3 / 2}\left(F^{\prime}=\right.$ 4). Durante a exposição dos átomos ao feixe de imagem também iluminamo-los com o feixe de rebombeio, para que fiquem sempre em ressonância com o mesmo. Devemos ressaltar que o feixe de rebombeio não é paralelo ao feixe de prova e os átomos, depois de carregados na armadilha, estão no estado $\mathrm{F}$ de mais baixa energia do estado fundamental. 


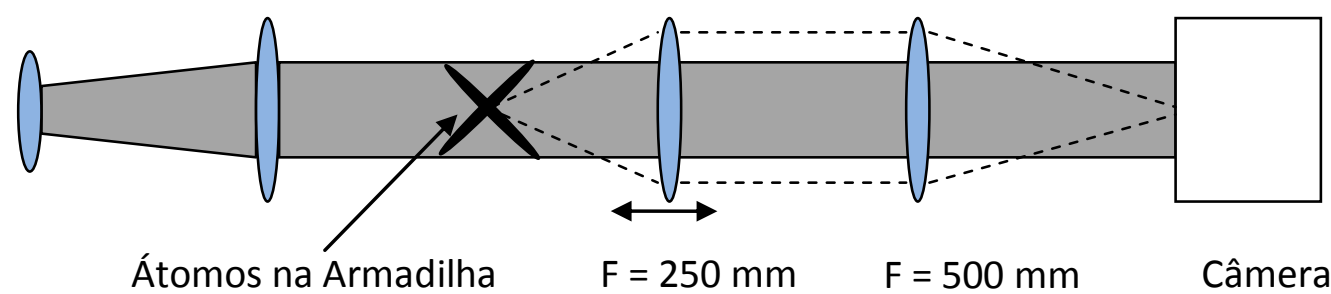

Figura 3.18 - Montagem óptica para imagens de absorção.

A figura 3.19 mostra as três imagens obtidas de uma armadilha de dipolo de ${ }^{85} \mathrm{Rb}$. As quatro imagens: a), b), c) representam as variáveis $S(x, y), S_{0}(x, y)$ e $S_{b}(x, y)$ e a imagem d) é o resultado do processamento através da equação 3.17. Com o software desenvolvido em LabView fazemos a análise da imagem final (d) obtendo o número de átomos, o tamanho e a densidade da armadilha simultaneamente. O tamanho da armadilha é calculado considerando o seguinte perfil de densidade da amostra:

$$
n(r, \theta, \phi)=n_{0} e^{\frac{-r^{2}}{2 w^{2}}}
$$

O ajuste da fatia central da imagem com essa função pode nos dar o valor de $\mathbf{w}$, como mostrado na interface do programa de processamento das imagens (figura 3.20). Esta medida também é importante para a medida da temperatura da amostra. Como mostrado em (86), a expansão balística de uma nuvem térmica, com um perfil gaussiano de densidade, resulta em uma distribuição gaussiana com uma velocidade dada por:

$$
w^{2}(t)=w_{0}^{2}+\frac{k T}{m} t^{2}
$$

em que t é o tempo de expansão. Na figura 3.21 temos um exemplo de como essa medida é feita. Neste caso a amostra foi aprisionada por $50 \mathrm{~ms}$ e expandida livremente, podemos obter imagens até o instante de 8,35 ms de expansão, a partir desse ponto a densidade da amostra se torna muito baixa chegando ao limite de resolução de nossos equipamentos. 

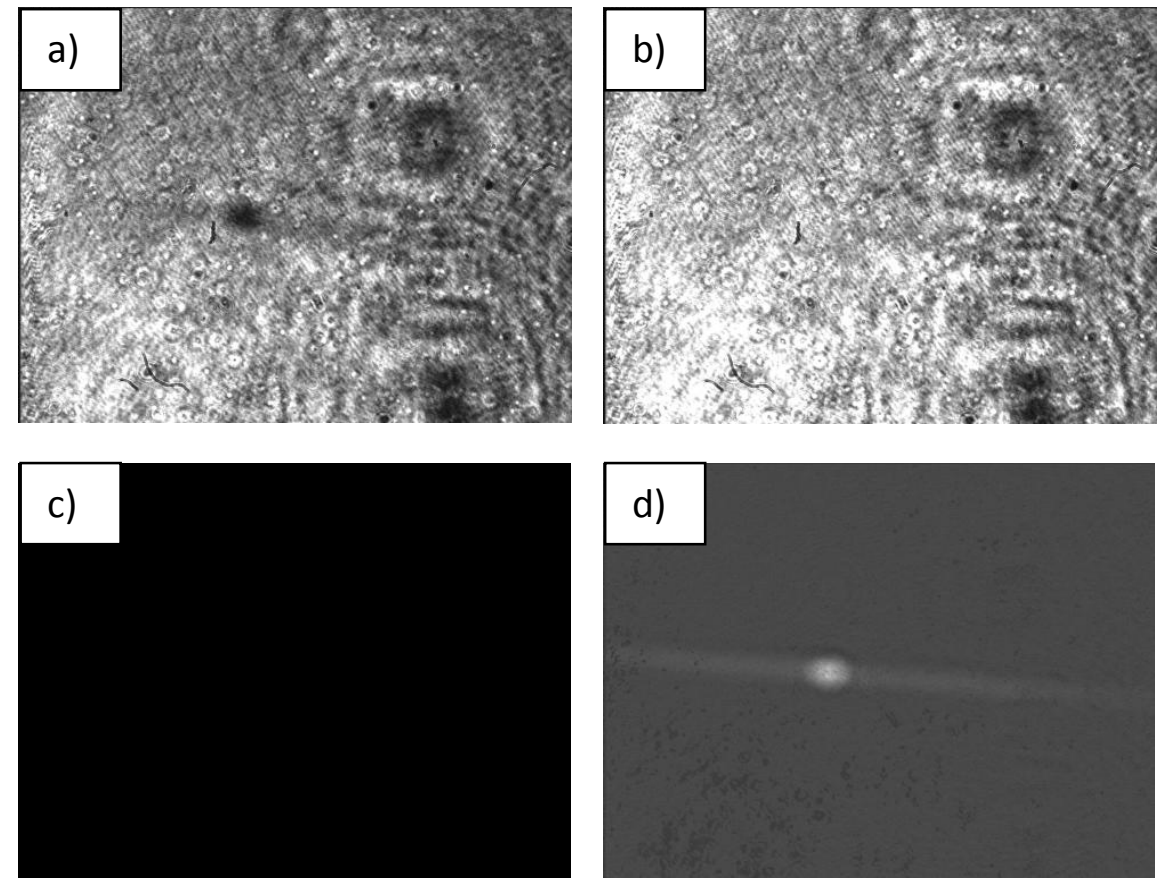

Figura 3.19 - Imagem de absorção de átomos de ${ }^{85} \mathrm{Rb}$ na armadilha de dipolo cruzada. a) imagem dos átomos, b) imagens sem átomos, c) imagem de fundo na ausência de átomos e do feixe de absorção. d) Imagem final processada. A freqüência utilizada foi a transição $5 S_{1 / 2}(F=3)-$ $5 P_{3 / 2}\left(F^{\prime}=4\right)$.

Com essas análises montamos a tabela 3.3 com os números típicos para a armadilha de dipolo para ${ }^{85} \mathrm{Rb}$ e ${ }^{87} \mathrm{Rb}$ :

Tabela 3.3 - Valores típicos obtidos nas armadilhas de dipolo para $o^{85} R b e^{87} R b$.

\begin{tabular}{cc}
\hline \hline & Armadilha de Dipolo ${ }^{85} \mathrm{Rb} /{ }^{87} \mathrm{Rb}$ \\
\hline \hline $\mathrm{N}$ de átomos & $3,2 / 2 \times 10^{6}$ \\
Densidade & $8 / 6 \times 10^{11} \mathrm{~cm}^{-3}$ \\
Tamanho & $62 / 52 \mu \mathrm{m}$ \\
Temperatura & $36 / 21 \mu \mathrm{K}$ \\
\hline
\end{tabular}

Nas medidas de imagens de absorção e fluorescência foram usadas duas câmeras CCDs, modelo $\mathrm{CV}^{-} \mathrm{m}^{+} / \mathrm{M}^{+} \mathrm{CL}$, fabricadas pela empresa JAl, com 1380 (h) x 1030 (v) pixels e 
24 frames/sec no modo Full. A placa de aquisição de imagens utilizada foi a PCle 1430, fabricada pela empresa National Instruments com capacidade pra controlar 2 câmeras sincronizadas.

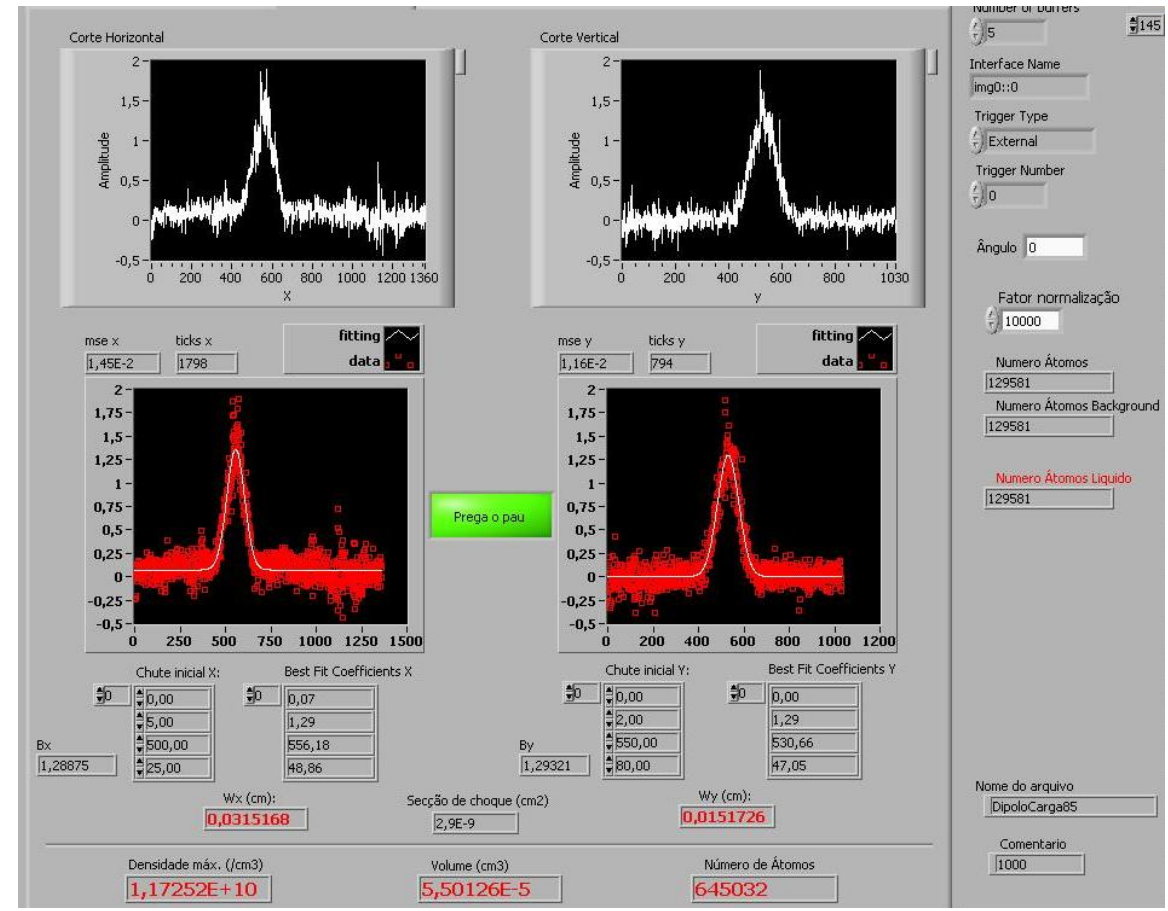

Figura 3.20 - Software para análise das imagens, nele podemos medir o número de átomos, densidade e tamanho da armadilha. 
a)

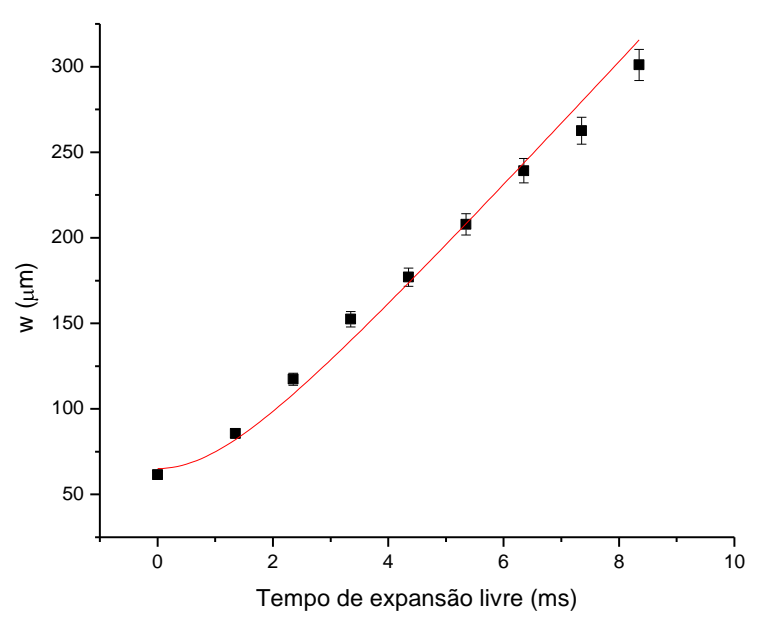

b)

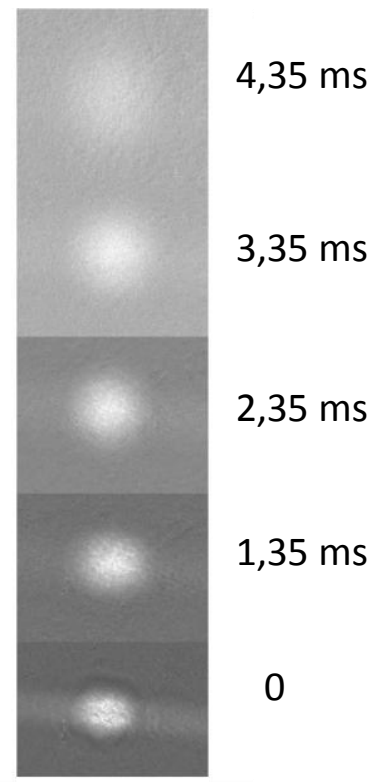

Figura 3.21 - Técnica de medida da temperatura por imagens de absorção. Neste caso particular os átomos são aprisionados por $50 \mathrm{~ms}$ e liberados, sofrendo uma expansão livre. Em a) temos o ajuste dos dados experimentais pela expressão 3.21, em b) temos as imagens propriamente ditas para alguns intervalos de expansões. Neste presente, obtivemos uma temperatura de $36 \boldsymbol{\mu} K$ para ${ }^{85} \mathrm{Rb}$.

\subsubsection{Detecção de moléculas por fotoionização}

As moléculas no estado eletrônico fundamental são difíceis de serem detectadas por absorção de luz, visto que após uma absorção elas podem decair para diversos estados vibracionais e não mais interagir com um laser de prova. A solução é fotoionizá-las e detectar o íon pela técnica de espectroscopia por tempo de vôo. Ou seja, cada pulso do laser ioniza uma fração de moléculas aprisionadas que é atraído pelo detector de íons, seu sinal é medido pelo osciloscópio gerando um espectro que chamamos de tempo de vôo (figura 3.22). Neste espectro podemos distinguir as moléculas ionizadas dos átomos, por sua massa ser 2 vezes maior elas levam um tempo de um fator $\sqrt{2}$ vezes maior que os átomos. Assim o pico moléculas é selecionado utilizando um Boxcar integrador que faz a contagem do 
número total de moléculas que chegaram num dado instante e nos devolve um valor em tensão que é medido novamente pelo osciloscópio.

A fotoionização é feita através da ionização por dois fótons. Nesse mecanismo, o primeiro fóton ( $\left.\omega_{\text {laser }}\right)$ acopla moléculas em certo estado vibracional do estado eletrônico fundamental em um estado intermediário, como exemplo da figura 3.23 temos o estado molecular $2{ }^{3} \Pi_{\mu}^{+}$. Nesse estado intermediário a molécula absorve mais um fóton e é levada ao estado da molécula ionizada $\left(\mathrm{Rb}_{2}{ }^{+}\right)$.

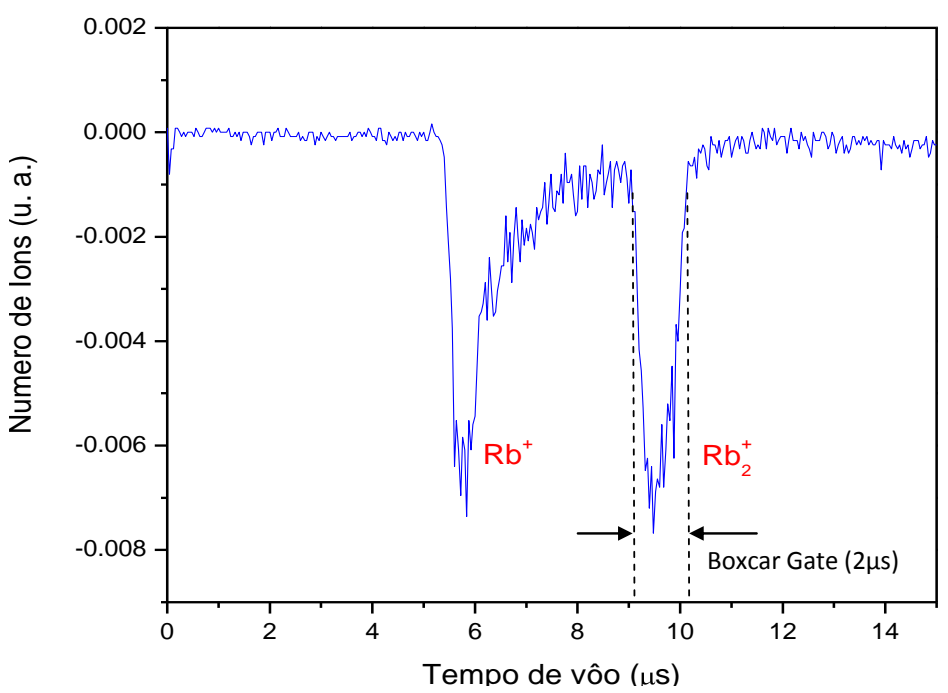

Figura 3.22 - Espectro de tempo de vôo de ${ }^{85} \mathrm{Rb}^{+} e^{85} \mathrm{Rb}_{2}{ }^{+}$fotoionizados no MOT. Nele podemos distinguir o sinal de íons atômicos e moleculares pela diferença de tempo que as partículas levam para atingirem o detector. 


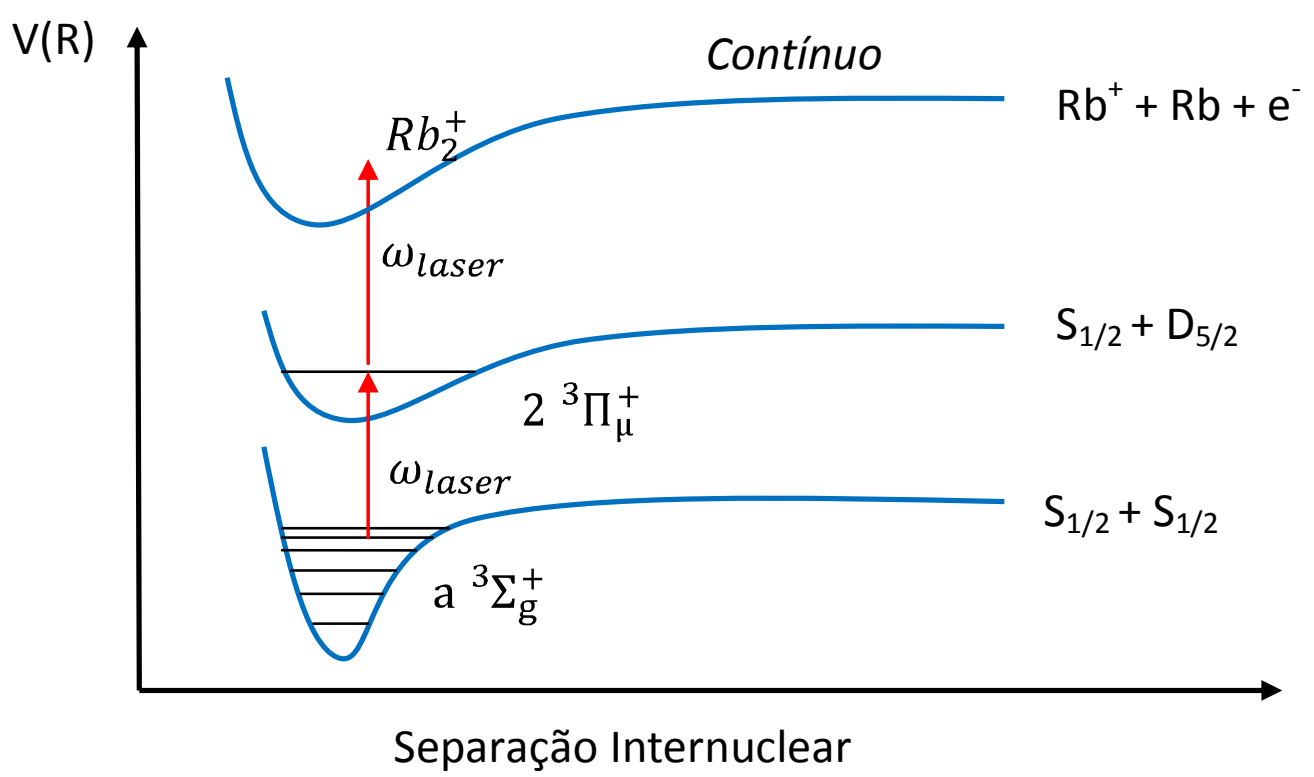

Figura 3.23 - Esquema para Fotoionização de $R b_{2}$ no estado fundamental.

Nosso sistema de detecção é constituído por um laser de corante pulsado, modelo JAGUAR (figura 3.24) que é bombeado pelo segundo harmônico de um laser Nd: YAG (532 $\mathrm{nm}$, com pulsos de $9 \mathrm{~ns}$, taxa de repetição de 10 a $20 \mathrm{~Hz}$, e energia de $25 \mathrm{~mJ} /$ pulso); um detector de íons do tipo Channeltron Electron Multiplier (fabricante BURLE TECHNOLOGIES), localizado no interior da câmera de aprisionamento; e um integrador boxcar (gate integrator and boxcar averager, modelo: SR250 - fabricante Stanford Research Systems). 


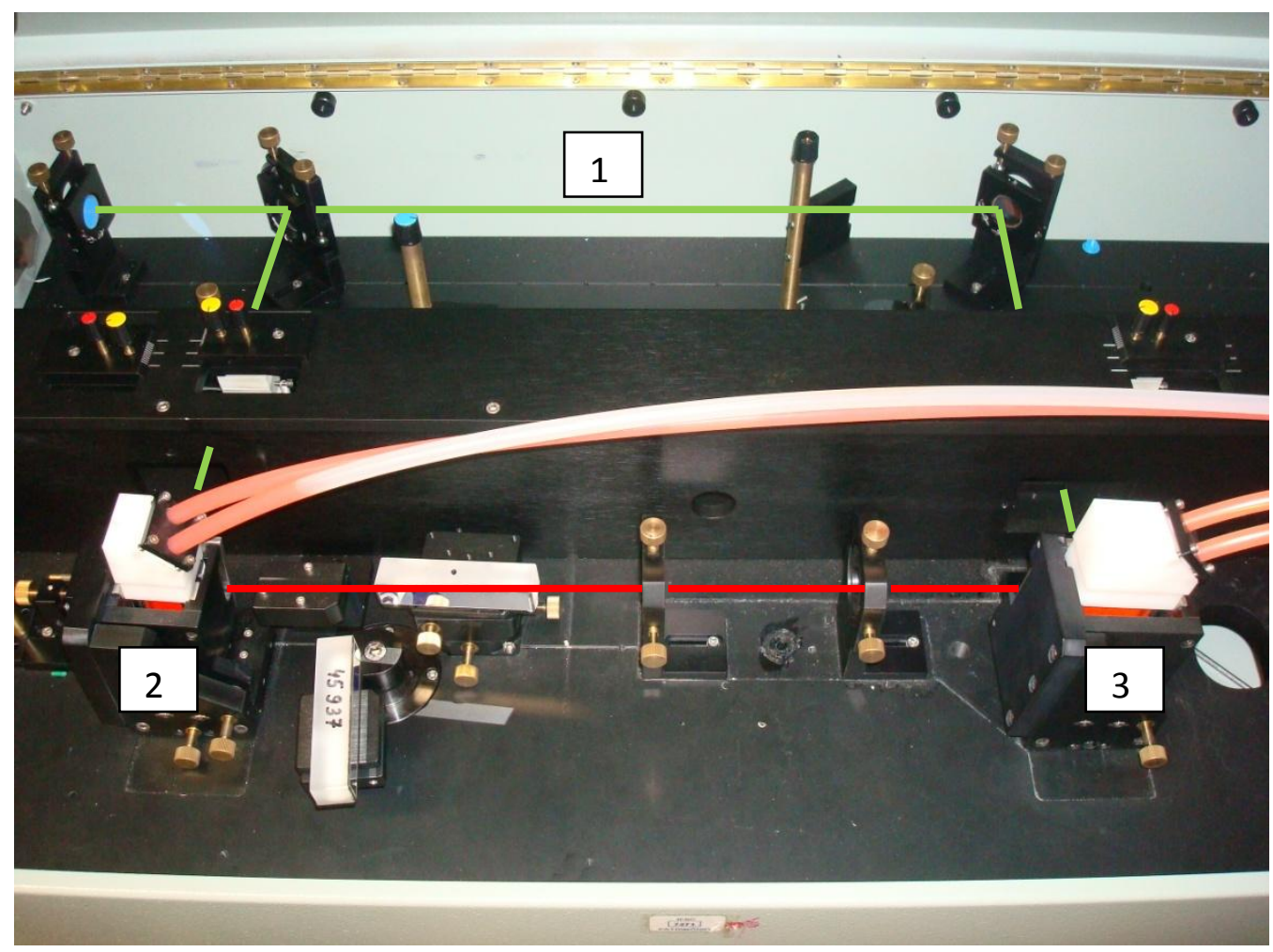

Figura 3.24 - Laser de corante (Jaguar) para fotoionização de moléculas de Rb2. 1) Laser de bombeamento Nd: Yag pulsado em $530 \mathrm{~nm}$. 2) Oscilador gerando laser com eficiência em 600 a $610 \mathrm{~nm}$. 3) Amplificador.

Para a fotoionização de moléculas de $\mathrm{Rb}_{2}$ operamos o laser de corante no intervalo de 600 a $610 \mathrm{~nm}$ utilizando uma combinação de dois corantes: Rhodamina 610 para o estágio do oscilador (concentração: $271,51 \mathrm{mg}$ para $500 \mathrm{ml}$ de solvente) e Rhodamina 640 para o estágio de amplificação (concentração: 26,95 mg para $1200 \mathrm{ml}$ de sovente). 0 solvente utilizado foi o etanol e os corantes são da marca Exciton. 



\section{4 Átomos de $\mathrm{Rb}$ aprisionados na armadilha de dipolo em $1064 \mathrm{~nm}$}

Neste capítulo, descreveremos os experimentos realizados na armadilha de dipolo em $1064 \mathrm{~nm}$. Estes experimentos consistem em medidas da evolução temporal da população de átomos de ${ }^{85} \mathrm{Rb}$ e ${ }^{87} \mathrm{Rb}$ e as medidas de variação da temperatura em função do tempo de aprisionamento da amostra.

\subsection{Evolução temporal de átomos aprisionados}

Nos experimentos, descritos a seguir, foi utilizada a seqüência experimental de aprisionamento apresentada na figura 3.14 e as medidas do número de átomos na armadilha de dipolo eram feitas através de imagens por absorção, como descrito no capítulo 3. Para cada isótopo aprisionado, um estado fundamental hiperfino era populado, para isso, assim que os átomos eram carregadas na armadilha (fase de carregamento), bombeávamolos, durante $300 \mu \mathrm{s}$, para um determinado estado hiperfino $\mathrm{F}$ do estado fundamental os quais podem ser $5 S_{1 / 2}(F=1$ ou 2$)$ para o ${ }^{87} \mathrm{Rb}$ e $5 S_{1 / 2}(F=2$ e 3$)$ para o ${ }^{85} \mathrm{Rb}$. Contudo vale lembrar que em momento algum a amostra foi polarizada em nenhum dos possíveis subestados magnéticos $\left(m_{F}\right)$. Utilizando a técnica apresentada na seção 3.6 .2 do capítulo 3 , medimos também a temperatura da amostra atômica para cada espécie, em um determinado estado fundamental hiperfino, em função do tempo de aprisionamento. 
A primeira espécie estudada foi o ${ }^{85} \mathrm{Rb}$, a qual apresentou o maior número de átomos aprisionados na armadilha ( $\mathrm{N} \sim 3,3 \times 10^{6}$ átomos). As figuras $4.1 \mathrm{a}$ e $4.1 \mathrm{~b}$ representam a evolução temporal do número de átomos aprisionados e a temperatura em função do tempo para átomos bombeados para o nível hiperfino inferior $(F=2)$. As figuras $4.2 \mathrm{a}$ e $4.2 \mathrm{~b}$ representam as mesmas medidas, porém, os átomos são bombeados para o nível hiperfino superior $(F=3)$. A segunda espécie estudada foi o ${ }^{87} \mathrm{Rb}$ que apresentou um número máximo de átomos aprisionados de aproximadamente $1,9 \times 10^{6}$. As figuras $4.3 \mathrm{a}, 4.3 \mathrm{~b}, 4.4 \mathrm{a}$ e $4.4 \mathrm{~b}$ também são medidas da evolução do número de átomos e temperatura em função do tempo, com átomos bombeados para o nível hiperfino inferior $(F=1)$ e superior $(F=2)$.

Cada ponto dos gráficos apresentados é o resultado de uma média de cinco medidas que possuem uma pequena variação de $5 \%$ de seu valor. Cada medida é feita independentemente, pois a técnica de imagem por absorção é uma técnica que destrói a amostra, assim, como cada seqüência leva em torno de 12 segundos, cada curva de decaimento leva um tempo total de 30 minutos. O mesmo ocorre para as medidas de temperatura, para cada tempo de aprisionamento são medidos dez pontos de expansão, cada medida da cintura da amostra é uma média de cinco medidas, portanto uma medida de oito temperaturas levava um tempo total de uma hora.

Para uma análise quantitativa das curvas de decaimento do número de átomos, podemos assumir a princípio a seguinte equação de taxa:

$$
\frac{d n(t)}{d t}=-\Gamma n(t)-\beta n^{2}(t)
$$

Nesta equação duas grandezas físicas são incorporadas: $\Gamma$ e $\beta$, denominadas como a taxa de perda linear e a taxa de perda por dois corpos respectivamente. A primeira trata-se da perda causada por colisões de átomos aprisionados com átomos do vapor de fundo residual, e também por instabilidades na potência do laser de aprisionamento (87), a qual pode acarretar no aquecimento na amostra. A segunda taxa está relacionada às colisões que ocorrem entre átomos aprisionados. Considerando a densidade atômica como sendo 
$n(\boldsymbol{r}, t)=n_{0} \exp \left(-r^{2} / 2 w^{2}\right)$, em que $w$ é a cintura da amostra e integrando no volume, temos que a evolução da população atômica $(\mathrm{N}(\mathrm{t}))$ é dada por:

$$
\frac{d N(t)}{d t}=-\Gamma N(t)-\frac{\beta}{8 \pi^{\frac{3}{2}} w^{3}} N^{2}(t)
$$

Observe que nesta expressão $N(t)$ representa a evolução do número de átomos na amostra e a sua solução analítica é dada por:

$$
N(t)=\frac{N_{0} e^{-\Gamma t}}{1+\left(\frac{N_{0} \beta}{8 \pi^{3 / 2} w^{3} \Gamma}\right)\left(1-e^{-\Gamma t}\right)}
$$

em que $\mathrm{N}_{0}$ é o número de átomos no instante $\mathrm{t}=0$.

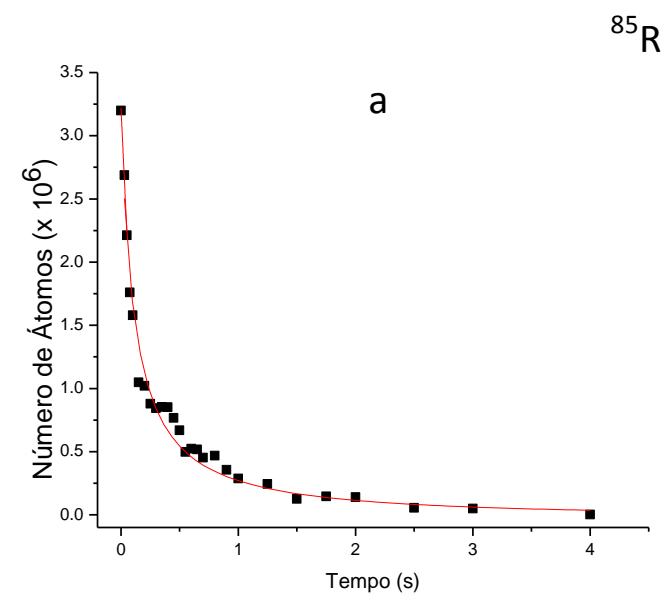

$$
{ }^{85} \mathrm{Rb}\left(5 \mathrm{~S}_{1 / 2}, \mathrm{~F}=2\right)
$$

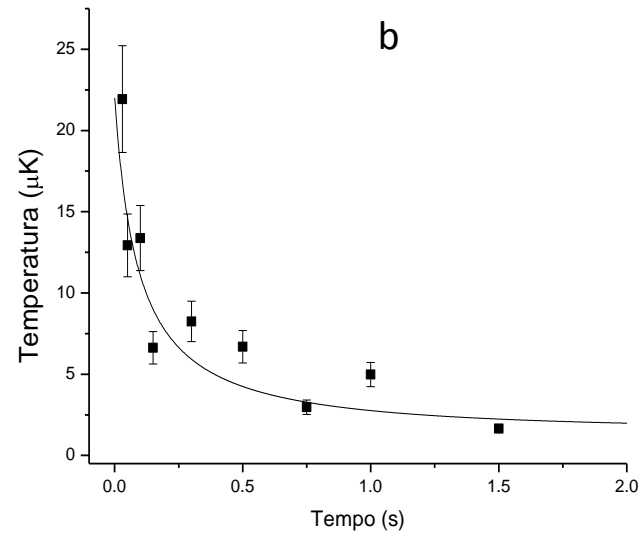

Figura 4.1 - a) Gráfico do tempo de vida de átomos de ${ }^{85} \mathrm{Rb}$ na armadilha de dipolo com população $100 \%$ no estado hiperfino inferior $F=2$. A linha vermelha $(\rightarrow)$ corresponde ao ajuste pela equação 4.2. b) Temperatura da respectiva amostra, ${ }^{85} R b(F=2)$, em função do tempo de aprisionamento. A linha preta $(\longrightarrow$ foi introduzida apenas para melhor visualização. 


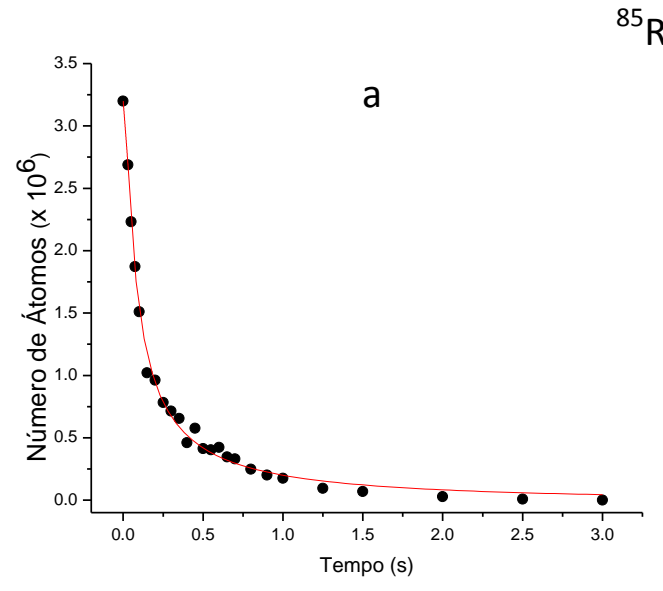

$$
{ }^{85} \mathrm{Rb}\left(5 \mathrm{~S}_{1 / 2}, \mathrm{~F}=3\right)
$$

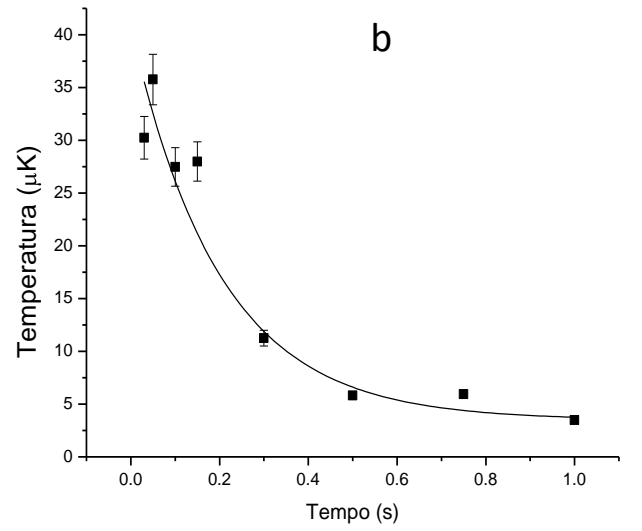

Figura 4.2 - a) Gráfico do tempo de vida de átomos de ${ }^{85} \mathrm{Rb}$ na armadilha de dipolo com população 100 $\%$ no estado hiperfino inferior $F=3$. A linha vermelha $(\rightarrow$ corresponde ao ajuste pela equação 4.2. b) Temperatura da respectiva amostra, ${ }^{85} R b(F=3)$, em função do tempo de aprisionamento. A linha preta $(\longrightarrow$ foi introduzida apenas para melhor visualização.

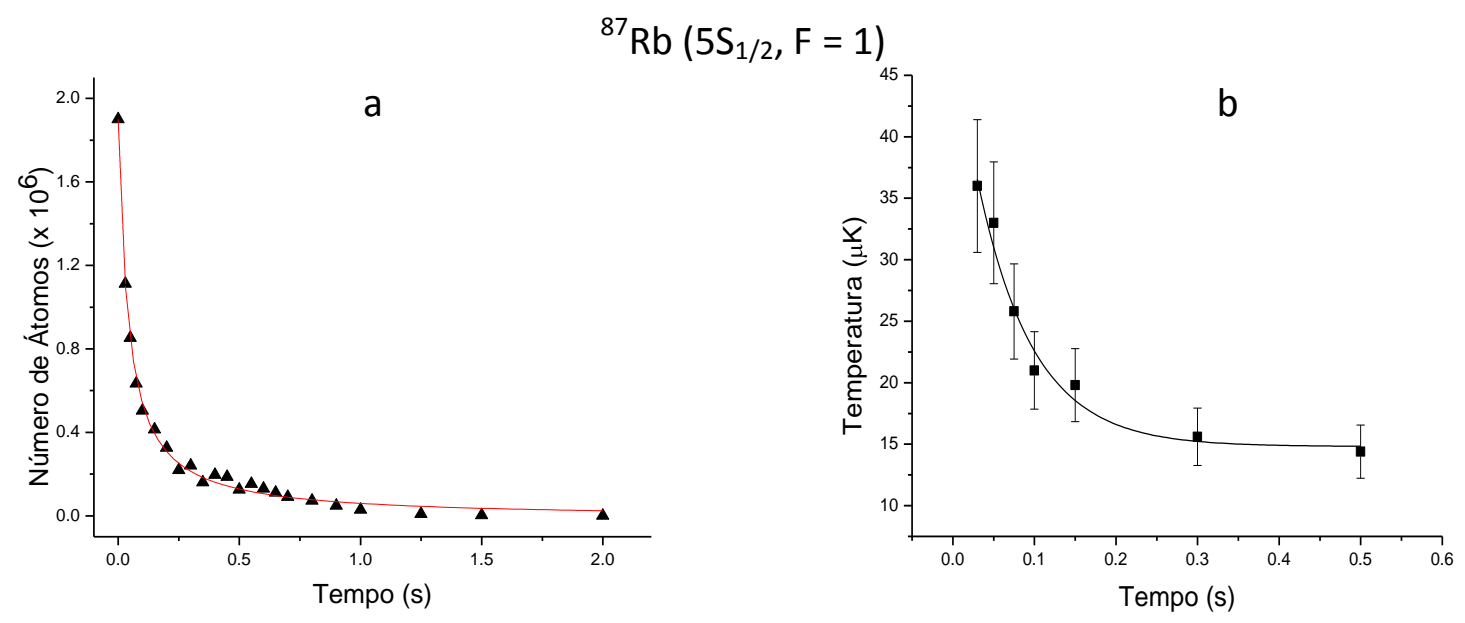

Figura 4.3 - a) Gráfico do tempo de vida de átomos de ${ }^{87} R b$ na armadilha de dipolo com população $100 \%$ no estado hiperfino inferior $F=1$. A linha vermelha $(\rightarrow$ corresponde ao ajuste pela equação 4.2. b) Temperatura da respectiva amostra, ${ }^{87} R b(F=1)$, em função do tempo de aprisionamento. A linha preta $(\longrightarrow$ foi introduzida apenas para melhor visualização. 


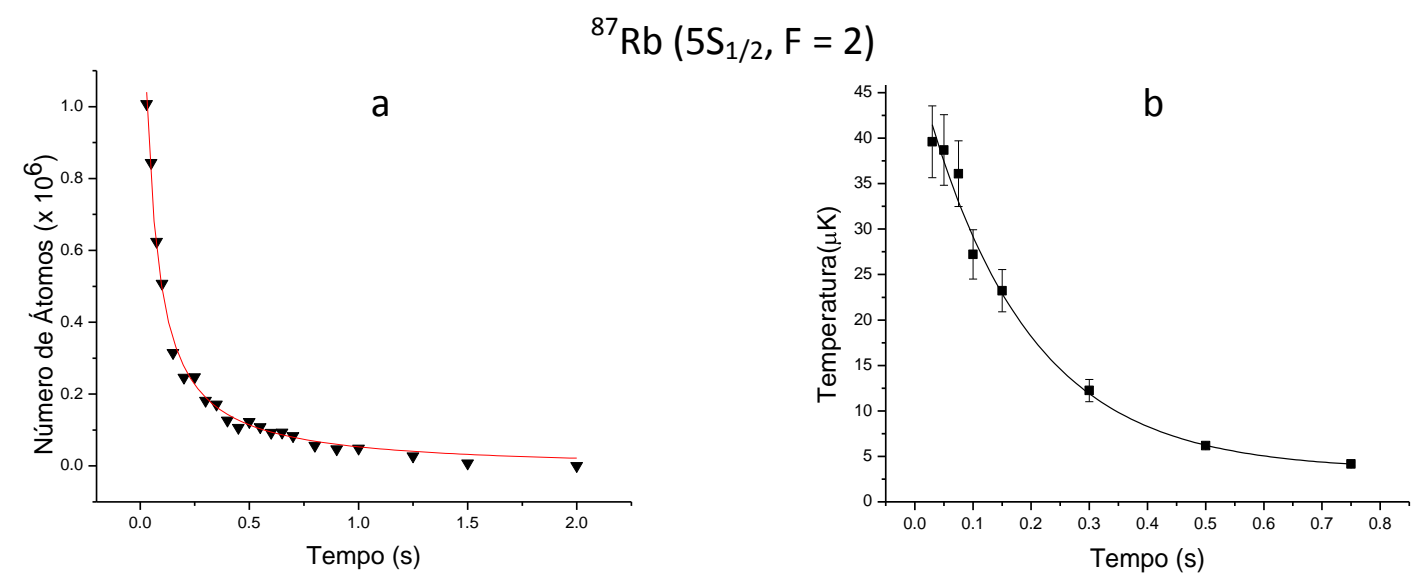

Figura 4.4 - a) Gráfico do tempo de vida de átomos de ${ }^{87} R b$ na armadilha de dipolo com população $100 \%$ no estado hiperfino inferior $F=2$. A linha vermelha $(\rightarrow$ corresponde ao ajuste pela equação 4.2. b) Temperatura da respectiva amostra, ${ }^{87} R b(F=2)$, em função do tempo de aprisionamento. A linha preta $\longrightarrow$ foi introduzida apenas para melhor visualização.

Ajustando as curvas de decaimento do número de átomos pela equação 4.3 obtemos os valores para as constantes de taxa de perda $\Gamma$ e $\beta$, tabela 4.1. Nesta tabela, $\mathrm{n}_{0}$ representa a densidade no instante inicial, devemos observar que nosso programa de aquisição, descrito na seção 3.6.2, calcula o número de átomos, a cintura e a densidade da amostra simultaneamente, assim é possível obter as mesmas curvas de decaimento para a densidade da amostra em função do tempo de aprisionamento.

Tabela 4.1 - Tabela das constantes $N_{0}, n_{0}, \Gamma$ e $\beta$ calculadas pelo ajuste da equação 4.3. $O$ valor de $w$ considerado nesta expressão foi $52 \mu \mathrm{m}$ e $62 \mu \mathrm{m}$ para ${ }^{87} \mathrm{Rb}$ e ${ }^{85} \mathrm{Rb}$ respectivamente.

\begin{tabular}{ccccc}
\hline $\begin{array}{c}{ }^{85} \mathbf{R b} \text { (estado } \\
\text { hiperfino) }\end{array}$ & $\mathbf{n}_{\mathbf{0}}\left(\times 10^{12} \mathrm{~cm}^{-3}\right)$ & $\mathbf{N}_{0}\left(\times 10^{6}\right)$ & $\boldsymbol{\Gamma}\left(\mathrm{s}^{-1}\right)$ & $\boldsymbol{\beta}\left(\times 10^{-12} \mathrm{~cm}^{3} \cdot \mathrm{s}^{-1}\right)$ \\
\hline $\mathrm{F}=2$ & $3,1 \pm 0,3$ & $3,1 \pm 0,1$ & $0,40 \pm 0,02$ & $2,3 \pm 0,2$ \\
$\mathrm{~F}=3$ & $3,9 \pm 0,4$ & $3,9 \pm 0,2$ & $0,40 \pm 0,02$ & $3,7 \pm 0,3$ \\
& & & & \\
${ }^{87} \mathbf{R b}$ (estado & & & & \\
hiperfino) & $3,3 \pm 0,3$ & $1,9 \pm 0,1$ & $0,40 \pm 0,02$ & $7,6 \pm 0,7$ \\
$\mathrm{~F}=1$ & $3,3 \pm 0,3$ & $1,9 \pm 0,1$ & $0,40 \pm 0,02$ & $8,6 \pm 0,8$ \\
$\mathrm{~F}=2$ & & &
\end{tabular}


A primeira grandeza que observarmos foi a densidade da amostra em que atingimos um pico de aproximadamente $3,9 \times 10^{12} \mathrm{~cm}^{-3}$ para $0{ }^{85} \mathrm{Rb}$ no instante inicial, resultado satisfatório mostrando uma considerável transferência de átomos entre as armadilhas, estando de acordo com outros trabalhos em armadilhas de dipolo na literatura $(65,85)$. Com relação à taxa de perda linear $\Gamma$ obtemos um valor de $0,4 \mathrm{~s}^{-1}$ e as taxas devido ao processo de dois corpos $\beta$ medidas foram: de 2,3 e 3,7 $\times 10^{-12} \mathrm{~cm}^{3} \mathrm{~s}^{-1}$ para as amostras de ${ }^{85} \mathrm{Rb}$ e 7,6 e $8,6 \times 10^{-12} \mathrm{~cm}^{3} \mathrm{~s}^{-1}$ para as amostras de ${ }^{87} \mathrm{Rb}$ preparadas respectivamente nos estados hiperfinos inferior e superior.

Comparando o valor de $\Gamma$ de nossa armadilha de dipolo com o valor medido na armadilha magneto-óptica $\Gamma_{\text {MOT }}=0,03 \mathrm{~s}^{-1}$, obtemos uma diferença de aproximadamente uma ordem de grandeza. Acreditamos que $\Gamma_{\mathrm{MOT}}$ inclua ainda colisões exotérmicas frias, mas por simplicidade consideraremos que se trata apenas de colisões com átomos quentes. Essa diferença está relacionada ao fato de que a profundidade do potencial de um MOT é em torno de 3 ordens de grandeza maior do que a de uma armadilha de dipolo. Assim, colisões com o vapor de fundo para átomos em uma armadilha de dipolo serão mais suscetíveis a perdas do que para átomos em um MOT, este efeito já foi muito bem explorado em (65). Além do mais em armadilhas de dipolo devemos considerar a instabilidade do laser, a qual pode gerar uma excitação paramétrica (88). Mas tal efeito esta associado também ao aumento da temperatura da amostra (89), o qual nunca observamos em nossas medidas. A medida da taxa de perda linear medida em nosso MOT ( $\left.\Gamma_{\text {MOT }}\right)$ está condizente com a literatura (90). Neste trabalho encontramos uma constante de tempo para um MOT de Rb de 3,3 $\mathrm{s}$ a qual resulta em $\Gamma_{\mathrm{MOT}}=0,3 \mathrm{~s}^{-1}$. Considerando a pressão em que o experimento foi realizado ( $P=1,3 \times 10^{-9}$ torr), ou seja, uma pressão com uma ordem de grandeza maior que o nosso, concluímos que nosso resultado está dentro do esperado.

Com relação às taxas de perda devido ao processo de dois corpos $\beta$ para amostras preparadas no nível hiperfino superior, o primeiro fato físico que devemos considerar é a ocorrência de mudança de estrutura hiperfina do par atômico durante uma colisão inelástica. Neste tipo de colisão, um par atômico preparado inicialmente nos níveis hiperfinos superiores pode resultar em um par atômico com um átomo no nível hiperfino superior e o outro no nível inferior ou dois átomos no nível hiperfino inferior. Este fenômeno é muito bem conhecido tanto em armadilhas de dipolo quanto em armadilhas magneto- 
ópticas e a energia liberada durante essa variação de estrutura hiperfina é da ordem de 130 $\mathrm{mK}$ para o ${ }^{85} \mathrm{Rb}$ e $290 \mathrm{mK}$ para $0^{87} \mathrm{Rb}$, ou seja, duas ordens de grandeza acima do potencial da armadilha de dipolo ( $1 \mathrm{mK}$ ). Portanto é de se esperar que as taxas de perda por dois corpos nas amostras preparadas nos estados hiperfinos superiores estejam presentes, como demonstrado em (89) para átomos de Cs.

A surpresa é que as amostras nos estados hiperfinos inferiores também apresentem uma taxa devido às colisões de dois corpos, mas discutiremos isso mais adiante neste capítulo. No momento, nos preocuparemos apenas com as diferenças entre $\beta$ entre os estados hiperfinos para o mesmo isótopo. Da tabela 4.1, temos que para ${ }^{85} \mathrm{Rb}$ a diferença de $\beta$ entre $F=3$ e $F=2$ é de $1,4 \times 10^{-12} \mathrm{~cm}^{3} \mathrm{~s}^{-1}$, e para ${ }^{87} \mathrm{Rb}$ a diferença de $\beta$ entre $\mathrm{F}=2$ e $\mathrm{F}=1$ é de $1,0 \times 10^{-12} \mathrm{~cm}^{3} \mathrm{~s}^{-1}$. A única diferença entre estas amostras de estados hiperfinos distintos para o mesmo isótopo é a existência de colisões com mudança de estrutura fina no estado hiperfino superior. Sendo, assim esta é uma medida direta deste processo.

Podemos tentar comparar tais medidas com outras da literatura. As medidas anteriores deste processo foram realizadas em MOTs para $\mathrm{Rb}(91,92)$ e em armadilhas de dipolo para Cs (89). Em MOTs, uma taxa de $3,6 \times 10^{-12} \mathrm{~cm}^{3} . \mathrm{s}^{-1}$ foi medida para o ${ }^{85} \mathrm{Rb}$ e uma taxa com fator de 4 vezes menor foi medida para $0{ }^{87} \mathrm{Rb}$. Contudo, em um MOT sempre há uma mistura de estados hiperfinos de modo que essas taxas são uma média de vários processos, além do fato que a profundidade do MOT não ser bem conhecida (93). Também é sabido, que a intensidade dos feixes laser utilizados no MOT pode modificar tais taxas. Na realidade o experimento realizado por Mudrich e colaboradores (89) é o primeiro a medir tal processo em uma armadilha com profundidade bem definida (Quest) e sem luz ressonante. Neste trabalho os autores mediram a taxa de perda por dois corpos para átomos de Cs em uma armadilha de dipolo com laser de $\mathrm{CO}_{2}$. Neste trabalho a amostra também era preparada de modo a obter átomos no estado hiperfino superior, $6 \mathrm{~S}_{1 / 2}(\mathrm{~F}=4)$, ou uma mistura de estados hiperfinos superior e inferior, $6 \mathrm{~S}_{1 / 2}(\mathrm{~F}=4$ e 3$)$. Os autores foram capazes de mostrar que as medidas na armadilha de dipolo estavam em concordância com a teoria vigente, a qual considerava as perdas devido à mudança de estrutura hiperfina na amostra.

Em outro trabalho em MOT, os autores demonstram claramente que a presença de luz ressonante modifica as taxas medidas. Eles sugerem várias possíveis explicações que não 
são de nosso interesse. Mas vale lembrar que neste trabalho (92), os autores também calculam o valor teórico de valor de $\beta$ para o isótopo ${ }^{87} \mathrm{Rb}$ considerando apenas a mudança de estrutura hiperfina. $O$ valor obtido foi da ordem de $1 \times 10^{-12} \mathrm{~cm}^{3} . \mathrm{s}^{-1}$, o que esta em perfeita concordância com o valor medido por nós de $1,0 \times 10^{-12} \mathrm{~cm}^{3} \mathrm{~s}^{-1}$. Caso a teoria seja aplicada em ${ }^{85} \mathrm{Rb}$, esperamos que o valor seria desta ordem de grandeza também.

Vamos retomar os átomos no estado hiperfino inferior. Neste caso, em que átomos são preparados no nível fundamental inferior, o esperado seria uma taxa de perda por dois corpos nula, pois não podem ocorrer colisões inelásticas nesse sistema. Em nossa técnica de bombeamento e imagem podemos garantir com precisão que $99,9 \%$ dos átomos são bombeados para um determinado estado hiperfino escolhido. Assim não é possível que ocorra perda por mudança de estrutura hiperfina, portanto esperaríamos um decaimento puramente exponencial determinado apenas pela taxa de perda linear, já que não há evidências de aquecimento como já foi visto em outros trabalhos (65).

\subsection{Evaporação em um potencial constante e colisões de três corpos}

Como discutido anteriormente, para as amostras no estado hiperfino inferior, o decaimento deveria ser puramente exponencial. Visto que o processo de mudança de estrutura hiperfina não pode contribuir para as perdas. Entretanto, há outros mecanismos de perda presentes nesse sistema. Isso nos leva a considerar uma equação de taxa mais elaborada:

$$
\frac{d N}{d t}=-\Gamma N+\dot{N}_{e v}+\dot{N}_{3 B}
$$


Nesta expressão incluímos dois novos termos relacionados às perdas na armadilha $\dot{N}_{e v}$ e $\dot{N}_{3 B}$. O primeiro baseia-se na da perda por evaporação, ou seja, o escape de átomos que possuem energia cinética acima do potencial da armadilha; e o segundo termo está relacionado ao processo de formação de moléculas por três corpos (three body recombination).

Evaporação é um processo natural em que átomos com elevados valores de energia cinética escapam de uma armadilha com profundidade finita. Devido ao fato de que esses átomos possuem uma energia maior que a energia média do sistema, o processo tende a diminuir a energia média do sistema diminuindo a temperatura da amostra. Qualitativamente, este processo pode ser esquematizado pela figura 4.5 , nesta $\mathbf{U}_{0}$ representa a profundidade da armadilha e a curva azul, representa a distribuição de Maxwell em função da energia das partículas, correspondente a uma temperatura inicial $T_{1}$. A região tracejada da curva azul representa a quantidade de partículas que tem energia suficiente para romper o potencial da armadilha. Conforme as partículas evaporam a energia do sistema se redistribui, através de colisões de dois corpos, gerando uma nova distribuição com temperatura $T_{2}$, em que $T_{2}<T_{1}$.

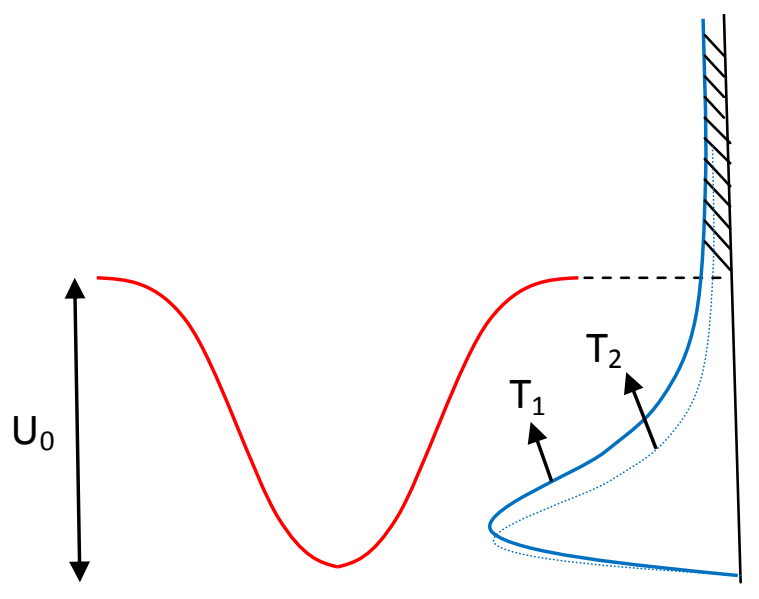

Figura 4.5 - Esquema de evaporação do sistema. A curva vermelha representa o potencial da armadilha com potencial $U_{0}$. As curvas azuis $T_{1}$ e $T_{2}$ são as distribuições Maxwell do sistema antes e depois de um processo evaporativo.

Conforme apresentado anteriormente, fica evidente que nosso sistema sofre um resfriamento em função do tempo de aprisionamento (Figuras $4.1 \mathrm{~b}-4.4 \mathrm{~b}$ ). Com isso 
concluímos que talvez possa haver uma considerável influência do processo evaporativo, contribuindo para um decaimento não exponencial. Diante disto, buscamos na literatura um modelo evaporativo a fim de testar nossos resultados. Nas referências $(94,95)$ encontramos expressões, obtidas através dos conceitos básicos da teoria cinética dos gases, que descrevem as taxas de evaporação para o número de átomos e a energia de um sistema, considerando um potencial arbitrário de aprisionamento:

$$
\begin{aligned}
& \dot{N}_{e v}=-n_{0}^{2} \sigma \bar{v} e^{-\eta} V_{e v} \\
& \dot{E}_{e v}=\dot{N}_{e v}\left(\eta+1-\frac{X_{e v}}{V_{e v}}\right) k_{b} T
\end{aligned}
$$

Na equação 4.5 temos a taxa em que átomos escapam da armadilha pelo processo evaporativo. Nesta, $\sigma$ representa a secção de choque de colisão elástica, $\bar{v} \equiv\left(8 k_{b} T / \pi m\right)^{1 / 2}$ é a velocidade média dos átomos aprisionados, $\eta=\epsilon_{t} / k_{b} T$, em que $\epsilon_{t}$ é a profundidade da armadilha, $n_{0}$ é a chamada densidade de referência relacionada com o número de átomos da forma $n_{0}=N / V_{e}$, em que $V_{e}$ é dado por:

$$
V_{e}=\Lambda^{3} \int_{0}^{\epsilon_{t}} \rho(\epsilon) \exp \left(-\frac{\epsilon}{k_{b} T}\right) \mathrm{d} \epsilon
$$

em que $\rho(\epsilon)$ é a densidade de estados do sistema definida por:

$$
\begin{aligned}
\rho(\epsilon) \equiv & (2 \pi \hbar)^{-3} \int \delta\left(\epsilon-\mathrm{U}(\mathbf{r})-\mathrm{p}^{2} / 2 \mathrm{~m}\right) \mathrm{d}^{3} \mathrm{r} \mathrm{d}^{3} \mathrm{p} \\
& =\frac{2 \pi(2 \mathrm{~m})^{3 / 2}}{(2 \pi \hbar)^{3}} \int \sqrt{\epsilon-\mathrm{U}(\mathbf{r})} \mathrm{d}^{3} \mathrm{r}
\end{aligned}
$$


A equação 4.6 representa a taxa em que a energia varia no sistema e os volumes $V_{e v}$ e $X_{e v}$ podem ser expressos também em função da densidade de estados:

$$
\begin{aligned}
& V_{e v}=\frac{\Lambda^{3}}{k_{b} T} \int_{0}^{\epsilon_{t}} \rho(\epsilon)\left[\left(\epsilon_{t}-\epsilon-k_{b} T\right) \mathrm{e}^{-\epsilon / k_{b} T}+k_{b} T e^{-\eta}\right] \mathrm{d} \epsilon \\
& X_{e v}=\frac{\Lambda^{3}}{k_{b} T} \int_{0}^{\epsilon_{t}} \rho(\epsilon)\left[k_{b} T e^{-\epsilon / k_{b} T}-\left(\epsilon_{t}-\epsilon+k_{b} T\right) \mathrm{e}^{-\eta}\right] \mathrm{d} \epsilon
\end{aligned}
$$

Para o cálculo das taxas de evaporação, precisamos primeiramente calcular a densidade de estados (eq 4.8) a qual depende do formato do potencial de aprisionamento. Neste cálculo, assumimos um potencial harmônico no centro da armadilha, fazendo com que as expressões possuam uma solução analítica. Nesta aproximação obtemos:

$$
\rho(\epsilon)=\frac{1}{2(\hbar \bar{\omega})^{3}} \epsilon^{2}
$$

em que $\bar{\omega}$ é a média geométrica das freqüências de oscilação da armadilha. Com esta expressão todos os termos acima podem ser generalizados em termos das funções gama.

Para verificar que nossas simulações teóricas estavam corretas, utilizamos curvas de decaimento medidas em uma amostra de Cs carregada em uma armadilha de dipolo com laser de $\mathrm{CO}_{2}$ (96). Fomos capazes de reproduzir as curvas teóricas do artigo, garantindo assim que o modelo estava sendo utilizado corretamente. Assim, demos seqüência às simulações do nosso sistema assumindo uma profundidade de 1,53 $\mathrm{mK}$ para potencial da armadilha de dipolo cruzada e freqüência de oscilação de $\bar{\omega}=2,1 \mathrm{KHz}$. Para a secção de choque de espalhamento $(\sigma)$, foram considerados valores entre 260 à 2600 u.a. e não obtivemos nenhuma variação no resultado. Os gráficos a seguir (figura 4.6) representam as curvas experimentais e teóricas do decaimento de número de átomos e temperatura em função do tempo de aprisionamento. 


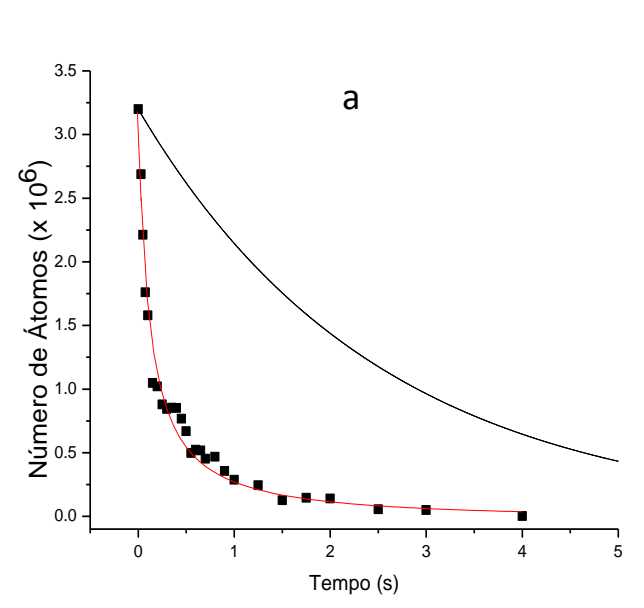

${ }^{85} \mathrm{Rb}(\mathrm{F}=2)$
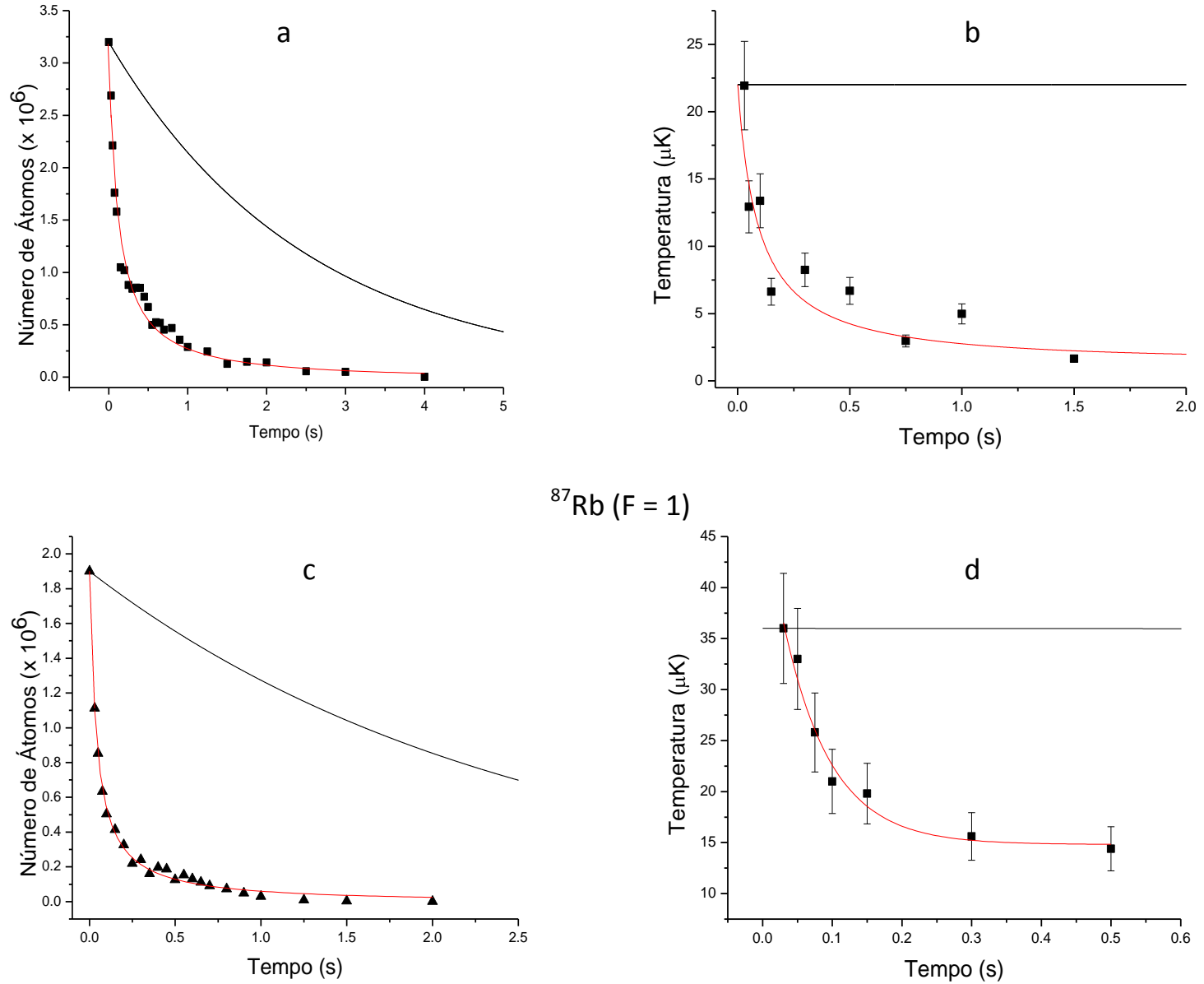

${ }^{87} \mathrm{Rb}(\mathrm{F}=1)$

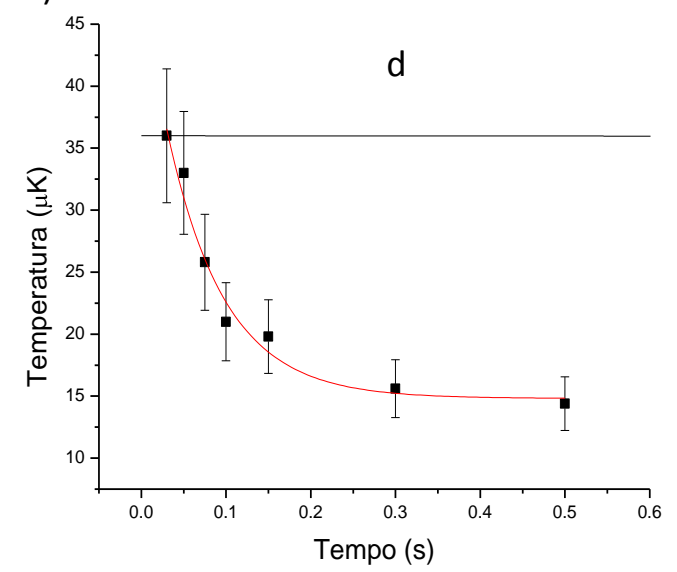

Figura 4.6 - Comparações entre as curvas experimentais de decaimento de número de átomos (a e c) e temperatura ( $b$ e d) (linhas vermelhas) com as curvas geradas pelas simulações do modelo evaporativo (linhas pretas). As medidas foram feitas com ambas as espécies ${ }^{85} \mathrm{Rb}$ $e^{87} R b$ no estado fundamental hiperfino inferior. Observamos uma grande discrepância entre o experimento e a teoria mostrando que o mecanismo de evaporação que ocorre em nosso sistema não pode explicar os decaimentos medidos.

As linhas pretas dos gráficos da figura 4.6a e 4.6c representam decaimentos que consideram a soma do termo de perda linear medido com o termo de evaporação simulado. As linhas pretas das figuras $4.6 \mathrm{~b}$ e $4.6 \mathrm{~d}$ representam as simulações feitas para o decaimento da temperatura do sistema. A conclusão que chegamos, diante disso, é que em nenhum dos casos o modelo evaporativo pode explicar de fato a perda que realmente acontece em nosso sistema. Assim concluímos que o efeito de evaporação em nosso sistema pode ser desprezado tanto para o ${ }^{85} \mathrm{Rb}$ como para o ${ }^{87} \mathrm{Rb}$. Não é surpresa, que este modelo não seja 
capaz de explicar nossos resultados, visto que a temperatura da amostra ( $40 \mu \mathrm{K}$ ) é muito inferior à profundidade da armadilha ( $1500 \mu \mathrm{K}$ ). Ou seja, não há na amostra átomos suficientes com energias acima de $1500 \mu \mathrm{K}$ para iniciar a evaporação.

O próximo passo foi verificar a importância do processo de três corpos em nossos experimentos. No mecanismo de perda por três corpos, a colisão entre três átomos resulta na formação de uma molécula diatômica e um átomo livre, figura 4.7. Devido aos fatores de Franck-Condon, a molécula é formada nos mais altos níveis vibracionais do estado fundamental com uma energia de ligação de alguns $\mathrm{MHz}$; por outro lado, o átomo livre resultante recebe o excedente de energia na forma de energia cinética mantendo a conservação de energia e momentum do sistema. Portanto, este é um processo que gera perdas diminuindo o número de átomos em uma armadilha.

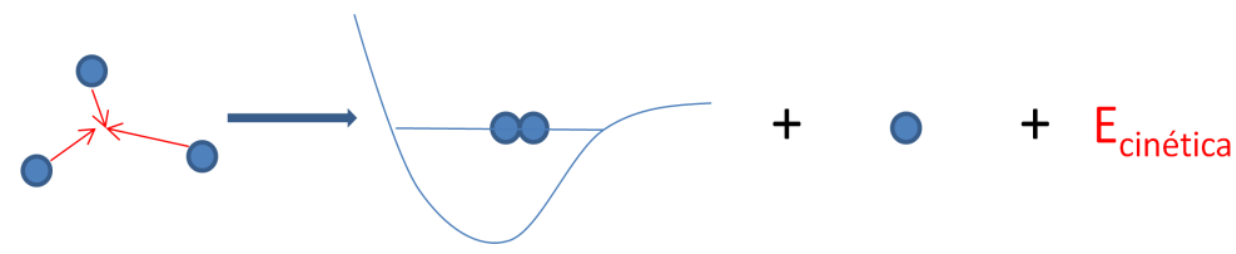

Figura 4.7 - Processo de formação de moléculas por 3 corpos. A colisão entre três átomos resulta na formação de uma molécula diatômica e um átomo livre. $O$ átomo livre resultante recebe o excedente de energia na forma de energia cinética mantendo a conservação de energia e momentum do sistema.

Como descrito na referência (97), a taxa de perda por três corpos do sistema pode ser escrita como:

$$
\dot{N}_{3 B}=-k_{3} \int_{V} n^{3}(\boldsymbol{r}, t) d^{3} \boldsymbol{r}
$$

Uma vez que o efeito de perda por três corpos é considerável em densidades da ordem de $10^{14} \mathrm{~cm}^{-3}$, analisamos este problema comparando a taxa de formação de moléculas por três corpos medidos na literatura para o ${ }^{85} \mathrm{Rb}(14)$ e ${ }^{87} \mathrm{Rb}$ (97) com a taxa 
inicial de perda do nosso sistema. Para isso, ajustamos os quatro primeiros pontos de cada curva de decaimento (figuras 4.8 a e b) por uma reta, assim o coeficiente angular dessa reta é a taxa $d N / d t$ do sistema. Essa aproximação é satisfatória, pois a maior contribuição para o mecanismo de perda por três corpos deve ocorrer quando a amostra se encontra na maior densidade possível. Assim obtemos:
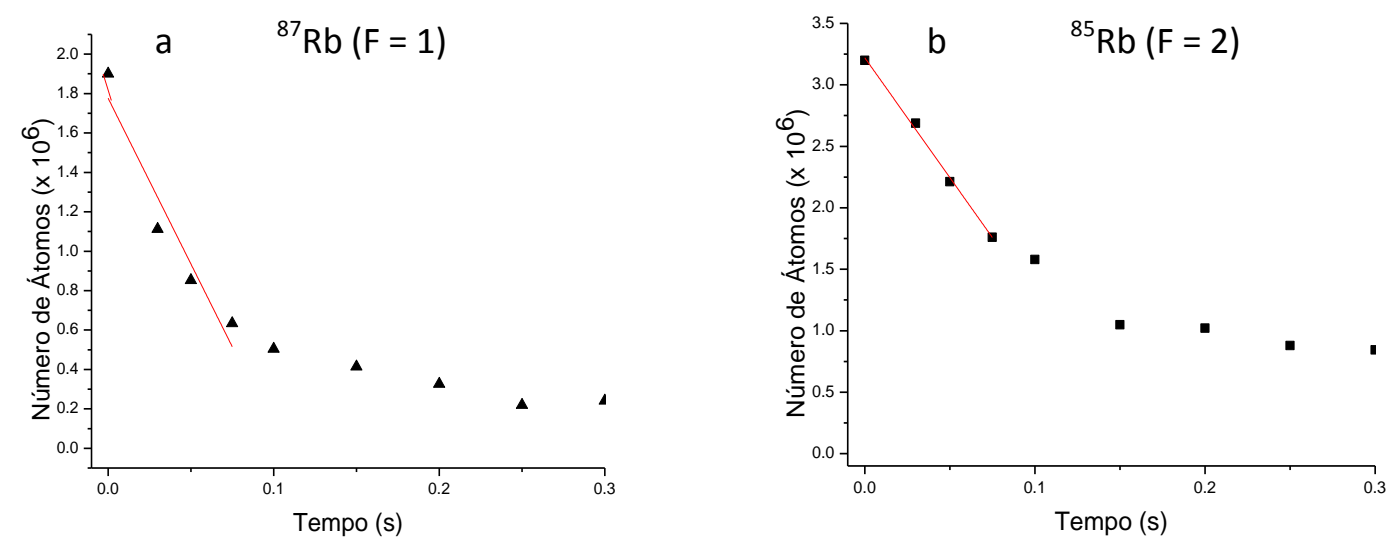

Figura 4.7 - Ajuste dos quatro primeiros pontos das curvas de decaimento para $0{ }^{87} R b(a) e{ }^{85} R b(b)$ nos estados hiperfinos inferiores por uma reta. $O$ coeficiente angular dessa reta é a taxa $d N / d t$.

$$
\begin{array}{ll}
\frac{d N(t)}{d t} \approx 1,95 \times 10^{7} \mathrm{~s}^{-1} & \left({ }^{85} \mathrm{Rb}\right) \\
\frac{d N(t)}{d t} \approx 1,68 \times 10^{7} \mathrm{~s}^{-1} & \left({ }^{87} \mathrm{Rb}\right)
\end{array}
$$

Nas expressões 4.14 e 4.15 temos o valor da variação do número de átomos do nosso sistema para $0{ }^{85} \mathrm{Rb}$ e ${ }^{87} \mathrm{Rb}$, respectivamente, nos primeiros $100 \mathrm{~ms}$ de aprisionamento. Também sabemos que dN/dt, devido a 3 corpos, deve ser dado por 4.16. Este resultado é obtido calculando-se a integral em 4.13 e assumindo novamente a densidade $n(\boldsymbol{r}, t)=$ $n_{0} \exp \left(-r^{2} / 2 w^{2}\right)$. Assim, para o decaimento dos dois isótopos, teremos: 


$$
\frac{d N(t)}{d t} \approx-k_{3} n_{0}^{2} N \sqrt{\frac{\pi}{6}}
$$

Considerando o valor de $k_{3}{ }^{*}=1,1 \times 10^{-25} \mathrm{~cm}^{6} \cdot \mathrm{s}^{-1}$ para o ${ }^{85} \mathrm{Rb}$ encontrado em (14), $k_{3}=$ $4,3 \times 10^{-29} \mathrm{~cm}^{6} \cdot \mathrm{s}^{-1}$ para ${ }^{87} \mathrm{Rb}$ encontrado em (97), a densidade e o número de átomos no instante inicial do nosso sistema mostrados na tabela 4.1, obtemos:

Tabela 4.2 - Coeficentes para taxa de três corpos calculados para $o^{85} R b e^{87} R b$.

\begin{tabular}{ccc}
\hline \hline & $k_{3} n_{0}^{2} N_{0}\left(s^{-1}\right)$ & $d N(t) / d t\left(s^{-1}\right)$ \\
\hline \hline${ }^{85} \mathrm{Rb}$ & $2,13 \times 10^{6}$ & $1,95 \times 10^{7}$ \\
${ }^{87} \mathrm{Rb}$ & $6,40 \times 10^{2}$ & $1,68 \times 10^{7}$ \\
\hline
\end{tabular}

Comparando os valores considerando processos de 3 corpos e os valores obtidos em nossos resultados experimentais concluímos que a taxa de perda por três corpos pode ser completamente desprezada para o caso do ${ }^{87} \mathrm{Rb}$, e no caso do ${ }^{85} \mathrm{Rb}$ sua contribuição é aproximadamente uma ordem de grandeza menor. Este resultado é esperado, pois esse mecanismo de perda só é relevante em sistemas com densidades da ordem de $10^{14} \mathrm{~cm}^{-3}$, como reportado na literatura. Além do mais, a temperatura da amostra deveria aumentar, já que os átomos remanescentes desse processo recebem um acréscimo de energia cinética, fato que não é observado nas medidas das figuras $4.1 \mathrm{~b}$ e $4.3 \mathrm{~b}$. Aqui, chegamos ao ponto em que a evaporação e o processo de perda por 3 corpos não podem explicar as curvas de decaimento do número de átomos na armadilha, assim na próxima seção, relacionaremos este decaimento à fotoassociação de átomos em moléculas causadas pelo laser em 1064 nm da armadilha dipolo.

\footnotetext{
* Informação fornecida por Greene, C. em 2011.
} 


\subsection{Fotoassociação com laser em 1064 nm}

Como descrito na seção 2.6 do capítulo 2, a fotoassociação de átomos de Rb por um comprimento de onda de $1064 \mathrm{~nm}$ é algo fisicamente possível como mostram os potenciais da figura 4.9 e o trabalho da referência (72). Neste artigo, considerando uma amostra de Rb com densidade de $\mathrm{n}=10^{11} \mathrm{~cm}^{-3}$ a uma temperatura de $100 \mu \mathrm{k}$, os autores estimaram uma probabilidade de fotoassociação de valor de $5 \times 10^{-8} /$ pulso. Como a largura do pulso é de 750 $\mathrm{ns}$, a probabilidade por segundo se torna $0,066 / \mathrm{s}$. Sendo $\beta \sim \tau / n$ podemos estimar uma taxa de fotoassociação de aproximadamente $6,6 \times 10^{-13} \mathrm{~cm}^{3} \cdot \mathrm{s}^{-1}$ para uma potência de $10^{4}$ $\mathrm{W} / \mathrm{cm}^{2}$, isto quando considerado um comprimento de onda estreito. Em nossos resultados, obtivemos taxas de dois corpos são uma ordem de grandeza maiores, $\beta=2,3$ e 8,6 $\times 10^{-12}$ $\mathrm{cm}^{3} \cdot \mathrm{s}^{-1}$ para $\mathrm{o}{ }^{85} \mathrm{Rb}$ e ${ }^{87} \mathrm{Rb}$, respectivamente. É de se esperar que nossas taxas sejam maiores comparadas ao modelo do artigo, pois utilizamos um laser de banda larga (largura efetiva de $\sim 2 \mathrm{~nm}$ ) com intensidade de 0,24 MW/ $\mathrm{cm}^{2}$, ou seja, utilizamos uma intensidade uma ordem de grandeza acima, e a possibilidade de acoplamento entre os estados vibracionais moleculares é de certa forma favorecida pela largura do laser. Além disso, em nossa situação é esperado que haja alargamento das linhas devido à alta intensidade do laser de aprisionamento. Devemos ressaltar que a teoria desenvolvida em (72) não possui sensibilidade para diferenciar a taxa de fotoassociação entre os isótopos ${ }^{85} \mathrm{Rb}$ do ${ }^{87} \mathrm{Rb}$, e os potenciais utilizados nos cálculos também não consideram colisões entre os estados $m_{F}$, as quais estão presentes em nossa armadilha, pois a amostra não é polarizada. 


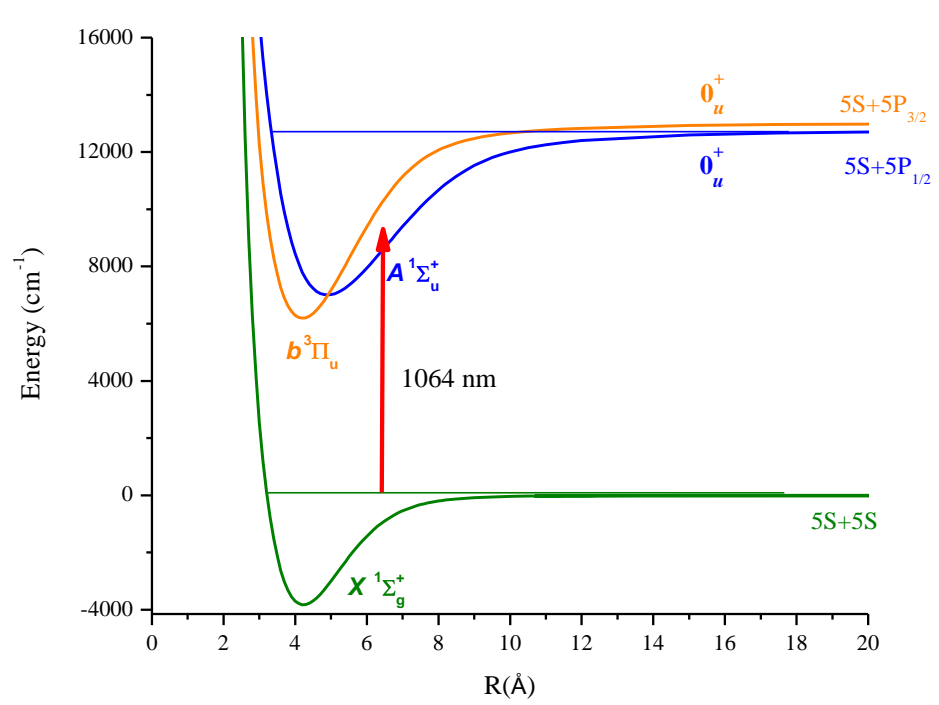

Figura 4.8 - Potenciais de interesse para a molécula de $R b_{2}$. A seta vermelha representa em escala a energia do laser em $1064 \mathrm{~nm}$ mostrando a possibilidade de acoplamento entre o estado fundamental e os estados excitados $A^{1} \Sigma_{u}$ e $b^{3} \Pi_{u}$.

A fotoassociação, com certeza, pode explicar o decaimento devido à perda por dois corpos observados por nós em nossa armadilha de dipolo. Contudo, ainda há a questão do resfriamento da amostra. A referência, no qual estamos baseando nossa análise, possui uma figura (figura 4.10) (figura extraída da referência (72)), a qual pode nos sugerir algumas hipóteses do que está acontecendo. Nesta simulação, os autores exploram a influência das ressonâncias colisionais e métodos de interpolação nos fatores de Franck-Condon para transições entre estados livre e ligados para pares atômicos de ${ }^{85} \mathrm{Rb}$. Esta interpolação é necessária devido ao fato do potencial a longo alcance ser obtido diferentemente do potencial interno. Assim, abaixo de 40 u.a., os autores utilizam os resultados obtidos em (98) e acima de 40 u.a. utilizam os resultados de (99) do potencial fundamental singleto. Dois modelos de interpolação são propostos. Em um deles (linha tracejada) observamos que os fatores de Franck-Condon tornam-se mais favoráveis para as partículas mais energéticas da armadilha, assim, ocorreria um resfriamento da amostra conforme a mesma é fotoassociada, fato que concorda com nossas medidas. 


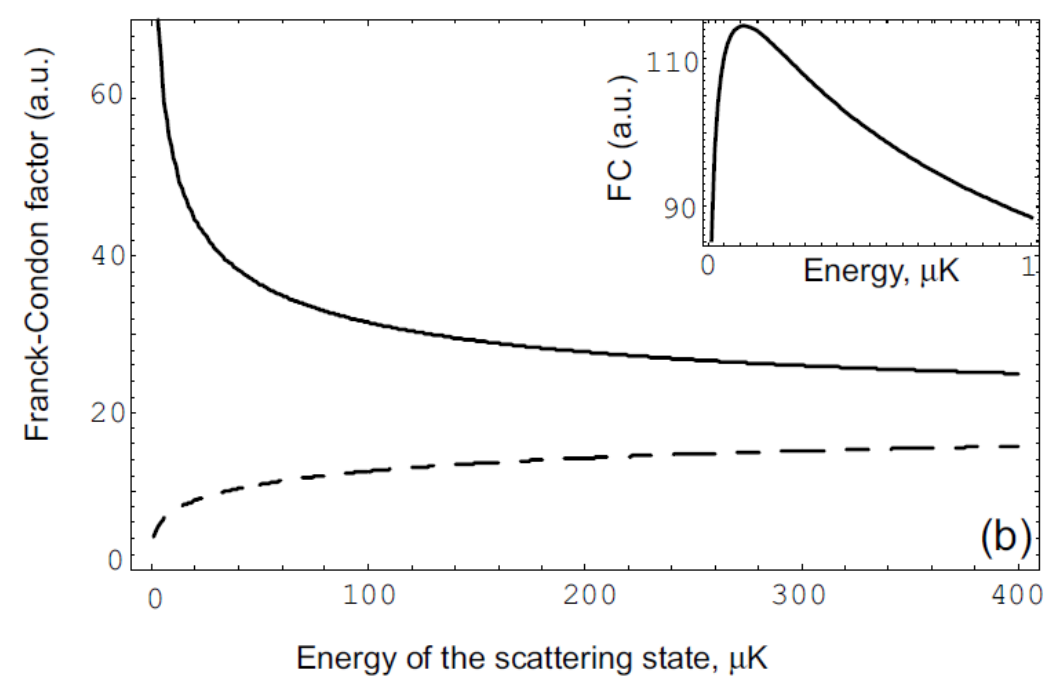

Figura 4.9 - Modelos para interpolação dos potenciais de longo e curto alcance do estado fundamental singleto. A interpolação obtida pela linha tracejada sugere que os fatores de Franck-Condon aumentam em função da energia de espalhamento de uma colisão para átomos de ${ }^{85} \mathrm{Rb}$. Obs: Figura extraída da referência (72).

É importante salientar que tais previsões teóricas, ainda são muito simples, pois não considera a estrutura hiperfina do estado da amostra aprisionada, nem os subníveis magnético. E em nossa amostra temos todos os possíveis subníveis. Então não é surpresa que a comparação entre este modelo teórico e nossos resultados seja feita de forma qualitativa.

No capítulo 2 fizemos uma previsão de que essas moléculas fotoassociadas pelo laser em $1064 \mathrm{~nm}$ estão sendo formadas entre os níveis vibracionais $v=70-100$ do estado singleto fundamental. Entretanto, como a seqüência temporal do experimento para o aprisionamento é lenta (10 s para cada carregamento), até o momento não foi possível a observação direta destas moléculas por fotoionização.

Para tentar confirmar este processo de fotoassociação, observamos o decaimento do número de átomos em função da potência do laser de aprisionamento. O esperado é que houvesse uma redução da taxa de perda por dois corpos, visto que o processo envolve a absorção de um fóton. Porém, quando a potência do laser atingia a metade do valor usual ( $\approx$ $12 \mathrm{~W}$ ) não era possível obter medidas precisas, pois o número de átomos aprisionados era reduzido por um fator de 10 vezes. Além do mais, nesse nível de potência ainda é esperado, considerando os cálculos da referencia (72), que a taxa de fotoassociação esteja saturada. 


\section{Moléculas $\mathrm{Rb}_{2}$ aprisionadas em uma armadilha de dipolo}

Como discutido no capítulo 3, o aprisionamento em uma armadilha dipolo deve-se a interação do momento de dipolo induzido da partícula com o laser. Desta forma, tanto átomos quanto moléculas podem ser aprisionados. Neste capítulo, descreveremos o aprisionamento de moléculas de ${ }^{85} \mathrm{Rb}_{2}$ e ${ }^{87} \mathrm{Rb}_{2}$, a técnica de observação e os resultados envolvendo moléculas aprisionadas na armadilha de dipolo óptica com laser em 1064 nm. Esses resultados serão muito importantes para os futuros experimentos em nosso grupo.

\subsection{A técnica de trem de pulsos para observação de moléculas aprisionadas}

Atualmente essa medida é feita de forma destrutiva, como descrita na literatura. Ou seja, para cada tempo de aprisionamento, a população de moléculas é medida e em seguida a amostra descartada. Desta forma, este tipo de medida é muito lento e só alguns pontos são coletados em função do tempo de aprisionamento (65). O ideal seria a observação contínua das moléculas aprisionadas na armadilha. Com isso em mente, partimos para o desenvolvimento de uma nova técnica, a qual utiliza uma seqüência de pulsos para fotoionizar a amostra. Como a energia de cada pulso é relativamente pequena, a ionização da amostra molecular como um todo é muito baixa, e assim podemos observar a evolução temporal de modo contínuo na mesma amostra. A grande vantagem desta técnica é a sua 
rapidez, permitindo a obtenção de vários pontos em uma única vez. Ou seja, médias podem ser realizadas com maior precisão.

A seqüência experimental para o carregamento de moléculas da armadilha é a mesma apresentada no capítulo 3 para o aprisionamento de átomos. Por simplicidade, decidimos demonstrar a técnica com as moléculas formadas durante a fase de carregamento da armadilha diretamente do MOT. Ou seja, estas moléculas são fracamente ligadas e apresentam um número quântico vibracional elevado como no trabalho de Caires e colaboradores (100). Além disso, podem ser formadas tanto no estado singleto quanto tripleto.

O carregamento e a detecção das moléculas na armadilha estão descritos na figura 5.1. Iniciamos o processo aprisionando $10^{8}$ átomos a uma densidade de $2 \times 10^{10} \mathrm{~cm}^{-3}$ na armadilha magneto-óptica. Para $0{ }^{85} \mathrm{Rb}$, o laser de aprisionamento foi ajustado para o vermelho da transição atômica $5 S_{1 / 2}(F=3) \rightarrow 5 P_{3 / 2}\left(F^{\prime}=4\right)$ e o laser de rebombeio foi ajustado para a transição atômica $5 S_{1 / 2}(F=2) \rightarrow 5 P_{3 / 2}\left(F^{\prime}=3\right)$. No caso do ${ }^{87} R b$, o laser de aprisionamento foi ajustado para o vermelho da transição atômica $5 S_{1 / 2}(F=2) \rightarrow 5 P_{3 / 2}\left(F^{\prime}=\right.$ 3) e o laser de rebombeio foi ajustado para a transição atômica $5 S_{1 / 2}(F=1) \rightarrow 5 P_{3 / 2}\left(F^{\prime}=2\right)$. Independentemente do isótopo aprisionado, a intensidade do laser de aprisionamento foi de $\mathrm{I}_{\mathrm{T}}=8 \mathrm{~mW} / \mathrm{cm}^{2}$ por feixe e sua dessintonia para o vermelho foi de $\Delta_{\mathrm{T}}=-3,4 \Gamma$, em que $\Gamma=$ $2 \pi \times 5,9 \mathrm{MHz}$, a intensidade do rebombeio foi de $I_{R}=1,6 \mathrm{~mW} / \mathrm{cm}^{2}$ sem nenhuma dessintonia, ou seja, $\Delta_{\mathrm{R}}=0$. A armadilha de dipolo cruzada foi produzida pelo laser de fibra de banda larga em $1064 \mathrm{~nm}$, descrito anteriormente no capítulo 3, o qual era focalizado no MOT com uma cintura de $57 \mu \mathrm{m}$ a uma potência de $25 \mathrm{~W}$. O experimento seguia de acordo com a seguinte seqüência: i) Fase de carregamento do MOT, cuja duração era de 4 - $8 \mathrm{~s}$, em que os lasers de aprisionamento e rebombeio eram ajustados na condição inicial, descrita previamente. Nesta fase a armadilha de dipolo permanece desligada; ii) Fase de carregamento da armadilha de dipolo, cuja duração era de 50 ms. Nesta fase, o laser da armadilha de dipolo é ligado e a intensidade e freqüência do laser de aprisionamento e rebombeio são ajustadas para a condição de carregamento $\left(I_{T}=1,6 \mathrm{~mW} / \mathrm{cm}^{2}, \Delta_{T} \sim-6 \Gamma, I_{R}=\right.$ $60 \mu \mathrm{W} / \mathrm{cm}^{2}$ e $\Delta_{\mathrm{R}}=0$ ). Isto permitia-nos resfriar e aprisionar átomos na armadilha de dipolo cruzada. As moléculas $\mathrm{Rb}_{2}$, formadas por fotoassociação pelos lasers do MOT durante esta fase $(100,101)$, eram carregadas na armadilha de dipolo cruzada, como foi feito em (102); 
iii) Na seqüência, o campo magnético e os lasers de aprisionamento e rebombeio do MOT eram desligados. Após $50 \mathrm{~ms}$, átomos não aprisionados caíam pelo efeito da gravidade deixando uma amostra pura de átomos e moléculas aprisionadas na armadilha de dipolo. Em condições típicas, tínhamos $3 \times 10^{6}$ átomos aprisionados a uma densidade de $3 \times 10^{12} \mathrm{~cm}^{-3}$; iv) Finalmente, depois de um tempo de aprisionamento $(\tau)$ na armadilha de dipolo, um trem de pulsos era aplicado na amostra para fotoionizar as moléculas de $\mathrm{Rb}_{2}$ aprisionadas, cujos íons $\mathrm{Rb}_{2}{ }^{+}$eram detectados por um detector do tipo channeltron electron multiplier. O laser de ionização era constituído de um laser de corante (Jaguar - Continuum) bombeado pelo segundo harmônico de um laser Nd:YAG (duração do pulso de 5 ns, e taxa de repetição de 20 $\mathrm{Hz}$ ), operando a um comprimento de onda de $602 \mathrm{~nm}$. O laser pulsado era focalizado em 1 $\mathrm{mm}$ de diâmetro. Este comprimento de onda corresponde à banda difusa do $\mathrm{Rb} a^{3} \Sigma_{\mathrm{u}}^{+} \rightarrow$ $2^{3} \Pi_{g}$, bem conhecida por estudos no início dos anos 80 no contexto de experimentos de fluorescência induzida por luz (LIF) (103). Um boxcar integrador era usado para integrar o sinal de íons, aquisicionado por um osciloscópio e transferido para o computador. Para uma aquisição completa eram necessários 80 pulsos de laser.

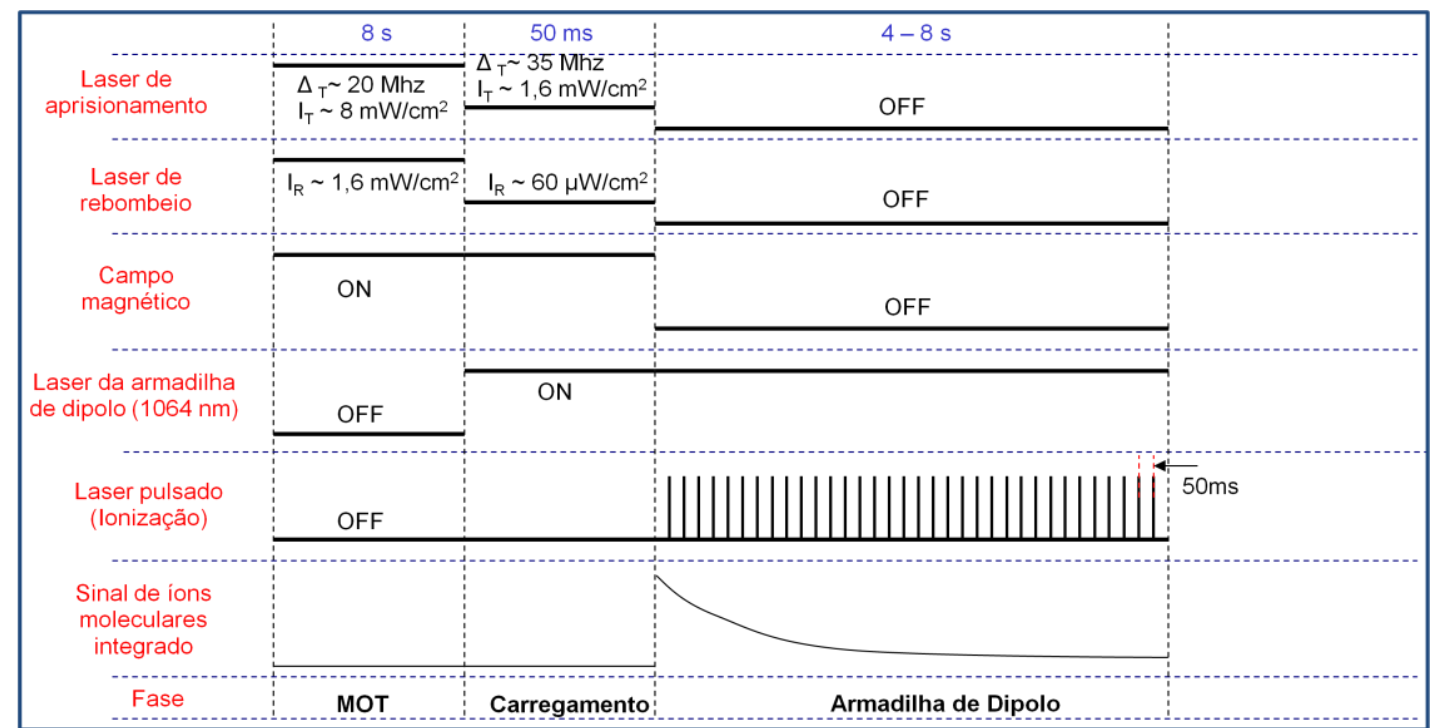

Figura.5.1 - Seqüência experimental para a observação de moléculas de ${ }^{85} R b_{2} e{ }^{87} R b_{2}$ na armadilha de dipolo.

Cada pulso de laser ioniza uma fração de moléculas aprisionadas formando $\mathrm{Rb}_{2}{ }^{+}, \mathrm{o}$ qual é atraído pelo detector de íons. Seu sinal é medido pelo osciloscópio gerando um 
espectro de tempo de vôo, assim podemos fazer a contagem do número total de moléculas como descrito no capítulo 3. Na figura 5.2, mostramos uma típica curva de evolução temporal de moléculas em uma armadilha de dipolo para um pulso com $1 \mathrm{~mJ} /$ pulso.

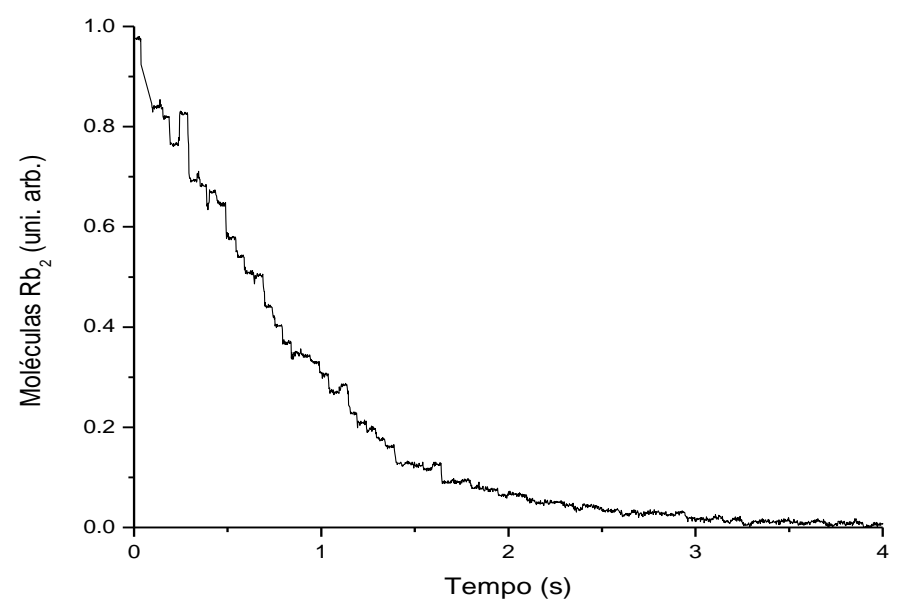

Figura 5.2 - Decaimento da amostra molecular $\left({ }^{85} \mathrm{R} b_{2}\right)$ em uma armadilha de dipolo.

\subsection{Caracterização da técnica de trem de pulsos}

Para caracterizar a técnica de trem de pulsos realizamos vários testes variando diferentes parâmetros. Primeiramente, medimos a curva de decaimento para moléculas de ${ }^{85} \mathrm{Rb}_{2}$ iniciando o trem de pulso em diferentes tempos de aprisionamento da armadilha de dipolo. Na figura 5.3a mostramos um esquema deste experimento, e na figura 5.3b as curvas de decaimento após diferentes tempos de aprisionamento $\Delta t: 0,400,800,1200$ e $1600 \mathrm{~ms}$. Cada uma dessas curvas é o resultado de uma média de 10 medidas consecutivas. Devemos frisar que o curto tempo de vida de tais moléculas na armadilha de dipolo (aproximadamente 1s), ainda não é compreendido e requer mais investigação. Talvez as mesmas estejam sendo bombeadas oticamente pelo laser em 1064 nm como já explicado no capítulo 4. 
a)

Carregamento da Armadilha: Moléculas aprisionadas na armadilha

a)

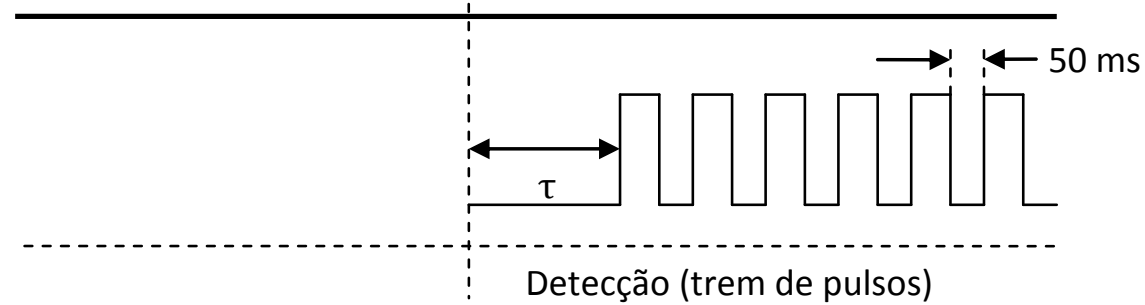

b)

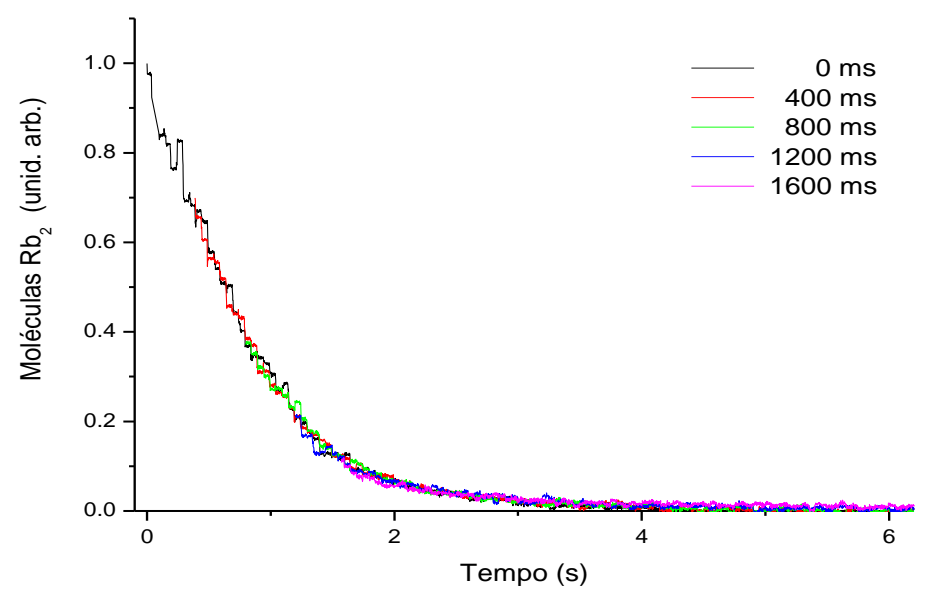

c)

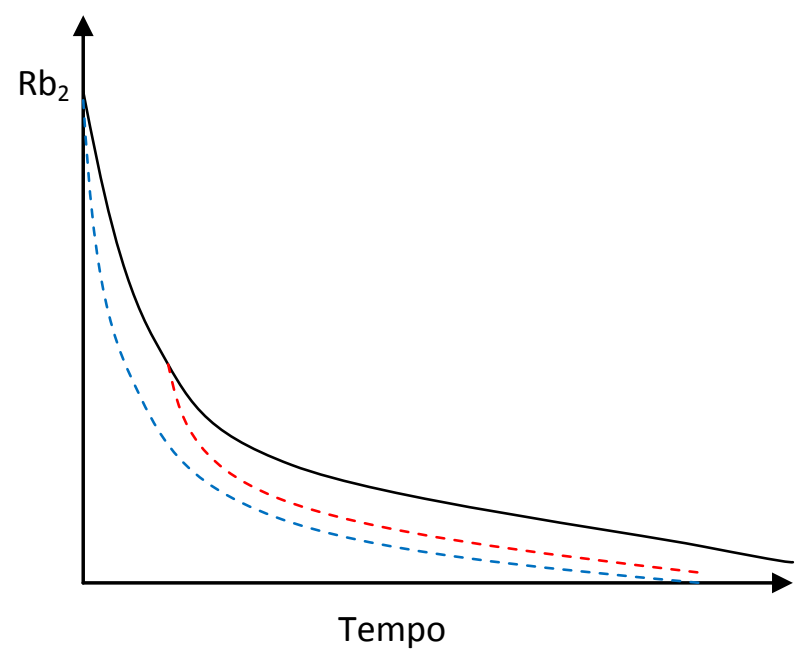

Figura 5.3 - a) Esquema do experimento. b) Demonstração da técnica, as curvas de tempo de vida da armadilha medidas a partir de 400 a 1600 ms complementam perfeitamente a curva medida no instante 0 . Assim, mostramos que a fração de íons produzida pelo laser pulsado é desprezível não prejudicando a medida como um todo. c) Neste gráfico ilustrativo, a curva preta representa o decaimento real das moléculas, as curvas azul e vermelha representam o decaimento caso o laser pulsado perturbasse a medida. 
O objetivo deste experimento é verificar se o laser pulsado está interferindo na população de moléculas aprisionadas. Pois caso ele interferisse, criaria um canal de perdas de moléculas e o decaimento seria rápido na sua presença. Em caso afirmativo, teríamos que o primeiro ponto da medida iniciada em 400 ms estaria em uma valor maior do que o ponto medido à $\mathrm{t}=400 \mathrm{~ms}$ para a medida iniciada em $\mathrm{t}=0 \mathrm{~s}$ e assim sucessivamente. $\mathrm{O}$ mesmo aconteceria com as demais medidas realizadas em outros tempos. Esta situação pode ser ilustrada na figura 5.3c. Mas isso não acontece no resultado experimental da figura 5.3.b, onde cada curva complementa a curva medida no instante inicial.

Este resultado nos permite concluir que mesmo a ionização sendo um processo destrutivo, a ionização da amostra por pulso é tão pequena, que não influencia o decaimento da amostra como um todo. Esta técnica poderá ser aplicada em outros sistemas, mas para isso precisaremos considerar o produto da ionização por pulso pelo número de pulsos usados e compará-lo com o decaimento devido colisão com gás de fundo. Se o produto for pequeno comparado às colisões com gás de fundo, a técnica poderá ser utilizada.

Para investigar o efeito da energia do pulso do laser na população de moléculas $R b_{2}$, nós medimos a curva de decaimento das moléculas para diferentes energias do pulso de ionização iniciando a medida no instante $\tau=0 \mathrm{~s}$, figura 5.4a. Nós variamos a energia do pulso em um intervalo onde o sinal de $\mathrm{Rb}_{2}{ }^{+}$é proporcional ao quadrado de tal parâmetro (100), nós também verificamos esta dependência em nosso sistema. Cada curva na figura 5.4a é uma média de 10 curvas, e os dados foram normalizados para comparação. Desta figura, podemos concluir que: i) A razão sinal/ruído melhora conforme a energia do pulso aumenta, com esperado; ii) A evolução da população de $\mathrm{Rb}_{2}$ é basicamente a mesma para as energias de 0,5, 0,7 e 0,9 mJ/pulso. Em outras palavras, a perda por ionização pode ser desprezada para essas condições.

Notamos também, que a curva de decaimento da população de $\mathrm{Rb}_{2}$ para 0,9 $\mathrm{mJ} /$ pulso, pode ser ajustada com um simples decaimento exponencial $N_{1}(t)=N_{0} e^{-t / \tau_{c}}$, em que $\mathrm{N}_{0}$ é a população inicial de $\mathrm{Rb}_{2}$ e $\tau_{c}$ é a constante de decaimento. Acreditamos que $\tau_{c}$ ( $^{2}$ $500 \mathrm{~ms}$ ), para 0,9 mJ/pulso, é devido apenas à colisões com o gás de fundo ou colisões com átomos/moléculas aprisionadas. Porém, a curva obtida com a energia de 1,7 mJ/pulso não 
pôde ser ajustada por um simples decaimento exponencial, como mostrado da figura 5.4b. Combinando estes resultados somos capazes de estimar a eficiência de ionização por pulso. Consideraremos que cada pulso ioniza uma fração $\mathbf{s}$ da população de moléculas $\mathrm{Rb}_{2}$, assim após n pulsos a população, para 1,7 mJ/pulso, pode ser escrita como $N_{2}(t)=N_{0} e^{-t / \tau}(1-$ $s)^{n}$. Além do mais, além das perdas por colisões, perdas devido à fotoassociação também estarão presentes. Se calcularmos a razão entre essas duas populações em um instante $t=n \Delta t$ (em que $\Delta t$ é o intervalo entre os pulsos), nós termos $N_{2}(n \Delta t) / N_{1}(n \Delta t)=$ $(1-s)^{n}$. Para $\mathrm{t}=1,5 \mathrm{~s}(\mathrm{n}=30$ e $\Delta t=50 \mathrm{~ms}$ na figura $5.4 \mathrm{a})$, a população de $\mathrm{Rb}_{2}$ para 0,9 $\mathrm{mJ} /$ pulso é aproximadamente 2,5 vezes maior que a população de $\mathrm{Rb}_{2}$ para $1,7 \mathrm{~mJ} / \mathrm{pulso}$, o qual resulta em $\mathrm{s}=0,03$ por pulso. Por comparação, em $50 \mathrm{~ms}$ (tempo de intervalo entre os pulsos) as perdas devido a colisões são aproximadamente $10 \%$ da população, muito maior que a perda devido a fotoinização por pulso (3\%).

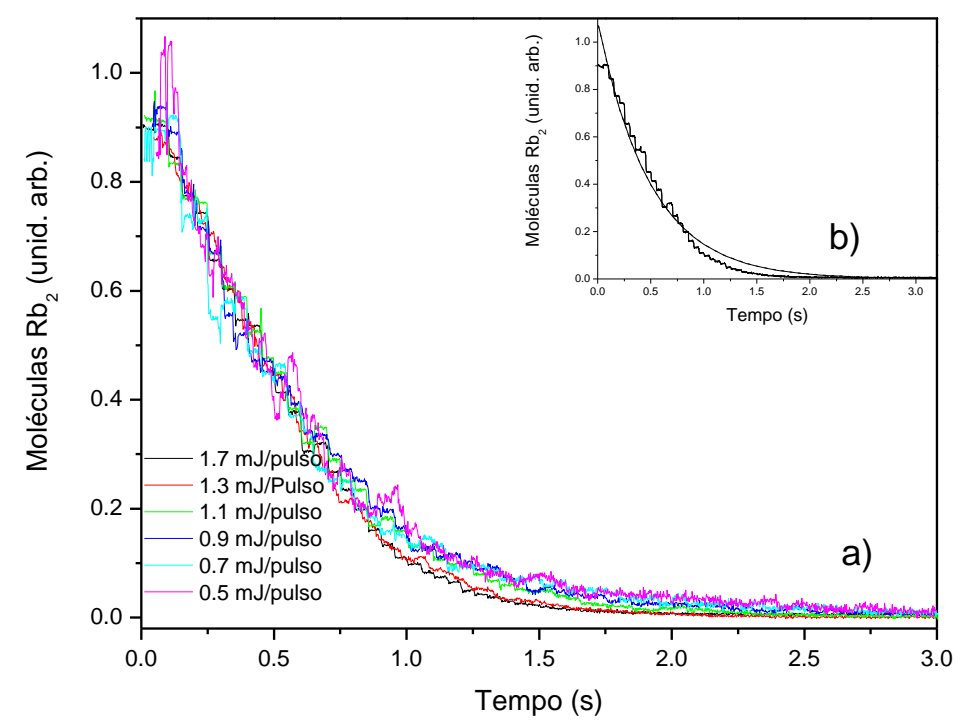

Figura 5.4 - a) Gráfico do tempo de vida das moléculas para vários valores de energia/pulso do laser pulsado. Observamos curvas de 0,5 a 1,7 mJ/pulso as quais estão no limite inferior $e$ superior e de operação do laser. Conforme a potência de operação é aumentada a medida sofre uma perturbação, no tempo 1,5 s a medida com baixa potência acusa um número de 2,5 vezes maior que o medido com alta potência. b) Decaimento exponencial da população de moléculas da amostra para 1,7 mJ/pulso. 
O sinal de íons molecular observado na armadilha de dipolo para uma energia de 1,7 $\mathrm{mJ} /$ pulso do laser pulsado é tipicamente da ordem de 100 íons/pulso para o primeiro pulso. Este valor é obtido relacionando o sinal de íons molecular observado com as características de tempo e amplitude de resposta de nosso detector de íons (channeltron). Considerando que a eficiência do detector é de $70 \%$, a taxa de coleta de íons de $95 \%$, e a eficiência de ionização do processo é de $3 \%$, nós obtemos que o valor inicial da população de moléculas na armadilha de dipolo é aproximadamente $5 \times 10^{3}$. Este valor está consistente com o número de moléculas produzidas devido à fotoassociação durante a fase de carregamento da armadilha de dipolo (100).

Em futuros experimentos teremos uma amostra mista aprisionada de átomos e moléculas, assim é fundamental saber se a técnica de trem de pulso interfere na população atômica. Para investigar este aspecto, medimos a evolução temporal da população de átomos via imagem de absorção com e sem a presença do laser pulsado. Na figura 5.5, mostramos a evolução temporal da população atômica nas duas situações. Para comparação também mostramos a população molecular. Não temos nenhuma evidência que o trem de pulsos perturba a população atômica.

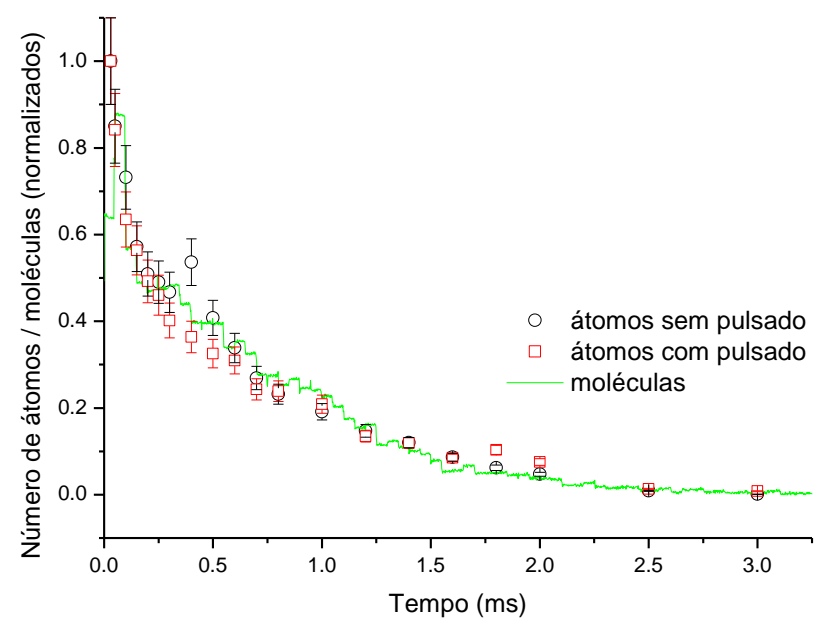

Figura 5.5 - Gráfico do tempo de vida de moléculas e átomos de ${ }^{85} \mathrm{Rb}$ na armadilha de dipolo. A linha verde (- ) corresponde à medida do número de moléculas, as bolas pretas (0) ao número de átomos e os quadrados vermelhos ( $\square$ ) ao número de átomos na presença do laser pulsado. Vemos que os três resultados são idênticos mostrando que o laser pulsado não interfere no tempo de vida dos átomos na armadilha. 


\subsection{Temperatura da amostra molecular usando a técnica de trem de pulsos}

Até aqui demonstramos o aprisionamento de moléculas na armadilha de dipolo óptica e o desenvolvimento de uma nova técnica de estudo. Nesta seção caracterizamos a amostra molecular aprisionada medindo sua temperatura. Para tal, aprisionamos a amostra por 50 ms, em seguida a armadilha era desligada e a amostra sofria uma expansão balística. Assim que a amostra era carregada na armadilha o trem de pulsos recebia o sinal para ser liberado. Como os pulsos são separados por $50 \mathrm{~ms}$ e o feixe é liberado a partir de um bloqueador mecânico, apenas um pulso consegue provar a fase de expansão da amostra, pois esta possui um tempo menor que $50 \mathrm{~ms}$. 0 instante que este pulso atinge a amostra é aleatório, e desta forma não temos controle, pois o laser fica constantemente ligado. Este problema é devido uma limitação técnica do laser. Assim esse tipo de medida torna-se trabalhosa sendo necessárias várias tentativas para acertar o ponto desejado e medir uma boa curva de expansão.

Com esta técnica, fomos capazes de medir o número de moléculas remanescentes na região de ionização após a expansão, como mostrado na figura 5.6. Este decaimento pode ser ajustado por um modelo teórico (104) que considera uma distribuição de MaxwellBoltzman de velocidades e uma distribuição gaussiana espacial de densidade, permitindonos calcular a temperatura translacional das moléculas $\mathrm{Rb}_{2}$ :

$$
C(t)=C(0) \frac{\tau_{r}^{2}}{\tau_{r}^{2}+t^{2}} \exp \left[\frac{-t^{2}}{\tau_{g}^{2}\left(\tau_{r}^{2}+t^{2}\right)}\right]
$$

em que $C$ é o número de partículas, $\tau_{r}=w / v, w$ é o raio da amostra e $v$ a velocidade da molécula relacionado com a temperatura por $T=m \bar{v}^{2} / 3 k_{B}$ e $\tau_{g}=2 \sqrt{2} v / g, g$ é a aceleração da gravidade. Na figura 5.6, os pontos pretos são os dados experimentais, as 
curvas são simulações da expressão 5.1. O resultado mostra que a temperatura das moléculas na armadilha é de $(30 \pm 6) \mu \mathrm{K}$.

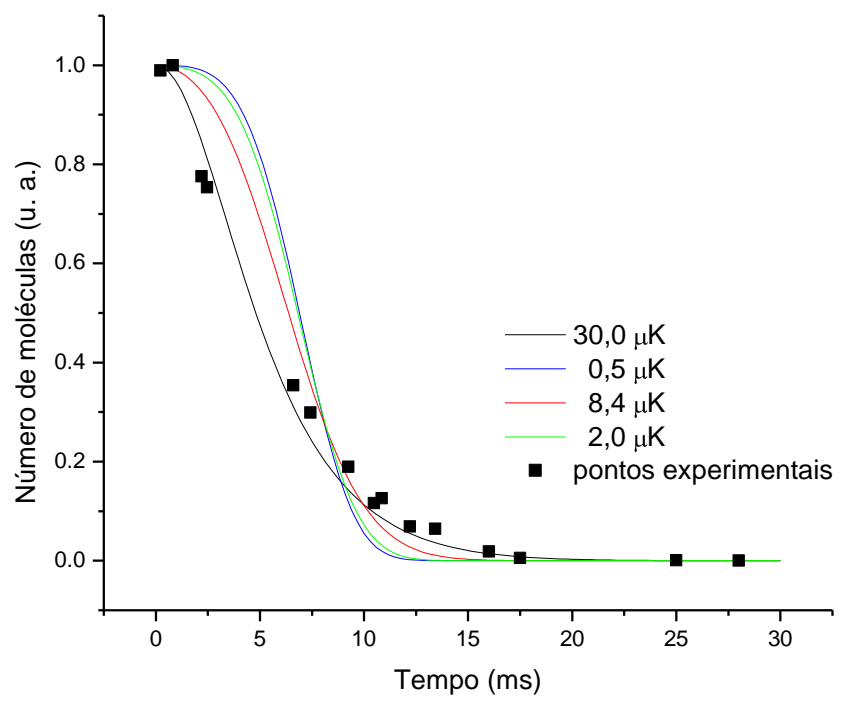

Figura 5.6 - Medida da temperatura das moléculas na armadilha de dipolo. As moléculas são carregadas e aprisionadas por 50 ms na armadilha, na seqüência a amostra sofre uma expansão livre e o laser pulsado prova o número de moléculas remanescentes em função do tempo da expansão.

Recentemente publicamos um artigo (101) e nele medimos a temperatura de moléculas $\mathrm{Rb}_{2}$ em função da temperatura dos átomos em um MOT, a menor temperatura medida para essas moléculas foi de $40 \mu K$, portanto nossos resultados para a armadilha de dipolo estão condizentes com este trabalho. 


\subsection{Moléculas aprisionadas em uma armadilha de dipolo.}

Visto que dominamos o aprisionamento e detecção de moléculas em uma armadilha de dipolo, passamos a estudar sua evolução temporal em mais detalhes. Como foi mencionado anteriormente, as moléculas eram aprisionadas junto com os átomos. Seria interessante ter apenas as moléculas aprisionadas, contudo todas nossas tentativas de remover os átomos da armadilha foram frustradas. Estas tentativas foram realizadas introduzindo um feixe ressonante com os átomos sobre a amostra, eventualmente a pressão de radiação removeria os átomos da amostra. Mas isso acabou por afetar a amostra molecular também, acreditamos que isso ocorreu porque as moléculas estão nos últimos estados vibracionais excitados dos potenciais, e assim também podem absorver luz ressonante com a amostra atômica. Assim decidimos estudar a evolução temporal da amostra molecular na presença de átomos em diferentes estados fundamentais hiperfinos. Para realizar o estudo com átomos no estado fundamental hiperfino inferior, não precisamos fazer nada, pois eles já se encontram a priori neste estado. Para obtermos átomos no estado hiperfino superior acrescentamos uma fase de bombeamento, na qual os átomos são bombeados durante $300 \mu$ s para hiperfino superior $\mathrm{F}$ do estado fundamental, o qual pode ser $5 S_{1 / 2}(F=2)$ para o ${ }^{87} \mathrm{Rb}$ e $5 S_{1 / 2}(F=3)$ para o ${ }^{85} \mathrm{Rb}$.

Na figura 5.7a temos o resultado mais geral desse experimento, as linhas preta e vermelha representam o decaimento da população de moléculas ${ }^{85} \mathrm{Rb}_{2}$ na presença de átomos de ${ }^{85} \mathrm{Rb}$ nos estados hiperfinos $\mathrm{F}=1$ e $\mathrm{F}=2$ respectivamente, as linhas azul e verde representam o decaimento da população de moléculas ${ }^{87} \mathrm{Rb}_{2}$ na presença de átomos de ${ }^{87} \mathrm{Rb}$ nos estados hiperfinos $F=2$ e $F=3$ respectivamente. Na figura $5.7 \mathrm{~b}$ temos o mesmo resultado, mas com as curvas normalizadas pelo número de moléculas inicial. 
a)

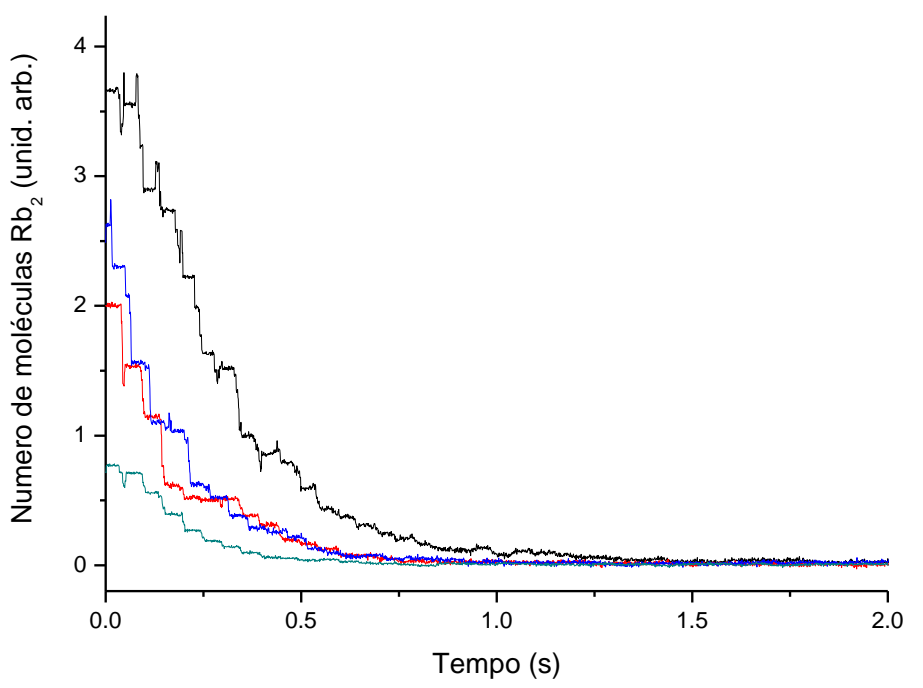

b)

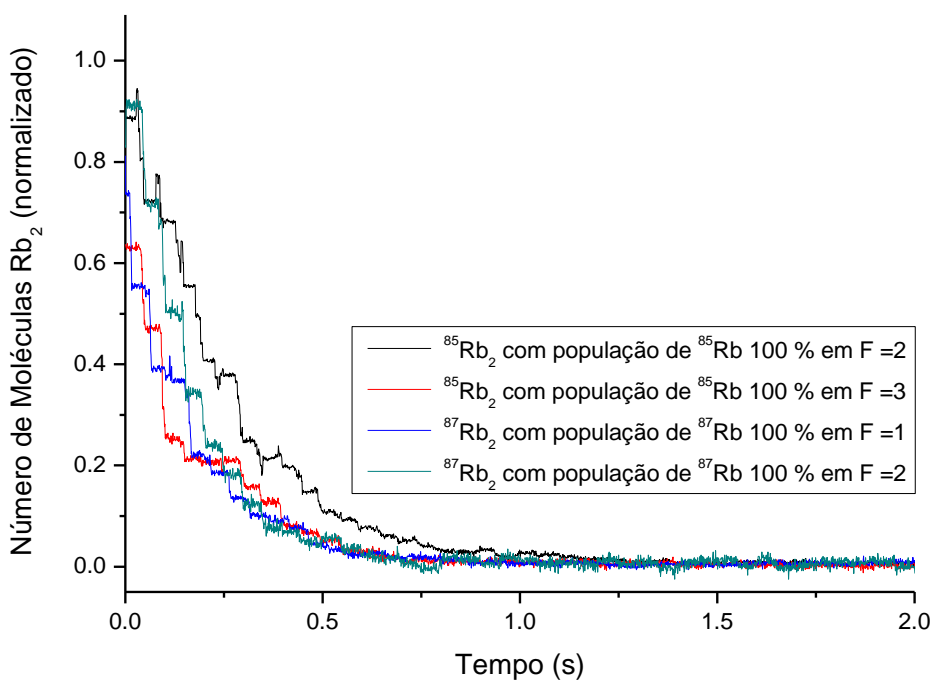

Figura 5.7 - a) Tempo de vida da armadilha de dipolo para as duas espécies moleculares ${ }^{85} R b_{2} e^{87} R b_{2}$. O decaimento da população de moléculas é estudado para duas condições: moléculas com átomos no estado fundamental hiperfino inferior ( $F=1$ e $F=2)$, e moléculas com átomos no estado fundamental hiperfino superior $(F=2$ e $F=3)$. b) Neste temos a mesma medida, porém com o número de moléculas normalizado.

Trabalhos recentes observaram colisões átomo-molécula em uma mistura aprisionada em uma armadilha de dipolo (65). A princípio, a evolução temporal das moléculas aprisionadas deve ser descrita pela seguinte equação de taxa: 


$$
\begin{array}{r}
\frac{d n_{R b_{2}}}{d t}=-\Gamma n_{R b_{2}} \\
\Gamma=\left(\Gamma_{R b_{2}}-\beta \mathrm{n}_{\mathrm{Rb}}(\mathbf{r}, \mathrm{t})\right)
\end{array}
$$

Em que $\Gamma_{R b_{2}}$ é a taxa de perda devido a colisões com o gás de fundo; $\beta$ é a taxa de perda devido a colisões entre átomos e moléculas; $\mathrm{n}_{\mathrm{Rb}}(\mathrm{r}, \mathrm{t})$ é a densidade atômica, e $\mathrm{n}_{\mathrm{Rb} 2}$ é a densidade molecular. Acreditamos que devido à baixa densidade de moléculas em nossa armadilha, a taxa de perda devido a colisões molécula-molécula pode ser desprezada. Além do mais, foi verificado que as curvas de decaimento da população de moléculas, obtidas a $0,9 \mathrm{~mJ} /$ pulso, podem ser ajustadas com uma simples exponencial, figura 5.8

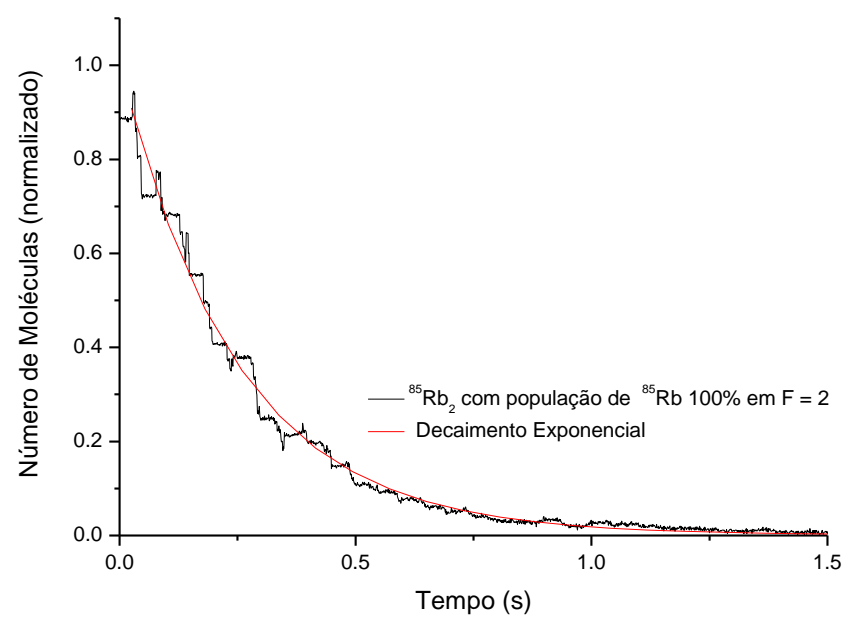

Figura 5.8 - Decaimento da população molecular ${ }^{85} \mathrm{Rb}_{2}$ na armadilha de dipolo. A linha vermelha representa o ajuste exponencial

A princípio o decaimento deve depender da densidade atômica, caso haja colisões entre átomos e moléculas. Para verificar isso, medimos o decaimento das moléculas em função da densidade atômica como mostrado na figura 5.9. Os quadrados vermelhos ( $\square$ ) e as bolas pretas (•) representam a taxa de perda medida para moléculas de ${ }^{87} \mathrm{Rb}_{2}$ e ${ }^{85} \mathrm{Rb}_{2}$ 
respectivamente em amostras com átomos nos seu estados fundamentais hiperfinos inferiores. Nesta medida a densidade atômica é de aproximadamente $3 \times 10^{12} \mathrm{~cm}^{-3}$ e a taxa de perda $\Gamma$, permaneceu constante mostrando que colisões entre átomos e moléculas frias não estão presentes no experimento. Entretanto, há uma diferença nesta medida entre os dois isótopos, a taxa de perda $\Gamma$ medida para $0{ }^{85} \mathrm{Rb}_{2}$ é 2,5 vezes menor que a taxa medida para $0{ }^{87} \mathrm{Rb}_{2}$. Este é um resultado inesperado, porém, já foi demonstrado teoricamente que existem diferenças entre os potenciais moleculares eletrônicos entre os dois isótopos (105) e diferenças nos espectros de fotoassociação também já foram observadas (106). Além do mais, não seria surpreendente que um isótopo poderia formar moléculas em níveis vibracionais mais elevados que o outro. Tais níveis vibracionais elevados poderiam resultar em uma seção de choque geométrica maior para colisões elásticas ou uma energia de ligação menor, a qual favoreceria a dissociação molecular. Nos dois casos, elevados níveis vibracionais deveriam apresentar maiores taxas de perda devido às colisões com o gás de fundo. Este efeito já foi observado em moléculas de $\mathrm{Cs}_{2}$ (65), onde um fator de 2 foi medido entre a taxa de perda entre níveis vibracionais altos e baixos do estado fundamental tripleto. Como a fotoassociação, por luz ressonante, não é fácil de modelar teoricamente, nós não podemos ter certeza de qual é o isótopo que formará moléculas com níveis vibracionais mais altos. Assim não podemos comparar nosso resultado com nenhuma teoria, mas esse não é o objetivo deste trabalho. Outra observação interessante é que $\Gamma_{R b_{2}}$ para o isótopo ${ }^{85} \mathrm{Rb}_{2}$ é aproximadamente 4 vezes maior que a perda por colisões de gás de fundo para $0{ }^{85} \mathrm{Rb}$ na armadilha de dipolo, o qual também está de acordo com as observações recentes em Cs (107). 


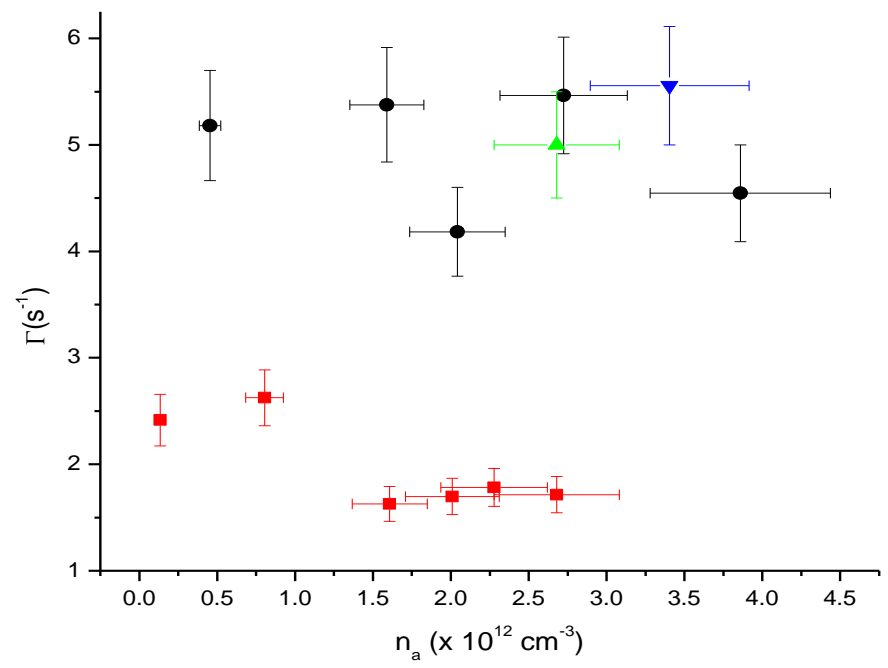

Figura 5.9 - Gráfico da taxa de perda Bda armadilha em função da densidade dos átomos. ${ }^{87} R b_{2}$ com população de ${ }^{87} \mathrm{Rb} 100 \%$ em $\mathrm{F}=1(\bullet) .{ }^{85} \mathrm{Rb}$. com população de ${ }^{85} \mathrm{Rb} 100 \%$ em $\mathrm{F}=2$ (घ). ${ }^{85} R b_{2}$ com população de ${ }^{85} R b 100 \%$ em $F=3(\triangle) .{ }^{87} R b_{2}$ com população de ${ }^{87} R b 100 \%$ em $F=2(\nabla)$.

Para os estados hiperfinos superiores, não conseguimos medir em função da densidade atômica porque o sinal molecular diminui consideravelmente. Isto pode ser porque a fase de bombeamento talvez destrua as moléculas como foi observado na referência (108). De qualquer forma, observamos que $\Gamma$ aumenta para ${ }^{85} \mathrm{Rb}(\mathrm{F}=3)$ e se mantêm inalterado para ${ }^{87} \mathrm{Rb}(F=2)$. Como $\Gamma$ não depende da densidade atômica podemos afirmar com certeza que colisões com mudança de estrutura hiperfina entre átomos e moléculas é pouco provável que ocorra na amostra. Uma explicação mais plausível seria que no caso de ${ }^{85} \mathrm{Rb}(\mathrm{F}=3)$ a fase de bombeamento transfere as moléculas de um estados vibracional mais ligado para um menos ligado, e conseqüentemente, a perda por colisões com átomos quentes aumentam. No caso do ${ }^{87} \mathrm{Rb}(\mathrm{F}=2)$, o bombeamento talvez não faça efeito porque a molécula já está em um nível vibracional alto. De qualquer forma, estas são possíveis explicações, visto que comparação com teoria não é possível. 



\section{Conclusões e perspectivas}

Nosso trabalho demonstrou importantes avanços para o estudo de moléculas ultrafrias aprisionadas. Primeiramente elaboramos uma revisão da literatura explorando os fundamentos básicos da teoria diatômica, e descrevemos os mais recentes e importantes trabalhos a respeito da produção e aprisionamento de moléculas homo e heteronucleares no estado eletrônico e vibracional fundamental. Comparando os experimentos com moléculas realizados no estado ${ }^{1} \Sigma^{+}(v=0)$ e o fato de termos um laser banda larga (por razões econômicas) nos inspiraram a desenvolver teoricamente um modelo para fotoassociação, resfriamento vibracional e aprisionamento de moléculas no estados vibracionais mais baixos do estado fundamental eletrônico. Esta é uma idéia concebida por nós e inédita, que a princípio poderia ser publicada como proposta teórica, mas decidimos esperar pelos resultados experimentais para que o trabalho tenha um impacto maior. Visto que esta técnica promete em simplificar o processo quando comparada com as demais (5558).

Na montagem experimental, a qual é bem complexa, projetamos e construímos um novo sistema experimental adaptado para nossos experimentos. Este novo experimento baseou-se em uma armadilha de dipolo totalmente óptica, formada por um laser de fibra com $40 \mathrm{~W}$ de potência com comprimento de onda em 1064 nm, capaz de aprisionar tanto átomos como moléculas. Para que isso fosse possível, construímos um sistema de vácuo para desacelerar e aprisionar as duas espécies Rb e K. Este sistema foi baseado no sistema do Prof. Ketterle (74) e foi construído em três partes: o forno misto; o desacelerador misto (Zeeman slower), e a câmara de aprisionamento. Neste novo sistema, pudemos demonstrar o aprisionamento simultâneo de $\mathrm{Rb}$ e $\mathrm{K}$ em um $\mathrm{MOT}$, e o aprisionamento de $\mathrm{K}, \mathrm{Rb}$ e $\mathrm{Rb}_{2}$ na armadilha de dipolo. É importante salientar que esta etapa foi a mais trabalhosa e a que exigiu um período muito longo. Contudo, mesmo que este trabalho não venha a ser publicado em um artigo, o conhecimento gerado nesta montagem está conosco pelos anos a vir. E com certeza terá impacto em futuras gerações de alunos, na sua formação e no 
laboratório. Além do mais, hoje dispomos de um robusto e excelente sistema de aprisionamento, via armadilha de dipolo óptica, e detecção de átomos e moléculas que, na atual situação, possui condições de produzir resultados inéditos para os próximos anos, estando num patamar equivalente a experimentos em outros laboratórios no mundo.

Com relação aos experimentos realizados, pudemos demonstrar o aprisionamento e a caracterização das amostras dos isótopos ${ }^{85} \mathrm{Rb}$ e ${ }^{87} \mathrm{Rb}$. Primeiramente realizamos experimentos que se basearam no carregamento de dos dois isótopos do $\mathrm{Rb}$ na armadilha nos níveis superiores do estado hiperfino fundamental, os quais foram $5 \mathrm{~S}_{1 / 2}(\mathrm{~F}=2)$ para 0 ${ }^{87} \mathrm{Rb}$ e $5 \mathrm{~S}_{1 / 2}(\mathrm{~F}=3)$ para o ${ }^{85} \mathrm{Rb}$. Neste, através das curvas de decaimento da população de átomos, medimos pela primeira vez o processo de mudança de estrutura hiperfina em átomos sem a presença de luz ressonante. Os resultados medidos estão de acordo com as teorias apresentadas na literatura.

Nos experimentos realizados com aprisionamento de átomos no nível hiperfino inferior $\left(5 S_{1 / 2}(F=1)\right.$ para o ${ }^{87} \mathrm{Rb}$ e $5 S_{1 / 2}(F=2)$ para o $\left.{ }^{85} \mathrm{Rb}\right)$, observamos um decaimento não exponencial, e a taxa de perda por dois corpos $\beta$ deveria ser nula. Para explicar esse fenômeno, dois mecanismos de perda foram incorporados à dinâmica da população de átomos na armadilha, são eles: o termo de perda por três corpos e o termo de perda pelo processo evaporativo. Fomos incapazes de explicar tais dados por estes processos. Assim, só nos sobrou relacionar o decaimento à fotoassociação os átomos pelo laser em $1064 \mathrm{~nm}$ da armadilha de dipolo, embora a existência das moléculas ainda precisa ser verificada. Estes resultados serão submetidos à publicação em breve.

Recentemente foi publicado um trabalho por D. Sofikitis e colaboradores (109) em que estudaram a dinâmica de átomos de Cs em uma armadilha de dipolo com laser de fibra em $1070 \mathrm{~nm}$ e potência máxima de $100 \mathrm{~W}$. Neste trabalho, os autores estudaram a dinâmica de carregamento da armadilha através de diferentes reservatórios como: armadilha magnética, Dark-SPOT MOT e um C-MOT. Em todos os casos o número de átomos decaía rapidamente depois da fase de carregamento. Este decaimento era até esperado no caso do carregamento por C-MOT, mas o carregamento via armadilha magnética ou mesmo DarkSPOT não pôde ser explicado pela equação de taxa elaborada, a qual possuía como termo de decaimento, apenas um termo linear $(-\gamma N)$. Assim, concluíram que para uma explicação 
mais elaborada, devem adicionar novos fenômenos em seu modelo teórico, tais como: o aquecimento da amostra, que em fato não foi medido; o efeito de perda por três corpos; e excitação de átomos pelo laser da armadilha. É importante ressaltar que estes fenômenos apenas foram citados como possíveis explicações e não foram incorporados em seu modelo para comparação.

Nos experimentos envolvendo o aprisionamento de moléculas, primeiramente pudemos demonstrar o seu respectivo aprisionamento na armadilha de dipolo cruzada, e desenvolvemos e caracterizamos uma técnica de trem de pulsos para a observação de $R b_{2}$ na armadilha de dipolo. Esta técnica nos permite obter uma taxa de aquisição de dados mais rápida que técnicas destrutivas utilizadas até o momento. Além do mais, esta técnica nos permite medir uma eficiência de fotoionização mais confiável e também a temperatura translacional molecular.

Com esta técnica, medimos também a evolução temporal da população molecular aprisionada. Neste experimento produzimos uma amostra mista de átomos e moléculas e observamos o comportamento dessas moléculas na presença de átomos preparados em um determinado estado hiperfino do estado fundamental. Devido ao fato de que as curvas de decaimento podem ser ajustadas por uma exponencial, e o tempo de decaimento não depende da densidade atômica, concluímos que podemos desprezar colisões moléculamolécula e átomo-molécula em nossa armadilha.

Outro fato interessante, é que existem diferenças na taxa de perda $\Gamma$ medida para o ${ }^{85} \mathrm{Rb}_{2}$ e a taxa medida para $0{ }^{87} \mathrm{Rb}_{2}$ para o caso em que moléculas são carregadas com átomos no estado hiperfino inferior. Isto foi justificado pelas diferenças entre os potenciais moleculares eletrônicos entre os dois isótopos, assim no processo de fotoassociação, podemos produzir moléculas em níveis vibracionais mais elevados para um isótopo do que para o outro. Tais níveis vibracionais elevados poderiam resultar em uma seção de choque geométrica maior para colisões elásticas ou uma energia de ligação menor, a qual favoreceria a dissociação molecular. Nos dois casos, elevados níveis vibracionais deveriam apresentar maiores taxas de perda devido às colisões com o gás de fundo.

Nos experimentos em que moléculas são carregadas com átomos no estado hiperfino superior, não conseguimos medir a taxa de perda em função da densidade. Neste caso, duas 
características são apontadas: primeiramente, o sinal de moléculas medido é bem menor, isto é explicado pelo fato de que moléculas podem estar sendo destruídas da fase de carregamento; segundo, é que e a taxa de perda $\Gamma$ aumenta para $0{ }^{85} \mathrm{Rb}(\mathrm{F}=3)$ e se mantêm inalterado para ${ }^{87} \mathrm{Rb}(\mathrm{F}=2)$, a justificativa para isso é que a fase de bombeamento esteja transferindo as moléculas de ${ }^{85} \mathrm{Rb}(\mathrm{F}=3)$ de estados vibracional mais ligados para estados menos ligados, e conseqüentemente, a perda por colisões com átomos quentes aumenta. É importante ressaltar que essas explicações ainda não podem ser comparadas a nenhuma teoria.

Concluindo, conseguimos produzir amostras de átomos de $\mathrm{Rb}$ em uma armadilha de dipolo, com aproximadamente $2 \times 10^{6}$ átomos aprisionados, densidades da ordem de $10^{12}$ $\mathrm{cm}^{-3}$ e temperaturas da ordem $10 \mu \mathrm{K}$. Nossos resultados em Rb, estudando a evolução temporal da população de átomos aprisionados, mostram que a fotoassociação ocorre naturalmente em tais armadilhas. Assim nossas perspectivas para futuros trabalhos é a investigação em mais detalhes da fotoassociação de tais moléculas inclusive envolvendo átomos de $\mathrm{Rb}$ e $\mathrm{K}$ em uma armadilha óptica de dipolo em $1064 \mathrm{~nm}$, para produção de moléculas de $\mathrm{KRb}$. Como estudado no capítulo 2, acreditamos que as moléculas de $\mathrm{KRb}$ serão bombeadas oticamente para estados vibracionais baixos pelo laser em $1064 \mathrm{~nm}$ e na seqüência, técnicas diferentes, como por exemplo, a técnica utilizada para resfriamento de $\mathrm{Cs}_{2}$ (55) com laser de fentosegundo, poderão ser empregadas para produzir moléculas no estado vibracional fundamental $(v=0)$ do potencial eletrônico fundamental $\left({ }^{1} \Sigma^{+}\right)$. Para esse experimento, já possuímos um laser de fibra (FemtoFiber pro NIR - Toptica) que foi comprado com recursos do Instituto Nacional de Ciência e Tecnologia em Informação Quântica coordenado pelo Prof. Amir Caldeira da Unicamp. Para utilização desta técnica de bombeamento poderemos acoplar os níveis vibracionais do estado fundamental os estados vibracionais das curvas de potencial ${ }^{3} \Pi,{ }^{1} \Sigma,{ }^{3} \Sigma,{ }^{1} \Pi$, da molécula de KRb. Para a detecção das moléculas no estado fundamental, poderemos realizar a fotoionização das moléculas por dois fótons e detectaremos tais estados em função do comprimento de onda utilizado. Para isso poderemos utilizar a técnica de trem de pulso, desenvolvida nesse trabalho, para monitorar a evolução temporal das moléculas na armadilha. Finalizando, construímos uma armadilha e desenvolvemos uma técnica que poderá ser uma implementação direta para o 
estudo e a produção de uma amostra pura de moléculas homo e heteronucleares no estado eletrônico e vibracional fundamental. 



\section{Referências}

1 EISTEIN, A. On the quantum theory of radiation. Physika Zeitschrift, v. 18, p. 121-128, 1917.

2 PHILLIPS, W.D. Nobel Lecture: Laser cooling and trapping of neutral atoms. Reviews of Modern Physics, v. 70, n. 3, p. 721, 1998.

$3 \mathrm{CHU}$, S.; BJORKHOLM, J.E.; ASHKIN, A.; CABLE, A. Experimental observation of optically trapped atoms. Physical Review Letters, v. 57, n. 3, p. 314, 1986.

4 RAAB, E.L.; PRENTISS, M.; CABLE, A.; CHU, S.; PRITCHARD, D.E. Trapping of neutral sodium atoms with radiation pressure. Physical Review Letters, v. 59, n. 23, p. 2631, 1987.

5 WEINER, J.; BAGNATO, V.S.; ZILIO, S.; JULIENNE, P.S. Experiments and theory in cold and ultracold collisions. Reviews of Modern Physics, v. 71, n. 1, p. 1, 1999.

6 METCALF H. J.; STRATEN, P.V.D. Laser cooling and trapping. Berlin:Springer. 1999.

7 WEYERS, R.W.A.S. Atomic fountain clocks. Metrologia v. 42, n. S64, 2005.

8 GILL, P. Optical frequency standards Metrologia, v. 42, n. S125, p. 3, 2005.

9 ANDERSON, M. H.; ENSHER, J.R.; MATTHEWS, M. R.; WIEMAN, C. E.; CORNELL, E. A. Observation of Bose-Einstein condensation in a dilute atomic vapor. Science, v. 269, n. 5221 p. 198-201, 1995.

10 DAVIS, K.B.; MEWES, M.O.; ANDREWS, M.R.; VAN DRUTEN, N.J.; DURFEE, D.S.; KURN, D.M.; KETTERLE, W. Bose-Einstein condensation in a gas of sodium atoms. Physical Review Letters, v. 75, n. 22, p. 3969, 1995.

11 BRADLEY, C.C.; SACKETT, C.A.; TOLLETT, J.J.; HULET, R.G. Evidence of Bose-Einstein condensation in an atomic gas with attractive interactions. Physical Review Letters, v. 75, $\mathrm{n}$. 9, p. 1687, 1995. 
12 BRADLEY, C.C.; SACKETT, C.A.; HULET, R.G. Bose-Einstein condensation of Lithium: observation of limited condensate number. Physical Review Letters, v. 78, n. 6, p. 985, 1997.

13 FIORETTI, A.; COMPARAT, D.; CRUBELLIER, A.; DULIEU, O.; MASNOU-SEEUWS, F.; PILLET, P. Formation of cold $\mathrm{Cs}_{2}$ molecules through photoassociation. Physical Review Letters, v. 80, n. 20, p. 4402, 1998.

14 GABBANINI, C.; FIORETTI, A.; LUCCHESINI, A.; GOZZINI, S.; MAZZONI, M. Cold Rubidium molecules formed in a magneto-optical trap. Physical Review Letters, v. 84, n. 13, p. 2814, 2000.

15 BAHNS, J.T.; GOULD, P.L.; STWALLEY, W.C. Formation of cold ( $T \leq 1 \mathrm{~K}$ ) molecules. Advances In Atomic, Molecular, and Optical Physics, v. 42, n. 5, p. 171-224, 2000.

16 DEMILLE, D. Quantum computation with trapped polar molecules. Physical Review Letters, v. 88, n. 6, p. 067901, 2002.

17 BARENCO, A.; DEUTSCH, D.; EKERT, A.; JOZSA, R. Conditional quantum dynamics and logic gates. Physical Review Letters, v. 74, n. 20, p. 4083, 1995.

18 BRENNEN, G.K.; CAVES, C.M.; JESSEN, P.S.; DEUTSCH, I.H. Quantum logic gates in optical lattices. Physical Review Letters, v. 82, n. 5, p. 1060, 1999.

19 PLATZMAN, P. M.; DYKMAN, M. I. Quantum computing with electrons floating on liquid helium. Science, v. 284, p. 1967-1969, 1999.

20 IGEL-MANN, G.; WEDIG., U.; FUENTEALBA, P.; STOLL, D. H. Ground-state properties of alkali dimers $X Y$ (X, Y=Li to Cs). The Journal of Chemical Physics, v. 84, n. 9, p. 5007, 1986.

21 LO, H.K.S.P.; SPILLER T. Introduction to quantum computation and information. Singapore: World Scientific, 1998.

22 TSCHERBUL, T.V.; KREMS, R.V. Controlling electronic spin relaxation of cold molecules with electric fields. Physical Review Letters, v. 97, n. 8, p. 083201, 2006.

23 ZELEVINSKY, T.; KOTOCHIGOVA, S.; YE, J. Precision test of mass-ratio variations with lattice-confined ultracold molecules. Physical Review Letters, v. 100, n. 4, p. 043201, 2008. 
24 HUNTER, L.R.; MAXWELL, S.E.; ULMER, K.A.; CHARNEY, N.D.; PECK, S.K.; KRAUSE, D.; TERAVETISYAN, S.; DEMILLE, D. Detailed spectroscopy of the $a(1)\left[{ }^{3} \Sigma^{+}\right]$state of PbO. Physical Review A, v. 65, n. 3, p. 030501, 2002.

25 WEINSTEIN, J. D.; DECARVALHO, R.; AMAR, K.; BOCA, A.; ODOM, B. C.; FRIEDRICH, B.; DOYLE, J. M. Spectroscopy of buffer-gas cooled vanadium monoxide in a magnetic trapping field. The Journal of Chemical Physics, v. 109, n. 7, p. 2656-2661, 1998.

26 WEINSTEIN, J. D.; DECARVALHO, R.; GUILLET, T.; FRIEDRICH, B. ; DOYLE, J. M. Magnetic trapping of calcium monohydride molecules at millikelvin temperatures. Nature, v. 395, p. 148-150, 1998.

27 EGOROV, D.; WEINSTEIN, J.D.; PATTERSON, D.; FRIEDRICH, B.; DOYLE, J.M. Spectroscopy of laser-ablated buffer-gas-cooled $\mathrm{PbO}$ at $4 \mathrm{~K}$ and the prospects for measuring the electric dipole moment of the electron. Physical Review A, v. 63, n. 3, p. 030501, 2001.

28 EGOROV, D.; CAMPBELL, W. C.; FRIEDRICH, B.; MAXWELL, S. E.; TSIKATA, E.; VAN BUUREN, L. D.; DOYLE, J. M. Buffer-gas cooling of $\mathrm{NH}$ via the beam loaded buffer-gas method. The European Physical Journal D, v. 31, n. 2 p. 307-311, 2004.

29 BETHLEM, H.L.; BERDEN, G.; MEIJER, G. Decelerating neutral dipolar molecules. Physical Review Letters, v. 83, n. 8, p. 1558, 1999.

30 MEIJER, H.L.B.A.G. Production and application of translationally cold molecules. International Reviews in Physical Chemistry, v. 22, n.1, p.73 -128, 2003.

31 THORSHEIM, H.R.; WEINER, J.; JULIENNE, P.S. Laser-induced photoassociation of ultracold sodium atoms. Physical Review Letters, v. 58, n. 23, p. 2420, 1987.

32 FESHBACH, H.A. Unified theory of nuclear reactions, II. Annals of Physics, v. 19, n.5 p. 287, 1962.

33 STWALLEY, W.C. Stability of spin-aligned hydrogen at low temperatures and high magnetic fields: new field-dependent scattering resonances and predissociations. Physical Review Letters, v. 37, n. 24, p. 1628, 1976.

34 TIESINGA, E.; VERHAAR, B.J.; STOOF, H.T.C. Threshold and resonance phenomena in ultracold ground-state collisions. Physical Review A, v. 47, n. 5, p. 4114, 1993. 
35 NIKOLOV, A.N.; EYLER, E.E.; WANG, X.T.; LI, J.; WANG, H.; STWALLEY, W.C.; GOULD, P.L. Observation of ultracold ground-state potassium molecules. Physical Review Letters, v. 82, n. 4, p. 703, 1999.

36 NIKOLOV, A.N.; ENSHER, J.R.; EYLER, E.E.; WANG, H.; STWALLEY, W.C.; GOULD, P.L. Efficient production of ground-state potassium molecules at sub-mk temperatures by twostep photoassociation. Physical Review Letters, v. 84, n. 2, p. 246, 2000.

37 FATEMI, F.K.; JONES, K.M.; LETT, P.D.; TIESINGA, E. Ultracold ground-state molecule production in sodium. Physical Review A, v. 66, n. 5, p. 053401, 2002.

38 KERMAN, A.J.; SAGE, J.M.; SAINIS, S.; BERGEMAN, T.; DEMILLE, D. Production and stateselective detection of ultracold RbCs molecules. Physical Review Letters, v. 92, n. 15, p. 153001, 2004.

39 KERMAN, A.J.; SAGE, J.M.; SAINIS, S.; BERGEMAN, T.; DEMILLE, D. Production of ultracold, polar RbCs ${ }^{*}$ molecules via photoassociation. Physical Review Letters, v. 92, n. 3, p. 033004, 2004.

40 MANCINI, M.W.; TELLES, G.D.; CAIRES, A.R.L.; BAGNATO, V.S.; MARCASSA, L.G. Observation of ultracold ground-state heteronuclear molecules. Physical Review Letters, v. 92, n. 13, p. 133203, 2004.

41 WANG, D.; QI, J.; STONE, M.F.; NIKOLAYEVA, O.; WANG, H.; HATTAWAY, B.; GENSEMER, S.D.; GOULD, P.L.; EYLER, E.E.; STWALLEY, W.C. Photoassociative production and trapping of ultracold KRb molecules. Physical Review Letters, v. 93, n. 24, p. 243005, 2004.

42 HAIMBERgER, C.; KLEINERT, J.; BHATTACHARYA, M.; BIGELOW, N.P. Formation and detection of ultracold ground-state polar molecules. Physical Review A, v. 70, n. 2, p. 021402, 2004.

43 KRAFT, S. D.; STAANUM, P.; LANGE, J.; VOGEL, L.; WESTER, R.; WEIDEMÜLLER, M. Formation of ultracold LiCs molecules. Journal Physics B: Atomic, Molecular and Optical Physics, v. 39, p. S993-S1000, 2006.

44 TIMMERMANS, E.; TOMMASINI, P.; HUSSEIN M.; KERMAN A. Feshbach resonances in atomic Bose-Einstein condensates. Physics Reports, v. 315, n. 1-3, p. 199-230, 1999.

45 DONLEY, E. A.; CLAUSSEN, N.R.; THOMPSON, S. T.; WIEMAN, C. E. Atom-molecule coherence in a Bose-Einstein condensate. Nature, v. 417, p.529-533, 2002. 
46 CHIN, C.; KERMAN, A.J.; VULETICACUTE, V.; CHU, S. Sensitive detection of cold cesium molecules formed on feshbach resonances. Physical Review Letters, v. 90, n. 3, p. 033201, 2003.

47 REGAL, C.A.; TICKNOR, C.; BOHN, J.L.; JIN, D.S. Creation of ultracold molecules from a Fermi gas of atoms. Nature, v. 424, n. 6944, p. 47-50, 2003.

48 STRECKER, K.E.; PARTRIDGE, G.B.; HULET, R.G. Conversion of an atomic fermi gas to a long-lived molecular bose gas. Physical Review Letters, v. 91, n. 8, p. 080406, 2003.

49 CUBIZOLLES, J.; BOURDEL, T.; KOKKELMANS, S.J.J.M.F.; SHLYAPNIKOV, G.V.; SALOMON, C. Production of long-lived ultracold $\mathrm{Li}_{2}$ molecules from a fermi gas. Physical Review Letters, $\mathrm{v}$. 91, n. 24, p. 240401, 2003.

50 JOCHIM, S.; BARTENSTEIN, M.; ALTMEYER, A.; HENDL, G.; CHIN, C.; DENSCHLAG, J.H.; GRIMM, R. Pure gas of optically trapped molecules created from fermionic atoms. Physical Review Letters, v. 91, n. 24, p. 240402, 2003.

51 XU, K.; MUKAIYAMA, T.; ABO-SHAEER, J.R.; CHIN, J.K.; MILLER, D.E.; KETTERLE, W. Formation of quantum-degenerate sodium molecules. Physical Review Letters, v. 91, n. 21, p. 210402, 2003.

52 GREINER, M.; REGAL, C.A.; JIN, D.S. Emergence of a molecular Bose-Einstein condensate from a Fermi gas. Nature, v. 426, n. 6966, p. 537-540, 2003.

53 JOCHIM, S.; BARTENSTEIN, M.; ALTMEYER, A.; HENDL, G.; RIEDL, S.; CHIN, C.; HECKER DENSCHLAG, J.; GRIMM, R.Bose-Einstein condensation of molecules. Science, v. 302, n. 5653, p. 2101-2103, 2003.

54 ZWIERLEIN, M.W.; STAN, C.A.; SCHUNCK, C.H.; RAUPACH, S.M.F.; GUPTA, S.; HADZIBABIC, Z.; KETTERLE, W. Observation of Bose-Einstein condensation of molecules. Physical Review Letters, v. 91, n. 25, p. 250401, 2003.

55 VITEAU, M.; CHOTIA, A.; ALLEGRINI, M.; BOULOUFA, N.; DULIEU, 0.; COMPARAT, D.; PILLET, P. Optical pumping and vibrational cooling of molecules. Science, v. 321, n. 1159496, p. 232-234, 2008.

56 SAGE, J.M.; SAINIS, S.; BERGEMAN, T.; DEMILLE, D. Optical production of ultracold polar molecules. Physical Review Letters, v. 94, n. 20, p. 203001, 2005. 
57 DEIGLMAYR, J.; GROCHOLA, A.; REPP, M.; OUML; RTLBAUER, K.; GL; UUML; CK, C.; LANGE, J.; DULIEU, O.; WESTER, R.; WEIDEM; LLER, M. Formation of ultracold polar molecules in the rovibrational ground state. Physical Review Letters, v. 101, n. 13, p. 133004, 2008.

58 NI, K.-K.; DE MIRANDA, M. H. G.; PE'ER, A.; NEYENHUIS, B.; ZIRBEL, J. J.; KOTOCHIGOVA, S.; JULIENNE, P. S.; JIN, D. S.; YE J. A High phase-space-density gas of polar molecules. Science, v. 322, n. 5899 p. 231-235, 2008.

59 JOACHAIN, C.J.; BRANSDEN, B. H.; THEODORE, P. Physics of atoms and molecules. New York:Prentice Hall, 2003.

60 MOHAlLeM, F. R.; PRUDENTE, F. V. Métodos de química teórica e modelagem molecular. São Paulo: MORGON, N. H.; COUTINHO K., (Livraria da física - 2007).

61 HERZBERG, G. Molecular spectra and molecular structure. New York: Prentice-Hall. 1950.

62 BAGNATO, V.S.; MARCASSA, L.G.; MIRANDA, S.G.; MUNIZ, S.R.; DE OLIVEIRA, A.L. Measuring the capture velocity of atoms in a magneto-optical trap as a function of laser intensity. Physical Review A, v. 62, n. 1, p. 013404, 2000.

63 LOZEILLE, J.; FIORETTI, A.; GABBANINI, C.; HUANG, Y.; PECHKIS, H.K.; WANG, D.; GOULD, P.L.; EYLER, E.E.; STWALLEY, W.C.; AYMAR, M.; DULIEU, O. Detection by two-photon ionization and magnetic trapping of cold $\mathrm{Rb}_{2}$ triplet state molecules. The European Physical Journal D, v. 39, n. 2, p. 261-269, 2006.

64 VANHAECKE, N.; DE SOUZA MELO, W.; LABURTHE TOLRA, B.; COMPARAT, D.; PILLET, P. Accumulation of cold cesium molecules via photoassociation in a mixed atomic and molecular trap. Physical Review Letters, v. 89, n. 6, p. 063001, 2002.

65 STAANUM, P.; KRAFT, S.D.; LANGE, J.; OUML; RG; WESTER, R.; WEIDEM; UUML; LLER, M. Experimental investigation of ultracold atom-molecule collisions. Physical Review Letters, v. 96, n. 2, p. 023201, 2006.

66 ZIRBEL, J.J.; NI, K.K.; OSPELKAUS, S.; NICHOLSON, T.L.; OLSEN, M.L.; JULIENNE, P.S.; WIEMAN, C.E.; YE, J.; JIN, D.S. Heteronuclear molecules in an optical dipole trap. Physical Review A, v. 78, n. 1, p. 013416, 2008.

67 OSPELKAUS, C.; OSPELKAUS, S.; HUMBERT, L.; ERNST, P.; SENGSTOCK, K.; BONGS, K. Ultracold heteronuclear molecules in a 3d optical lattice. Physical Review Letters, v. 97, n. 12, p. 120402, 2006. 
68 WEICKENMEIER, W.; DEIMER, U.; WAHL, M.; RAAB, M.; DEMTRÖDER, W.; MÜLLER, W. Accurate ground state potential of $\mathrm{Cs}_{2}$ up to the dissociation limit. The Journal of Chemical Physics, v. 82, n. 12, p. 5354-5356, 1985.

69 DIEMER, U.; DUCHOWICA, R.; ERTEL, M.; MEHDIZADEH, E.; DEMTRÖDER, W. Doppler-free polarization spectroscopy of the $\mathrm{B}^{1} \mathrm{Pi}_{\mathrm{u}}$ state of $\mathrm{Cs}_{2}$. The Journal of Chemical Physics, v. 164, n. 4, p. 419-426, 1989.

70 STEIN, A.; PASHOV, A.; STAANUM, P. F.; KNÖCKEL, H.; TIEMANN, E. The $B^{1} \Pi$ and $D^{1} \Pi$ states of LiCs studied by fourier-transform spectroscopy. The European Physical Journal $D$, v. 48, n. 2, p. 177-185, 2008.

71 STAANUM, P.; PASHOV, A.; KN; OUML; CKEL, H.; TIEMANN, E. $X^{1} \Sigma^{+}$and $a^{3} \Sigma^{+}$states of LiCs studied by fourier-transform spectroscopy. Physical Review A, v. 75, n. 4, p. 042513, 2007.

72 SHAPIRO, E. A.; SHAPIRO, M.; PE'ER, A.; YE, J. Photoassociation adiabatic passage of ultracold $\mathrm{Rb}$ atoms to form ultracold $\mathrm{Rb}_{2}$ molecules. Physical Review A, v. 75, n. 1, p. 013405, 2007.

73 DELCHAR, T.A. Vaccum physics and techniques. London: Chapman, 1993.

74 STREED, E. W. ${ }^{87}$ Rubidium Bose-Einstein condensates: machine construction and quantum zeno experiments. 2005,p. 128, Ph.D. Thesis (Philosophy)-Department of Physics, Massachusetts Institute of Technology, Cambridge, 2005.

75 STREED, E.W.; CHIKKATUR, A.P.; GUSTAVSON, T. L.; BOYD, M.; TORII, Y.; SCHNEBLE, D.; CAMPBELL, G. K.; PRITCHARD, D. E.; KETTERLE, W. Large atom number Bose-Einstein condensate machines. Review of Scientific Instruments, v. 77, n. 023106, p. 1-13, 2006.

76 PHILLIPS, W.D.; METCALF, H. Laser deceleration of an atomic beam. Physical Review Letters, v. 48, n. 9, p. 596, 1982.

77 FIRMINO, M.E.; FARIA LEITE, C.A.; ZILIO, S.C.; BAGNATO, V.S. Process of stopping atoms with the Zeeman tuning technique with a single laser. Physical Review A, v. 41, n. 7, p. 4070, 1990.

78 BAGNATO, V.S.; ASPECT, A.; ZILIO, S.C. Study of laser deceleration of an atomic beam by monitoring the fluorescence along the deceleration path. Optics Communications, v. 72, n. 1-2, p. 76-81, 1989. 
79 CHU, S.; HOLLBERG, L.; BJORKHOLM, J.E.; CABLE, A.; ASHKIN, A. Three-dimensional viscous confinement and cooling of atoms by resonance radiation pressure. Physical Review Letters, v. 55, n. 1, p. 48, 1985.

80 ASHKIN, A. Trapping of atoms by resonance radiation pressure. Physical Review Letters, v. 40, n. 12, p. 729, 1978.

81 ZÍLIO, S.C. Óptica moderna - fundamentos e aplicações. São Carlos: IFSC, 2001.

82 ARNAUD, J.A. Modes of propagation of optical beams in helical gas lense. Applied Optics, v. 10, n. 5 , p. 2775-2776, 1971.

83 COHEN, D.K.; Little, B.; LUECKE, F. S. Techniques for measuring 1-[mgr ]m diam gaussian beams. Applied Optics, v. 23, n. 23, p. 4187-4196, 1984.

84 DEMTRÖDER, W. Laser spectroscopy. Berlin: Springer, 2003.

85 KUPPENS, S.J.M.; CORWIN, K.L.; MILLER, K.W.; CHUPP, T.E.; WIEMAN, C.E. Loading an optical dipole trap. Physical Review A, v. 62, n. 1, p. 013406, 2000.

86 WEISS, D.S.; RIIS, E.; SHEVY, Y.; UNGAR, P.J.; CHU, S. Optical molasses and multilevel atoms: experiment. Journal of the Optical Society of America B, v. 6, n. 11, p. 2072-2083, 1989.

87 GRANADE, S.R. All-optical production of a degenerate gas of ${ }^{6} \mathrm{Li}$ : characterization of degeneracy. 2002, p. 239, Ph.D. Thesis (Philosophy) - Department of Physics, DUKE UNIVERSITY, DUKE, 2002.

88 JINWEI, W.U.; RAYMOND, N.; HAUSMANN, M.; VIEIRA, D. J.; ZHAO, X. Loading dynamics of optical trap and parametric excitation resonances of trapped atoms. Journal of Applied Physics, v. 100, n. 5, p. 054903 - 054903-7, 2006.

89 MUDRICH, M.; KRAFT, S.; LANGE, J.; OUML; RG; MOSK, A.; WEIDEM; UUML; LLER, M.; TIESINGA, E. Hyperfine-changing collisions in an optically trapped gas of ultracold cesium and lithium. Physical Review A, v. 70, n. 6, p. 062712, 2004.

90 RAPOL, U.D.; WASAN, A.; NATARAJAN, V. Loading of a Rb magneto-optic trap from a getter source. Physical Review A, v. 64, n. 2, p. 023402, 2001. 
91 HOFFMANN, D.; FENG, P.; WILLIAMSON, R.S.; WALKER, T. Excited-state collisions of trapped ${ }^{85} \mathrm{Rb}$ atoms. Physical Review Letters, v. 69, n. 5, p. 753, 1992.

92 GENSEMER, S.D.; GOULD, P.L.; LEO, P.J.; TIESINGA, E.; WILLIAMS, C.J. Ultracold ${ }^{87} \mathrm{Rb}$ ground-state hyperfine-changing collisions in the presence and absence of laser light. Physical Review A, v. 62, n. 3, p. 030702, 2000.

93 TELLES, G.D.; BAGNATO, V.S.; MARCASSA, L.G. Alternative to the hyperfine-changecollision interpretation for the behavior of magneto-optical-trap losses at low light intensity. Physical Review Letters, v. 86, n. 20, p. 4496, 2001.

94 YOU, L.; HOLLAND, M. Ballistic expansion of trapped thermal atoms. Physical Review A, v. 53, n. 1, p. R1, 1996.

95 BARRETT, M.D. A QUEST for BEC : an all optical alternative. 2002. p. 144 . (Doctor of Philosophy in Physics)- The Academic Faculty, Georgia, 2002.

96 ENGLER, H.; WEBER, T.; MUDRICH, M.; GRIMM, R.; WEIDEM; UUML; LLER, M. Very long storage times and evaporative cooling of cesium atoms in a quasielectrostatic dipole trap. Physical Review A, v. 62, n. 3, p. 031402, 2000.

97 BURT, E.A.; GHRIST, R.W.; MYATT, C.J.; HOLLAND, M.J.; CORNELL, E.A.; WIEMAN, C.E. Coherence, correlations, and collisions: what one learns about Bose-Einstein condensates from their decay. Physical Review Letters, v. 79, n. 3, p. 337, 1997.

98 EDVARDSSON, D.; LUNELL, S.; MARIAN, C. M. Calculation of potential energy curves for $\mathrm{Rb}_{2}$ including relativistic effects. Molecular Physics, v. 101, n. 15, p. 2381-2389, 2003.

99 MARINESCU, M.; SADEGHPOUR, H.R.; DALGARNO, A. Dispersion coefficients for alkalimetal dimers. Physical Review A, v. 49, n. 2, p. 982, 1994.

100 CAIRES, A.R.L.; NASCIMENTO, V.A.; REZENDE, D.C.J.; BAGNATO, V.S.; MARCASSA, L.G. Atomic density and light intensity dependences of the $\mathrm{Rb}_{2}$ molecule formation rate constant in a magneto-optical trap. Physical Review A, v. 71, n. 4, p. 043403, 2005.

101 MARANGONI, B. S.; MENEGATTI, C. R.; MARCASSA, L. G. Temperature dependence of $\mathrm{Rb}_{2}$ molecule formation rate constant in a magneto-optical trap. Laser Physics, v. 20, n. 2, p. 557-560, 2010. 
102 TAKEKOSHI, T.; PATTERSON, B.M.; KNIZE, R.J. Observation of optically trapped cold cesium molecules. Physical Review Letters, v. 81, n. 23, p. 5105, 1998.

103 PICHLER, G.; MILOSEVIK, S.; VEZA, D.; BEUC, R. Diffuse bands in the visible absorption spectra of dense alkali vapors. Journal of Physics B: Atomic, Molecular and Optical Physics, v. 16, p. 4619-4631, 1983.

104 LAMBRECHT, A.; COUDREAU, T.;. STEINBERG, A. M.; GIACOBINO E. Squeezing with cold atoms. Europhysics Letters, v. 36, n. 2, p. 93-98, 1996.

105 SETO, J.Y.; LE ROY, R.J.; VERGES, J.; AMIOT, C. Direct potential fit analysis of the $X^{1} \Sigma_{\mathrm{g}}^{+}$ state of $\mathrm{Rb}_{2}$ : nothing else will do! The Journal of Chemical Physics, v. 113, n. 8, p. 30673076, 2000.

106 FIORETTI, A.; DULIEU, O.; GABBANINID, C. Experimental evidence for an isotopic effect in the formation of ultracold ground-state rubidium dimers Journal of Physics B: Atomic, Molecular and Optical Physics, v. 40, n. 16, p. 3283, 2007.

107 ZAHZAM, N.; VOGT, T.; MUDRICH, M.; COMPARAT, D.; PILLET, P. Atom-molecule collisions in an optically trapped gas. Physical Review Letters, v. 96, n. 2, p. 023202, 2006.

108 HUANG, Y. Production, detection and trapping of ultracold molecular rubidium. 2006, p. 185, Ph.D. Thesis (Philosophy)-Department of Physics, University of Connecticut, Connecticut, 2006.

109 SOFIKITIS, D.; STERN, G.; KIME, L.; DIMOVA, E.; FIORETTI, A.; COMPARAT, D.; PILLET, P. Loading a dipole trap from an atomic reservoir. The European Physical Journal D, v. 61, n. 2, p. 437-442, 2011. 